\title{
WestVirginiaUniversity
}

THE RESEARCH REPOSITORY @ WVU

Graduate Theses, Dissertations, and Problem Reports

2012

\section{Hot Mix Asphalt Concrete Density, Bulk Specific Gravity, and Permeability}

Yu Yan

West Virginia University

Follow this and additional works at: https://researchrepository.wvu.edu/etd

\section{Recommended Citation}

Yan, Yu, "Hot Mix Asphalt Concrete Density, Bulk Specific Gravity, and Permeability" (2012). Graduate Theses, Dissertations, and Problem Reports. 3348.

https://researchrepository.wvu.edu/etd/3348

This Thesis is protected by copyright and/or related rights. It has been brought to you by the The Research Repository @ WVU with permission from the rights-holder(s). You are free to use this Thesis in any way that is permitted by the copyright and related rights legislation that applies to your use. For other uses you must obtain permission from the rights-holder(s) directly, unless additional rights are indicated by a Creative Commons license in the record and/ or on the work itself. This Thesis has been accepted for inclusion in WVU Graduate Theses, Dissertations, and Problem Reports collection by an authorized administrator of The Research Repository @ WVU. For more information, please contact researchrepository@mail.wvu.edu. 


\title{
Hot Mix Asphalt Concrete Density, Bulk Specific Gravity, and Permeability
}

\author{
Yu Yan
}

Thesis submitted to the

Benjamin M. Statler College of Engineering and Mineral Resources

at West Virginia University

in partial fulfillment of the requirements

for the degree of

Master of Science

in

Civil Engineering

Dr. John P. Zaniewski, Chair

Dr. John Quaranta, PE

Dr. Avinash Unnikrishnan

Department of Civil and Environmental Engineering

Morgantown, West Virginia

2012

Keywords: Permeability, Bulk specific gravity, Density, NMAS, Air voids, Gradation 


\section{Abstract \\ Hot Mix Asphalt Concrete Density, Bulk Specific Gravity, and Permeability}

\section{Yu Yan}

Field permeability test using NCAT Permeameter were conducted at four project sites before and after the application of fog seal. Due to the fact that it is difficult to estimate the thickness of pavement tested, instead of permeability, the infiltration rate is calculated to estimate the effectiveness of fog seal on reducing the permeability of pavement.

Cores from I-79, I-64 and Route-19 projects were collected and sent to the WVUATL for bulk specific gravity $\left(G_{m b}\right)$ measurements. According to AASHTO T 166 , when the percent of water absorbed by the specimen exceeds $2 \%$, AASHTO T 275 or T 331 should be used to determine the bulk specific gravity. There is a proposal to reduce this threshold to one percent which is supported by the data and analysis in this study. Paired student test, and a line of equality regression analysis were used to analyze the data provided by the contractor and collected in the WVUATL, the AASHTO T166 is proven to be repeatable, and CoreLok is a viable device for determining the $\mathrm{G}_{\mathrm{mb}}$ and corresponding air voids of field cores. Based on density data from the I-79 project, provided by the contractor and WVDOH, the thin-lift gauge had smaller correction factors than standard nuclear gauges. Developing correction factors based on the ration of means may be better than using the difference of means methods which is currently used by the WVDOH.

Laboratory permeability tests were conducted on all field cores following Florida Testing Method 5-565. In general the permeability of the field cores on this project is consistent with the rule of thumb that permeability becomes an issue when the air voids of the sample are greater than eight percent. The regression model of the field cores permeability indicates that at eight percent air voids the permeability is about $80 \times 10-5 \mathrm{~cm} / \mathrm{sec}$ which is less than the recommended criteria of $100 \times 10^{-5} \mathrm{~cm} / \mathrm{sec}$ to $125 \times 10^{-5} \mathrm{~cm} / \mathrm{sec}$.

In addition, eight HMA mixtures including $9.5 \mathrm{~mm}$ fine and coarse, $12.5 \mathrm{~mm}$ coarse, $19 \mathrm{~mm}$ fine and coarse, $25 \mathrm{~mm}$ fine, and $37.5 \mathrm{~mm}$ fine and coarse, were evaluated. For each mixture, gyratory compacted samples were produced and tested at target air voids contents of 4, 7, 9 and 11 percent, with two samples at each target. Laboratory permeability tests were performed to determine how air voids content, nominal maximum aggregate size, and aggregate gradation affect eh permeability of HMA mixtures. The model developed by Vivar et al. was found to be suitable for data collected in this study, and new coefficients were suggested. The results of multi regression analysis indicated that air voids and nominal maximum aggregate size significantly affect the permeability, but aggregate gradation does not.

Comparing the permeability data from field cores and laboratory compacted pills, it is clear cores have higher permeability than laboratory compacted pills when the air voids are lower than approximately 10 percent, and the pills have a higher permeability at more than 10 percent air voids. This observation is consistent with previous research. 


\section{Acknowledgements}

It is my pleasure to thank the many people who made this thesis possible.

I would like to express my sincere gratitude to Dr. John P. Zaniewski, my advisor, under whose guidance I chose this topic. I specially thank him for his infinite patience, and invaluable conversations with me through the past two years.

I would like to express my appreciation to my advisory committee: Dr. John Quaranta, Dr. Avinash Unnikrishnan. Special thanks to Dr. Quaranta for his time, patience, and understanding. Dr. Unnikrishnan, it has been an honor to work with you. Also, great thanks to West Virginia Department of Transportation for providing funding to Asphalt Technology Laboratory at West Virginia University.

This work would not have been possible without the support from Mr. Chadley Miller, and J.F. Allen Company for providing testing materials and data in this study.

My gratitude also goes to Mr. John Elias Crane, who helped me with the laboratory work. I am grateful to all my friends, Kevin A. Butler, Hadi Rashidi, and most importantly to Jennifer Bustos Rios for being my surrogate family during the past two years I stayed in Morgantown and for her continued love and support.

The most special thanks go to my parents, Xiaoxiang Wang and Yufa Yan, for the love and unconditional support throughout all this long process. 


\section{Table of Content}

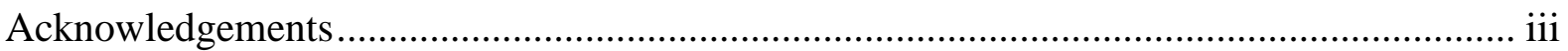

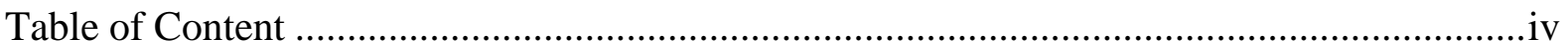

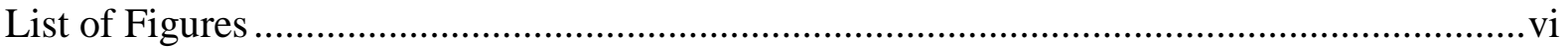

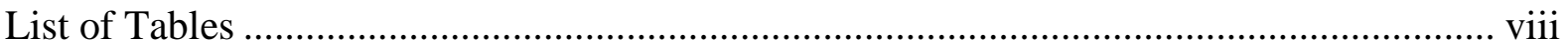

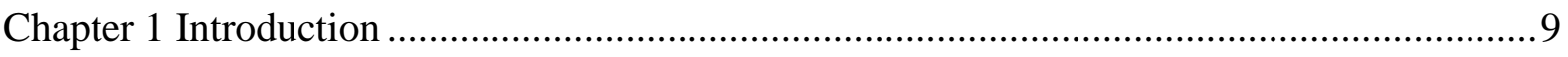

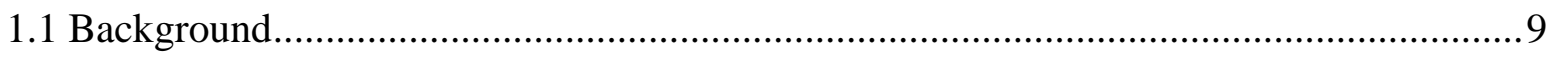

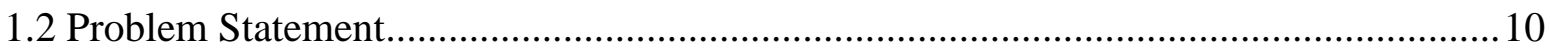

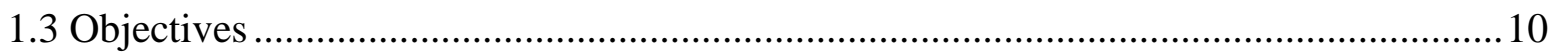

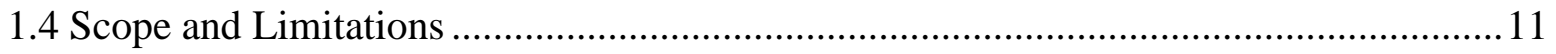

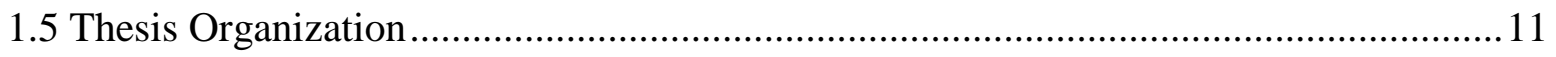

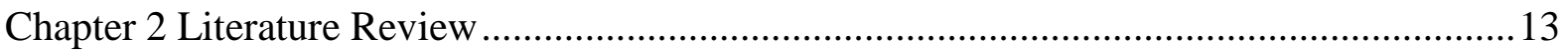

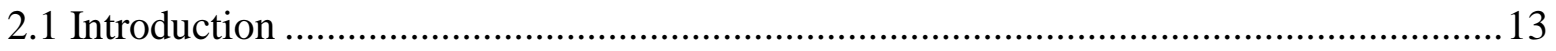

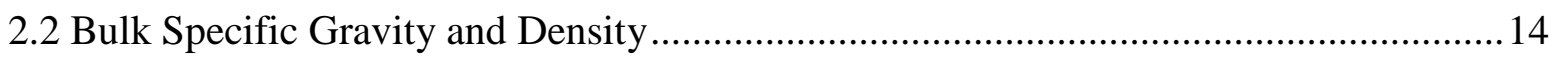

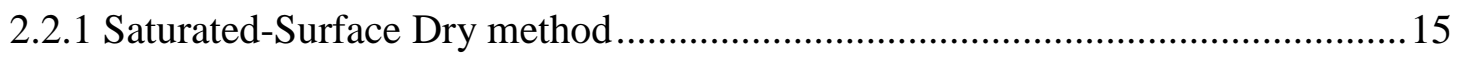

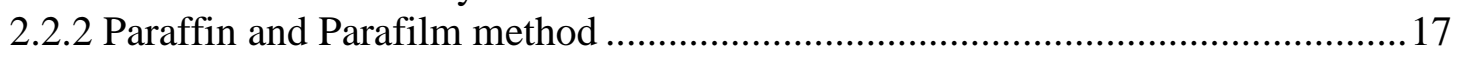

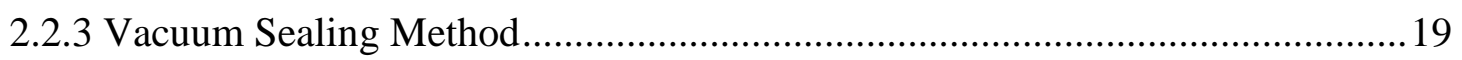

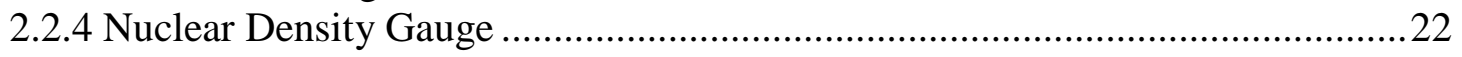

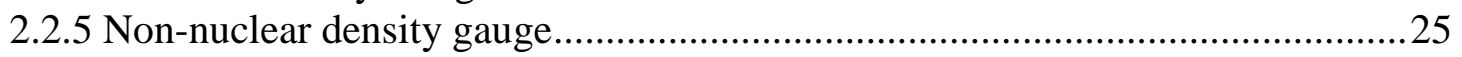

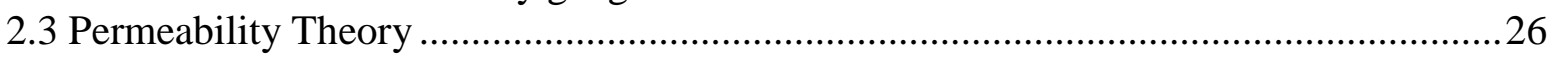

2.4 Factors Affecting Permeability of Superpave Designed Mixes .....................................27

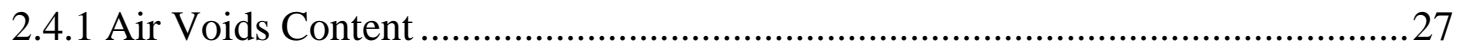

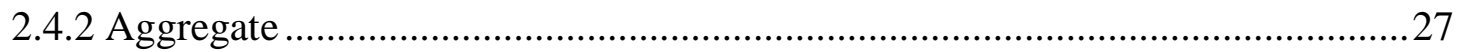

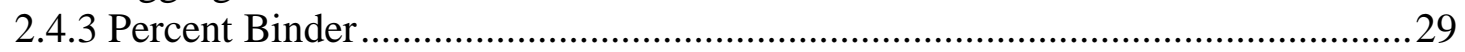

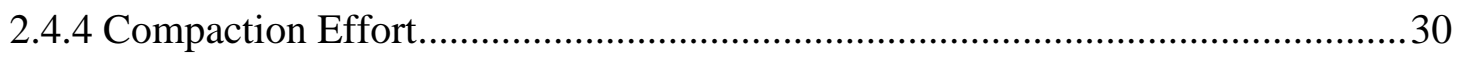

2.5 Laboratory Permeability Test ................................................................................ 31

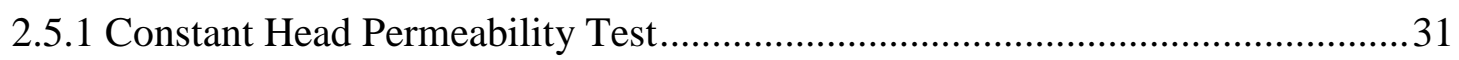

2.5.2 Falling Head Permeability Test...................................................................33

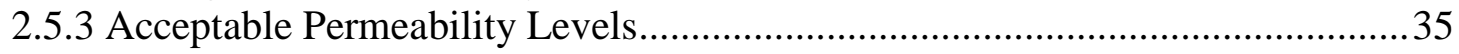

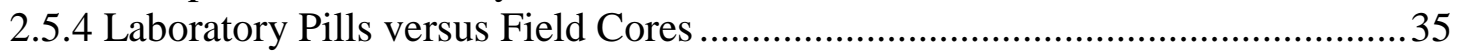

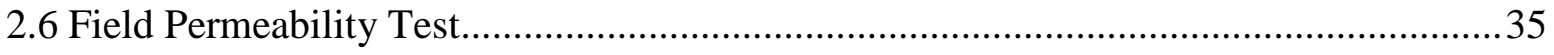

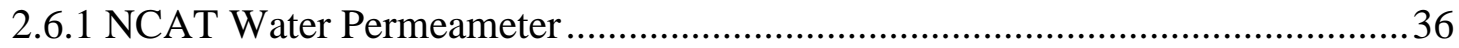

2.6.2 Kuss Constant Head Field Permeameter (KCHFP) .............................................39

2.6.3 Kentucky Air Induced Permeameter (AIP) ...................................................39

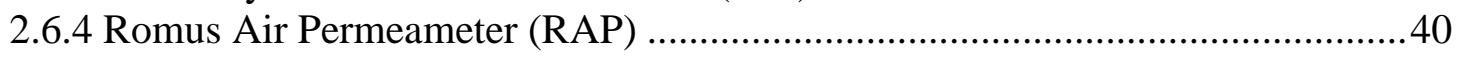

2.7 Mathematical Approach to the Permeability Estimation................................................ 41

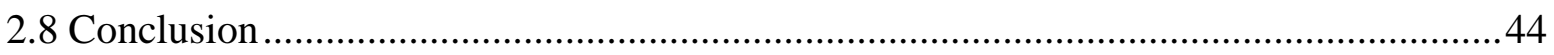




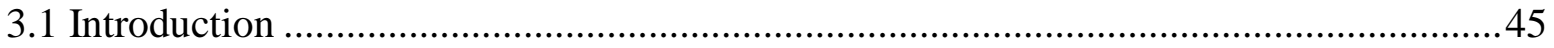

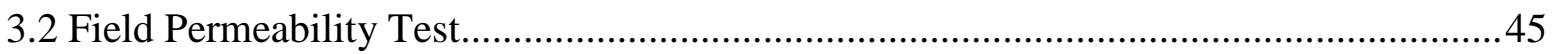

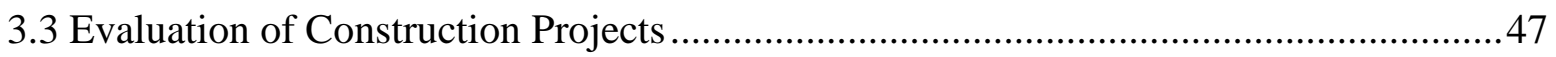

3.4 Laboratory Permeability of Gyratory Compacted Pills................................................48

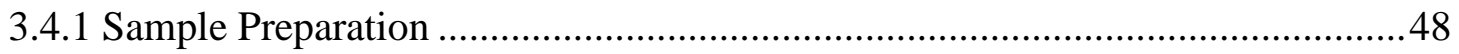

3.4.2 Laboratory Permeability Tests on Gyratory Compacted Samples........................50

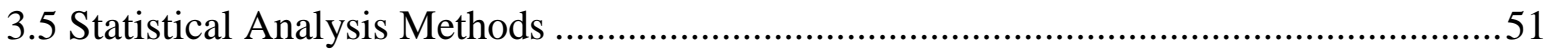

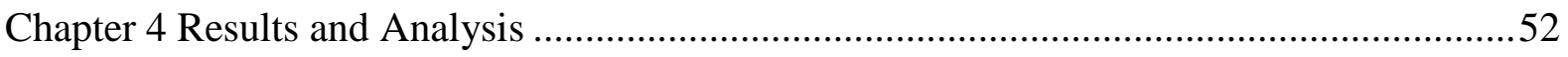

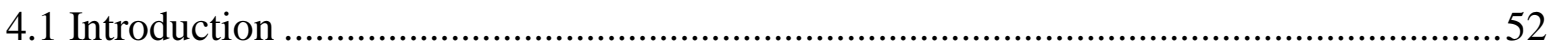

4.2 NCAT Permeameter Testing Results ............................................................................52

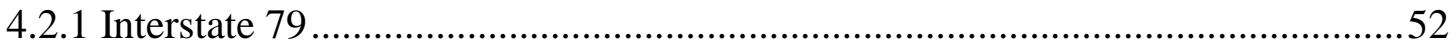

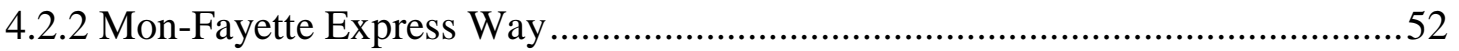

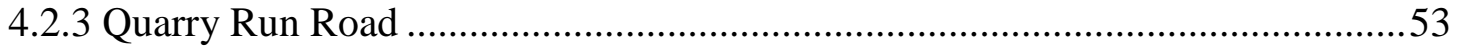

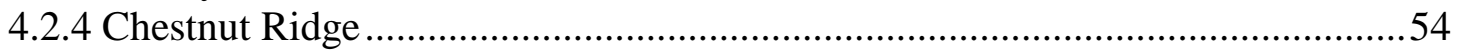

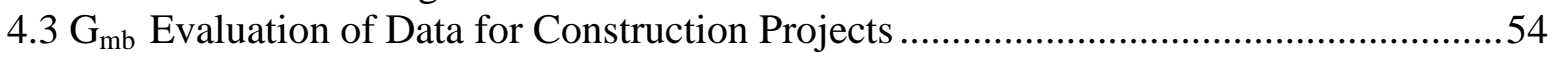

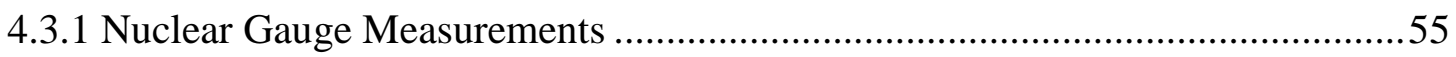

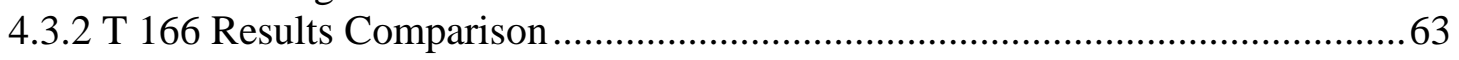

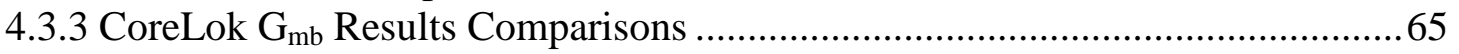

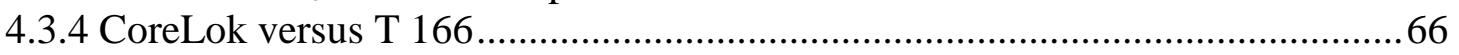

4.4 Laboratory Permeability Test Results of Field Cores ….................................................68

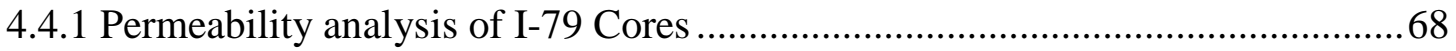

4.4.2 Permeability analysis of I-64 and Route-19 Projects........................................69

4.4.3 Composite Analysis of Samples from All Construction Projects .......................70

4.5 Laboratory Permeability Test Results of Gyratory Compacted Pills ..............................71

4.5.1 Relationship between Permeability and Percent Air Voids .................................75

4.5.2 Relationship between permeability and Gradation of HMA mixes .....................8 80

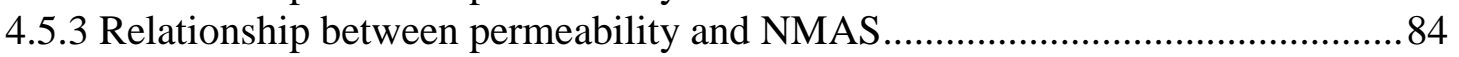

4.5.4 Composite Analysis of Permeability Results ...................................................... 87

Chapter 5 Conclusions and Recommendations..................................................................91

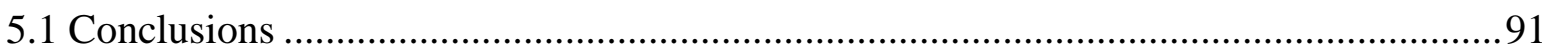

5.1.1 Field permeability/ Infiltration Rates ...............................................................91

5.1.2 Density and Bulk Specific Gravity Test Methods on Field Cores ......................91

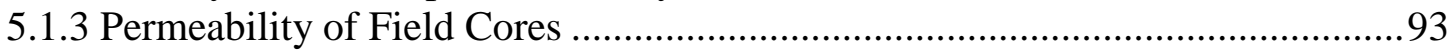

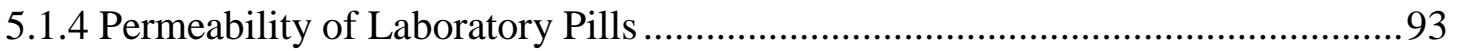

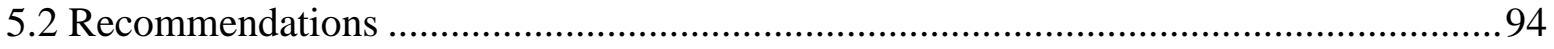

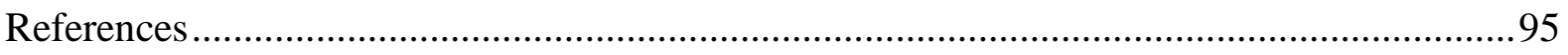

Appendix 1 Stockpile and Blend Gradations................................................................. 101

Appendix 2 Field Density Data and Bulk Specific Gravity of Field Cores...........................109 


\section{List of Figures}

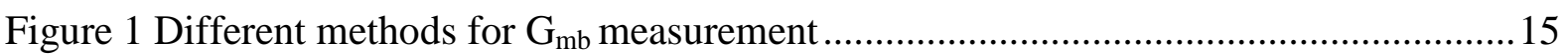

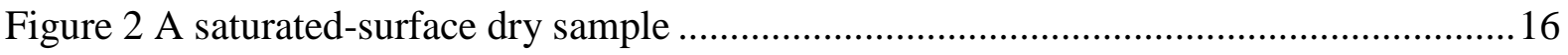

Figure 3 Compacted asphalt pill with voids filled with water (6) .........................................17

Figure 4 Compacted asphalt pill in SSD condition with potential water loss(6)....................17

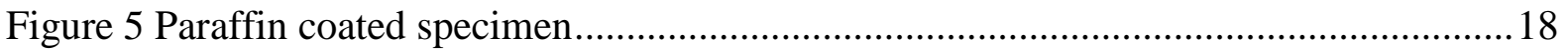

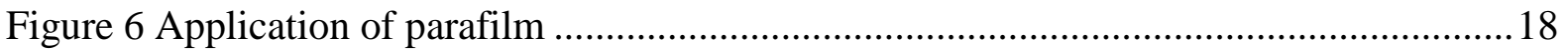

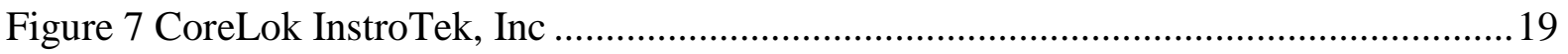

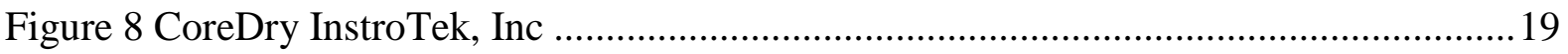

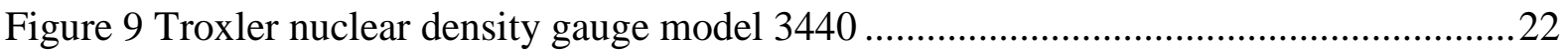

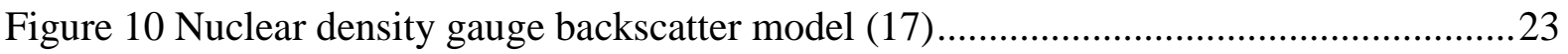

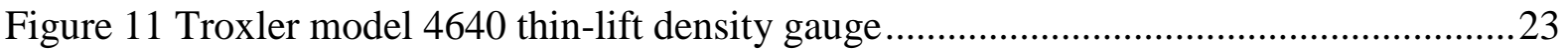

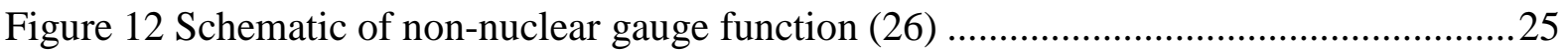

Figure 13 Pavement quality indicator ${ }^{\mathrm{TM}}$ (PQI), Model 301 .............................................26

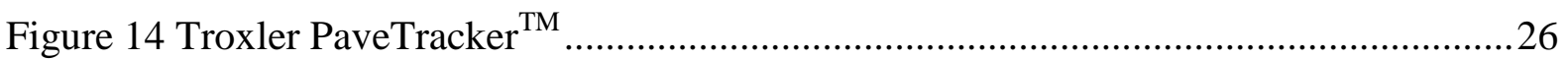

Figure 15 Typical laboratory regression line for permeability (28) ....................................27

Figure 16 Internal voids structure for coarse-graded and fine-graded mixes (6) ...................28

Figure 17 Best fit curves for air voids versus permeability for different NMAS (34) ............28

Figure 18 Comparison of permeability at different percent binder (38)...............................30

Figure 19 Relationship between permeability and t/NMAS (39) ..........................................31

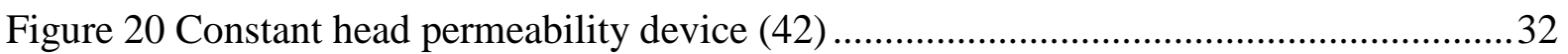

Figure 21 Karol-Warner falling head permeability device (45) ...........................................33

Figure 22 Permeability of laboratory pills versus field cores (57) .........................................36

Figure 23 NCAT Permeameter by Gilson Company. Inc., Model AP-1B .............................37

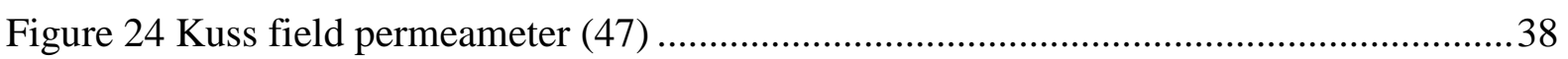

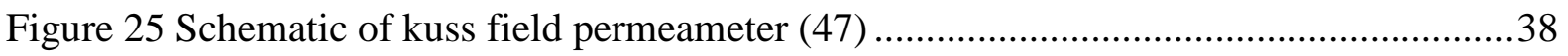

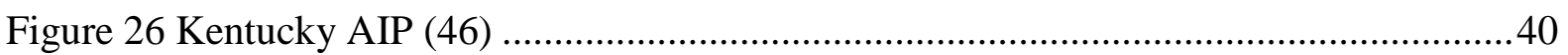

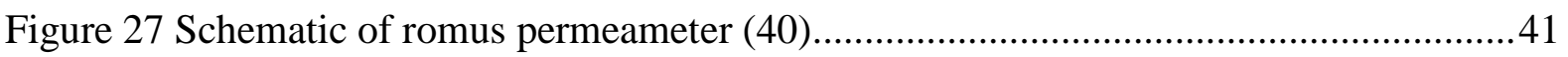

Figure 28 Field permeability test conducted at I-79 project ...............................................46

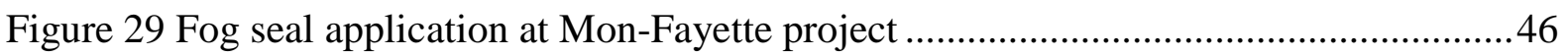

Figure 30 Fog seal application at Quarry Run Road project .............................................47

Figure 31 Mon-Fayette pavement surface before and after the fog seal................................47 
Figure 32 Water leakage on the pavement surface .53

Figure 33 Line of equality comparison for contractor gauges and CoreLok density ..............59

Figure 34 Line of equality comparison for WVDOH gauges and CoreLok density 60

Figure 35 Line of equality comparison for thin-lift gauge and CoreLok $G_{m b}$ 61

Figure 36 Comparisons of ratio of means and difference of means methods for establishing correction factors

Figure 37 I-79 Line of equality comparison for contractor and WVUATL T166, $\mathrm{G}_{\mathrm{mb}}$..........63

Figure 38 Line of equality comparison for WVUATL CoreLok replicated testing results.....66

Figure 39 Line of equality comparison for WVUATL and contractor CoreLok results .........66

Figure 40 Line of equality comparison for WVUATL CoreLok and T 166 .........................67

Figure 41 Relationship between permeability and percent air voids I-79 Project..................69

Figure 42 Relationship between permeability and percent air voids $\sim$ I-64 Project................. 70

Figure 43 Relationship between permeability and percent air voids $\sim$ Route-19 Project .........71

Figure 44 Permeability - Air Voids Data and Models for All Three Projects. ........................ 72

Figure 45 Permeability and percent air voids value ofe HMA mixes.................................... 74

Figure 46 Permeability vs. percent air voids, $9.5 \mathrm{~mm}$ fine mixes ........................................ 76

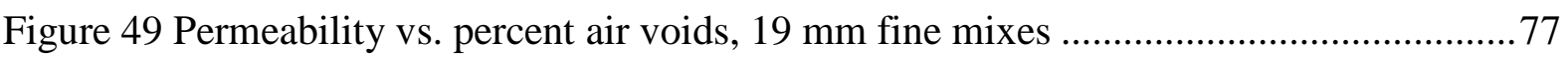

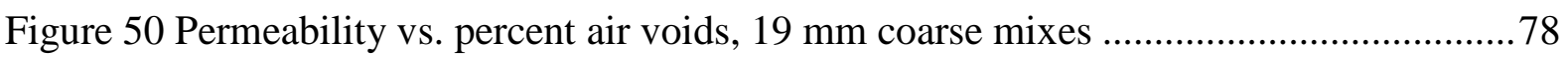

Figure 51 Permeability vs. Percent Air Voids, 25 mm fine mixes ........................................ 78

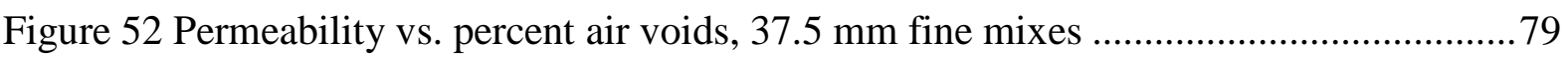

Figure 53 Permeability vs. percent air voids, 37.5 mm coarse mixes ......................................79

Figure 54 Permeability versus percent air voids, $9.5 \mathrm{~mm}$ fine and coarse mixes....................82

Figure 55 Permeability versus percent air voids, 19 mm fine and coarse mixes....................82

Figure 56 Permeability versus percent air voids, $37.5 \mathrm{~mm}$ fine and coarse mixes..................83

Figure 57 Relationship between NMAS and gradation versus permeability.........................84

Figure 58 Effect of NMAS on permeability of sample at 7 percent air voids level ................85

Figure 59 Effect of NMAS on permeability of sample at 9 percent air voids level ...............86

Figure 60 Effect of NMAS on permeability of sample at 11 percent air voids level .............86

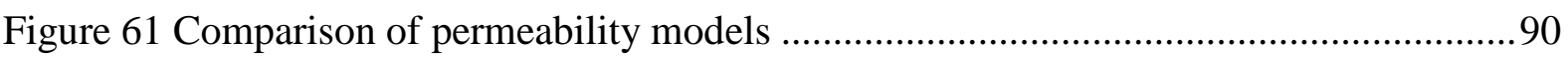

Figure 62 Combined Gradation Charts for NMAS 9.5 mm Fine Superpave Mixes...............101

Figure 63 Combined gradation charts for NMAS 9.5 mm coarse Superpave mixes.............102

Figure 64 Combined gradation charts for NMAS 12.5 mm coarse Superpave mixes...........103

Figure 65 Combined gradation charts for NMAS 19 mm fine Superpave mixes...................104

Figure 66 Combined gradation charts for NMAS 19 mm coarse Superpave mixes..............105

Figure 67 Combined gradation charts for NMAS 25 mm fine Superpave mixes..................106 
Figure 68 Combined gradation charts for NMAS $37.5 \mathrm{~mm}$ fine Superpave mixes 107

Figure 69 Combined gradation charts for NMAS 37.5 mm coarse Superpave mixes..... 108

\section{List of Tables}

Table 1 Comparison of air voids using CoreLok method versus T166 (14) .........................21

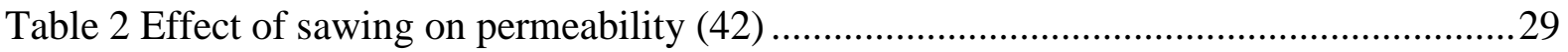

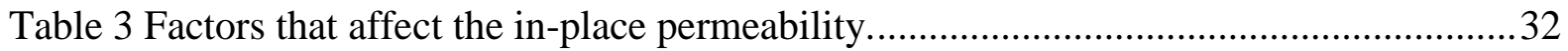

Table 4 Acceptable upper limit for permeability of five states .............................................35

Table 5 Advantages and disadvantages of NCATWP and AIP ...........................................37

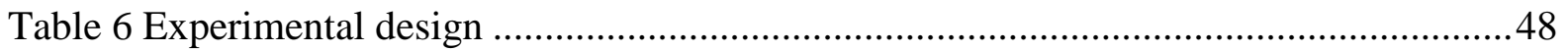

Table 7 Aggregate types and blend percentage ....................................................................

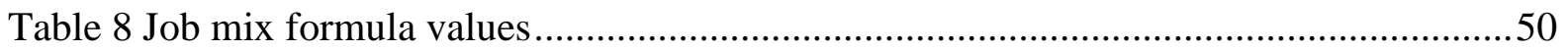

Table 9 Mon-Fayette NCAT permeameter test data ...............................................................53

Table 10 Quarry Run Road NCAT permeameter data............................................................54

Table 11 Chestnut-Bridge NCAT permeability test data.......................................................54

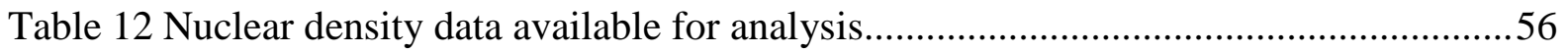

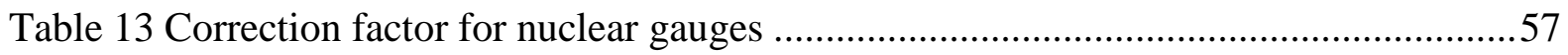

Table 14 Trend line coefficients for nuclear gauges and CoreLok density .............................63

Table 15 WVUATL versus Contractor T 166 paired t-Test .....................................................64

Table 16 WVUATL versus contractor T 166 Regression Analysis .......................................64

Table 17 Statistical comparison of CoreLok and T166 ........................................................68

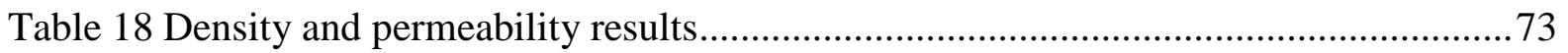

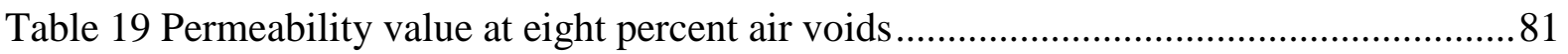

Table 20 Air voids content corresponding to select permeability values ...............................81

Table 21 Power-exponential model of all laboratory permeability data..................................8

Table 22 Power-exponential model of laboratory permeability data without

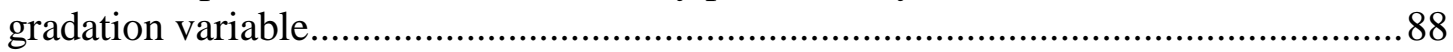

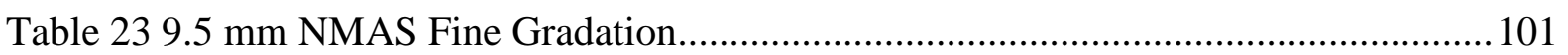

Table 249.5 mm NMAS Coarse Gradation........................................................................ 102

Table 2512.5 mm NMAS Coarse Gradation........................................................................103

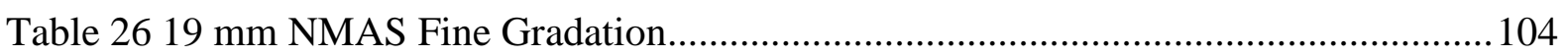

Table 2719 mm NMAS Coarse Gradation........................................................................... 105

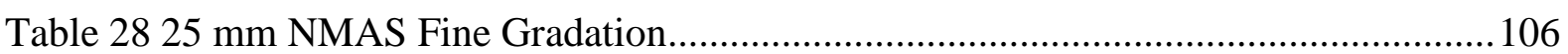

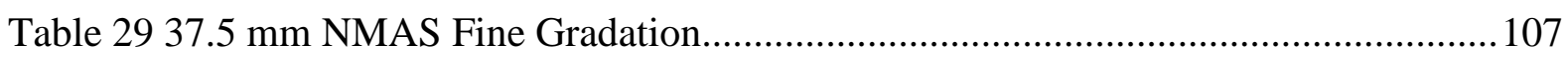

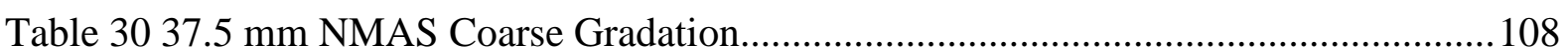




\section{Chapter 1 Introduction}

\subsection{Background}

One of the primary assumptions for conventional pavements made during the structural pavement design is that flexible pavements (hot mix asphalt) are impermeable (1). By minimizing moisture infiltration, adequate support from the underlying unbound materials is obtained. In 1993, Superior Performing Asphalt Pavement (Superpave) was introduced as a part of the Strategic Highway Research Program (SHRP). With the adoption of Superpave mix design system, hot mix asphalt (HMA) pavements have been produced with coarser gradation than previously used mix design methods. These coarse gradations have been successful at limiting distresses such as rutting; but, coarser mixes have led to other issues namely higher permeability values. Increased permeability allows water to enter the asphalt pavement easily, which results in increased susceptibility to moisture induced damage or stripping. The increases in permeability may also promote the oxidation of asphalt cement and consequently makes the pavement brittle and susceptible to longitudinal and fatigue cracking. A survey conducted by Brown et al. (2) showed that permeability was one of the prime issues observed for Superpave method designed asphalt concrete.

Previous work by Zube (3) in the 1950s and 1960s indicated that pavements become excessively permeable to water at air void contents greater than eight percent. In the Superpave method designed pavements, the probability of individual air voids to be interconnected is higher than conventional dense-graded pavements. Research conducted by Florida Department of Transportation (FDOT) (4) indicated that coarse-graded Superpave mixes can be excessively permeable to water at air void contents above six percent. Cooley and Brown (5) showed that coarse-graded Superpave mixes can be excessively permeable below eight percent air voids using the field permeability device. During the process of establishing the relationship between permeability and percent air voids, a major concern was the proper measurement of the bulk specific gravity $\left(\mathrm{G}_{\mathrm{mb}}\right)$ for compacted HMA samples. This issue has become a greater problem with the increasing use of coarse gradations (6). For many years, the water displacement method has been used to measure the $G_{m b}$, using saturated-surface dry (SSD) samples, AASHTO T166 ${ }^{1}$ Bulk Specific Gravity of Compacted Bituminous Mixtures Using Saturated Surface-Dry Specimens Method. When performing this method with coarse-graded mixtures, water tends to drain freely from the large

\footnotetext{
${ }^{1} \mathrm{~T} 166$ is used in following sections when referring to AASHTO T166.
} 
interconnected voids within the sample. Due to this, a lower SSD mass is obtained, and the air voids content of the sample is underestimated.

\subsection{Problem Statement}

With the adoption of the Superpave design method in 1993, permeability has become one of the prime issues. However, there is no widely accepted device, procedure or specification for measuring permeability of asphalt pavement, neither ASTM nor AASHTO have a standard test method. Currently, density requirements are specified by the West Virginia Department of Transportation as a measure of controlling permeability. T166, the currently used method for measuring the bulk specific gravity $\left(G_{m b}\right)$ can overestimate the $G_{m b}$ of coarse-graded HMA mixtures at high air voids level. A supplemental testing method, AASHTO T 275, exists for this situation but it has its own issues such as long time required to testing, and poor repeatability.

Previously research indicated that several factors influence the permeability of HMA mixtures, a few of these factors are air voids content, aggregate gradation, nominal maximum aggregate size (NMAS), and lift thickness. It is always assumed that air voids content is a predominant factor that controls the permeability. However, not all of the individual air voids are counted in the voids in total mix (VTM) affect the permeability of HMA mixtures, thus even at a high level of air voids content, the mixture can still have resistance to moisture intrusion if the air voids are not interconnected. Limited research has been done on the water permeable air voids content or percent porosity, and how those influential factors mentioned above affect the water permeable air voids.

\subsection{Objectives}

The overall objective of this research was to evaluate the permeability of asphalt concrete mixes. Several approaches were used to accomplish this objective; these are grouped into:

- Field permeability/ infiltration rates - to evaluate the National Center for Asphalt Technology (NCAT) Permeameter for measuring in place permeability

- Density and bulk specific gravity test methods on field cores - to determine if different methods for measuring the bulk specific gravity of asphalt concrete are comparable and if the proposed change to the AASHTO standard test method should be implemented. 
- Permeability of field cores - to measure permeability of cores from construction projects to determine if permeability is an issue with the pavements constructed in West Virginia.

- Permeability of laboratory pills ${ }^{2}$ - to evaluate the permeability of the different mix types, gradation types and percent air voids.

\subsection{Scope and Limitations}

This research contains three parts: 1) field permeability tests using NCAT Permeameter, 2) field density, bulk specific gravity, and permeability measurements on field cores, and 3) laboratory permeability tests on gyratory compacted samples. Part one and part two were conducted on an "availability” basis. Field cores in this research were obtained from Interstate 64, 79 and Route 19 in West Virginia. Part three included eight HMA mixes designs which are $9.5 \mathrm{~mm}$ fine-graded, $9.5 \mathrm{~mm}$ coarse-graded, $12.5 \mathrm{~mm}$ coarse-graded, 19 mm fine-graded, $19 \mathrm{~mm}$ coarse-graded, $25 \mathrm{~mm}$ fine-graded, $37.5 \mathrm{~mm}$ fine-graded, and 37.5 mm coarse-graded mixes. For each mix design eight cylindrical samples were produced using the Superpave Gyratory Compactor (SGC), these samples are $75 \mathrm{~mm}$ in height and $150 \mathrm{~mm}$ in diameter. Samples were designed and made at 4, 7, 9 and 11 target percent air voids for laboratory permeability tests. Aggregate material for making the gyratory compacted samples were crushed limestone obtained from J.F. Allen Inc.

A limitation of this research is that it did not consider lift thickness affects on the permeability of HMA mixtures, so all the testing samples in part 3 were compacted to $75 \mathrm{~mm}$ height. The bulk specific gravity of the gyratory compacted samples was measured with the T166 method. 12.5 mm fine HMA mixes design and 25 mm coarse HMA mixes design were not included into this study.

\subsection{Thesis Organization}

This thesis consists of five chapters including the introduction in the first chapter. The second chapter provides a comprehensive literature review on testing methods for both density and permeability. Also included in Chapter two are descriptions of various factors that affect permeability of HMA mixtures, and documented some empirical conclusions on predicting the permeability of HMA mixtures. The experimental plan and testing methodology are discussed in the third chapter. Chapter four presents the data provided by

\footnotetext{
${ }^{2}$ Samples compacted in the laboratory are referred to as pills. Samples extracted from pavements are called cores.
} 
local contractors and collected by the Asphalt Technology Laboratory ${ }^{3}$ here at West Virginia University. Density and bulk specific gravity data, and permeability data collected both from field and the laboratory samples were analyzed, and a detailed statistical analysis is presented. Finally, the fifth chapter outlines the findings, conclusions and recommendations for further research.

${ }^{3}$ WVUATL is used in following sections when referring to West Virginia University Asphalt Technology Laboratory. 


\section{Chapter 2 Literature Review}

\subsection{Introduction}

As an important construction variable, permeability affects the long-term durability of paved surfaces. Permanent deformation such as rutting and shoving can be caused by low percentage of in-place air voids, while high air voids may lead to increased permeability which allows water to enter the asphalt easily, and results in increased susceptibility to longitudinal and fatigue cracking as well as moisture induced damage or stripping.

Bulk specific gravity $\left(\mathrm{G}_{\mathrm{mb}}\right)$ of an asphalt mixture is defined as the ratio of the mass of a given volume of material at $25^{\circ} \mathrm{C}$ to the mass of an equal volume of water at the same temperature. Proper measurements of the $\mathrm{G}_{\mathrm{mb}}$ of compacted hot-mix asphalt (HMA) samples are essential to HMA mix design, field control and construction acceptance. When designing a HMA mix, the calculation of volumetric properties such as voids in the total mix (VTM), voids in mineral aggregates (VMA), voids filled with asphalt (VFA) and percent maximum density at a certain number of gyrations are all based upon $G_{m b}$.

The most accepted density or bulk specific gravity of the mix is obtained by taking samples from the pavement and measuring in the laboratory using standard procedures such as T-166: Bulk Specific Gravity of Compacted Bituminous Mixtures Using Saturated Surface-Dry Specimens. For high air void specimen (high absorption) other measuring methods should be applied, such as AASHTO T-275, Bulk Specific Gravity of Compacted Bituminous Mixtures Using Paraffin-Coated Specimens, or AASHTO T331, Bulk Specific Gravity and Density of Compacted Hot Mix Asphalt (HMA) Using Automatic Vacuum Sealing Method.

For field density measurements, the gamma ray method is a well-known simple and non-destructive method to obtain the in-place density of HMA. Based upon the scattering and adsorption properties of gamma rays with matter, the nuclear gauge is used to estimate the density of pavement. However, the nuclear density gauge has shortcomings such as the licenses, training, and specialized storage. The non-nuclear electro-magnetic density gauges are considered as a replacement of nuclear density gauge and the process of coring (8). Few years ago, non-nuclear electro-magnetic density gauges entered the market. A detailed literature review of both laboratory and field density measurements is presented in the following sections. 
Several factors affect the permeability of HMA, such as voids in total mix, size of air voids, percent of interconnected air voids, aggregate gradation, NMAS, aggregate particle shape, percent binder $\left(\mathrm{P}_{\mathrm{b}}\right)$, lift thickness and compaction effort. In the recent years, there has been a considerable effort in exterminating of permeability of HMA in field as well as in laboratory.

Two kinds of laboratory permeability tests have been developed are constant head test, and falling head test. Using a falling head testing device, the Florida permeability test method, Florida Method of Test for Measurement of Water Permeability of Compacted Asphalt Paving Mixtures (43), was applied on gyratory compacted samples in this research. A detailed literature review of field permeability testing devices is also presented in the following sections.

\subsection{Bulk Specific Gravity and Density}

In most states, acceptance of constructed pavements is based upon percent compaction which is the density computed using $G_{m b}$ and theoretical maximum specific gravity $\left(G_{m m}\right)$. An erroneous $G_{m b}$ may lead to incorrect pay bonuses or penalties for both agency and producer.

For many years, the water displacement concept has been applied to measure the $G_{m b}$ of gyratory compacted samples in the lab or cores from the field, using saturated-surface dry (SSD) samples, paraffin/parafilm coated samples, or CoreLok vacuumed samples. These methods are time-consuming and cannot provide real-time information for contractors during the construction process. As an alternative, a nuclear density gauge, which uses gammy ray, also has its limitations. For instance, a nuclear density gauge needs to be calibrated to the $G_{m b}$ of cores before taking readings. If cores for calibration purposes are not accurately measured, the nuclear density gauge will provide inaccurate data (5). Also, nuclear density gauges require strict licensing and usage procedures. Non-nuclear gauges offer the ability to take numerous density readings in a short period time, and no intensive licensing, training and maintenance efforts are required. However, Williams et al. (8) pointed out that non-nuclear gauges can be significantly affected by factors such as the existence of water or sand present between the gauge and the mat. Figure 1 illustrates main methods for $G_{m b}$ measurements and a brief description of each of these density measurement techniques follows. 


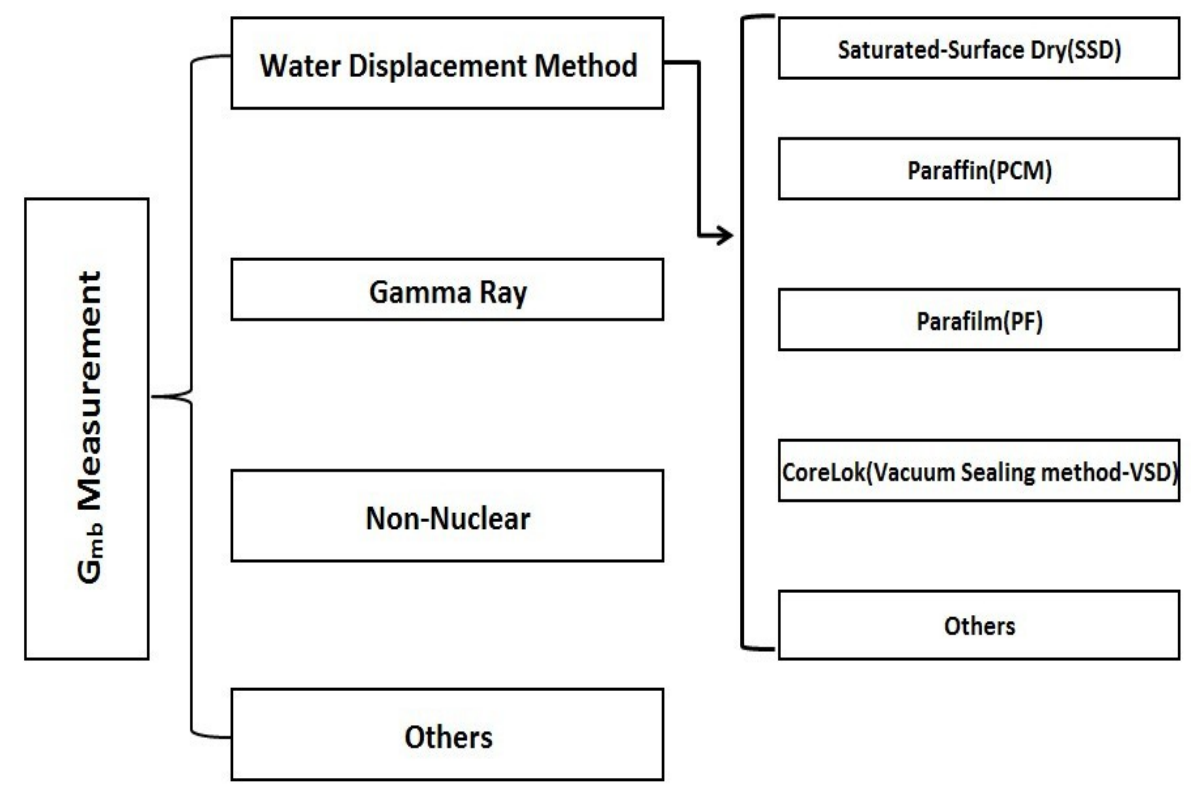

Figure 1 Different methods for $\mathrm{G}_{\mathrm{mb}}$ measurement

\subsubsection{Saturated-Surface Dry method}

The most commonly used method to determine bulk specific gravity of compacted hot mix asphalt is the water displacement method, or Saturated-Surface Dry (SSD) method. Water displacement method is based on Archimedes' Principle. This method consists of first weighing a dry sample in air, then obtaining a submerged mass after the sample has been placed in a water bath for $4 \pm 1$ minutes. Finally, the SSD mass is determined by removing the sample from the water bath and dry its surface using a damp towel within 5 seconds. Figure 2 shows a SSD sample. The difference between the SSD mass and submerged mass is used to calculate the weight of water displaced. Using the specific gravity of water $\left(\sim 1 \mathrm{~g} / \mathrm{cm}^{3}\right)$, the volume of the specimen can be determined. Procedures for this test method can be found in $\mathrm{T}$ 166 or American Society for Testing and Materials (ASTM) D 2726. The $G_{m b}$ of the specimen is computed using the Equation 2.1 and the percent of water absorbed by the specimen is calculated using the Equation 2.2. If the specimen absorbs more than two percent of water by volume, AASHTO T 275 or ASTM D 1188 should be performed for determining the bulk specific gravity. ${ }^{4}$

\footnotetext{
${ }^{4}$ This is the current requirement of AASHTO T166. At the time of this writing, AASHTO is
} considering altering the method to require the vacuum method AASHTO T331 when water absorption is greater than 1 percent. 


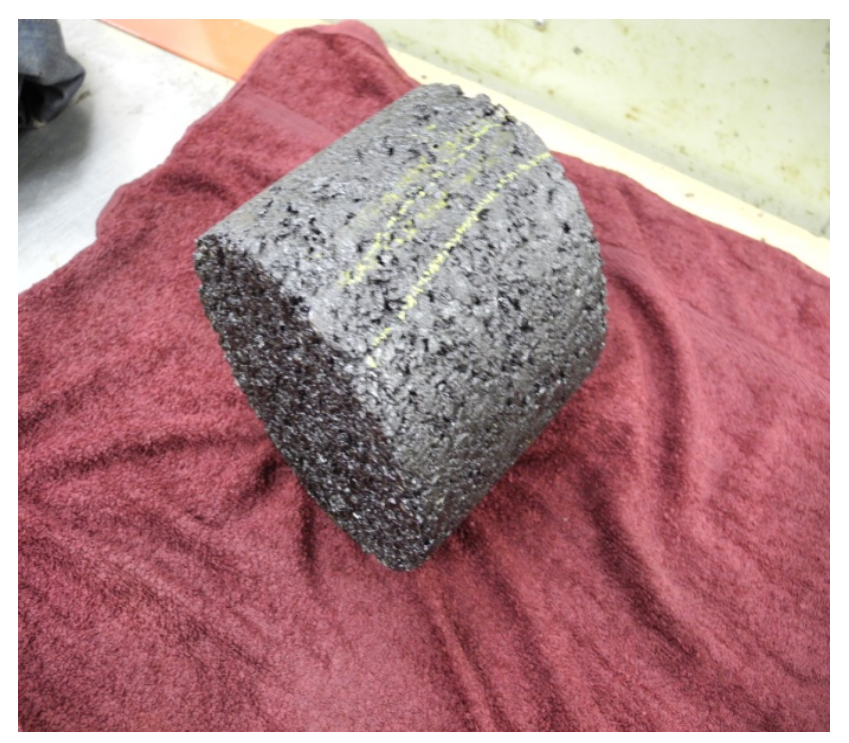

Figure 2 A saturated-surface dry sample

$G_{m b}=\frac{A}{B-C}$

$\%$ Water Absorbed by Volume $=\frac{B-A}{B-C} \times 100$

where:
$A=\quad$ the mass of specimen in air;
$\mathrm{B}=\quad$ the mass of the surface-dry specimen in air; and
$\mathrm{C}=\quad$ the mass of the specimen in water

The SSD method has been proven adequate for Marshall and Hveem mix design methods; however, for Superpave and stone matrix asphalt (SMA), the SSD method may produce erroneous $G_{m b}$ results (6 and 13). Mixes with coarser gradation have a higher percentage of large aggregate particles; the internal air voids can become interconnected. When measuring the SSD mass, it is assumed that the water contained in the pores of the specimen is intact and weighed along with the specimen. Any water that seeps from the specimen during weighing is considered part of the SSD specimen weight, as shown in Figure 3. In practice, for coarse-graded mix, water can easily and quickly drain from the interconnected voids when removing the specimen from the water bath and drying its surface using the damp tower, as shown in Figure 4. The loss of water leads to a lower SSD mass. According to Equation 2.1, $\mathrm{G}_{\mathrm{mb}}$ would be calculated higher than it actually is. Values for both VTM and VMA will be lower, consequently. 


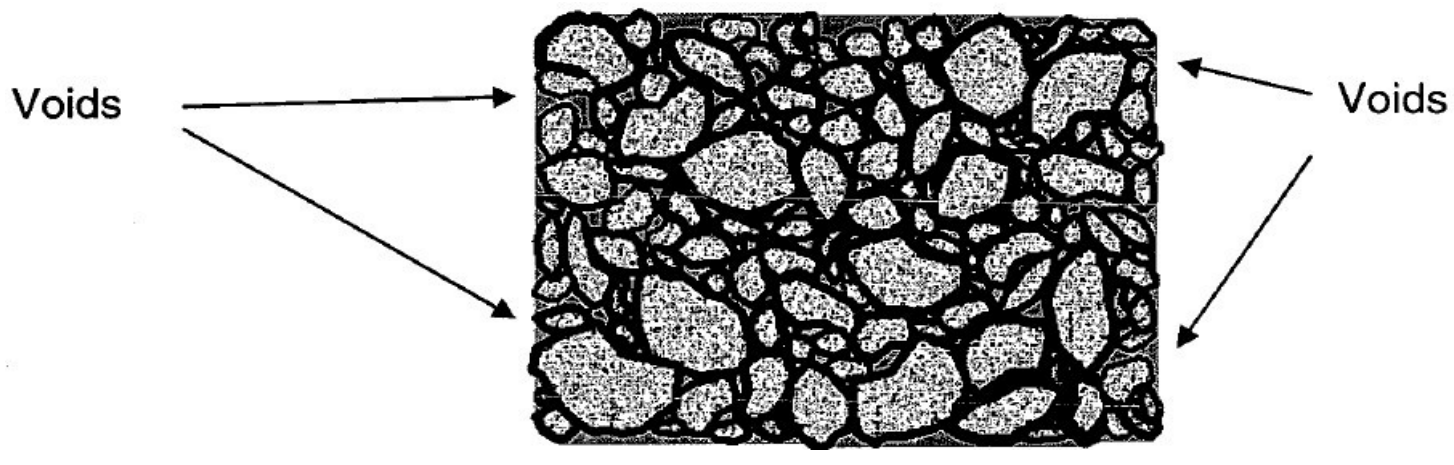

Figure 3 Compacted asphalt pill with voids filled with water (6)

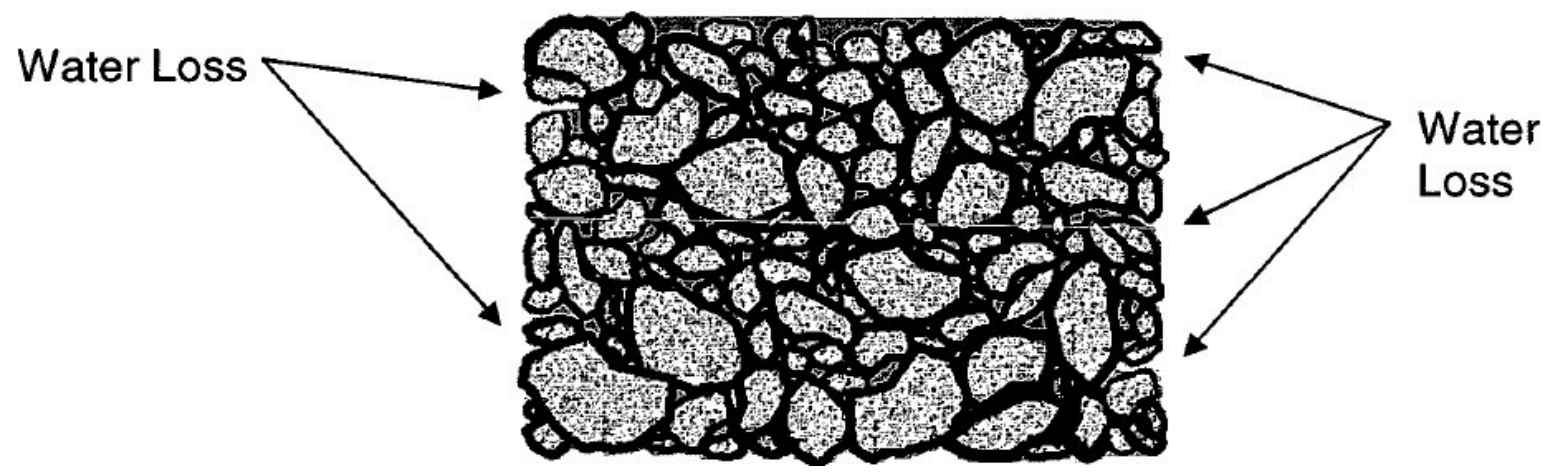

Figure 4 Compacted asphalt pill in SSD condition with potential water loss(6)

\subsubsection{Paraffin and Parafilm method}

Procedures for paraffin and parafilm method are described in AASHTO T 275 or ASTM D 1188 to deal with the water absorption issue encountered in the water displacement method. When a specimen absorbs more than two percent water by volume or it contains open or interconnecting voids, AASHTO T 275 should be used.

Paraffin method determines the volume of specimen using a melted paraffin wax for the external sealing (not filling) of a specimen's surface voids (9), Figure 5.In this method, the mass of the oven-dried specimen is determined before and after coating it with liquid paraffin wax. The coated specimen is then weighed in a water bath. The bulk specific gravity is determined as:

$$
G_{m b}=\frac{A}{D-E-\left(\frac{D-A}{F}\right)}
$$


where:
$A=\quad$ the mass of the dry specimen in air;
$\mathrm{D}=$ the mass of the dry specimen plus paraffin coating in air;
$\mathrm{E}=$ the mass of the dry specimen plus paraffin coating in water; and
$\mathrm{F}=$ the specific gravity of the paraffin at $25 \pm 1^{\circ} \mathrm{C}\left(77 \pm 1.8^{\circ} \mathrm{F}\right)$.

The parafilm method is similar to the paraffin method. A thin paraffin film wraps the specimen instead of using melted paraffin, Figure 6. An oven-dried HMA specimen is weighed in air. After wrapping the specimen with parafilm, the specimen is then weighed in air again. Then, the wrapped specimen is submerged in a water bath and weighed. The bulk specific gravity is determined by Equation 2.3.

A study conducted by Buchanan (10) indicated the paraffin method and parafilm method can be time consuming and difficult to perform. AASHTO T 275 shows poor repeatability, high sensitivity to operator involvement and training, and there is no specification for sealing $150 \mathrm{~mm}$ diameter specimens (11). The test results for parafilm method are somewhat inconsistent, especially when air voids are high (9).

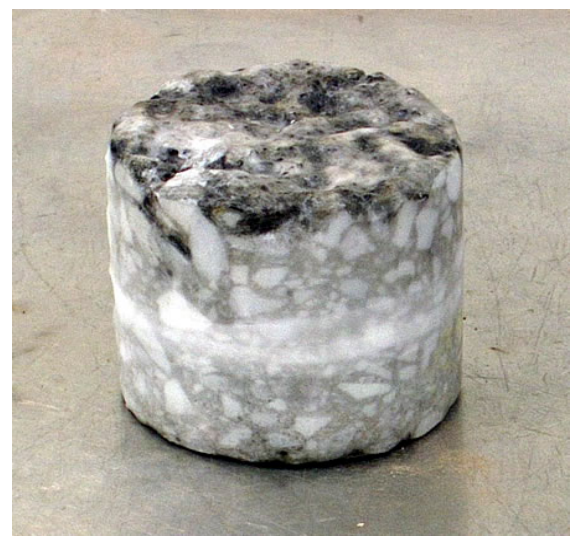

Figure 5 Paraffin coated specimen

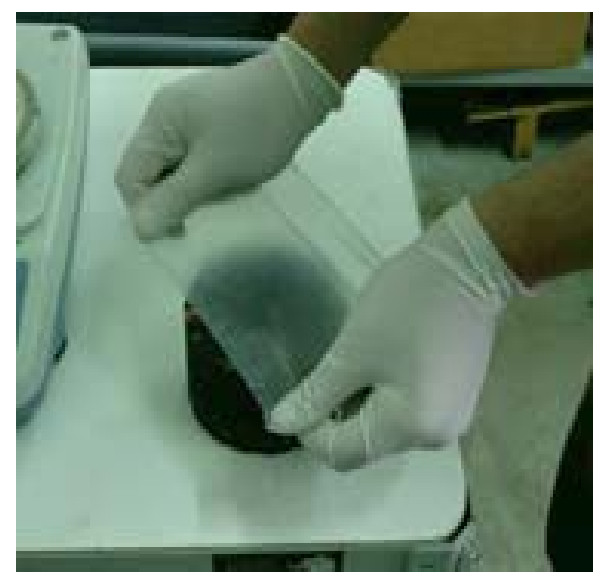

Figure 6 Application of parafilm 


\subsubsection{Vacuum Sealing Method}

The vacuum Sealing Method (VSM) measures specimen volume in a similar way to parafilm but uses a vacuum chamber to shrink-wrap the specimen in a specially designed, puncture resistant, resilient plastic bag instead of using parafilm to coat the specimen. The CoreLok vacuum-sealing device, invented by InstroTek Inc. Figure 7, has been adopted by researchers and transportation agencies to determine the $G_{m b}(6) . G_{m b}$ measurement with the CoreLok self-vacuuming device is standardized by AASHTO T331 and ASTM D 6752. $\mathrm{G}_{\mathrm{mb}}$ is calculated by Equation 2.4. The CoreLok Operator's Guide (12) outlines procedures for determining $G_{\mathrm{mb}}$ of compacted HMA specimens:

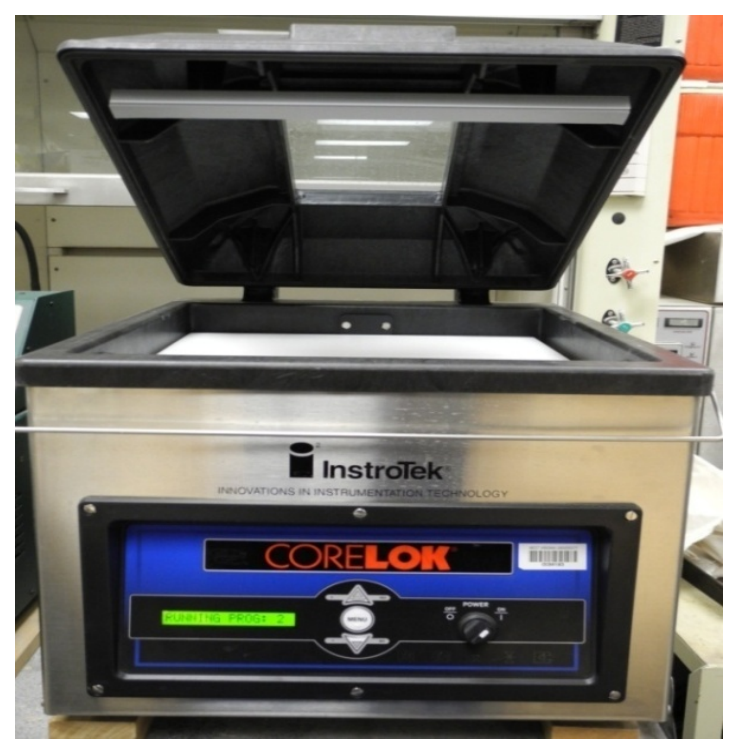

Figure 7 CoreLok InstroTek, Inc

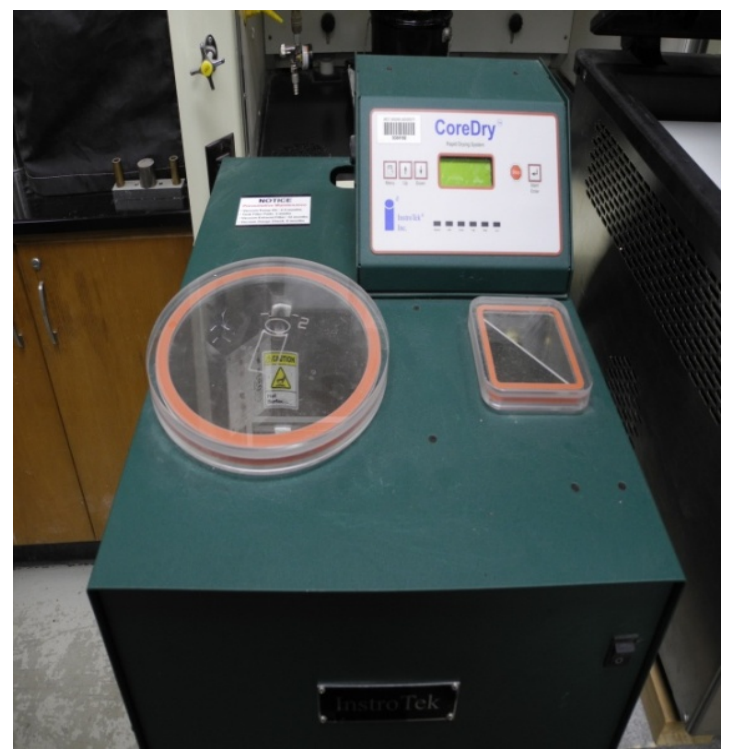

Figure 8 CoreDry InstroTek, Inc 
1. Determine the density of the plastic specimen bag (InstroTek provided), and weighthe bag.

2. Weigh the compacted HMA specimen (dried by an oven or a CoreDry device, Figure 8), and then put the specimen into the bag.

3. Place the bag and specimen inside the CoreLok vacuum chamber.

4. Close the vacuum chamber door. For cores or lab-compacted specimen, program \#1 should be selected. The vacuum pump will start and evacuate the chamber to $760-\mathrm{mm}$ (30-in) Hg automatically.

5. The chamber door will open automatically when the specimen is completely sealed in the plastic bag and ready for water displacement testing.

6. Transfer the plastic bag (sample inside) into the water bath immediately, and record the stabilized submerged weight.

7. Remove the seal core from the water, cut open the bag and record the weight of the sample being tested.

$\mathrm{G}_{\mathrm{mb}}=\frac{\mathrm{A}}{(\mathrm{A}+\mathrm{B}-\mathrm{C})-(\mathrm{B} / \mathrm{D})}$

where:
$\mathrm{A}=\quad$ the mass of specimen;
$\mathrm{B}=\quad$ the mass of the plastic bag;
$\mathrm{C}=\quad$ the mass of plastic bag and specimen in water; and
$\mathrm{D}=\quad$ the density of plastic bag.

Buchanan and White (13) found significant difference in $G_{m b}$ data collected using the CoreLok and water-displacement method, with water-displacement procedures resulting in slightly higher $G_{m b}$ values. The difference became more significant with the increasing water absorption value for coarse-graded mixes, but kept constant for fine-graded mixes. HMA gradation was the most significant factor that affected the difference between CoreLok and water-displacement procedures. The CoreLok procedures were recommended as a potential method to determine $G_{m b}$ of specimen more accurately, particularly for coarse-graded mixes during both HMA mix design and QA/QC testing (13). The same conclusion was made by Williams (14) based on computing VTM, as illustrated by Table 1. 
Table 1 Comparison of air voids using CoreLok method versus T166 (14)

\begin{tabular}{|c|c|c|c|c|c|}
\hline Gradation & $\begin{array}{l}\text { Density } \\
\text { Methods }\end{array}$ & $\begin{array}{l}\text { Mean of } \\
\text { Computed VTM }\end{array}$ & $\begin{array}{l}\text { Std. } \\
\text { Dev }\end{array}$ & $\begin{array}{l}\text { Sample } \\
\text { Size }\end{array}$ & $\begin{array}{l}\text { Statistical } \\
\text { Difference }\end{array}$ \\
\hline \multirow{2}{*}{$\begin{array}{l}\text { Fine- } \\
\text { graded }\end{array}$} & CoreLok & 6.73 & 4.22 & \multirow{2}{*}{53} & \multirow{2}{*}{ No, p-value $=0.950$} \\
\hline & $\mathrm{T} 166$ & 6.75 & 4.22 & & \\
\hline \multirow{2}{*}{$\begin{array}{l}\text { Coarse- } \\
\text { graded }\end{array}$} & CoreLok & 6.56 & 2.72 & \multirow{2}{*}{81} & \multirow{2}{*}{ Yes, p-value $=0.011$} \\
\hline & $\mathrm{T} 166$ & 5.95 & 1.77 & & \\
\hline \multirow{2}{*}{$\begin{array}{l}\text { All } \\
\text { Mixes }\end{array}$} & CoreLok & 6.62 & 3.29 & \multirow{2}{*}{134} & \multirow{2}{*}{ No, p-value $=0.098$} \\
\hline & $\mathrm{T} 166$ & 6.27 & 2.87 & & \\
\hline
\end{tabular}

Cooley et al. (6) found the CoreLok procedure is a better measure of sample density, especially when the air void content is higher. When the mixes have gradations passing below the restricted zone ${ }^{5}$, there were significant differences between the T166 and CoreLok results, and the differences were not constant and were influenced by mix type and air voids content. Unlike the T166 test method, the CoreLok procedure does not overestimate $\mathrm{G}_{\mathrm{mb}}$ at high air void levels.

Hall et al. (15) found that the CoreLok method had smaller multi-operator variability (standard deviation of the test results) than the water displacement method. This small variability can be explained by the little involvement from the operator during the measuring process, and indicated that the CoreLok method is repeatable. However, analyses results from a round-robin study conducted by Cooley et al. (6) indicated that the experience with CoreLok procedure can influence the testing results. Thus, the repeatability and reproducibility of the procedure needs to be evaluated before the CoreLok vacuum-sealing device is specified by agencies.

Cooley et al. (6) found several potential factors that may reduce the variability of CoreLok method. One of the major concerns is the plastic bag thickness. The bags are designed to be puncture resistant and resilient, but in practice, some bags were punctured in the study. Once punctured, water infiltrates the plastic bag. The GravitySuite software provided by the InstroTek, Inc. for calculating the $\mathrm{G}_{\mathrm{mb}}$ results accepts $5 \mathrm{~g}$ as a maximum difference of sample's dry weight before and after the $G_{m b}$ measurement. The time interval

\footnotetext{
${ }^{5}$ When the Superpave method was introduced the restricted zone concept was used in an attempt to eliminate mixes that were difficult to compact (tender mixes). Blended aggregation when plotted on a 0.45 power gradation which passed above or below the restricted zone will be designated as fine or coarse blends, respectively. The restricted zone concept has been replaced with the primary control sieve.
} 
between the vacuum sealing and remove the sample to a water bath is very short, “immediately” as described by the CoreLok Operator’s Guide. The CoreLok bags can lose vacuum over time which leads to an overestimated volume of the specimen.

\subsubsection{Nuclear Density Gauge}

Nuclear density gauge, Figure 9, utilizes a radioactive isotope, such as gamma photon emitter Cesium 137 or 241-Beryllium to estimate pavement density by measuring the amount of direct transmitted or backscattered gamma radiation photons (16). Based on the scattering and adsorption properties of gamma rays with matter, the gamma ray method for bulk specimen specific gravity measurement is a simple and non-destructive method (1).

The fundamental mechanism for the application of gamma rays during the density measurements is called Compton scattering or Inelastic scattering. When gamma rays penetrate through a specimen, there is a decrease in energy caused by the collision between photons of gamma rays and electrons of the specimen (16). Typically, there are two kinds of modes for nuclear density gauges: 1) direct transmission; and 2) backscatter. Usually, the backscatter model is used to measure the density of HMA pavement, Figure 10.

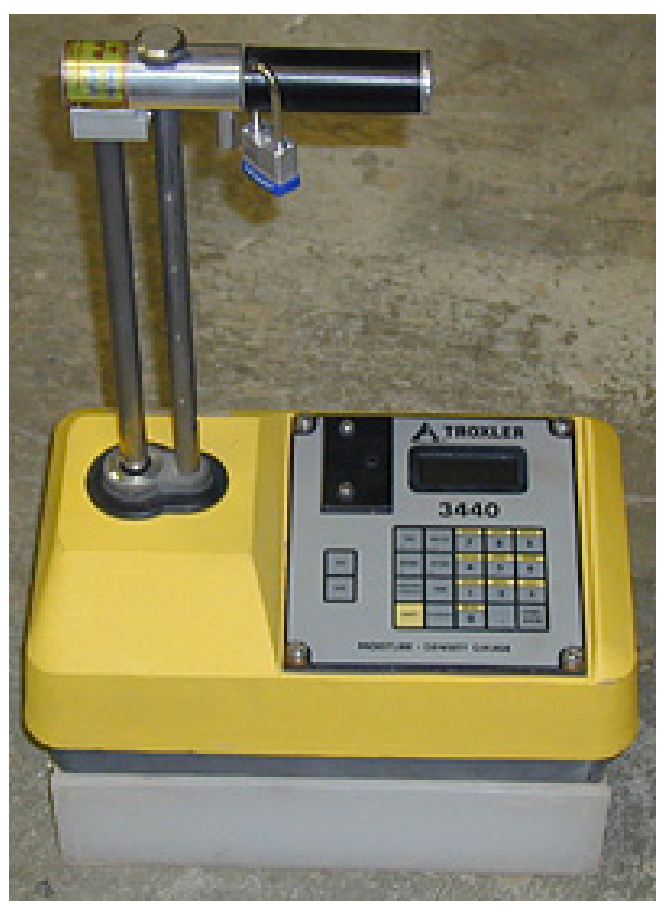

Figure 9 Troxler nuclear density gauge model 3440 


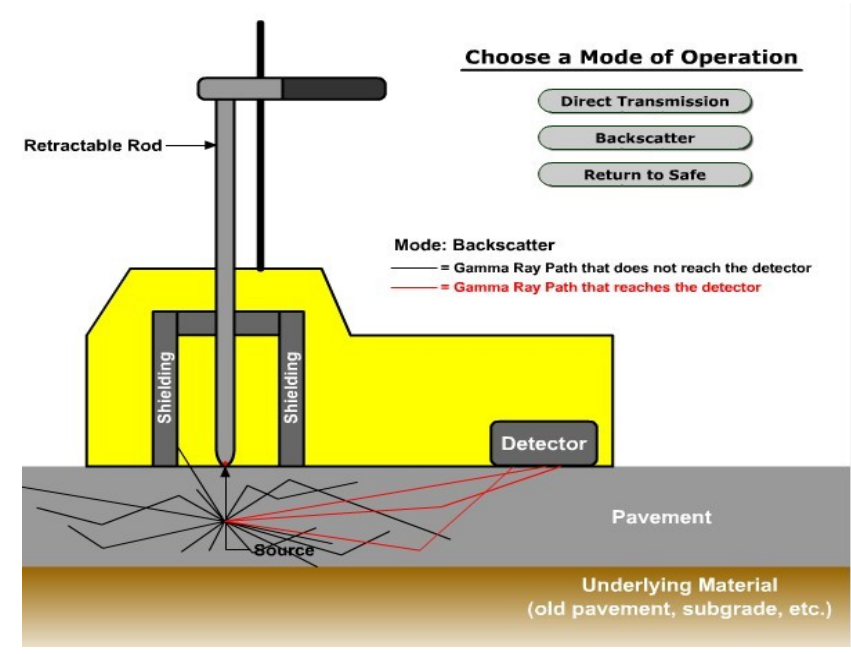

Figure 10 Nuclear density gauge backscatter model (17)

Troxler Electronic Laboratories, Inc. manufactures a thin-lift density gauge to measure the density of thin-lift asphalt and concrete overlays from 2.5 to $10 \mathrm{~cm}$ (1 to 4 inches) without influence from the underlying material, Figure 11 . The Troxler Model $4640-\mathrm{B}^{6}$ can be used to measure the backscattered gamma radiation photons and to compute the true density of the overlay without nomograph and manual corrections.

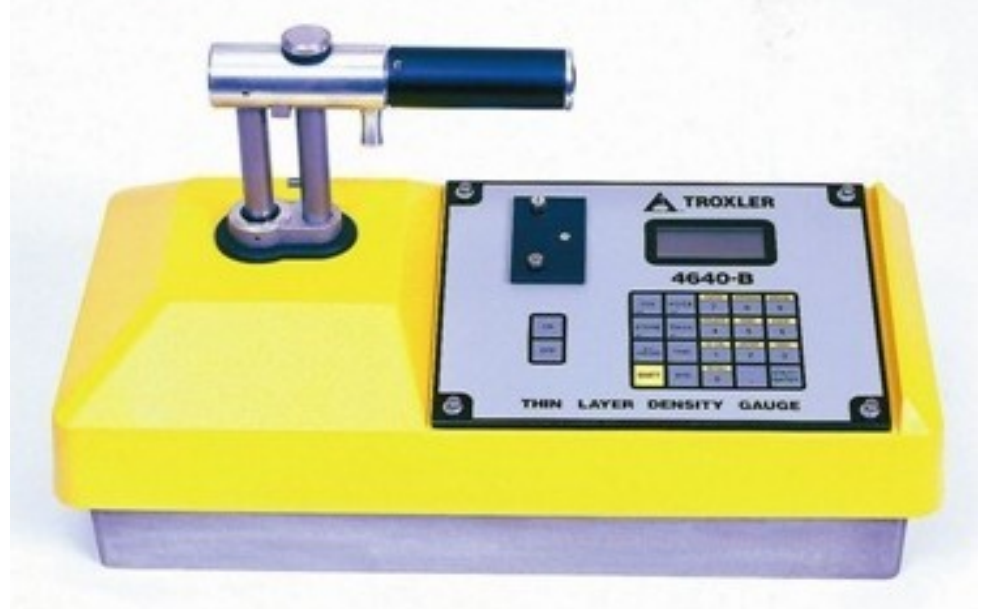

Figure 11 Troxler model 4640 thin-lift density gauge

The retractable rod is within the instrument and even with the detector. Radiation scattered towards the detector is counted, thus thicker the pavement higher the probability

\footnotetext{
${ }^{6}$ The Troxler Model 4640 gauge is described on the Troxler Website as a thin layer gauge for compaction control of thin lift asphalt and concrete overlays. In the following sections, this gauge is referred to its common name, the "thin-lift gauge".
} 
that radiation will be redirected towards the detector. The calibration factor should be used to correlate the count to the actual density (17). The photon count is directly converted to the bulk specific gravity of the specimen based on the fact that Compton scattering is a function of electronic specific gravity of the material, or even further a function of the calibrated mass specific gravity of the material (18).

The nuclear density gauge must be calibrated, preferably against actual core densities obtained from the same material it will be used to measure (19). A relationship between the counts and known density blocks is usually established during the calibration process at the factory (20). Several factors such as the rugged use, the rough construction industry environment, changes in the gauge's mechanical geometry, degradation of the radioactive source or the electronic drift of the gauge's components will change the gauge calibration with the time (20). Research by California Department of Transportation (21) indicated that the nuclear gage density calibration should be performed at least once every 15 months with gage radiation count reading taken on a set of three standard density blocks, for example, three metal density blocks located at Trans Lab, CA (21).

One of the main concerns that affect the nuclear gauge accuracy is the thickness of HMA mat. Some gauges require a thickness value be keyed into the instrument before obtaining the density results. In practice, the exact thickness of the test location does not equal to the keyed value which is the specified project thickness. A misleading HMA density value can be obtained from differences between the specified thickness and the field thickness (22). Proper pre-construction surface treatments such as milling are suggested to reduce the variability in nuclear density gauge reading caused by inconsistencies in overlay projects (8). Though most of the influential factors like environment surrounding the equipment as well as variations in the material, surface texture, aggregate types, temperature, and moisture can be compensated by proper field adjustment, further research should be conduct concerning issues related with the overall accuracy and consistency (16).

Although the nuclear gauge overcomes the destructive nature of coring, and accomplishes the density measurement within one to five minutes, the nuclear density gauge generates more variable results than core measurements (23). The accuracy of measured density using the nuclear density gauge depends on a good relationship with core data from the project (8). Furthermore, because the nuclear density gauges contain radioactive materials, the operators must be certified, the records of exposure must be kept. The gauges and 
operators require monitoring to ensure safety. The cost of operating the gauges is higher than laboratory methods (23).

\subsubsection{Non-nuclear density gauge}

Non-nuclear density gauge use electro-magnetic signals to estimate the in-place density. When an electrical current is transmitted through an asphalt pavement, the change in electromagnetic field is measured by the non-nuclear density gauge (24). When an electrical current passes from the transmitter, it is forced around an isolation ring, through the pavement, and is detected by the receiver. The dielectric constant is determined by measuring the impedance, or resistance to electrical flow, Figure 12. The use of electro-magnetic signals eliminates the licensing, training, specialized storage, exposure records, and radiation exposure risks associated with nuclear density gauges (25).

In 1998, Trans Tech System Inc. (Schenectady, NY) introduced the first non-nuclear density gauge, the Pavement Quality Indicator (PQI), to measure uniformity in HMA pavement joints. With subsequent improvements, more models were introduced into the market. Figure 13 illustrates the PQI 301. In 2000, the PaveTracker density gauge, which is based on the same principles as the PQI, was developed and currently is marketed by Troxler Electronic Laboratories, Inc. Troxler PaveTracker ${ }^{\mathrm{TM}}$ is shown in Figure 14.

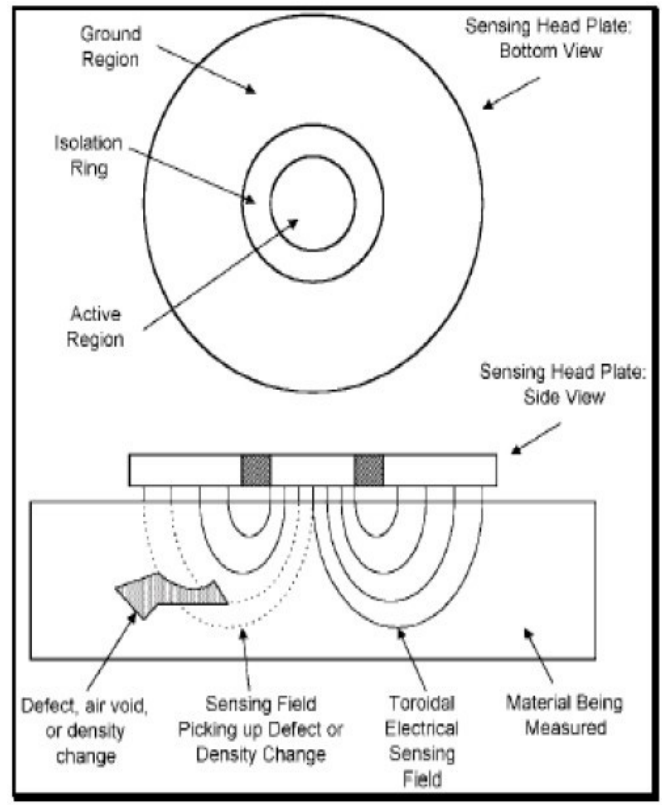

Figure 12 Schematic of non-nuclear gauge function (26) 


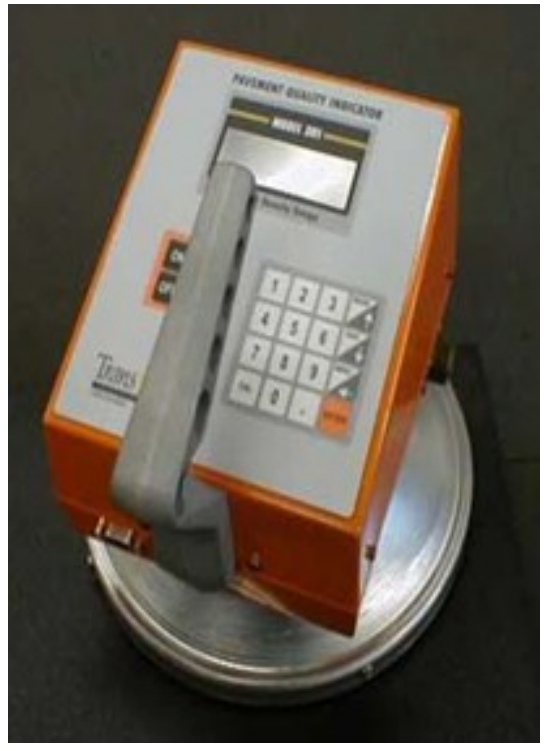

Figure 13 Pavement quality indicator ${ }^{\mathrm{TM}}$ (PQI), Model 301

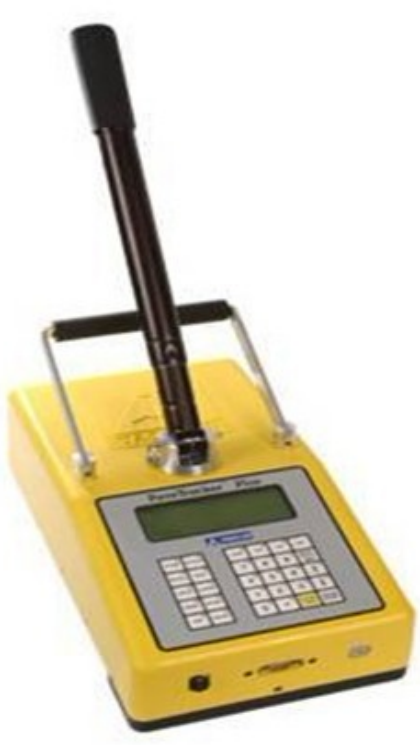

Figure 14 Troxler PaveTracker ${ }^{\mathrm{TM}}$

\subsection{Permeability Theory}

Permeability is defined as the rate of flow of a fluid through a porous medium. Some of the earliest permeability work was performed by Henry Darcy (27) in which he studied the flow of water through clean sand. The rate of water flow was shown to be dependent upon the hydraulic gradient and the cross-sectional area of the sample through which it flows, related by a coefficient of permeability, as shown in the following Equation 2.5:

$\mathrm{Q}=\mathrm{AK} \frac{\left(\mathrm{h}_{1}+\mathrm{Z}_{1}\right)-\left(\mathrm{h}_{2}+\mathrm{Z}_{2}\right)}{\mathrm{L}}$

where:

$\mathrm{Q}=$ the volume flow rate;

$\mathrm{K}=$ hydraulic conductivity;

$A=$ the area of porous media normal to the flow;

$\mathrm{Z}=$ the elevation, and the subscripts 1 and 2;

$\mathrm{L}=$ the length of the flow path; and

$\mathrm{h}=$ the pressure head and the subscripts 1 and 2 (pressure divided by the specific weight).

The coefficient of permeability is measured based on several assumptions: 1) a homogenous material; 2) steady state flow conditions; 3) laminar flow; 4) incompressible fluid; 5) saturated material; and 6) one dimensional flow. 


\subsection{Factors Affecting Permeability of Superpave Designed Mixes}

\subsubsection{Air Voids Content}

Air void content is the predominant factor that controls the permeability of HMA mixes. Work by Zube (3) in the 1950s and 1960s indicated that conventional dense-graded mixes become excessively permeable to water at air void contents above 8 percent. As for Superpave designed mixes, individual air voids are easily to be interconnected than Marshall Mix designed mixes (28). Research conducted by FDOT (4) has indicated that coarse-graded Superpave mixes can be excessively permeable to water at air void contents above 6 percent. Research by Virginia Department of Transportation (VDOT) indicated that excessive permeability for Superpave designed pavements is often caused by excessive air voids (29). Figure 15 illustrated a typical laboratory regression for permeability.

Hudson and Davis (30) concluded that permeability not only depends on the percent air voids (VTM), but also depends on the size of air voids within pavements. As the size of voids increase, the potential for interconnected air voids also increase. The in-place permeability of pavements is directly related to the amount of interconnected voids (31).

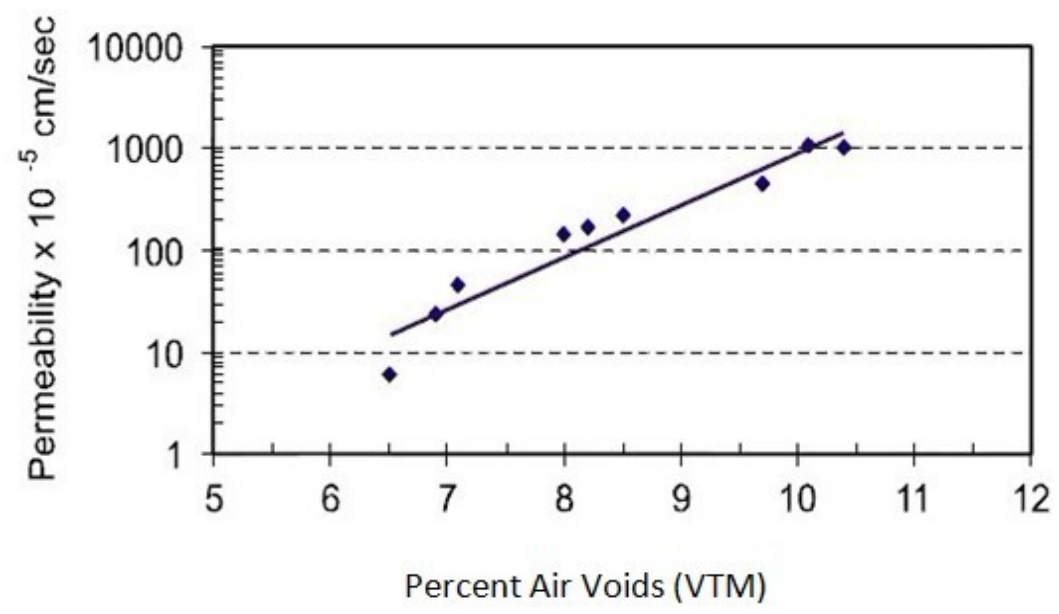

Figure 15 Typical laboratory regression line for permeability (28)

\subsubsection{Aggregate}

Kanitpong et al. (7) found the permeability of HMA mixtures cannot be estimated by air void contents alone; it also depends on the aggregate gradation. Coarse-graded Superpave mixes appear to be more permeable than conventional dense-graded mixes at similar air void levels. Cooley et al. (32) showed that aggregate gradation shape affects the size of voids in 
the pavements. The coarser the gradations, the larger the individual air voids, Figure 16. Tan et al. (33) found similar results.

Coarse-Graded Mix

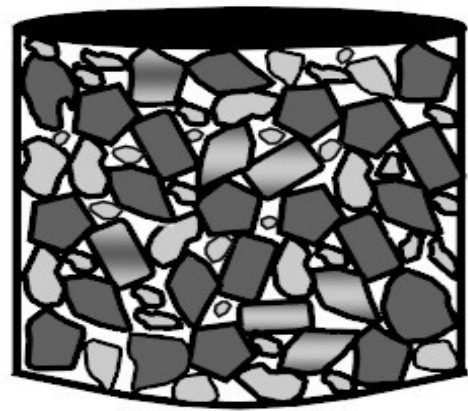

- Coarser Gradation

- Larger Sized Voids (more chance for inter-connected voids)
Fine-Graded Mix

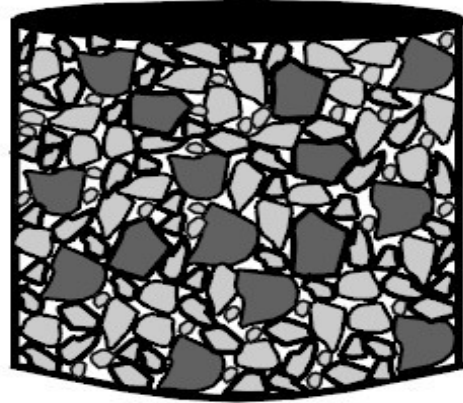

Figure 16 Internal voids structure for coarse-graded and fine-graded mixes (6)

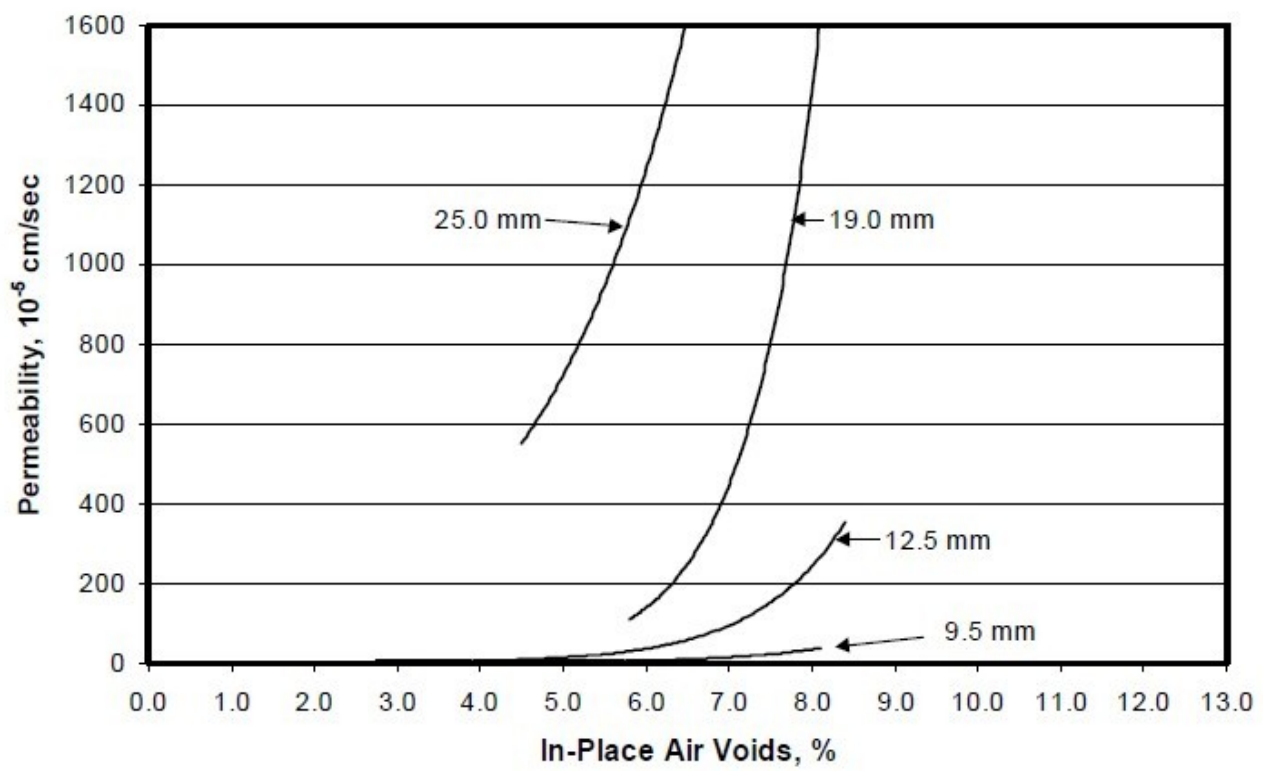

Figure 17 Best fit curves for air voids versus permeability for different NMAS (34)

Mallick and Cooley (34) concluded that NMAS affect the permeability of coarse graded Superpave designed mixes significantly. The permeability increased by an order of magnitude at a given in-place air void content with the increase of NMAS (34), as shown in Figure 17. The size of individual voids increases with increasing NMAS which results in 
higher potential for interconnected air voids (35). If a maximum $100 \times 10^{-5} \mathrm{~cm} / \mathrm{s}$ laboratory permeability was specified, then for 9.5, 12.5, 19.0 and 25.0 NMAS mixtures, the corresponding air void contents would be 7.7, 7.7, 5.5, and 4.4 percent, respectively (35).

Other factors identified in the literature as affecting permeability include aggregate shape and preparation of cores. The shape of aggregate particles can affect the permeability. Compared to smooth, rounded aggregates, irregular shaped particles (angular, flat and/or elongated) can create more tortuous flow path which decreases the permeability of pavements (36). Maupin (42) found that removing the surface of the core by sawing can decrease the permeability of field cores, as illustrated in Table 2.

Table 2 Effect of sawing on permeability (42)

\begin{tabular}{|c|c|c|c|}
\hline \multirow{2}{*}{} & Mixture & \multicolumn{2}{|c|}{ Falling Head Permeability $\times 10^{-5} \mathrm{~cm} / \mathrm{s}$} \\
\cline { 2 - 4 } & Identification & Before Sawing & After Sawing \\
\hline \multirow{2}{*}{$\begin{array}{c}\text { Sawed at Room } \\
\text { Temperature }\end{array}$} & 1140 & 1250 & 700 \\
\cline { 2 - 4 } & 1052 & 110 & 50 \\
\hline $\begin{array}{c}\text { Sawed After } \\
\text { Soaking in Ice } \\
\text { Bath }\end{array}$ & 1140 & 1330 & 880 \\
\cline { 2 - 4 } & 1052 & 170 & 80 \\
\hline
\end{tabular}

Research by Gogula et al. (37) indicated that the amount of material passing a $0.6 \mathrm{~mm}$ sieve has a significant influence on permeability. By performing regression analysis, a conclusion was made that as the amount of material passing $0.6 \mathrm{~mm}$ sieve increases, i.e. when more fine sand is present in the mix, the permeability decreases. This decrease in permeability can be attributed to the fact as finer material fills the interconnected voids between the larger aggregate particles; the percolation of water through the mix is prevented.

\subsubsection{Percent Binder}

Giompalo (38) indicated that percent of binder $\left(\mathrm{P}_{\mathrm{b}}\right)$ can affect the permeability of mixtures. For a given VTM, permeability decreases with increases of $\mathrm{P}_{\mathrm{b}}$. The void volume is the same but the void structure must be different. Figure 18 illustrates the comparison of permeability at different percent binder. 


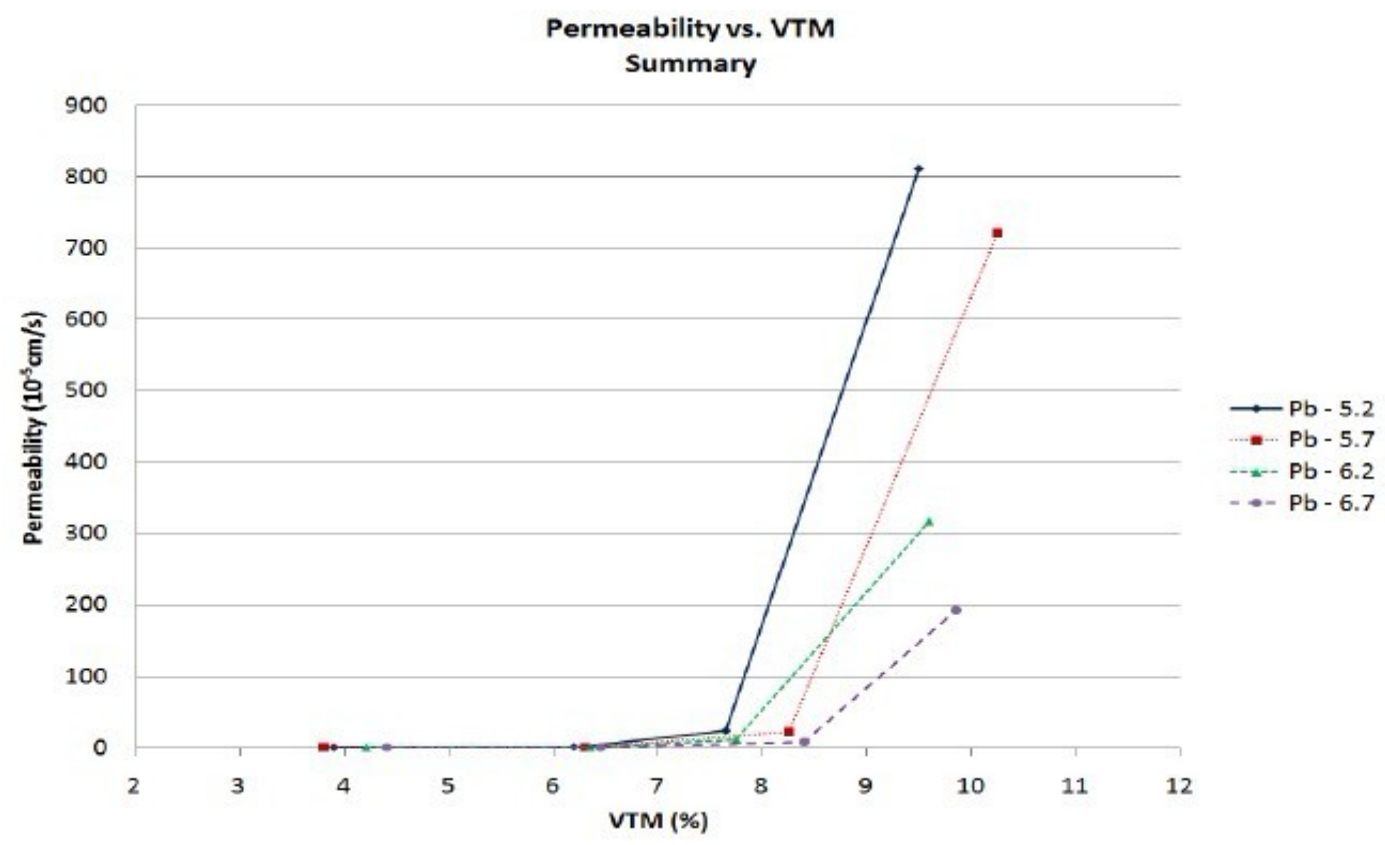

Figure 18 Comparison of permeability at different percent binder (38)

\subsubsection{Compaction Effort}

A study conducted by Cooley indicated that the lift thickness can affect the permeability of pavements. By comparing laboratory permeability of compacted samples with different thicknesses at a particular air void level, he concluded that an increase in thickness will result in a decrease in permeability (35).A thicker lift thickness reduces the amount of interconnected voids at a given in-place air void contents. Since the NMAS and lift thickness affect the permeability based on the same principle (interconnected air voids), a terminology named thickness-to-NMAS ratio was developed. Brown et al. (39) found that at least a 3.0 t/NMAS ratio should be achieved for fine graded mixes and at least 4.0 for coarse graded mixes, and at least 4.0 for Stone Matrix Asphalt (SMA). Figure 19 illustrates the relationship between Laboratory permeability and Ratio of Thickness to NMAS.

The t/NMAS is an influential factor for permeability because it has effects on density, as well as the temperature of the mixture when compact it. Regardless of the t/NMAS, a thin section will cool quickly and therefore will difficult to compact and achieve the required density. If large NMAS aggregate is used which has a relative low rate of cooling, the mixes would be easy for compaction even when the t/NMAS is low. Therefore, for mixes designed with large NMAS, the t/NMAS could be smaller (39). 


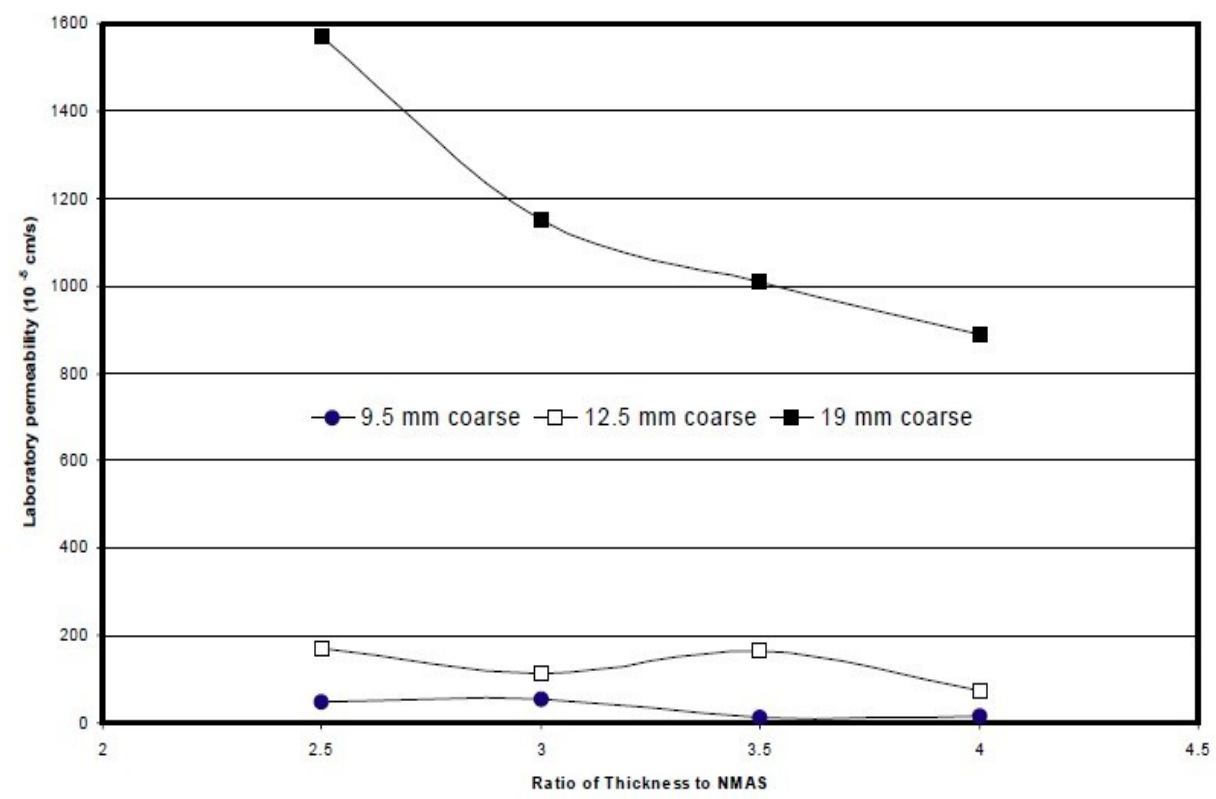

Figure 19 Relationship between permeability and t/NMAS (39)

Retzer (40) found pneumatic rollers had the potential to increase the asphalt pavements' resistance to permeability-related distresses. A better sealed pavement surface would yield lower permeability. The rubber tire rollers would seal the surface better because the texture of the rubber tires is softer than that of steel and it would knead or smooth out the surface of the mat better than steel.

The literature suggests that several factors could affect the in-place permeability of HMA pavements. Table 3 illustrates the factors that affect the in-place permeability characteristics from research done across the United States:

\subsection{Laboratory Permeability Test}

\subsubsection{Constant Head Permeability Test}

Usually, the constant head test is performed to measure sand samples or permeable asphalt samples. For instance, permeability of HMA mixtures designed to transmit water should be measured by performing a constant head test (41). Testing samples can be saw cut field cores or laboratory compacted pills, and the diameter of the specimen should be around $150 \mathrm{~mm}$. A rubber membrane should be used to wrap the specimen, and porous stones should be placed at the top and bottom. When water flows through the length of the specimen, both 
Table 3 Factors that affect the in-place permeability.

\begin{tabular}{|l|l|}
\hline \multirow{2}{*}{ 1. Air Voids } & Voids in total mix \\
\cline { 2 - 2 } & Size of air voids \\
\hline \multirow{2}{*}{ 2. Aggregate } & Percent of interconnected air voids \\
\cline { 2 - 2 } & Aggregate Gradation \\
\cline { 2 - 2 } & Nominal Maximum Aggregate Size (NMAS) \\
\cline { 2 - 2 } & Percent material passing $0.6 \mathrm{~mm}$ sieve \\
\hline 3. Percent Binder $\left(\mathrm{P}_{\mathrm{b}}\right)$ & Aggregate particle shape \\
\hline \multirow{2}{*}{ 4. Compaction Effort } & \\
\cline { 2 - 2 } & Lift thickness to NMAS ratio (t/NMAS) \\
\cline { 2 - 2 } & The use of pneumatic rollers \\
\hline
\end{tabular}

the inlet pressure and outlet pressure is controlled. Low differential inlet and outlet pressure is required to achieve a laminar low (42). Figure 20 illustrates the constant head permeability test on a highly permeable sand specimen.

The coefficient of permeability can be calculated using Equation2.6:

$\mathrm{K}=\frac{\mathrm{QL}}{\mathrm{Ath}}$

where:

$\mathrm{K}=$ permeability, $\mathrm{cm} / \mathrm{m}$;

$\mathrm{Q}=$ quantity of flow, $\mathrm{cm}^{3}$;

$\mathrm{L}=$ length of specimen, $\mathrm{cm}$;

$\mathrm{A}=$ cross-sectional area of specimen, $\mathrm{cm}^{2}$;

$\mathrm{t}=$ interval of time over which flow $\mathrm{Q}$ occurs, $\mathrm{s}$; and

$\mathrm{h}=$ difference in hydraulic head across specimen, $\mathrm{cm}$.

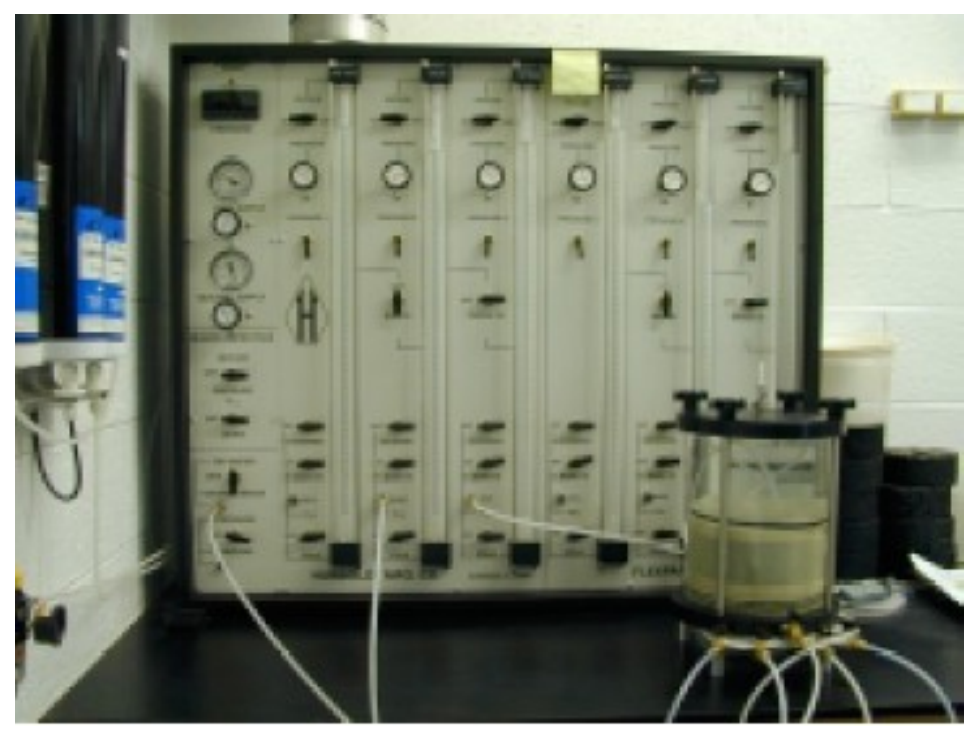

Figure 20 Constant head permeability device (42) 


\subsubsection{Falling Head Permeability Test}

Based on Darcy's Principle, the falling head permeability test is performed on low permeable asphalt concrete or clay samples. Figure 21 illustrates the Karol-Warner falling head permeability device. Water in a graduated cylinder is allowed to flow through a saturated asphalt sample and the interval of time taken to reach a known change in head is recorded. The coefficient of permeability can be calculated according to Equation 2.7.

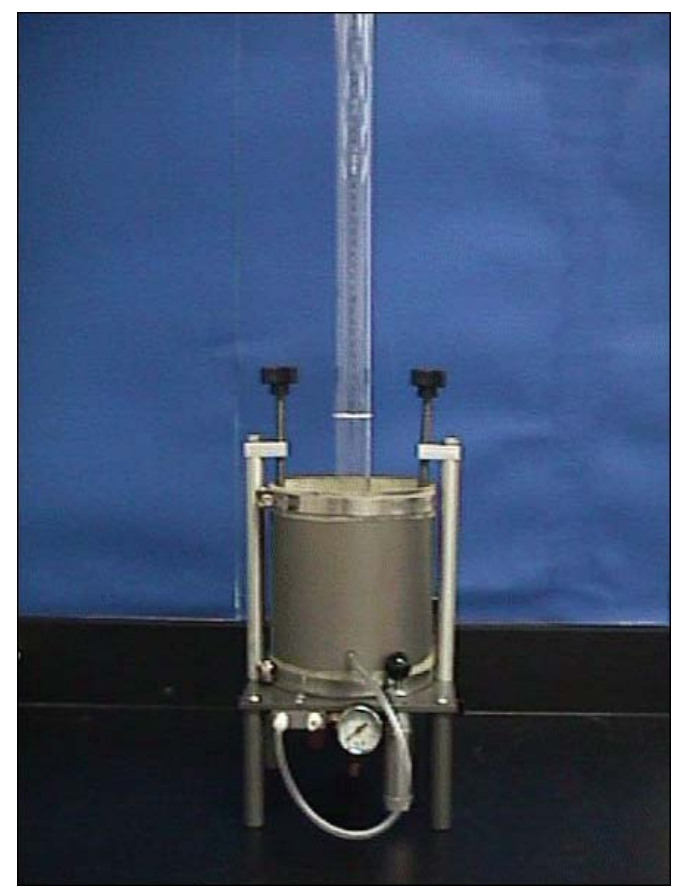

Figure 21 Karol-Warner falling head permeability device (45)

$$
\mathrm{K}=\frac{\mathrm{aL}}{\mathrm{At}} \times \ln \left(\frac{\mathrm{h}_{1}}{\mathrm{~h}_{2}}\right)
$$

where:

$\mathrm{K}=$ permeability, $\mathrm{cm} / \mathrm{m}$;

$\mathrm{L}=$ length of specimen, $\mathrm{cm}$;

$\mathrm{A}=$ cross-sectional area of cylinder, $\mathrm{cm}^{2}$;

$\mathrm{t}=\quad$ time of flow between heads, $\mathrm{s}$;

$\mathrm{a}=\quad$ area of graduated cylinder, $\mathrm{cm}^{2}$;

$\mathrm{h}_{1}=$ initial head of water, $\mathrm{cm}$; and

$\mathrm{h}_{2}=$ final head of water, $\mathrm{cm}$.

A standard procedure, FM 5-565(43) for falling head permeability test was developed by Florida Department of Transportation in 2000 and revised in 2006. 
When performing laboratory permeability test following FM 5-565, it is assumed that Darcy's Law is valid, and applies to one-dimensional, laminar flow. Before performing laboratory permeability test, the height of each core was measured at three locations recorded to the nearest $0.5 \mathrm{~mm}$. According to Florida Permeability Testing method, the maximum difference in height of the three measurements for each core is $5 \mathrm{~mm}$, any core exceeds this tolerance should be discarded.

In order to reach a saturated condition, the sample was submerged into water for one to two hours before performing laboratory permeability tests. One technique that aids in achieving saturation is to fill the graduated cylinder with water and adjust the water inflow to equal the outflow, and keep this condition for five to ten minutes. Next, the membrane was inflated to $68.9 \pm 3.4 \mathrm{kPa}(10 \pm 0.5 \mathrm{psi})$ to confine the core being tested and maintained throughout this test. Start the timing device when the bottom of meniscus of the water reaches the upper time mark. The time it takes the water level to travel from the upper mark to the lower mark is recorded as the elapsed test time. If a $4 \%$ or greater difference existed in the three elapsed times was observed, this means the core being tested did not meet the saturation requirement, and this test should be performed again. Considering the relationship between temperature and water viscosity, a temperature of $20^{\circ} \mathrm{C}$ is standardized by FDOT. The coefficient of permeability can be calculated using Equation 2.8.

$\mathrm{K}=\frac{\mathrm{aL}}{\mathrm{At}} \times \ln \left(\frac{\mathrm{h}_{1}}{\mathrm{~h}_{2}}\right) \times \mathrm{t}_{\mathrm{c}}$

where:

$$
\begin{array}{ll}
\mathrm{K}= & \text { permeability, } \mathrm{cm} / \mathrm{m} ; \\
\mathrm{L}= & \text { length of specimen, } \mathrm{cm} ; \\
\mathrm{A}= & \text { cross-sectional area of cylinder, } \mathrm{cm}^{2} ; \\
\mathrm{t}= & \text { time of flow between heads, } \mathrm{s} ; \\
\mathrm{a}= & \text { area of graduated cylinder, } \mathrm{cm}^{2} ; \\
\mathrm{h}_{1}= & \text { initial head of water, } \mathrm{cm} ; \\
\mathrm{h}_{2}= & \text { final head of water, } \mathrm{cm} \text {; and } \\
\mathrm{t}_{\mathrm{c}}= & \text { temperature correction for water viscosity. }
\end{array}
$$

Though the Florida Testing Method is widely used, Kanipong et al. (7) found this testing method yielded variable and unrepeatable data. One potential cause can be the method to ensure samples saturation. The maximum 4 percent difference between two testing time of one sample required by the FM 5-565 does not ensure or control the degree of saturation, and due to that, the permeability results obtained cannot be directly applied to describe the capability of HMA to transmit water. 


\subsubsection{Acceptable Permeability Levels}

A survey was conducted by Solaimanian to determine eight states' approach in dealing with the issue of permeability. The eight states included in the survey were Alabama, Arkansas, Florida, Georgia, Minnesota, New Hampshire, Texas, and Virginia. Georgia and Virginia use HMA permeability measurement as part of the mix design, and the remaining six states use density as a measure of controlling permeability (41). The acceptable upper limit for permeability in each of the eight states varies from $1 \times 10^{-3} \mathrm{~cm} / \mathrm{sec}$ to $1.5 \times 10^{-3} \mathrm{~cm} / \mathrm{sec}$. Table 4 illustrates the survey findings.

Table 4 Acceptable upper limit for permeability of five states

\begin{tabular}{|l|c|}
\hline Agency Name & $\begin{array}{c}\text { Acceptable Permeability } \\
\text { Upper Limit }\left(\times 10^{-3}\right) \mathrm{cm} / \mathrm{sec}\end{array}$ \\
\hline Florida Department of Transportation & 1.25 \\
\hline Virginia Department of Transportation & 1.50 \\
\hline Arkansas State Highway and Transportation Department & 1.00 \\
\hline Georgia Department of Transportation & 1.25 \\
\hline New England Transportation Consortium & 1.00 \\
\hline
\end{tabular}

\subsubsection{Laboratory Pills versus Field Cores}

Cooley et al. (57) found differences in the permeability of laboratory pills versus field cores, Figure 22. The laboratory pills were made from the same material as the field cores, and were compacted to a range of air voids. Cooley et al. (57) concluded the trends between permeability and air voids are different depending on the sample source. At less than 10 percent air voids the field samples have a higher permeability than lab cores. At greater than 10 percent air voids the slope of the curve fit to the lab pills is greater than the slope of the field cores.

\subsection{Field Permeability Test}

As a non-destructive method, field permeability testing describes a pavement's susceptibility to distresses commonly caused by water and air penetration. This has received growing concerns from State transportation departments (4, 16, 32 and 45).Table 5 lists advantages and disadvantages of the National Center for Asphalt Technology (NCAT) Permeameter and the Kentucky Air Induced Permeameter (AIP). Few researches were done on Kuss Constant Head Field Permeameter (KSHFP) and Romus Air Permeameter (RAP). 


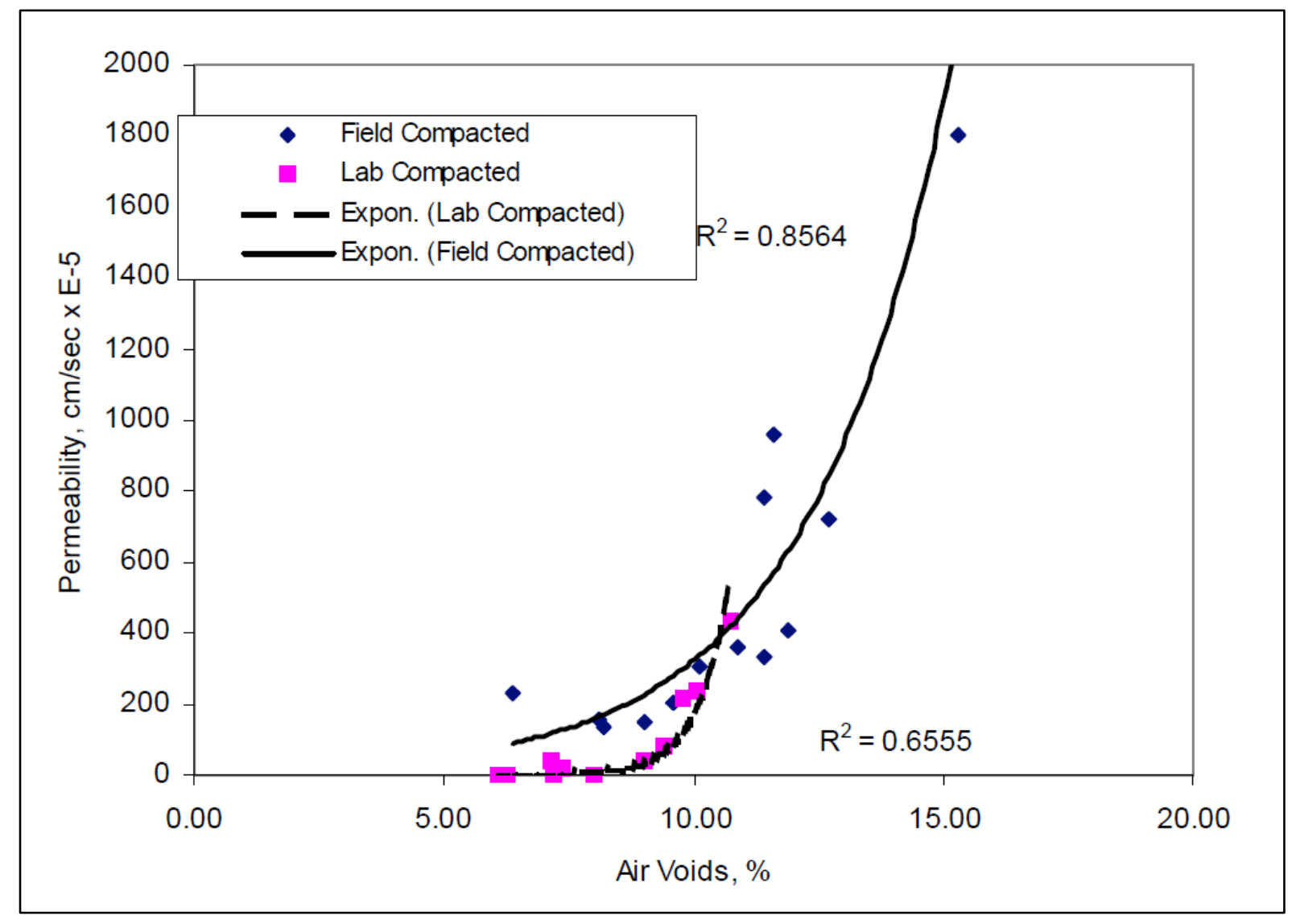

Figure 22 Permeability of laboratory pills versus field cores (57)

\subsubsection{NCAT Water Permeameter}

The NCAT Permeameter, shown in Figure 23, is a falling head test which uses a three-tier standpipe, with each tier having an increasing diameter from the top to the bottom of the device. Water is stored within the standpipe and the rate of water flow out of the standpipe and through the pavement is measured. When measuring the low permeable pavement, the smallest diameter tier (top) is used to measure the rate of water fall. As the permeability of pavement increases, the rate of water fall increases, and the larger diameter tier should be used correspondingly (44).

Water is allowed to remain in the bottom of the standpipe for at least one minute to saturate the testing spots. When the water level is at the desired initial head, start the stopwatch and stop the stopwatch when the water level within the standpipe reaches the desired final head, record the initial head, final head, and the time interval that water takes to drop from initial head to final head within the same standpipe tier. The coefficient of permeability, $\mathrm{K}$, is estimated using the Equation 2.7. 
Table 5 Advantages and disadvantages of NCATWP and AIP

\begin{tabular}{|c|c|c|}
\hline Name & Advantages & Disadvantages \\
\hline $\begin{array}{c}\text { NCAT } \\
\text { Permeameter }\end{array}$ & $\begin{array}{l}\text { - A good performance } \\
\text { on level surface. } \\
\text { - Enough time to reach } \\
\text { saturation. }\end{array}$ & $\begin{array}{l}>\text { Saturation affects the performance significantly } \\
\text { difficult to saturate low permeability pavement within } \\
\text { testing time. } \\
>\text { Difficult to remove the silicon sealant after a long } \\
\text { time of using since it cured during the test. } \\
>\text { Impossible to measure the permeability of super } \\
\text { elevated area because of the sliding of the gauge on } \\
\text { the pavement. } \\
>\text { Large amount of water is required for multiple tests. }\end{array}$ \\
\hline AIP & $\begin{array}{l}\text { - It can be self-sealed } \\
\text { and testing time is } \\
\text { relative short (one } \\
\text { minute). } \\
\text { - No supply of water is } \\
\text { required. }\end{array}$ & $\begin{array}{l}\text { A gasoline operated air compressor or an electrical } \\
\text { generator is required to create a vacuum of } 68 \text { psi. } \\
>\text { A large compressor in the field may be cumbersome. }\end{array}$ \\
\hline
\end{tabular}

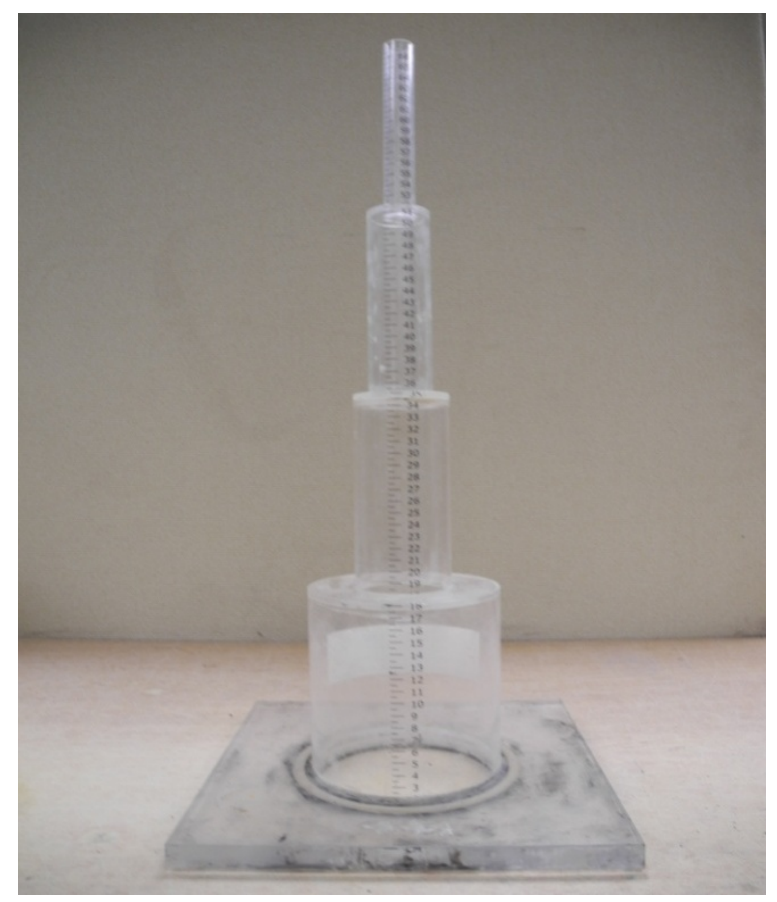

Figure 23 NCAT Permeameter by Gilson Company. Inc., Model AP-1B

It should be noted that the result from the NCAT Water Permeameter are an index of permeability rather than a true measurement. After water penetrates the pavement surface, it can flow vertically and/ or horizontally which is against the assumption that only one dimension flow exists. Without cutting the cores, the thickness and effective area of the pavement that water flows through can only be assumed which can lead to inaccurate results. 
Also, it is difficult to determine the degree of saturation of the underlying pavement.

Therefore, another parameter named infiltration rate was introduced.

In reality, water from the permeameter is not restricted to in-dimensional, and it can flow in all three dimensions. The infiltration rate is the velocity or speed at which water enters into the soil. In this study infiltration rate is a measure of the rate at which pavement is able to absorb the water on the surface. Rather than permeability, a measure of infiltration may be more appropriate (45). When performing the field permeability tests on longitudinal joints using the NCAT Permeameter, based upon data collected, Williams et al. (46) found that the computed permeability and infiltration value provided similar discrimination at joints with different quality.

The infiltration can be calculated using Equation 2.9.

$\inf =\frac{\mathrm{a}\left(\mathrm{h}_{1}-\mathrm{h}_{2}\right)}{\text { At }}$

where:

inf $=\quad$ the infiltration rate, $\mathrm{cm} / \mathrm{hr}$;

$\mathrm{a}=\quad$ inside cross-sectional area of standpipe $\left(\mathrm{cm}^{2}\right)$;

$\mathrm{h}_{1}=\quad$ initial head $(\mathrm{cm})$;

$\mathrm{h}_{2}=$ final head $(\mathrm{cm})$;

$\mathrm{A}=\quad$ cross-sectional testing area $\left(\mathrm{cm}^{2}\right)$; and

$\mathrm{t}=\quad$ elapsed time between $\mathrm{h}_{1}$ and $\mathrm{h}_{2}$, $\mathrm{hr}$

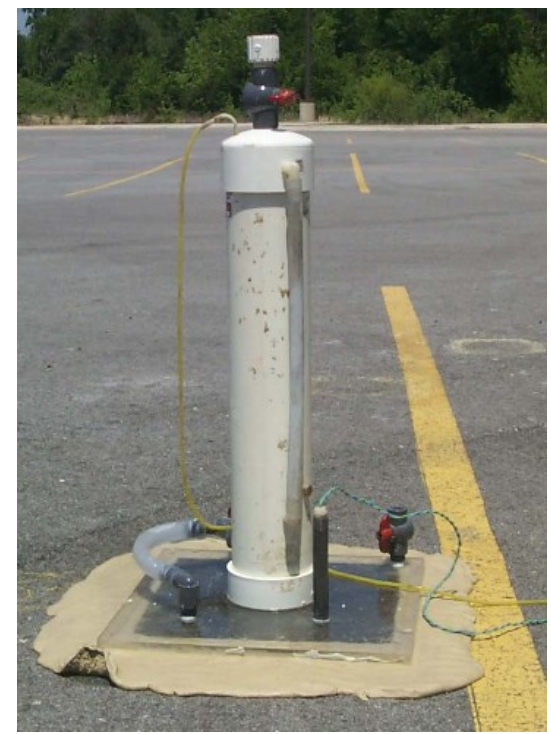

Figure 24 Kuss field permeameter (47)

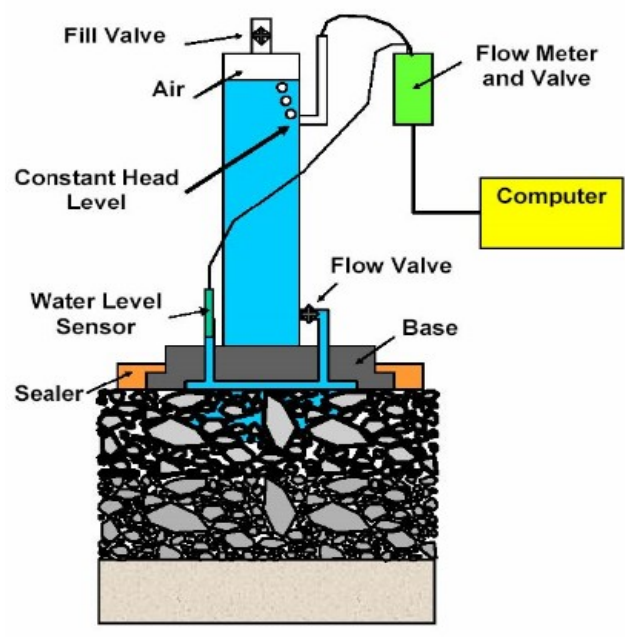

Figure 25 Schematic of kuss field permeameter (47) 


\subsubsection{Kuss Constant Head Field Permeameter (KCHFP)}

The KCHFP was developed by Mark L. Kuss in 2003, Figure 24. Based on constant head method, this device uses a patented gas-measurement system to measure the amount of air needed to replace the water to maintain a constant pressure head. When water from the standpipe infiltrates the pavement testing surface approximately 1 inch, a sensor which is connected to the flow meter box starts to monitor the water level. As water continues the infiltration, the water level over the pavement drops, and the sensor alerts the flow valve. The flow valve will allow air to enter the standpipe above the water column and the metered volume of air acts as a substitute for the head pressure originally applied by the water to maintain a constant head. The rate of water flow over time is automatically recorded by a data acquisition system. Figure 25 shows a schematic of the system.

The coefficient of permeability can be calculated using Equation 2.10.

$$
\mathrm{K}=\frac{\mathrm{Q}}{60 \times\left(\frac{2.54+\mathrm{L}}{\mathrm{L}}\right) \times \mathrm{A}}
$$

where:

$$
\begin{array}{ll}
\mathrm{K}= & \text { coefficient of permeability, } \mathrm{cm} / \mathrm{s} ; \\
\mathrm{Q}= & \text { flow rate } \mathrm{cm}^{3} / \mathrm{min} ; \\
\mathrm{A}= & \text { area of base plate }\left(1264.5 \mathrm{~cm}^{2}\right) ; \text { and } \\
\mathrm{L}= & \text { pavement thickness. }
\end{array}
$$

\subsubsection{Kentucky Air Induced Permeameter (AIP)}

Developed by Kentucky Transportation Center, the AIP utilizes a vacuum, rather than pressure to measure permeability, Figure 26. It is assumed that the smaller the voids spaces are, the more difficult it is for the AIP to draw air through pavement, and the size and percentage of voids are proportional to the permeability of pavement. The AIP uses an 8 inch diameter testing area. Silicone-rubber is used as a sealant, and the sealing ring is 3 inches in width to prevent air from "short-circuiting”. By using a vacuum, the AIP can be self-sealed. By using multi-port venturi vacuum tube, the AIP is capable of forcing pressurized air at a constant pressure of $68 \mathrm{psi}$. Air is drawn through the pavement, and the vacuum reading is recorded automatically. The more difficult it is to draw air through the pavement, the lesser the permeability is. Thus, high readings on the AIP represent low permeability (48). The coefficient of permeability can be calculated as:

$\mathrm{K}=25,757.53 \times \mathrm{V}^{-1.556}$ 
where:

$$
\begin{array}{ll}
\mathrm{k}= & \text { permeability }(\mathrm{ft} / \mathrm{day}) \text {; and } \\
\mathrm{V} & \text { vacuum reading in } \mathrm{mm} \mathrm{Hg} .
\end{array}
$$

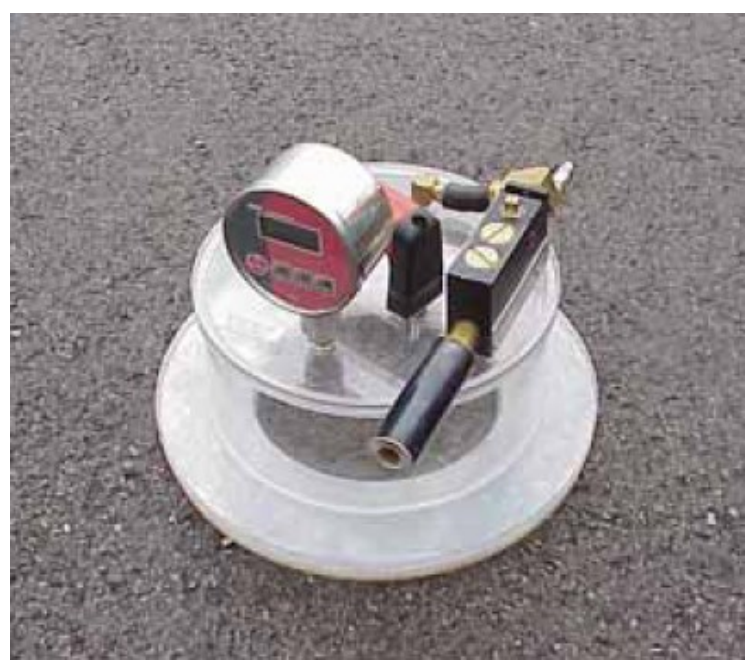

Figure 26 Kentucky AIP (46)

\subsubsection{Romus Air Permeameter (RAP)}

The RAP, manufactured by Romus Inc, determines the permeability of dry porous media, Figure 27. The falling water head is substituted by the pressure chamber, therefore the quantity of air flow through the porous media is related to the pressure drop in the air supply (47). The coefficient of permeability can be calculated using Equation 2.12.

$$
K_{w}=\left(\frac{V L \mu \gamma_{\mathrm{w}}}{A T P_{a} \mu_{w}}\right) \times \ln \left(\frac{\mathrm{p}_{1}}{\mathrm{p}_{2}}\right)
$$

where: $\mathrm{K}_{\mathrm{w}}=$ hydraulic conductivity or permeability;

$\mathrm{L}=\quad$ length of specimen;

$\mu=\quad$ dynamic viscosity of air at test temperature;

$\mathrm{A}=\quad$ cross-sectional area of sample;

$\mathrm{T}=\quad$ time for air pressure to drop from $\mathrm{p}_{1}$ to $\mathrm{p}_{2}$;

$\mathrm{P}_{\mathrm{a}}=\quad$ atmosphere pressure;

$\mathrm{p}_{1}=\quad$ air pressure at time $\mathrm{t}_{1}$;

$\mathrm{p}_{2}=$ air pressure at time $\mathrm{t}_{2}$;

$\mu_{\mathrm{w}}=$ dynamic viscosity of water;

$\rho_{\mathrm{w}}=$ mass density of water; and

$\mathrm{g}=$ acceleration due to gravity.

This device was used by Marquette University staff for the field permeability testing during projects in the state of Wisconsin (49). Compared to NCAT Water Permeameter, they 
found that the Romus air permeameter showed appreciably better data consistency for all sampling locations, and little change was observed in calculated layer permeability with successive test trials.

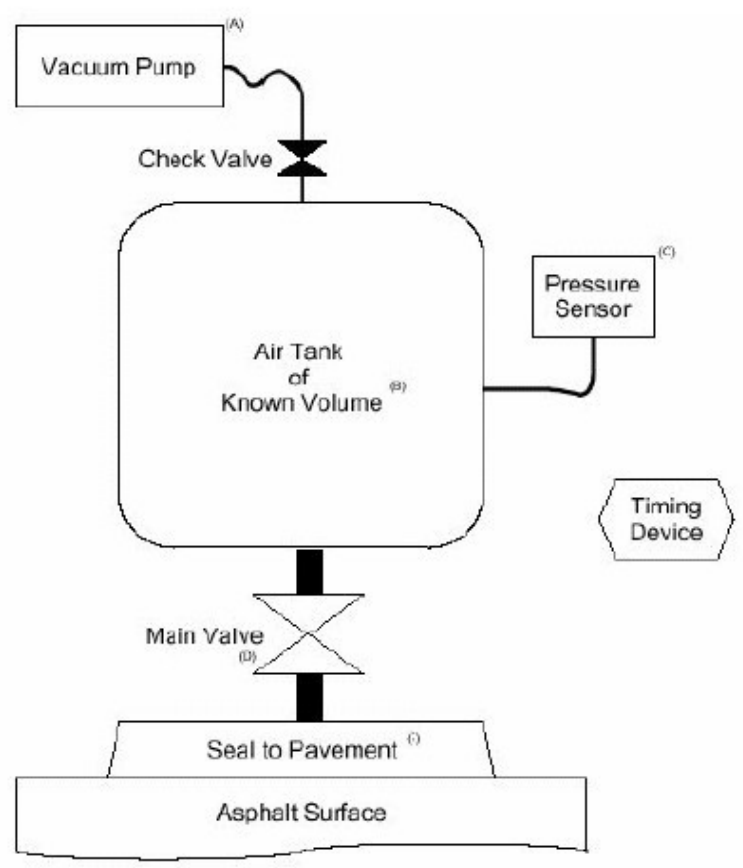

Figure 27 Schematic of romus permeameter (40)

\subsection{Mathematical Approach to the Permeability Estimation}

The literature review indicates that permeability is an important property that influences the performance of hot mix asphalt, and it is a function of several properties of HMA such as percent binder, shape, size distribution and gradation of aggregate, and compaction effort, etc. Currently, there is not a widely accepted device, procedure or specification for measuring permeability of asphalt pavements, neither ASTM nor AASHTO have a standard test method. Due to the multiple methods for permeability measurement (both field and laboratory), and the presence of interaction among the influential factors, it is difficult to develop an analytical equation that reflects the relationship between permeability and all these factors.

Based on the well-known Kozeny-Carman equation, Masasd et al. (50) developed an empirical equation that utilizes the percent air voids and surface area of aggregates for approximating the permeability of asphalt mixes. The surface area of air voids and aggregates from field was collected by using X-ray CT images. The c, $\mathrm{m}$ and t values in Equation 2.13 are obtained through statistical data fitting to permeability values expressed in the units of $10^{-}$ ${ }^{5} \mathrm{~cm} / \mathrm{sec}$. 
$\mathrm{K}=\frac{\mathrm{V}_{\mathrm{a}}^{\mathrm{m}}}{\mathrm{cS}_{\mathrm{agg}}^{2}} \frac{\gamma}{\mu}$

where:

$\mathrm{K}=$ Permeability $(\mathrm{m} / \mathrm{s})$;

$\mathrm{V}_{\mathrm{a}}=$ Air voids of porous media (\%);

$\mathrm{m}=$ Regression coefficient;

$\mathrm{c}=\quad$ Constant that depends of the idealized shape of the air voids;

$\mathrm{S}_{\mathrm{agg}}$ Average specific surface area of given gradation and NMAS $\left(1 / \mathrm{mm}^{2}\right)$;

$\gamma=\quad$ Unit weight of water at $20^{\circ} \mathrm{C}\left(9.79 \mathrm{kN} / \mathrm{m}^{3}\right)$; and

$\mu=$ Viscosity of water $\left(10^{-3} \mathrm{~kg} / \mathrm{m}-\mathrm{s}\right)$.

Westerman (51) developed an empirical equation that relates air voids and lift thickness to the in-place permeability. Later, Equation 2.14 was applied by Haddock et al. (52)in a pavement failure investigation project to estimate the permeability on Indiana State Road 38, and the permeability values obtained were confirmed by performing laboratory permeability test at VTRC following the FM 5-565.

$\mathrm{K}=\left(1.38 \times 10^{-7}\right)\left(3.92^{\mathrm{AV}}\right)\left(0.61^{\mathrm{T}}\right)$

Where:

$\mathrm{K}=\quad$ coefficient of permeability $(\mathrm{cm} / \mathrm{s})$;

$\mathrm{AV}=$ air voids (whole number); and

$\mathrm{T}=\quad$ lift thickness $(\mathrm{cm})$.

A research study was conducted by Louisiana Transportation Research Center (LTRC). Field cores from 17 Superpave projects in Louisiana were sent to LTRC, and permeability tests were performed using an LTRC modified version of Karol-Warner's falling-head permeameter. Mohammad et al. (53) conducted a sensitivity analysis to relate the permeability test results to the mixture air voids and gradation, and developed a statistical regression model to predict the permeability of Superpave mixtures from the mixture volumetric properties. The following equation was developed using multi linear regression analysis: 
$\mathrm{K}=10^{-4}\left\{76.6(\mathrm{AV})-17.2 \mathrm{P}_{0.075}+163.4 \mathrm{P}_{0.3}-197.5 \mathrm{P}_{0.6}+33.2 \mathrm{P}_{2.36}+4.5 \mathrm{P}_{12.5}-1.7 \mathrm{~L}\right\}$

where:
$\mathrm{K}=\quad$ coefficient of permeability $(\mathrm{mm} / \mathrm{s})$;
$\mathrm{AV}=$ air voids;
$\mathrm{P}_{0.075}=$ percent passing $0.075 \mathrm{~mm}$ sieve;
$\mathrm{P}_{0.3}=\quad$ percent passing $0.3 \mathrm{~mm}$ sieve;
$\mathrm{P}_{0.6}=$ percent passing $0.6 \mathrm{~mm}$ sieve;
$\mathrm{P}_{2.36}=$ percent passing $2.36 \mathrm{~mm}$ sieve;
$\mathrm{P}_{12.5}=$ percent passing $12.5 \mathrm{~mm}$ sieve; and
$\mathrm{L}=\quad$ height of specimen $(\mathrm{mm})$.

Based on the principle explained by Taylor in 1956 in channel theory work for soils, Vardanega and Waters derived representative pore size to help understand the parameters that affect permeability (54). Related to the air voids and $\mathrm{D}_{75}$ of the asphalt mix grading curve, the representative pore size is better correlated to the collected Superpave permeability data than air voids. An equation was proposed to estimate the permeability of in-place pavements:

$$
\mathrm{K}=\frac{46}{100}\left[\frac{2}{3} \times \frac{\mathrm{AV}}{100} \times \mathrm{D}_{75}\right]^{3.70}
$$

where:

$$
\begin{array}{ll}
\mathrm{K}= & \text { coefficient of permeability in } \mathrm{mm} / \mathrm{s}, \\
\mathrm{AV}= & \text { percent air voids, \%; and } \\
\mathrm{D}_{75}=75 \text { percentile particle size, } \mathrm{mm}
\end{array}
$$

Research by Vivar et al. (55) indicated that air void content, aggregate size and gradation significantly affect permeability. Both coarse-graded and fine-graded HMA mixtures with 9.5 and 19.0 mm NMAS were compacted to 4, 6, 8 and 10 percent levels air voids using a Superpave Gyration Compactor, and Florida Permeability tests were performed on all samples. An exponential relationship was observed between air voids content and permeability. By performing regression analysis, an equation was derived to investigate the relationships of permeability and influential factors. An excellent goodness of fit (adjusted $\mathrm{R}^{2}$ of 0.93 ) was achieved for this equation: 


$$
\mathrm{k}=\mathrm{VTM}^{6.8} \mathrm{e}^{(0.11 \mathrm{NMAS}-0.89 \mathrm{Gradation-10.97)}}
$$

where:

$$
\begin{array}{ll}
\text { K }= & \text { Permeability }(10-5 \mathrm{~cm} / \mathrm{s}) \\
\text { NMAS }= & \text { Nominal Maximum Aggregate Size }(\mathrm{mm}) \\
\text { VTM }= & \text { Voids in the Total Mixture; and } \\
\text { Gradation }= & 0 \text { for coarse-graded, } 1 \text { for fine-graded } .
\end{array}
$$

\subsection{Conclusion}

The literature review in this chapter presents: 1 , methods for the measurement of the bulk specific gravity, including SSD method, paraffin/parafilm method, and vacuum sealing method by CoreLok; 2, devices for HMA pavement density measurements, including nuclear density gauge and non-nuclear density gauge; 3 , factors that affect the permeability of HMA mixes, including air voids content, aggregate properties, percent binder, and compaction effort; 4, two kinds of laboratory devices for permeability measurements, including the constant head permeability test and falling head permeability test, and the critical permeability values accepted by different states; 5, four kinds of field permeameters, including NCATP, KCHFP, KAP and RAP; and 6, a summary of different models developed to predict the permeability of HMA mixes. 


\section{Chapter 3 Research Methodology}

\subsection{Introduction}

This research consists of three parts:

1) Field permeability tests were conducted at four projects using NCAT Water Permeameter. At three of the four projects, replicate permeability tests were conducted before and after the application of polymer modified emulsion asphalt which was sprayed on the pavement surface as a fog seal;

2) A total of 77 cores were removed from four construction projects and sent to the WVUATL to perform bulk specific gravity measurement and laboratory permeability test; and

3) Eight HMA mixtures, a total of 64 laboratory compacted pills were produced to perform laboratory permeability test.

\subsection{Field Permeability Test}

The field permeability testing device used in this study was developed by the National Center for Asphalt Technology, and manufactured by Gilson Company, Inc., as described in Section 2.6.1.

Putty is used to seal this device to the pavement surface. At the bottom there is a flexible rubber mat and a hole cut to the diameter of the bottom tier standpipe. After the putty is placed on the base plate, this unit is positioned on the test sites and gentle foot pressure is applied to help seat the unit against the pavement. The flexible rubber is designed to assist the foot pressure and base weight to push the putty into the pavement surface voids. When the sealing process is done, a weight is then placed on the top of the base plate to resist the hydrostatic uplift forces when the permeameter is filled with water and to provide a downward force to maintain the sealing condition (42).

In this study, field permeability test were carried out at four locations: 1) Interstate 79 at mile post 75 in West Virginia, 2) Mon-Fayette Expressway, WV State Route 43, in the north bound direction, right lane, approximately two miles from the Cheat Lake Exit, 3) Quarry Run Road, and 4) Darnell Hollow Road and Seven Springs Road within Chestnut Ridge Regional Park. 
I-79 was a 1.5 inch overlay project and the measurements were performed on the left lane, Figure 28. At the time of the research, the Mon-Fayette was not opened to traffic. The pavement structure was approximately eight years old, but was not opened to traffic due to the sequential funding of the different parts of the project. While there was no traffic damage to the pavement, the pavement was showing signs of oxidation and cracking. The WV DOT decided to apply a fog seal of Blacklidge emulsions LD-7 to help preserve the pavement surface. The infiltration rate was measured before and after the treatment to evaluate the extent of sealing of the surface. Figure 29 and 30 shows the application of fog seal at MonFayette and Quarry Run Road, and Figure 30 shows the pavement surface condition before and after the application of fog seal.

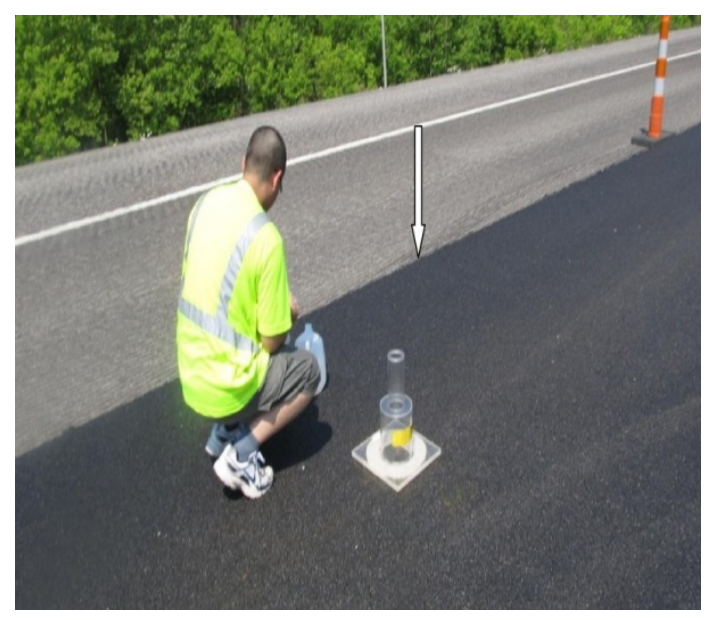

Figure 28 Field permeability test conducted at I-79 project

The LD-7, polymer modified emulsion asphalt was sprayed on the pavement surface at an application of $0.065 \mathrm{gal} / \mathrm{yd}^{2}$ and the residual rate is $0.026 \mathrm{gal} / \mathrm{yd}^{2}$. During the application, the fog seal application appeared uniform.

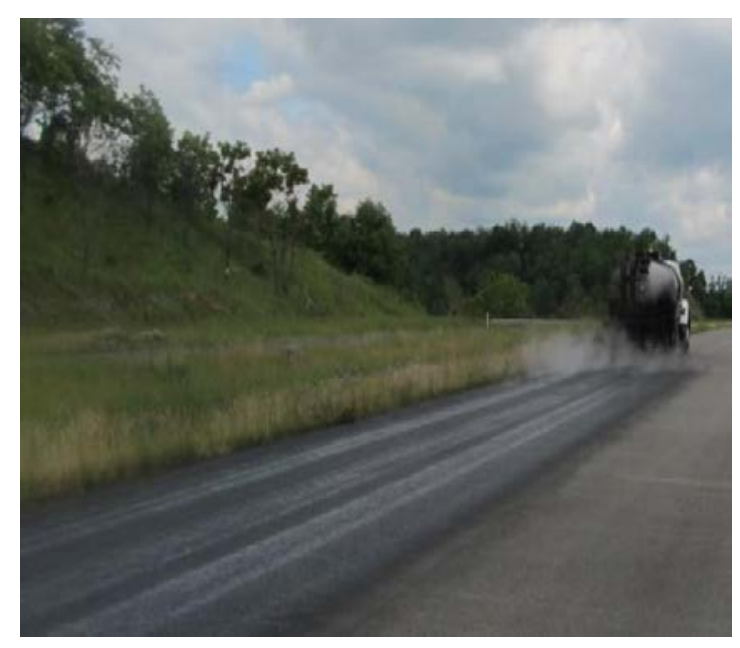

Figure 29 Fog seal application at Mon-Fayette project 


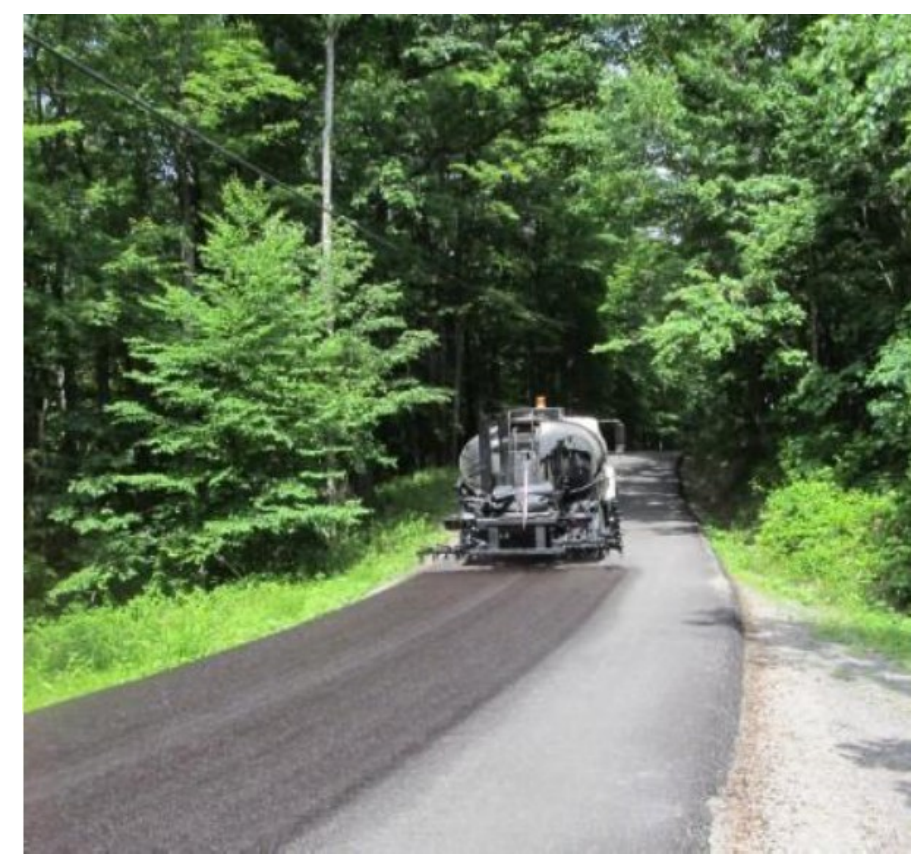

Figure 30 Fog seal application at Quarry Run Road project

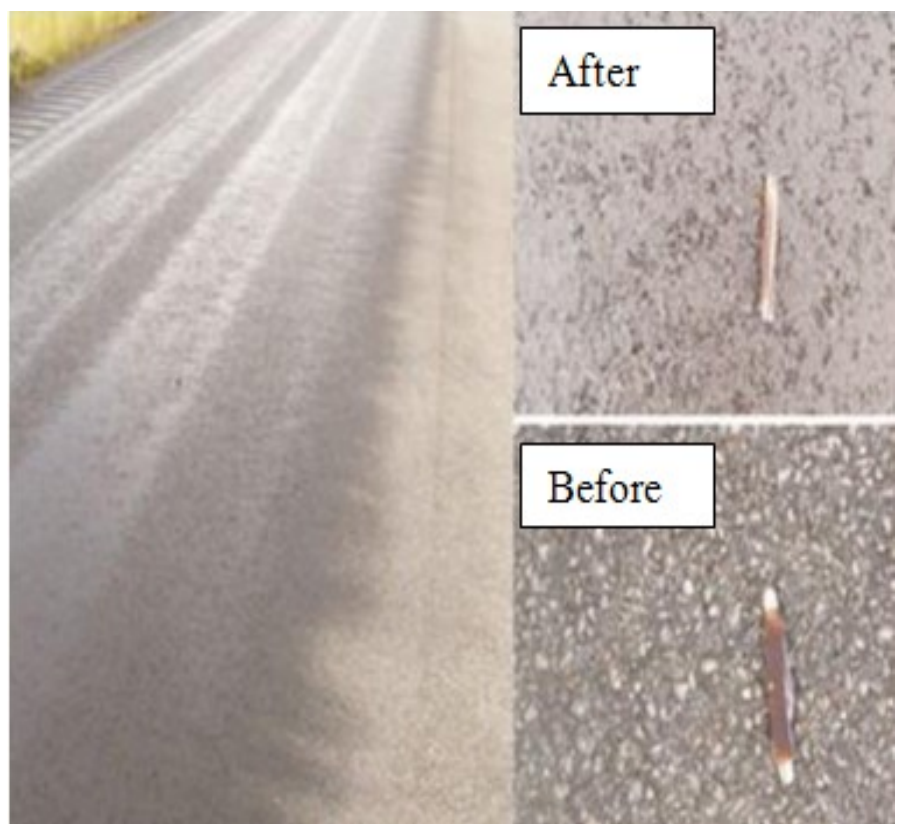

Figure 31 Mon-Fayette pavement surface before and after the fog seal

\subsection{Evaluation of Construction Projects}

During this phase of the research, cores from construction projects on I-79, I-64, and Route-19 were evaluated. Due to the nature of working with ongoing construction projects, it was not feasible to design an experiment with selected factors and levels; rather, data and samples were collected from the constructions on an "availability” basis. The bulk specific 
gravity and permeability was evaluated for a variety of samples. The bulk specific gravity was measured in several different ways.

(1) On the I-79 project, milling followed by a1.5 inch overlay of Superpave $9.5 \mathrm{~mm}$ skid resistant mix, the $G_{m b}$ was measured using several methods:

a. Four contractor nuclear gauges,

b. Two WVDOH standard nuclear gauges,

c. A thin-lift nuclear gauge on loan to the $\mathrm{WVDOH}$

d. T 166 measured by the contractor, WVDOH, and in the WVUATL.

e. CoreLok measured by the contractor and in the WVUATL.

(2) On I-64 project, 24 cores were collected. 16 cores were $9.5 \mathrm{~mm}$ mix, and 8 cores were $19 \mathrm{~mm}$ mix. The bulk specific gravity of these cores was measured by the contractor using the CoreLok method. These cores were delivered to the WV ATL, and $\mathrm{G}_{\mathrm{mb}}$ was measured using CoreLok and T166 methods.

(3) On Route-19 project, 8 cores were collected for a Superpave $9.5 \mathrm{~mm}$ mix. $\mathrm{G}_{\mathrm{mb}}$ was measured with a CoreLok by the contractor. These cores were delivered to the WVATL, and $\mathrm{G}_{\mathrm{mb}}$ was measured using CoreLok and T166 methods.

After the density measurement, the samples were tested using a laboratory permeameter following Florida Testing Method, “Testing Method for Measurement of Water Permeability of Compacted Asphalt Paving Mixtures”.

\subsection{Laboratory Permeability of Gyratory Compacted Pills}

\subsubsection{Sample Preparation}

Laboratory compacted pills were produced as a part of this study to evaluate how aggregate gradation, NMAS and air voids content affects the permeability of Superpave mixtures. Table 6 presents the factors and levels selected for the experimental design.

Table 6 Experimental design

\begin{tabular}{|l|l|}
\hline Factors & Levels \\
\hline Mix Type & $9.5,12.5,19,25,37.5 \mathrm{~mm}$ \\
\hline Gradation & Coarse and Fine \\
\hline Air Voids & $4,7,9,11$ percent \\
\hline
\end{tabular}

A completed experimental design would require ten different mixes types. Due to time considerations, two types were removed from the study: $12.5 \mathrm{~mm}$ fine and $25 \mathrm{~mm}$ coarse. The contractor provided mix design for 6 mixes, $9.5 \mathrm{~mm}$ coarse, $12.5 \mathrm{~mm}$ coarse, 19 
$\mathrm{mm}$ coarse and fine, $25 \mathrm{~mm}$ fine and $37.5 \mathrm{~mm}$ fine. For these mixes, the volumetric properties were verified by preparing and testing samples at the WV ATL. Mix designs were not available from the contractor for the $9.5 \mathrm{~mm}$ fine, $12.5 \mathrm{~mm}$ fine, $25 \mathrm{~mm}$ coarse and 37.5 mm coarse mix types.

A mix design was performed for the $9.5 \mathrm{~mm}$ fine mix to determine the design binder content while satisfying the volumetric requirements. The moisture sensitivity was not evaluated. An attempt was made to perform a mix design for a $37.5 \mathrm{~mm}$ coarse blend. However, the asphalt content of 4\% VTM was 4.9\%. When sample was prepared for the permeability test at this asphalt content, it was apparent that the percent binder was excessive as bleed down ${ }^{7}$ was observed. Based on engineering judgment and experience with the $37.5 \mathrm{~mm}$ fine gradation, it was decided to make the 37.5 coarse mixes with a percent binder of 3.6 percent for the permeability tests.

The aggregate for the experiment were produced by J F Allen Co. Buckhannon, WV. The aggregate types and blend percentages are summarized in Table 7. The stockpile gradation, blend gradation, and gradation curves for each blend are present in Appendix 1. The binder used for the $9.5 \mathrm{~mm}$ and $12.5 \mathrm{~mm}$ mixes was PG 70-22; for the $19 \mathrm{~mm}, 25 \mathrm{~mm}$ and 37.5 mm mixes, a PG 64-22 was used.

Table 7 Aggregate types and blend percentage

\begin{tabular}{|c|c|c|c|c|c|c|c|c|c|c|}
\hline \multirow{3}{*}{$\begin{array}{l}\text { Aggregate } \\
\text { Type }\end{array}$} & \multicolumn{10}{|l|}{ NMAS } \\
\hline & \multicolumn{2}{|c|}{$9.5 \mathrm{~mm}$} & \multicolumn{2}{|c|}{$12.5 \mathrm{~mm}$} & \multicolumn{2}{|l|}{$19 \mathrm{~mm}$} & \multicolumn{2}{|l|}{$25 \mathrm{~mm}$} & \multicolumn{2}{|c|}{$37.5 \mathrm{~mm}$} \\
\hline & Coarse & Fine & Coarse & Fine & Coarse & Fine & Coarse & Fine & Coarse & Fine \\
\hline Elk Sand & $37 \%$ & $58 \%$ & $30 \%$ & \multirow{11}{*}{ NA } & $36 \%$ & $32 \%$ & \multirow{11}{*}{ NA } & & $21 \%$ & $24 \%$ \\
\hline Elk 9's & $25 \%$ & $15 \%$ & $13 \%$ & & $7 \%$ & $14 \%$ & & $9 \%$ & & \\
\hline Elk 8's & & & & & $14 \%$ & & & $13 \%$ & & \\
\hline Skid 8's & $37 \%$ & $26 \%$ & $41 \%$ & & & & & & & \\
\hline Skid 78’s & & & $15 \%$ & & & & & & & \\
\hline Elk57’s & & & & & & & & $38 \%$ & & \\
\hline Elk 4's & & & & & & & & & $29 \%$ & $24 \%$ \\
\hline MG 8'S & & & & & & $20 \%$ & & & $20 \%$ & $23 \%$ \\
\hline MG Sand & & & & & & & & $40 \%$ & & \\
\hline MG 67’S & & & & & $43 \%$ & $33 \%$ & & & $29 \%$ & $28 \%$ \\
\hline Baghouse & $1 \%$ & $1 \%$ & $1 \%$ & & & $1 \%$ & & & $1 \%$ & $1 \%$ \\
\hline
\end{tabular}

\footnotetext{
${ }^{7}$ Bleed down is observed when the asphalt flows off the aggregate while the sample is hot. These results in an uneven distribution of the binder in the aggregate structure, and the samples are not suitable for permeability testing.
} 
The design binder content, bulk specific gravity of the stone $\left(\mathrm{G}_{\mathrm{sb}}\right)$, bulk specific gravity, theoretical maximum density $\left(\mathrm{G}_{\mathrm{mm}}\right)$, voids in total mix (VTM), voids in mineral aggregate (VMA), and voids filled with asphalt (VFA) for the eight mixes were summarized in Table 8. The volumetric properties were evaluated for samples compacted with 80 gyrations of the SGC.

Table 8 Job mix formula values

\begin{tabular}{|l|c|c|c|c|c|c|c|}
\hline & $\begin{array}{c}\text { Asphalt } \\
(\%)\end{array}$ & $\mathrm{G}_{\mathrm{sb}}$ & $\mathrm{G}_{\mathrm{mb}}$ & $\mathrm{G}_{\mathrm{mm}}$ & $\begin{array}{c}\text { VTM } \\
(\%)\end{array}$ & $\begin{array}{c}\text { VMA } \\
(\%)\end{array}$ & $\begin{array}{c}\text { VFA } \\
(\%)\end{array}$ \\
\hline 9.5 Fine & 4.9 & 2.640 & 2.393 & 2.494 & 4.0 & 13.8 & 70.6 \\
\hline 19 Fine & 4.9 & 2.660 & 2.408 & 2.500 & 3.7 & 13.9 & 73.5 \\
\hline 25 Fine & 5.0 & 2.647 & 2.405 & 2.491 & 3.5 & 13.7 & 74.7 \\
\hline 37.5 Fine & 3.8 & 2.669 & 2.419 & 2.531 & 4.4 & 12.8 & 65.5 \\
\hline 9.5 Coarse & 5.7 & 2.645 & 2.366 & 2.462 & 3.9 & 15.7 & 75.0 \\
\hline 12.5 Coarse & 5.2 & 2.647 & 2.381 & 2.482 & 4.1 & 13.8 & 73.4 \\
\hline 19 Coarse & 4.6 & 2.657 & 2.415 & 2.515 & 4.0 & 13.2 & 70.0 \\
\hline 37.5 Coarse & 3.6 & 2.672 & 2.449 & 2.533 & \multicolumn{4}{|c|}{ NA } \\
\hline
\end{tabular}

Samples used for permeability test were compacted using a SGC to a $75 \mathrm{~mm}$ height. $\mathrm{G}_{\mathrm{mb}}$ data of laboratory pills were measured using the T166. $\mathrm{G}_{\mathrm{mm}}$ data were measured with the AASHTO T 209, and $\mathrm{G}_{\mathrm{mm}}$ data provided by the contractor was verified, as well. The air voids of all laboratory pills were computed using the contractor's value for $G_{\mathrm{mm}}$ when available. A $\pm 0.5 \%$ tolerance was selected for target air voids content of $4 \%$ and $7 \%$, and $\pm 1 \%$ tolerance for target air voids content of $9 \%$ and $11 \%$. Samples were rejected if they did not meet the tolerance. At each target air voids content of each mix, there were two qualified samples prepared for the laboratory permeability tests.

\subsubsection{Laboratory Permeability Tests on Gyratory Compacted Samples}

The cylindrical samples were prepared for laboratory permeability following the Florida Testing Method, FM 5-565. Compared with testing field cores, a thin layer of petroleum jelly applied to the sides of the laboratory compacted samples is needed. The petroleum jelly fills the large voids on the sides of the specimen which are not representative of the level of compaction of the interior of the specimen. The procedure described in Section 2.5.2 was used for testing. The temperature of water is kept constantly at $20^{\circ} \mathrm{C}$ through the testing of the SGC pills. Equation 2.9 was used to calculate permeability. 


\subsection{Statistical Analysis Methods}

The paired student test was selected to determine different $G_{m b}$ measuring methods, and performed using Excel. The paired t test is appropriate when units are tested twice, a "repeated measures" $t$ test. The paired t test provides a hypothesis test of the difference between population means for a pair of random samples, and the differences of the random samples are approximately normally distributed. $\mathrm{H}_{\mathrm{n}}$, null hypothesis, is defined as the means of the populations from which the two samples were taken are equal, and the alternative hypothesis, $\mathrm{H}_{0}$, is for non-equal means. In this study, a confidence level of $95 \%$ was selected for all the statistical analysis of the $\mathrm{G}_{\mathrm{mb}}$ data collected. If two sided P-value provided by the ttest is less than 0.05 , then a decision can be made that there is sufficient evidence to reject the $\mathrm{H}_{\mathrm{n}}$, which infers the data analyzed are not from the similar dataset. If the two sided P-value is greater than 0.05 , then there is insufficient evidence to reject the $\mathrm{H}_{\mathrm{n}}$, which infers that the two data being compared are statistically the same.

A line of equality was used to better understand the relationship between the $G_{m b}$ data sets compared. If two test methods produce the same results, then when the two datasets were plotted versus each other, a straight line with a slope of one and an intercept of zero should be achieved. Equation 3.1 can be used to fit the two datasets that have a liner relationship. In this study, a confidence level of 95\% was applied, and at this level, the coefficients of the data compared can be tested to determine if $\mathrm{a}=1$ and $\mathrm{b}=0$.

$$
\mathrm{Y}=\mathrm{aX}+\mathrm{b} \pm \mathrm{e}
$$

where:

$$
\begin{aligned}
& \mathrm{a}=\text { the slope; } \\
& \mathrm{b}=\text { the intercept; and } \\
& \mathrm{e}=\text { the standard error. }
\end{aligned}
$$

The regression analysis function of Excel was used to compare the $G_{m b}$ data, and a Pvalue was picked from the results to determine if there was sufficient evidence to reject the null hypothesis of the intercept equals to 0 . A supplemental calculation procedure was used in this study to test for a null hypothesis of the slope equals to 1 (56). The adjusted t-value for a slope equal to 1 can be calculated in Equation 3.2. The P-value is computed using TDIST function based upon the adjusted t-value, the residual degrees of freedom and the two tail assumption as the arguments for the function.

$$
\mathrm{T}=(\text { Slope }-1) /(\text { Standard Error })
$$




\section{Chapter 4 Results and Analysis}

\subsection{Introduction}

There are three distinct phases to this research, the field permeability tests, the evaluation of materials from construction projects, and the laboratory investigation of permeability. The evaluation of materials for the construction projects provides information on both the measurement of $G_{m b}$ and the permeability of pavements. These are treated as separate issues in this chapter.

\subsection{NCAT Permeameter Testing Results}

As noted in Chapter 3, the NCAT Permeameter was used to evaluate infiltration at four locations. While this was not a design experiment, some insight into the infiltration rates under different pavement conditions can be gained by reviewing the data.

\subsubsection{Interstate 79}

The first attempt to use the permeameter was on Interstate 79. The contractor and WV DOT were evaluating methods for establishing field calibration of nuclear density devices using cores taken at the spot of nuclear density test. For this research, an attempt was made to make the permeability measures after the nuclear measurements were collected but before the cores were drilled for laboratory testing. Due to the contractor's needs to drill the cores shortly after the pavement was placed, the pavement surface was hot when the attempt was made to measure infiltration. The temperature of the pavement surface adversely affected the ability of the putty to seal the permeameter to the pavement surface. Consequently, water was observed to leak between the pavement and the pavement surface, Figure 32. Several attempts were made to resolve the leaking issue. The conclusion from the tests is the putty sealed with the permeameter is not adequate when the pavement surface temperature is high.

\subsubsection{Mon-Fayette Express Way}

Table 9 presents data collected on the Mon-Fayette project. The average infiltration rate was computed based on data collected using the NCAT Permeameter. A second test was performed immediately following curing of the fog seal, and data presents in Table 9 indicates the fog seal was very effective at reducing water penetration into the pavement, as the infiltration rate was reduced by more than an order of magnitude. 


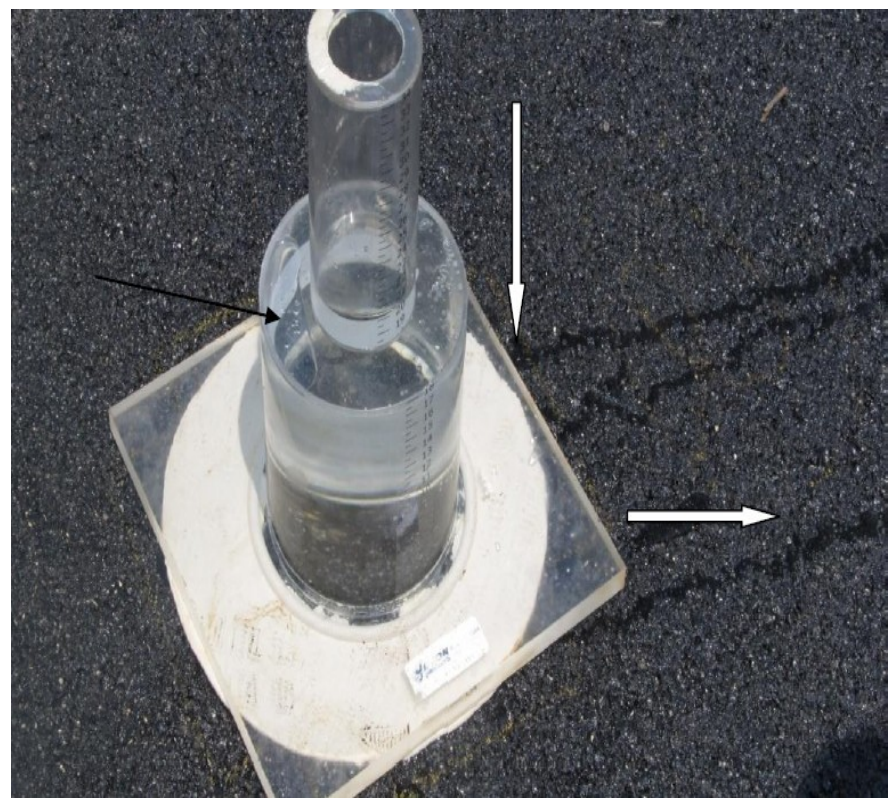

Figure 32 Water leakage on the pavement surface

Table 9 Mon-Fayette NCAT permeameter test data

\begin{tabular}{|c|c|c|c|c|c|c|c|}
\hline & & & $\mathrm{h}_{1}(\mathrm{~cm})$ & $\mathrm{h}_{2}(\mathrm{~cm})$ & $\mathrm{t}(\mathrm{s})$ & $\begin{array}{l}\text { Infiltration } \\
\text { rate }(\mathrm{cm} / \mathrm{hr})\end{array}$ & $\begin{array}{l}\text { Average } \\
\text { Infiltration } \\
\text { rate }(\mathrm{cm} / \mathrm{hr})\end{array}$ \\
\hline \multirow{4}{*}{$\begin{array}{l}\text { Testing } \\
\text { Spot1 }\end{array}$} & \multirow{2}{*}{ Before } & 1 & 50 & 40 & 87 & $3.00 \mathrm{E}+01$ & \multirow{2}{*}{$2.60 \mathrm{E}+01$} \\
\hline & & 2 & 50 & 40 & 119 & $2.19 \mathrm{E}+01$ & \\
\hline & \multirow{2}{*}{ After } & 1 & 64 & 63 & 76 & 6.30E-01 & \multirow{2}{*}{ 5.45E-01 } \\
\hline & & 2 & 61 & 60 & 104 & 4.61E-01 & \\
\hline \multirow{4}{*}{$\begin{array}{l}\text { Testing } \\
\text { Spot } 2\end{array}$} & \multirow{2}{*}{ Before } & 1 & 64.5 & 54.5 & 60 & $7.99 \mathrm{E}+00$ & \multirow{2}{*}{$7.58 \mathrm{E}+00$} \\
\hline & & 2 & 64 & 54 & 67 & $7.16 \mathrm{E}+00$ & \\
\hline & \multirow{2}{*}{ After } & 1 & 66.5 & 65.5 & 177 & $2.71 \mathrm{E}-01$ & \multirow{2}{*}{$3.44 \mathrm{E}-01$} \\
\hline & & 2 & 65 & 64 & 115 & $4.18 \mathrm{E}-01$ & \\
\hline
\end{tabular}

\subsubsection{Quarry Run Road}

Figure 25 shows the fog seal application on the Quarry Run Road. Table 14 shows data collected before and after the application of LD-7. The fog seal reduced the infiltration rate by 46 percent at one location and by 73 percent at the other location. It is unknown if this level of reduction in the infiltration rate will meaningfully affect pavement performance. 
Table 10 Quarry Run Road NCAT permeameter data

\begin{tabular}{|c|c|c|c|c|c|c|c|}
\hline & & & $\mathrm{h}_{1}(\mathrm{~cm})$ & $\mathrm{h}_{2}(\mathrm{~cm})$ & $\mathrm{t}(\mathrm{s})$ & $\begin{array}{l}\text { Infiltration } \\
\text { rate }(\mathrm{cm} / \mathrm{hr})\end{array}$ & $\begin{array}{l}\text { Average } \\
\text { Infiltration } \\
\text { rate }(\mathrm{cm} / \mathrm{hr})\end{array}$ \\
\hline \multirow{4}{*}{$\begin{array}{c}\text { Testing } \\
\text { Spot1 }\end{array}$} & \multirow{2}{*}{ Before } & 1 & 59 & 49 & 11 & $3.96 \mathrm{E}+04$ & \multirow{2}{*}{$7.56 \mathrm{E}+04$} \\
\hline & & 2 & 32 & 22 & 31 & $1.12 \mathrm{E}+05$ & \\
\hline & \multirow{2}{*}{ After } & 1 & 33 & 23 & 50 & $1.80 \mathrm{E}+05$ & \multirow{2}{*}{$1.96 \mathrm{E}+05$} \\
\hline & & 2 & 33 & 23 & 59 & $2.12 \mathrm{E}+05$ & \\
\hline \multirow{4}{*}{$\begin{array}{l}\text { Testing } \\
\text { Spot } 2\end{array}$} & \multirow{2}{*}{ Before } & 1 & 33 & 23 & 23 & $8.28 \mathrm{E}+04$ & \multirow{2}{*}{$9.36 \mathrm{E}+04$} \\
\hline & & 2 & 33 & 23 & 29 & $1.04 \mathrm{E}+05$ & \\
\hline & \multirow{2}{*}{ After } & 1 & 50 & 41 & 31 & $1.12 \mathrm{E}+05$ & \multirow{2}{*}{$2.59 \mathrm{E}+05$} \\
\hline & & 2 & 33 & 23 & 113 & $4.07 \mathrm{E}+05$ & \\
\hline
\end{tabular}

\subsubsection{Chestnut Ridge}

The effectiveness of the fog seal cannot be properly assessed from the Chestnut Ridge data as the infiltration rate of the pavement was not measured prior to the fog seal. It is not known if the pavements at the Darnell Hollow road and Seven Spring locations were sufficiently similar to allow a reasonable comparison. The data in Table 11 are presented only to document the work performed.

Table 11 Chestnut-Bridge NCAT permeability test data

\begin{tabular}{|c|c|c|c|c|c|c|c|}
\hline & & & $\mathrm{h}_{1}(\mathrm{~cm})$ & $\mathrm{h}_{2}(\mathrm{~cm})$ & $\mathrm{t}(\mathrm{s})$ & $\begin{array}{l}\text { Infiltration } \\
\text { rate }(\mathrm{cm} / \mathrm{hr})\end{array}$ & $\begin{array}{l}\text { Average } \\
\text { Infiltration rate } \\
(\mathrm{cm} / \mathrm{hr})\end{array}$ \\
\hline \multirow{3}{*}{$\begin{array}{l}\text { Testing } \\
\text { Spot1 }\end{array}$} & \multirow{3}{*}{ Sealed } & 1 & 50 & 45 & 59 & $2.12 \mathrm{E}+05$ & \multirow{3}{*}{$2.52 \mathrm{E}+05$} \\
\hline & & 2 & 50 & 45 & 70 & $2.52 E+05$ & \\
\hline & & 3 & 44 & 39 & 81 & $2.92 \mathrm{E}+05$ & \\
\hline \multirow{2}{*}{$\begin{array}{l}\text { Testing } \\
\text { Spot } 2\end{array}$} & \multirow{2}{*}{ Unsealed } & 1 & 50 & 48 & 94 & $3.38 \mathrm{E}+05$ & \multirow{2}{*}{$3.15 E+05$} \\
\hline & & 2 & 47.5 & 46 & 81 & $2.92 \mathrm{E}+05$ & \\
\hline
\end{tabular}

\section{3 $G_{m b}$ Evaluation of Data for Construction Projects}

As noted in Chapter 3 data were collected from construction projects on an availability basis. Table 12 shows the types of data available for analysis. The actual data are presented in Appendix 2. There are data for three projects, Interstate 79, Interstate 64, and Route 19. Field density measurements are only available for the Interstate 79 project. Data on the bulk specific gravity from cores, as measured by the contractor and the WVUATL are available for all three projects. 


\subsubsection{Nuclear Gauge Measurements}

Multiple nuclear gauge measurements were collected from the I-79 project; nuclear gauge measurements were not available for the other projects. As shown in Table 17 there were two contractor's nuclear gauges, four WVDOH nuclear gauges and a thin-lift gauge used on the project. Offset and centered measures were provided in some cases for the thinlift gauge. Correction factors were developed for four dates. The two contractor's gauges were used for each control strip. The WVDOH and thin-lift gauges used varied depending on the date of the control strip.

Examination of Table 13 indicates:

- The thin-lift gauge had the smallest correction factor. In fact when the contractor's T166 $\mathrm{G}_{\mathrm{mb}}$ values are used across all the available measurements the correction factor for the offset thin-lift gauge was zero.

- For two dates, June 6 and August 2 control strips were performed both on the joints and the mainline. The difference between the joint and mainline correction factors ranged from 3 to 15 for the contractor's gauges and 2 to 28 for the WVDOH gauges.

- Based on the contractor's T166 $\mathrm{G}_{\mathrm{mb}}$, the overall correction factor for the contractor's two gauges was -74 and -39 for gauges 35998 and 25500, respectively. Overall the correction factors for the WVDOH gauges were higher ranging from -76 to -115 .

- Comparing the correction factors for the CoreLok to the contractor's T166 $\mathrm{G}_{\mathrm{mb}}$ values shows the correction factors for the CoreLok are larger in magnitude in all but one case. This indicates the CoreLok and T166 results are different. This issue is more thoroughly evaluated later in this chapter. 
Table 12 Nuclear density data available for analysis

\begin{tabular}{|c|c|c|c|c|c|c|c|c|c|c|c|c|c|c|c|c|c|c|c|}
\hline 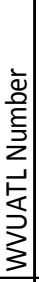 & 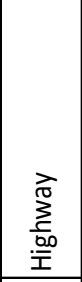 & 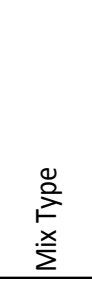 & 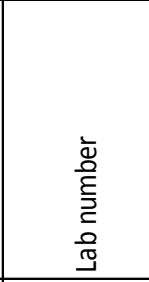 & $\bar{\Sigma}$ & 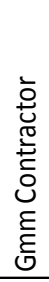 & 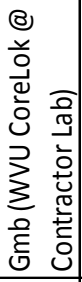 & 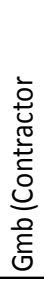 & 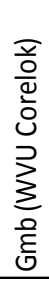 & 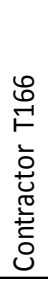 & 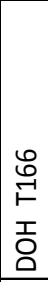 & $\begin{array}{l}\bullet \\
\bullet \\
\vdash \\
\supsetneq \\
\gtrless\end{array}$ & 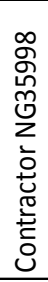 & 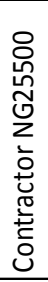 & 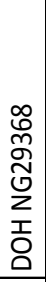 & 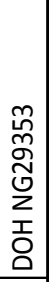 & 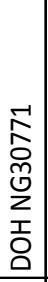 & 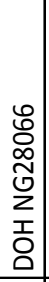 & 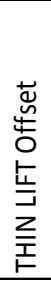 & 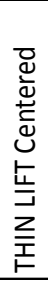 \\
\hline 1 & $1-79$ & $9.5 \mathrm{~mm}$ & JFA-A49-M & $M$ & $x$ & & & $x$ & $x$ & & $x$ & $x$ & $x$ & $x$ & & & & $x$ & $x$ \\
\hline 2 & $1-79$ & $9.5 \mathrm{~mm}$ & DOH-A49-M & $\mathrm{M}$ & $\mathrm{x}$ & & & $\mathrm{x}$ & & $x$ & $\mathrm{x}$ & $\mathrm{x}$ & $x$ & $\mathrm{x}$ & & & & $\mathrm{X}$ & $\mathrm{x}$ \\
\hline 3 & $1-79$ & $9.5 \mathrm{~mm}$ & \begin{tabular}{|l|}
$J F A-A 49-J$ \\
\end{tabular} & $\mathrm{~J}$ & $\mathrm{x}$ & & & $\mathrm{x}$ & $\mathrm{x}$ & & $\mathrm{x}$ & $\mathrm{x}$ & $\mathrm{x}$ & $\mathrm{x}$ & & & & $\mathrm{x}$ & $\mathrm{x}$ \\
\hline 4 & $1-79$ & $9.5 \mathrm{~mm}$ & DOH-A49-J & $\mathrm{J}$ & $\mathrm{x}$ & & & $\mathrm{x}$ & & $\mathrm{x}$ & $\mathrm{x}$ & $\mathrm{x}$ & $\mathrm{x}$ & $\mathrm{x}$ & & & & $\mathrm{x}$ & $\mathrm{x}$ \\
\hline 5 & $1-79$ & $9.5 \mathrm{~mm}$ & JFA-A57-M & $\mathrm{M}$ & $\mathrm{x}$ & & & $\mathrm{x}$ & $x$ & & $\mathrm{x}$ & $\mathrm{x}$ & $x$ & $\mathrm{x}$ & & & & $\mathrm{X}$ & $\mathrm{x}$ \\
\hline 6 & $1-79$ & $9.5 \mathrm{~mm}$ & DOH-A57-M & $\mathrm{M}$ & $\mathrm{x}$ & & & $\mathrm{x}$ & & $\mathrm{x}$ & $\mathrm{x}$ & $\mathrm{x}$ & $\mathrm{x}$ & $\mathrm{x}$ & & & & $\mathrm{x}$ & $x$ \\
\hline 7 & $1-79$ & $9.5 \mathrm{~mm}$ & \begin{tabular}{|l|} 
JFA-A57-J \\
\end{tabular} & $\mathrm{J}$ & $\mathrm{x}$ & & & $\mathrm{x}$ & $\mathrm{x}$ & & $\mathrm{x}$ & $x$ & $\mathrm{x}$ & $\mathrm{x}$ & & & & $\mathrm{x}$ & $\mathrm{x}$ \\
\hline 8 & $1-79$ & $9.5 \mathrm{~mm}$ & DOH-A57-J & $\mathrm{J}$ & $x$ & & & $\mathrm{x}$ & & $x$ & $\mathrm{x}$ & $x$ & $x$ & $\mathrm{x}$ & & & & $x$ & $x$ \\
\hline 9 & $1-79$ & $9.5 \mathrm{~mm}$ & JFA-A65-M & $\mathrm{M}$ & $\mathrm{x}$ & & & $\mathrm{x}$ & $\mathrm{x}$ & & $\mathrm{x}$ & $\mathrm{x}$ & $\mathrm{x}$ & $\mathrm{x}$ & & & & $\mathrm{x}$ & $\mathrm{x}$ \\
\hline 10 & $1-79$ & $9.5 \mathrm{~mm}$ & DOH-A65-M & $M$ & $x$ & & & $x$ & & $x$ & $\mathrm{x}$ & $x$ & $x$ & $\mathrm{x}$ & & & & $x$ & $x$ \\
\hline 11 & $1-79$ & $9.5 \mathrm{~mm}$ & JFA-A65-J & $\mathrm{J}$ & $\mathrm{x}$ & & & $\mathrm{x}$ & $\mathrm{x}$ & & $\mathrm{x}$ & $\mathrm{x}$ & $\mathrm{x}$ & $\mathrm{x}$ & & & & $\mathrm{x}$ & $\mathrm{x}$ \\
\hline 12 & $1-79$ & $9.5 \mathrm{~mm}$ & DOH-A65-J & $\mathrm{J}$ & $\mathrm{x}$ & & & $\mathrm{x}$ & & $\mathrm{x}$ & $\mathrm{x}$ & $\mathrm{x}$ & $\mathrm{x}$ & $\mathrm{x}$ & & & & $\mathrm{x}$ & $\mathrm{x}$ \\
\hline 13 & $1-79$ & $9.5 \mathrm{~mm}$ & JFA-A71-M & $M$ & $x$ & & & $x$ & $x$ & & $\mathrm{x}$ & $x$ & $x$ & $\mathrm{x}$ & & & & $x$ & $x$ \\
\hline 14 & $1-79$ & $9.5 \mathrm{~mm}$ & DOH-A71-M & $\mathrm{M}$ & $\mathrm{x}$ & & & $\mathrm{x}$ & & $\mathrm{x}$ & $\mathrm{x}$ & $\mathrm{x}$ & $\mathrm{x}$ & $\mathrm{x}$ & & & & $\mathrm{x}$ & $\mathrm{x}$ \\
\hline 15 & $1-79$ & $9.5 \mathrm{~mm}$ & \begin{tabular}{|l|} 
JFA-A71-J \\
\end{tabular} & $\mathrm{J}$ & $\mathrm{x}$ & & & $\mathrm{x}$ & $\mathrm{x}$ & & $\mathrm{x}$ & $x$ & $\mathrm{x}$ & $\mathrm{x}$ & & & & $\mathrm{x}$ & $\mathrm{x}$ \\
\hline 16 & $1-79$ & $9.5 \mathrm{~mm}$ & DOH-A71-J & $\mathrm{J}$ & $\mathrm{x}$ & & & $\mathrm{x}$ & & $\mathrm{x}$ & $\mathrm{x}$ & $\mathrm{x}$ & $\mathrm{x}$ & $\mathrm{x}$ & & & & $\mathrm{x}$ & $\mathrm{x}$ \\
\hline 17 & $1-79$ & $9.5 \mathrm{~mm}$ & $4222+95 / 3^{\prime}$ & $\mathrm{M}$ & $\mathrm{x}$ & & & $\mathrm{x}$ & $\mathrm{x}$ & & $\mathrm{x}$ & $\mathrm{x}$ & $\mathrm{x}$ & $\mathrm{x}$ & & & $\mathrm{x}$ & & \\
\hline 18 & $1-79$ & $9.5 \mathrm{~mm}$ & $4222+36 / 7^{\prime}$ & $\mathrm{M}$ & $\mathrm{x}$ & & & $\mathrm{x}$ & $\mathrm{x}$ & & $\mathrm{x}$ & $\mathrm{x}$ & $\mathrm{x}$ & $\mathrm{x}$ & & & $\mathrm{x}$ & & \\
\hline 19 & $1-79$ & $9.5 \mathrm{~mm}$ & $4222+00 / 4^{\prime}$ & $\mathrm{M}$ & $\mathrm{x}$ & & & $\mathrm{x}$ & $\mathrm{x}$ & & $\mathrm{x}$ & $\mathrm{x}$ & $\mathrm{x}$ & $\mathrm{x}$ & & & $\mathrm{x}$ & & \\
\hline 20 & $1-79$ & $9.5 \mathrm{~mm}$ & $4221+53 / 2^{\prime}$ & $\mathrm{M}$ & $\mathrm{x}$ & & & $\mathrm{x}$ & $\mathrm{x}$ & & $\mathrm{x}$ & $\mathrm{x}$ & $x$ & $\mathrm{x}$ & & & $\mathrm{x}$ & & \\
\hline 21 & $1-79$ & $9.5 \mathrm{~mm}$ & $4221+17 / 1^{\prime}$ & $\mathrm{M}$ & $\mathrm{x}$ & & & $\mathrm{x}$ & $\mathrm{x}$ & & $\mathrm{x}$ & $\mathrm{x}$ & $\mathrm{x}$ & $\mathrm{x}$ & & & $\mathrm{x}$ & & \\
\hline 22 & $1-79$ & $9.5 \mathrm{~mm}$ & $4220+84 / 6^{\prime}$ & $\mathrm{M}$ & $\mathrm{x}$ & & & $\mathrm{x}$ & $\mathrm{x}$ & & $\mathrm{x}$ & $\mathrm{x}$ & $\mathrm{x}$ & $\mathrm{x}$ & & & $\mathrm{x}$ & & \\
\hline 23 & $1-79$ & $9.5 \mathrm{~mm}$ & $4220+67 / 6^{\prime}$ & $\mathrm{M}$ & $\mathrm{x}$ & & & $\mathrm{x}$ & $\mathrm{x}$ & & $\mathrm{x}$ & $\mathrm{x}$ & $\mathrm{x}$ & $\mathrm{x}$ & & & $\mathrm{x}$ & & \\
\hline 24 & $1-79$ & $9.5 \mathrm{~mm}$ & $4220+33 / 10^{\prime}$ & $\mathrm{M}$ & $\mathrm{x}$ & & & $\mathrm{x}$ & $\mathrm{x}$ & & $\mathrm{x}$ & $\mathrm{x}$ & $\mathrm{x}$ & $\mathrm{x}$ & & & $\mathrm{x}$ & & \\
\hline 25 & $1-79$ & $9.5 \mathrm{~mm}$ & $-9+51 / 12^{\prime}$ & $\mathrm{M}$ & $\mathrm{X}$ & & & $\mathrm{x}$ & $x$ & & $\mathrm{x}$ & $x$ & $x$ & & $\mathrm{x}$ & $\mathrm{x}$ & & $x$ & \\
\hline 26 & $1-79$ & $9.5 \mathrm{~mm}$ & $-9+15 / 11^{\prime}$ & $M$ & $x$ & & & $x$ & $x$ & & $\mathrm{x}$ & $x$ & $x$ & & $x$ & $\mathrm{x}$ & & $x$ & \\
\hline 27 & $1-79$ & $9.5 \mathrm{~mm}$ & $-8+52 / 6^{\prime}$ & $M$ & $\mathrm{x}$ & & & $\mathrm{x}$ & $x$ & & $\mathrm{x}$ & $\mathrm{x}$ & $x$ & & $x$ & $\mathrm{x}$ & & $x$ & \\
\hline 28 & $1-79$ & $9.5 \mathrm{~mm}$ & $-8+23 / 10^{\prime}$ & $M$ & $x$ & & & $x$ & $x$ & & $\mathrm{x}$ & $x$ & $x$ & & $\mathrm{x}$ & $\mathrm{x}$ & & $x$ & \\
\hline 29 & $1-79$ & $9.5 \mathrm{~mm}$ & $-7+76 / 10^{\prime}$ & $\mathrm{M}$ & $\mathrm{x}$ & & & $\mathrm{x}$ & $\mathrm{x}$ & & $\mathrm{x}$ & $\mathrm{x}$ & $\mathrm{x}$ & & $\mathrm{x}$ & $\mathrm{x}$ & & $\mathrm{x}$ & \\
\hline 30 & $1-79$ & $9.5 \mathrm{~mm}$ & $-7+56 / 6^{\prime}$ & $\mathrm{M}$ & $\mathrm{x}$ & & & $\mathrm{x}$ & $\mathrm{x}$ & & $\mathrm{x}$ & $\mathrm{x}$ & $\mathrm{x}$ & & $\mathrm{x}$ & $\mathrm{x}$ & & $\mathrm{x}$ & \\
\hline 31 & $1-79$ & $9.5 \mathrm{~mm}$ & $-6+53 / 8^{\prime}$ & $\mathrm{M}$ & $\mathrm{x}$ & & & $\mathrm{x}$ & $\mathrm{x}$ & & $\mathrm{x}$ & $\mathrm{x}$ & $\mathrm{x}$ & & $\mathrm{x}$ & $\mathrm{x}$ & & $\mathrm{x}$ & \\
\hline 32 & $1-79$ & $9.5 \mathrm{~mm}$ & A23M-B & $\mathrm{M}$ & $\mathrm{x}$ & $\mathrm{x}$ & & $\mathrm{x}$ & $\mathrm{x}$ & & $\mathrm{x}$ & $\mathrm{x}$ & $\mathrm{x}$ & & & $\mathrm{x}$ & & & \\
\hline 33 & $1-79$ & $9.5 \mathrm{~mm}$ & A44M-A & $\mathrm{M}$ & $\mathrm{x}$ & $x$ & & $\mathrm{x}$ & $x$ & & $\mathrm{x}$ & $x$ & $x$ & & & $\mathrm{x}$ & & & \\
\hline 34 & $1-79$ & $9.5 \mathrm{~mm}$ & A44M-B & $M$ & $x$ & $x$ & & $x$ & $x$ & & $\mathrm{x}$ & $x$ & $x$ & & & $\mathrm{x}$ & & & \\
\hline 35 & $1-79$ & $9.5 \mathrm{~mm}$ & JFA-A103-M & $\mathrm{M}$ & $\mathrm{x}$ & $\mathrm{x}$ & & $\mathrm{x}$ & $\mathrm{x}$ & & $\mathrm{x}$ & $\mathrm{x}$ & $\mathrm{x}$ & & & $\mathrm{x}$ & & & \\
\hline 36 & $1-79$ & $9.5 \mathrm{~mm}$ & DOH-A103-M & $\mathrm{M}$ & $\mathrm{x}$ & $\mathrm{x}$ & & $\mathrm{x}$ & $\mathrm{x}$ & $\mathrm{x}$ & $\mathrm{x}$ & $\mathrm{x}$ & $\mathrm{x}$ & & & $\mathrm{x}$ & & & \\
\hline 37 & $1-79$ & $9.5 \mathrm{~mm}$ & DOH-A104-M & $\mathrm{M}$ & $\mathrm{x}$ & $\mathrm{x}$ & & $\mathrm{x}$ & $\mathrm{x}$ & $\mathrm{x}$ & $\mathrm{x}$ & $\mathrm{x}$ & $\mathrm{x}$ & & & $\mathrm{x}$ & & & \\
\hline 38 & $1-79$ & $9.5 \mathrm{~mm}$ & JFA-A104-M & $\mathrm{M}$ & $\mathrm{x}$ & $\mathrm{x}$ & & $\mathrm{x}$ & $\mathrm{x}$ & & $x$ & $\mathrm{x}$ & $\mathrm{x}$ & & & $\mathrm{x}$ & & & \\
\hline 39 & $1-79$ & $9.5 \mathrm{~mm}$ & A23J-B & $\mathrm{J}$ & $\mathrm{x}$ & $\mathrm{x}$ & & $\mathrm{x}$ & $\mathrm{x}$ & & $\mathrm{x}$ & $\mathrm{x}$ & $\mathrm{x}$ & & & $\mathrm{x}$ & & & \\
\hline 40 & $1-79$ & $9.5 \mathrm{~mm}$ & A23J-A & $\mathrm{J}$ & $x$ & $x$ & & $x$ & $x$ & & $\mathrm{x}$ & $x$ & $x$ & & & $\mathrm{x}$ & & & \\
\hline 41 & $1-79$ & $9.5 \mathrm{~mm}$ & A44J-A & $\mathrm{J}$ & $\mathrm{x}$ & $\mathrm{x}$ & & $\mathrm{x}$ & $\mathrm{x}$ & & $\mathrm{X}$ & $\mathrm{x}$ & $x$ & & & $\mathrm{x}$ & & & \\
\hline 42 & $1-79$ & $9.5 \mathrm{~mm}$ & A44J-B & $\mathrm{J}$ & $\mathrm{x}$ & $\mathrm{X}$ & & $\mathrm{x}$ & $\mathrm{x}$ & & $\mathrm{x}$ & $x$ & $x$ & & & $\mathrm{x}$ & & & \\
\hline 43 & $1-79$ & $9.5 \mathrm{~mm}$ & DOH-A103-J & $\mathrm{J}$ & $\mathrm{x}$ & $\mathrm{x}$ & & $\mathrm{x}$ & $\mathrm{x}$ & $\mathrm{x}$ & $\mathrm{x}$ & $\mathrm{x}$ & $\mathrm{x}$ & & & $\mathrm{x}$ & & & \\
\hline 44 & $1-79$ & $9.5 \mathrm{~mm}$ & DOH-A104-J & $\mathrm{J}$ & $\mathrm{x}$ & $\mathrm{x}$ & & $\mathrm{x}$ & $\mathrm{x}$ & $\mathrm{x}$ & $\mathrm{x}$ & $\mathrm{x}$ & $\mathrm{x}$ & & & $\mathrm{x}$ & & & \\
\hline 45 & $1-79$ & $9.5 \mathrm{~mm}$ & JFA-104-J & $\mathrm{J}$ & $\mathrm{x}$ & $x$ & & $\mathrm{x}$ & $\mathrm{x}$ & & $\mathrm{x}$ & $\mathrm{x}$ & $\mathrm{x}$ & & & $\mathrm{x}$ & & & \\
\hline 46 & Route-19 & $9.5 \mathrm{~mm}$ & & & $\mathrm{x}$ & & & $\mathrm{x}$ & & & $\mathrm{x}$ & & & & & & & & \\
\hline 47 & Route-19 & $9.5 \mathrm{~mm}$ & & & $\mathrm{x}$ & & & $\mathrm{x}$ & $\mathrm{x}$ & & $\mathrm{x}$ & & & & & & & & \\
\hline 48 & Route-19 & $9.5 \mathrm{~mm}$ & & & $\mathrm{x}$ & & & $x$ & $\mathrm{x}$ & & $\mathrm{x}$ & & & & & & & & \\
\hline 49 & Route-19 & $9.5 \mathrm{~mm}$ & & & $\mathrm{x}$ & & & $\mathrm{x}$ & $\mathrm{x}$ & & $\mathrm{x}$ & & & & & & & & \\
\hline 50 & Route-19 & $9.5 \mathrm{~mm}$ & & & $x$ & & & $x$ & $x$ & & $\mathrm{x}$ & & & & & & & & \\
\hline 51 & Route-19 & $9.5 \mathrm{~mm}$ & & & $\mathrm{x}$ & & & $\mathrm{x}$ & $\mathrm{x}$ & & $\mathrm{x}$ & & & & & & & & \\
\hline 52 & Route-19 & $9.5 \mathrm{~mm}$ & & & $\mathrm{x}$ & & & $\mathrm{x}$ & $\mathrm{x}$ & & $\mathrm{X}$ & & & & & & & & \\
\hline 53 & Route-19 & $9.5 \mathrm{~mm}$ & & & $\mathrm{x}$ & & & $\mathrm{x}$ & $\mathrm{x}$ & & $x$ & & & & & & & & \\
\hline 54 & $1-64$ & $9.5 \mathrm{~mm}$ & & & $x$ & & $\mathrm{x}$ & $x$ & & & $\mathrm{x}$ & & & & & & & & \\
\hline 55 & $1-64$ & $9.5 \mathrm{~mm}$ & & & $\mathrm{x}$ & & $\mathrm{x}$ & $x$ & & & $\mathrm{x}$ & & & & & & & & \\
\hline 56 & $1-64$ & $9.5 \mathrm{~mm}$ & & & $\mathrm{x}$ & & $\mathrm{x}$ & $\mathrm{x}$ & & & $\mathrm{x}$ & & & & & & & & \\
\hline 57 & $1-64$ & $9.5 \mathrm{~mm}$ & & & $\mathrm{x}$ & & $\mathrm{x}$ & $\mathrm{x}$ & & & $\mathrm{x}$ & & & & & & & & \\
\hline 58 & $1-64$ & $9.5 \mathrm{~mm}$ & & & $x$ & & $\mathrm{x}$ & $x$ & & & $\mathrm{x}$ & & & & & & & & \\
\hline 59 & $1-64$ & $9.5 \mathrm{~mm}$ & & & $\mathrm{x}$ & & $\mathrm{x}$ & $\mathrm{x}$ & & & $\mathrm{x}$ & & & & & & & & \\
\hline 60 & I-64 & $9.5 \mathrm{~mm}$ & & & $\mathrm{x}$ & & $\mathrm{x}$ & $\mathrm{x}$ & & & $x$ & & & & & & & & \\
\hline 61 & $1-64$ & $9.5 \mathrm{~mm}$ & & & $x$ & & $\mathrm{x}$ & $x$ & & & $\mathrm{x}$ & & & & & & & & \\
\hline 62 & $1-64$ & $9.5 \mathrm{~mm}$ & & & $x$ & & $\mathrm{x}$ & $x$ & & & $\mathrm{x}$ & & & & & & & & \\
\hline 63 & I-64 & $9.5 \mathrm{~mm}$ & & & $\mathrm{x}$ & & $\mathrm{x}$ & $\mathrm{x}$ & & & $\mathrm{x}$ & & & & & & & & \\
\hline 64 & $1-64$ & $9.5 \mathrm{~mm}$ & & & $\mathrm{x}$ & & $\mathrm{x}$ & $\mathrm{x}$ & & & $\mathrm{x}$ & & & & & & & & \\
\hline 65 & $1-64$ & $9.5 \mathrm{~mm}$ & & & $x$ & & $\mathrm{x}$ & $\mathrm{x}$ & & & $\mathrm{X}$ & & & & & & & & \\
\hline 66 & $1-64$ & $9.5 \mathrm{~mm}$ & & & $x$ & & $\mathrm{x}$ & $\mathrm{x}$ & & & $\mathrm{x}$ & & & & & & & & \\
\hline 67 & I-64 & $9.5 \mathrm{~mm}$ & & & $\mathrm{x}$ & & $\mathrm{x}$ & $\mathrm{x}$ & & & $x$ & & & & & & & & \\
\hline 68 & $1-64$ & $9.5 \mathrm{~mm}$ & & & $x$ & & $\mathrm{x}$ & $x$ & & & $x$ & & & & & & & & \\
\hline 69 & $1-64$ & $9.5 \mathrm{~mm}$ & & & $x$ & & $\mathrm{x}$ & $x$ & & & $x$ & & & & & & & & \\
\hline 70 & I-64 & $19 \mathrm{~mm}$ & & & $\mathrm{x}$ & & $\mathrm{x}$ & $x$ & & & $\mathrm{x}$ & & & & & & & & \\
\hline 71 & I-64 & $19 \mathrm{~mm}$ & & & $x$ & & $\mathrm{x}$ & $\mathrm{x}$ & & & $\mathrm{X}$ & & & & & & & & \\
\hline 72 & $1-64$ & $19 \mathrm{~mm}$ & & & $x$ & & $\mathrm{x}$ & $x$ & & & $\mathrm{X}$ & & & & & & & & \\
\hline 73 & I-64 & $19 \mathrm{~mm}$ & & & $x$ & & $\mathrm{x}$ & $x$ & & & $\mathrm{x}$ & & & & & & & & \\
\hline 74 & $1-64$ & $19 \mathrm{~mm}$ & & & $x$ & & $x$ & $x$ & & & $x$ & & & & & & & & \\
\hline 75 & $1-64$ & $19 \mathrm{~mm}$ & & & $x$ & & $\mathrm{x}$ & $x$ & & & $x$ & & & & & & & & \\
\hline 76 & I-64 & $19 \mathrm{~mm}$ & & & $x$ & & $\mathrm{x}$ & $x$ & & & $\mathrm{x}$ & & & & & & & & \\
\hline 77 & $1-64$ & $19 \mathrm{~mm}$ & & & $x$ & & $\mathrm{x}$ & $x$ & & & $x$ & & & & & & & & \\
\hline
\end{tabular}


Table 13 Correction factor for nuclear gauges

\begin{tabular}{|c|c|c|c|c|c|c|c|c|c|c|c|}
\hline & Source & & Number & $\begin{array}{l}\text { Contractor } \\
\text { Nuclear }\end{array}$ & $\begin{array}{l}\text { Contractor } \\
\text { Nuclear }\end{array}$ & $\begin{array}{l}\text { WV DOH } \\
\text { Nuclear }\end{array}$ & $\begin{array}{l}\text { WV DOH } \\
\text { Nuclear }\end{array}$ & $\begin{array}{l}\text { WV DOH } \\
\text { Nuclear }\end{array}$ & $\begin{array}{c}\text { WV } \\
\text { DOH } \\
\text { Nuclear }\end{array}$ & $\begin{array}{l}2220 \\
\text { THIN }\end{array}$ & $\begin{array}{l}2220 \\
\text { THIN }\end{array}$ \\
\hline & $5 / 31 / 2011$ & mainline & 8 & -67 & -27 & -64 & & & -76 & 20 & 20 \\
\hline 产 & $6 / 6 / 2011$ & Joint & 8 & -65 & -28 & -87 & & & & 21 & 27 \\
\hline 崖 & $6 / 6 / \angle 011$ & mainline & 8 & -78 & -31 & -89 & & & & -1 & -3 \\
\hline . & $7 / 20 / 2011$ & mainline & 8 & -88 & -57 & & -109 & -128 & & -23 & \\
\hline 芯 & & Joint & 8 & -70 & -42 & & & -96 & & & \\
\hline$\overline{0}$ & $8 / 2 / 2011$ & mainline & 8 & -85 & -54 & & & -124 & & & \\
\hline & & combined & 16 & -88 & -57 & & & -128 & & & \\
\hline & WVU & CoreLok & & -90 & -55 & -101 & -111 & -125 & -100 & -11 & -8 \\
\hline & Contra & ctor T166 & & -74 & -39 & -80 & -112 & -115 & -76 & 0 & 12 \\
\hline
\end{tabular}


To evaluate the nuclear gauges data more thoroughly the line of equality plots were prepared showing the nuclear gauge density versus laboratory measured density from cores taken at the location where the density measurements were made. Figures 33, 34 and 35 show the line of equality graphs for the contractor's, WVDOH, and thin-lift gauges respectively. These graphs show there is a strong correlation between the nuclear gauges and the bulk density from the CoreLok. However, there are differing amounts of variance depending on the nuclear gauges as indicated by the goodness of fit statistic, $\mathrm{R}^{2}$.

Two trend lines were fit to each graph, one that best fits the data and one that forces the intercept to zero. The coefficients and $\mathrm{R}^{2}$ results are summarized in Table 14 . In general, the intercept, $b_{1}$, is fairly large, more than 100 in most cases. For the best fit equations the slope varies from about 0.9 to 1.1 . When the slope is not equal to 1.0 , there is a divergence in the comparative values, the further the $\mathrm{x}$ value is from the mean of the data set, the more error there is in the prediction of the y value. For the trend lines that were forced to have an intercept of zero, the slope is always less than one. As expected, the $\mathrm{R}^{2}$ is lower than for the best fit equation, but the differences are relatively minor. The ratio of the average of the dependent variable to the average of the independent variable, in this case the average CoreLok to the average of the nuclear gauge readings, is equal to the slope of the regression equation constrained to have a zero intercept. This suggest the correction factor developed from control strips should be based on the ratio of the lab to field density, rather than the difference of the means as is currently done. Figure 35 shows this concept. By using the ratio method, the slope is closer to 1 and the intercept is closer to zero as compared to the differences in means method. The $\mathrm{R}^{2}$ of the two methods is the same as there is no alteration of the variability of the data. 

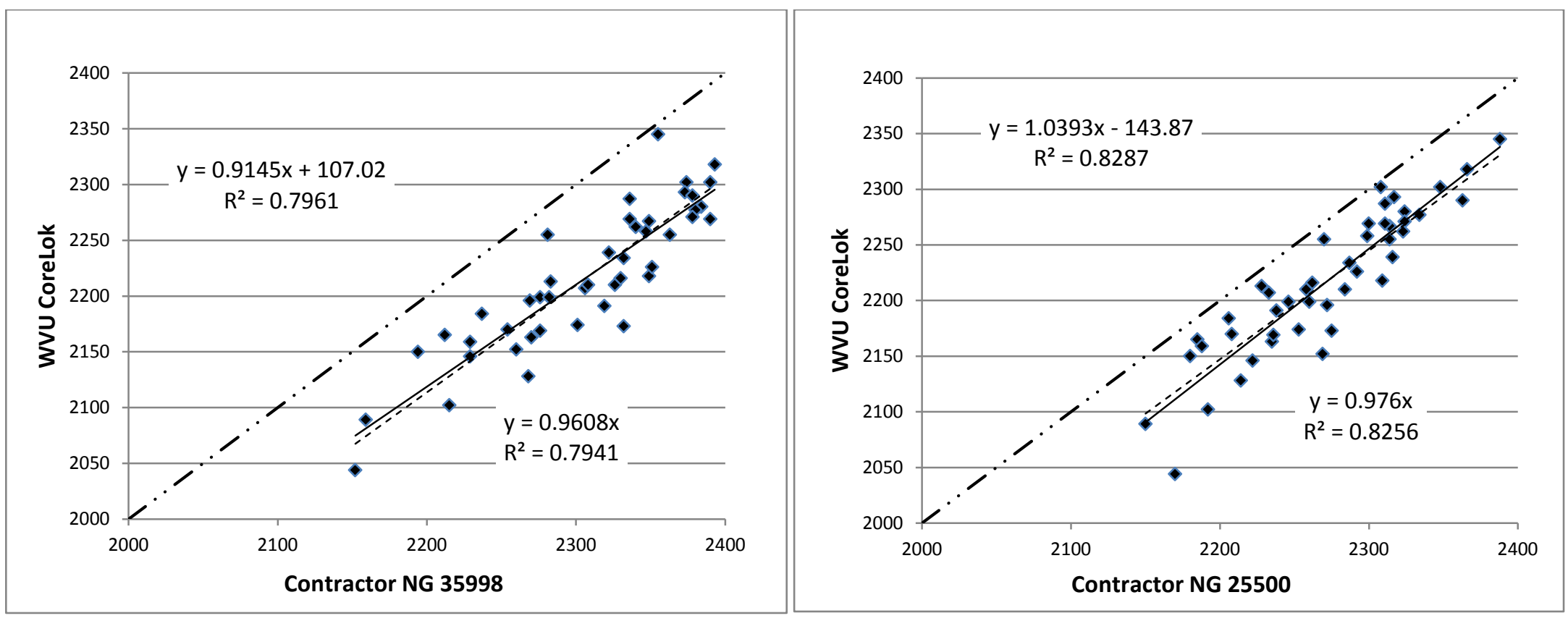

Figure 33 Line of equality comparison for contractor gauges and CoreLok density 

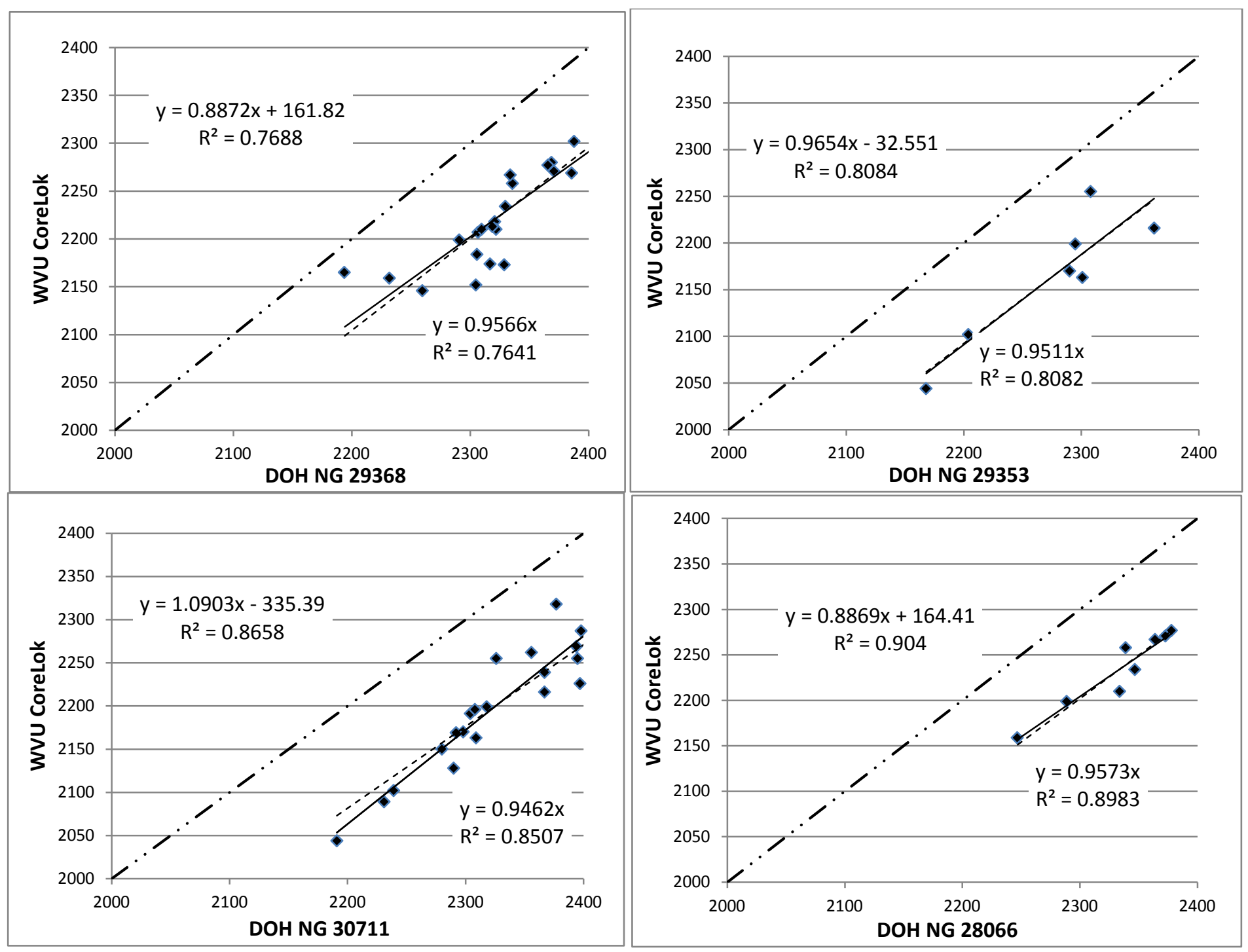

Figure 34 Line of equality comparison for WVDOH gauges and CoreLok density 

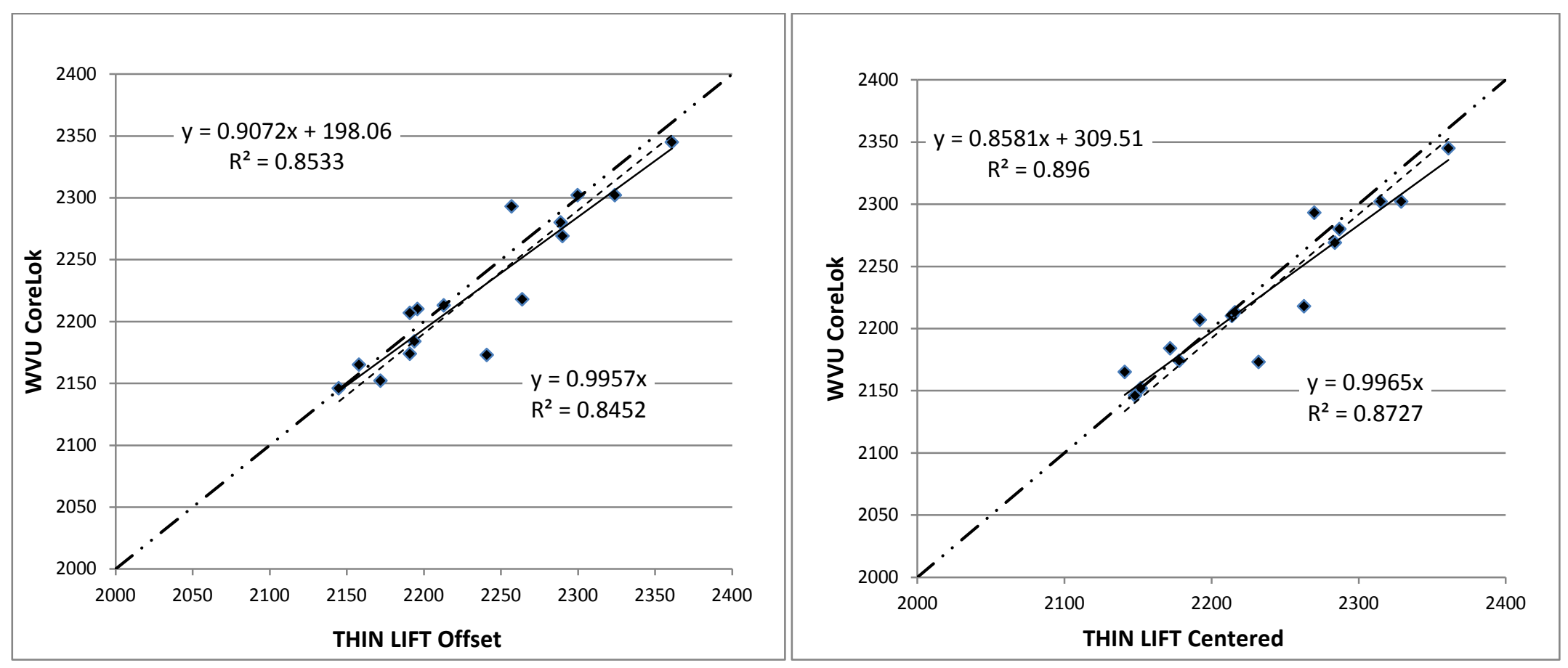

Figure 35 Line of equality comparison for thin-lift gauge and CoreLok $\mathrm{G}_{\mathrm{mb}}$ 


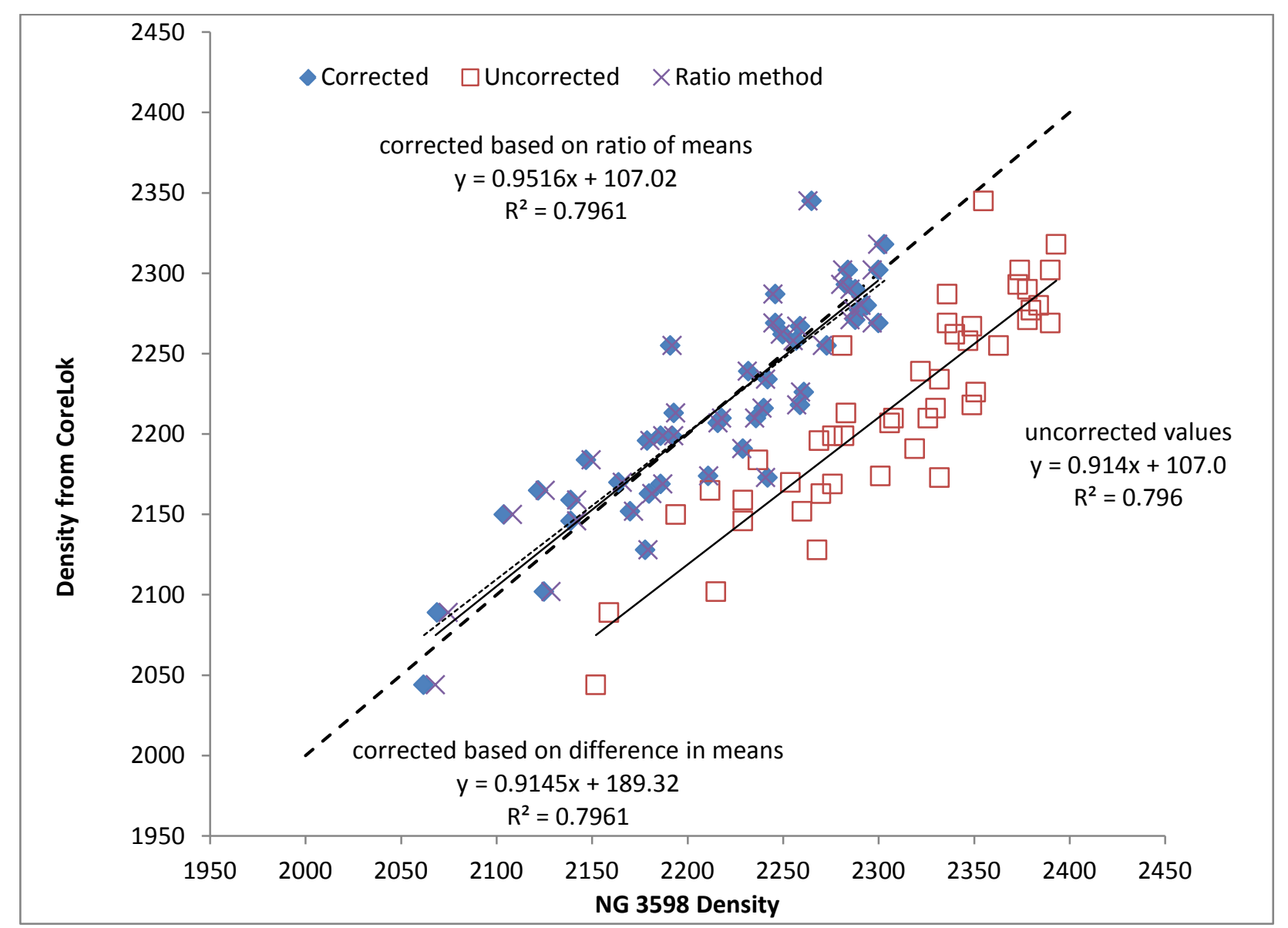

Figure 36 Comparisons of ratio of means and difference of means methods for establishing correction factors 
Table 14 Trend line coefficients for nuclear gauges and CoreLok density

\begin{tabular}{|c|c|c|c|c|c|c|}
\cline { 2 - 7 } \multicolumn{1}{c|}{} & \multicolumn{3}{c|}{$\mathrm{y}=\mathrm{a}_{1}+\mathrm{b}_{1}$} & \multicolumn{2}{c|}{$\mathrm{y}=\mathrm{a}_{2} \mathrm{x}$} & Ratio \\
\cline { 2 - 7 } \multicolumn{1}{c|}{} & $\mathrm{a}_{1}$ & $\mathrm{~b}_{1}$ & $\mathrm{R}^{2}$ & $\mathrm{a}_{2}$ & $\mathrm{R}^{2}$ & $\mathrm{CL} / \mathrm{NG}$ \\
\hline NG 35998 & 0.914 & 107.00 & 0.796 & 0.960 & 0.794 & 0.961 \\
\hline NG 25500 & 1.039 & -143.80 & 0.828 & 0.976 & 0.825 & 0.976 \\
\hline NG 29368 & 0.887 & 161.80 & 0.768 & 0.956 & 0.764 & 0.957 \\
\hline NG 29353 & 0.965 & -32.55 & 0.808 & 0.951 & 0.808 & 0.951 \\
\hline NG 30711 & 1.090 & -335.30 & 0.865 & 0.946 & 0.850 & 0.946 \\
\hline NG 28066 & 0.886 & 164.40 & 0.904 & 0.957 & 0.898 & 0.957 \\
\hline THIN-LIFT 1 & 0.907 & 198.00 & 0.853 & 0.995 & 0.845 & 0.995 \\
\hline THIN-LIFT 2 & 0.858 & 309.50 & 0.896 & 0.996 & 0.872 & 0.997 \\
\hline
\end{tabular}

\subsubsection{T 166 Results Comparison}

Figure 37 compares the $\mathrm{G}_{\mathrm{mb}}$ values gathered using $\mathrm{T} 166$ by the contractor of the Interstate 79 project and the WVUATL laboratory. Originally there were 48 cores from this project, however three cores were damaged when shipped to the WVUATL so 45 observations were available for the analysis. The linear regression shows a coefficient of determination, $\mathrm{R}^{2}$, of 0.95 . A pair t-test was conducted on the data in Figure 37 to see if a significant difference exists between the $G_{m b}$ collected by the contractor and the asphalt laboratory. Table 15 shows the results of the pair t-test. At a 95\% confidence level, the computed P-value is 0.338 which means there is insufficient evidence to reject the null hypothesis of equal means. This implies the data are from a similar dataset.

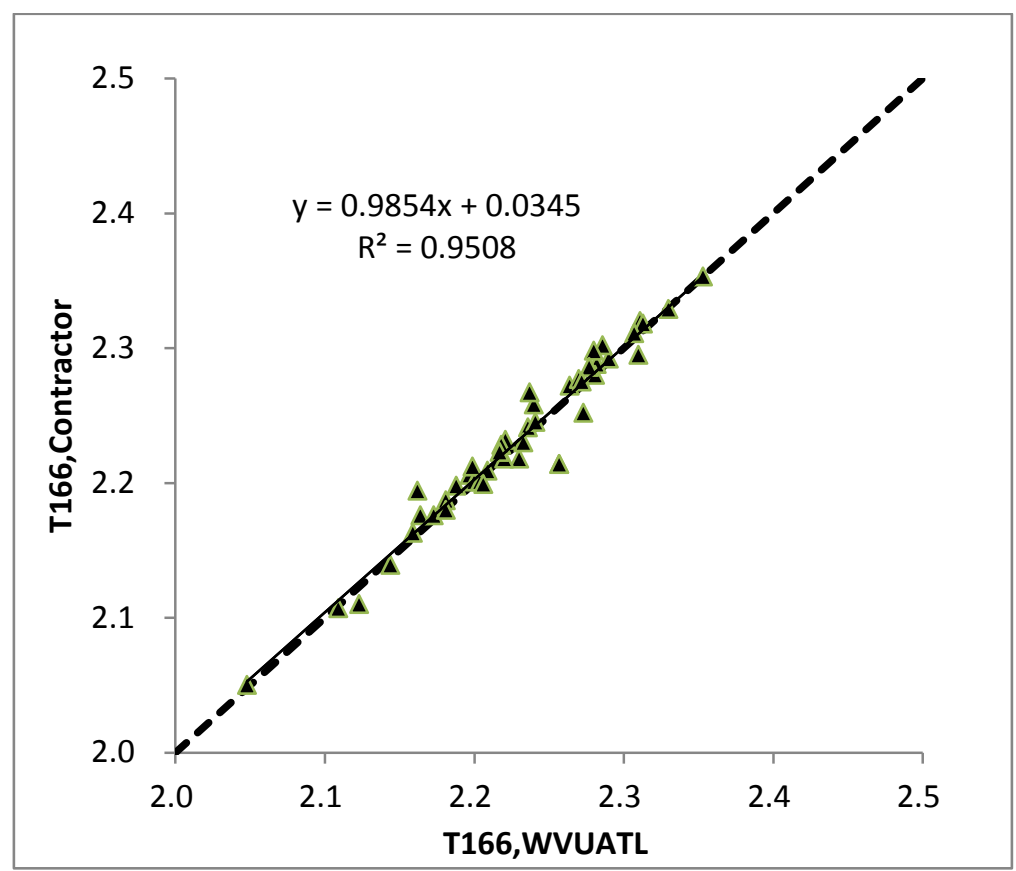

Figure 37 I-79 Line of equality comparison for contractor and WVUATL T166, $\mathrm{G}_{\mathrm{mb}}$ 
Table 15 WVUATL versus Contractor T 166 paired t-Test

\begin{tabular}{lll} 
& WVUATL & Contractor \\
& T166 & T166 \\
\hline Mean & 2.230 & 2.232 \\
Variance & 0.004 & 0.004 \\
$\mathrm{df}$ & 44 & \\
$\mathrm{P}(\mathrm{T}<=\mathrm{t})$ two-tail & 0.338 & \\
Decision & cannot reject Hn \\
\hline
\end{tabular}

The regression analysis comparing the contractor $G_{m b}$ versus the laboratory $G_{m b}$ using $T 166$ is shown in Table 16. At a confidence level of 95\%, the p-value of the intercept, 0.081 , is greater than 0.05 , the null hypothesis that the intercept is equal to 0 cannot be rejected, inferring that the computed intercept is statistically equal to 0 . The p-value of the slope, 0.108 , is greater than 0.05 , the null hypothesis that the slope is equal to 1 cannot be rejected, inferring that the computed slope is statistically equals to 1 .

Table 16 WVUATL versus contractor T 166 Regression Analysis

\begin{tabular}{|c|c|c|c|c|}
\hline \multicolumn{2}{|l|}{ Regression Statistics } & & & \\
\hline Multiple R & 0.943 & & & \\
\hline R Square & 0.890 & & & \\
\hline Adjusted R Square & 0.887 & & & \\
\hline Standard Error & 0.021 & & & \\
\hline Observations & 45 & & & \\
\hline \multicolumn{5}{|l|}{ ANOVA } \\
\hline & $\mathrm{df}$ & SS & MS & $\mathrm{F}$ \\
\hline Regression & 1 & 0.156 & 0.156 & 347.891 \\
\hline Residual & 43 & 0.019 & 0.000 & \\
\hline \multirow[t]{2}{*}{ Total } & 44 & 0.175 & & \\
\hline & Coefficients & Std Error & t Stat & P-value \\
\hline Intercept & 0.195 & 0.109 & 1.787 & 0.081 \\
\hline $\mathrm{X}$ Variable 1 & 0.919 & 0.049 & 18.652 & 0.000 \\
\hline tails & 2 & & Decision & \\
\hline $\mathrm{t}$ for $\mathrm{Hn}=1$ & -1.642 & & Intercept & cannot reject Hn \\
\hline p-value for Hn = 1 & 0.108 & & Slope & cannot reject Hn \\
\hline
\end{tabular}

Both the t-test and the regression analysis demonstrate the T166 tests performed on the cores from construction projects indicate the WVUATL and the contractor produced statistically similar results. 


\subsubsection{CoreLok $G_{m b}$ Results Comparisons}

During the Interstate 79 project the WVUATL the CoreLok and CoreDry equipment was transported to the contractor's lab to demonstrate the equipment. $G_{m b}$ was measured on 14 cores. These cores were subsequently transported to the WVUATL and retested. The results of the t-test are presented in Appendix 3; the relevant statistics for the paired t-test comparison of these data are:

\begin{tabular}{cccccc} 
& Mean & Variance & $\mathrm{df}$ & $\mathrm{p}$-value & Decision \\
\cline { 2 - 6 } WVUATL & 2.219 & 0.005 & 13 & $3.64 \mathrm{E}-05$ & reject Hn \\
I-79 Contractor Lab & 2.226 & 0.004 & & &
\end{tabular}

The decision is to reject the hypothesis of equal means. This is a situation where the variances of the tests is so small that even a minor difference in the means of the two populations results in the decision to reject the null hypothesis. The practical conclusion of this comparison is the populations are similar, and the t-test conclusion results from the abnormally small variances of the population.

The trend line equation is shown on Figure 38. The regression analysis statistics in Appendix 3 demonstrate the null hypotheses of zero and one for the intercept and slope, respectively, cannot be rejected, indicating the data are from statistically similar populations.

For the Interstate 64 project the contractor provided 24 cores and $G_{m b}$ measurements made with the CoreLok. These cores were retested at the WVUATL. The results of the t-test are presented in Appendix 3; the relevant statistics for the paired t-test comparison of these data are:

\begin{tabular}{cccccc} 
& Mean & Variance & $\mathrm{df}$ & $\mathrm{p}$-value & Decision \\
\cline { 2 - 6 } WVUATL CoreLok & 2.299 & 0.017 & 23 & $1.35 \mathrm{E}-02$ & reject Hn \\
Contractor CoreLok & 2.274 & 0.013 & & &
\end{tabular}

The decision is to reject the hypothesis of equal means.

The trend line equation is shown on Figure 39. The regression analysis statistics in Appendix 3 demonstrate the null hypotheses of zero and one for the intercept and slope, respectively, can be rejected, indicating the data are from statistically different populations, supporting the conclusion from the t-test. Comparing Figures 38 to 39 shows the comparison across two machines and labs has higher variability than the comparison for a single machine, as is expected. 


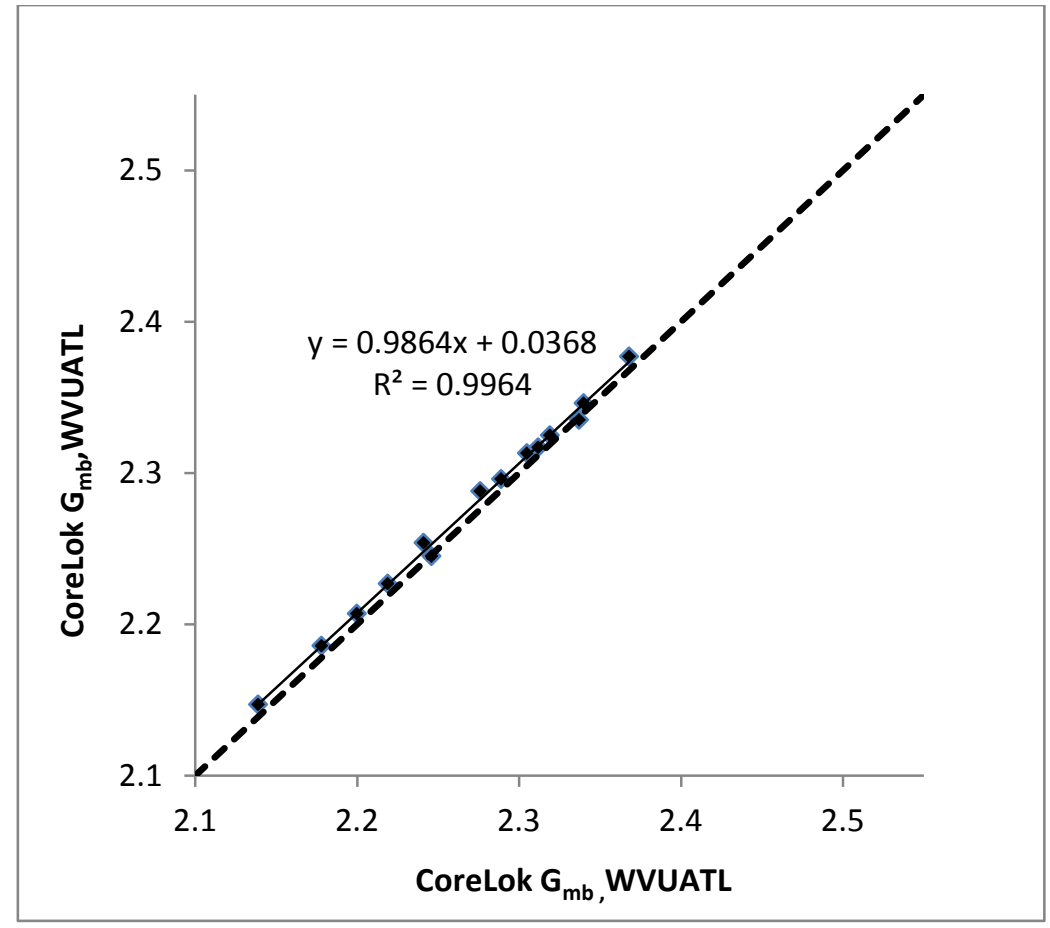

Figure 38 Line of equality comparison for WVUATL CoreLok replicated testing results

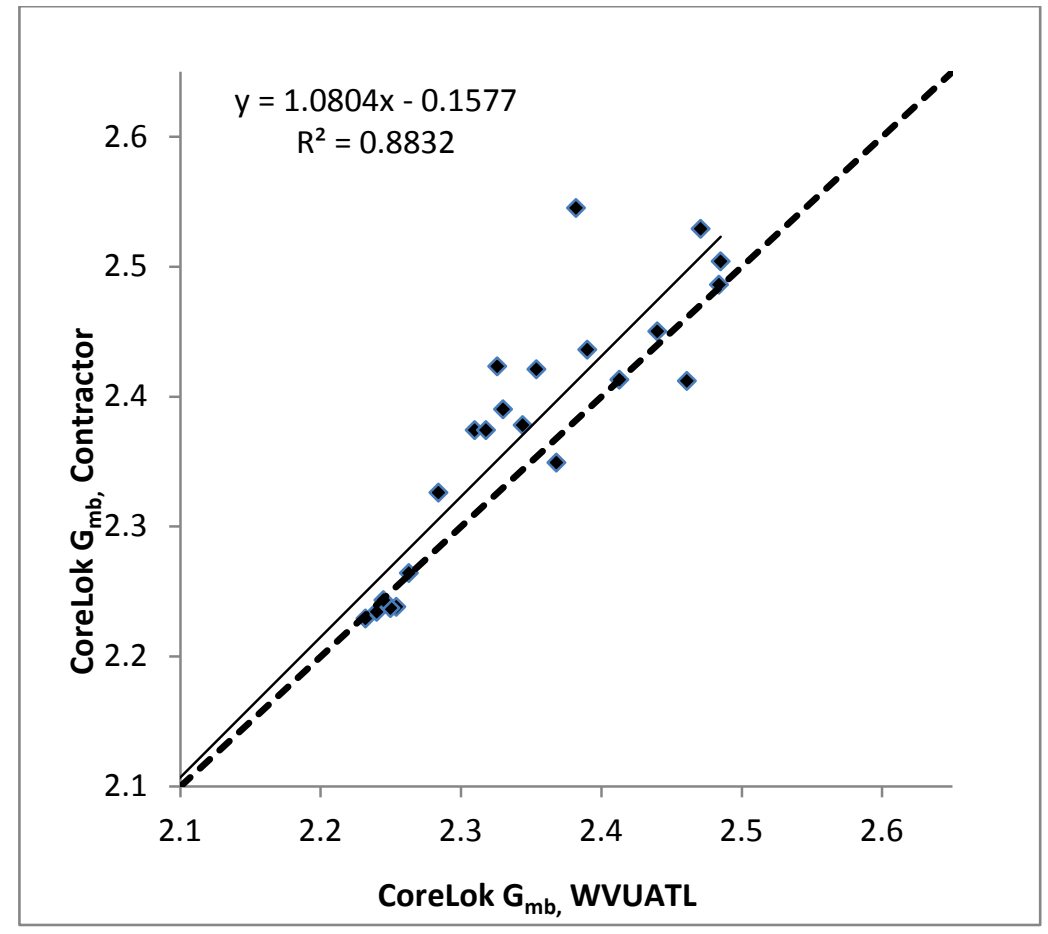

Figure 39 Line of equality comparison for WVUATL and contractor CoreLok results

\subsubsection{CoreLok versus T 166}

The preceding analysis demonstrated that the contractor and the WVUATL produced similar T 166 results. Therefore the following analysis used the WVUATL $\mathrm{G}_{\mathrm{mb}}$ data for the 
comparison between CoreLok and T 166. According to T 166, when the percent of water absorbed by the specimen exceeds $2 \%$, AASHTO T 275 or T 331 should be used to determine the bulk specific gravity. There is a proposal to reduce this threshold to one percent. Hence the following analysis considers these different threshold values. Figure 40 shows the line of equality for the data from the 77 cores with different symbols based on the threshold of absorption. One can observe that in general there is an inverse trend between absorption and specific gravity; the samples with less than one percent absorption have higher specific gravity than the other samples. This is logical as the samples with low absorption would also have low air voids and therefore higher specific gravity. It can also be observed that the samples with less than one percent absorption are on both sides on the line of equality while the preponderance of samples with more than one percent absorption are above the line of equality.

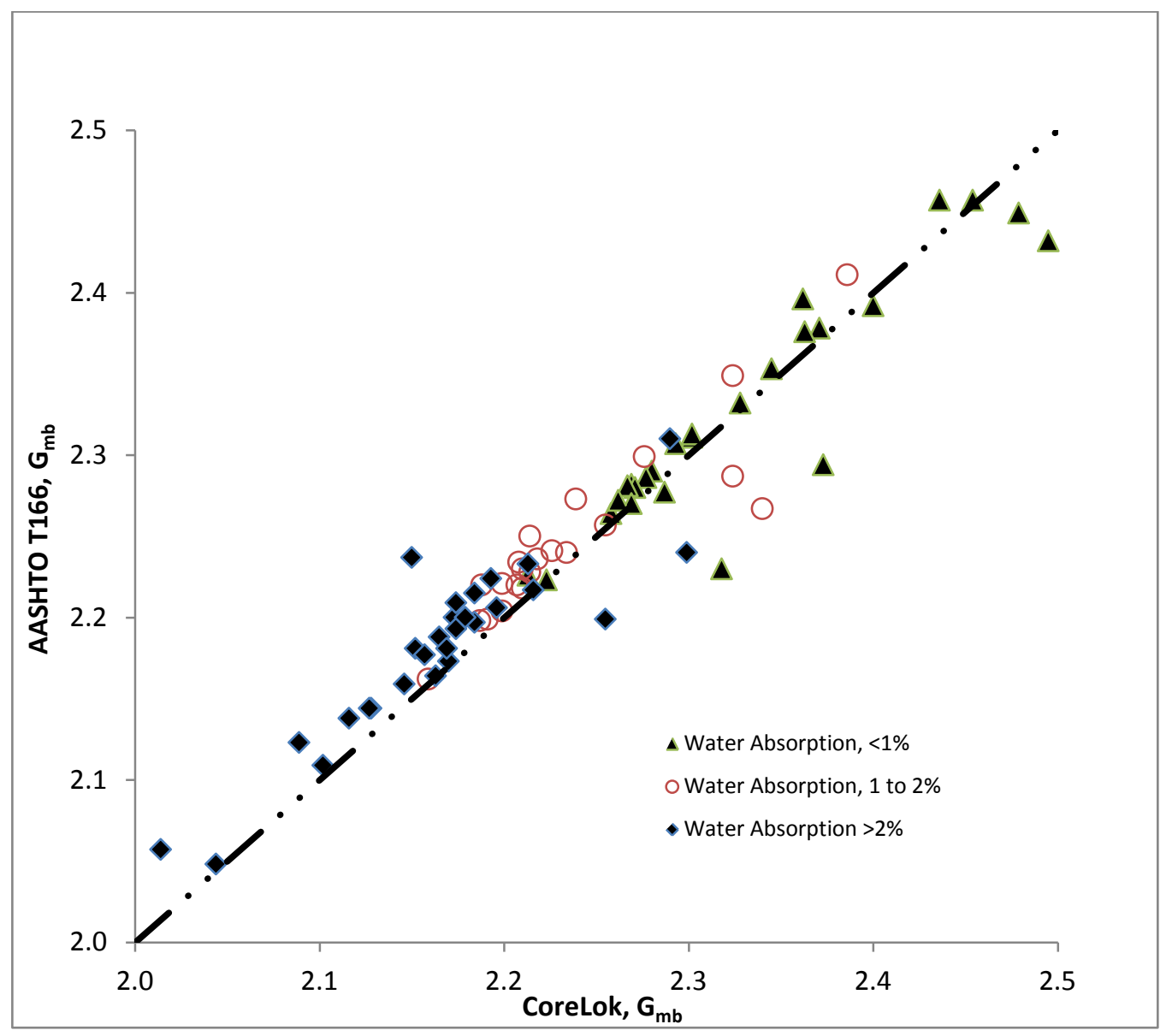

Figure 40 Line of equality comparison for WVUATL CoreLok and T 166

The complete results of the t-tests and regression analysis are presented in Appendix 3. Table 17 is a summary of the statistical results. The t-test and regression analysis are in 
agreement. The null hypothesis is not rejected is when the absorption is less than one percent and less than two percent. In all other cases the null hypothesis is rejected. This analysis supports the proposed change to $\mathrm{T} 166$ to limit the its use to samples with less than one percent absorption and use the vacuum method, $\mathrm{T} 331$, in all other cases.

Table 17 Statistical comparison of CoreLok and T166

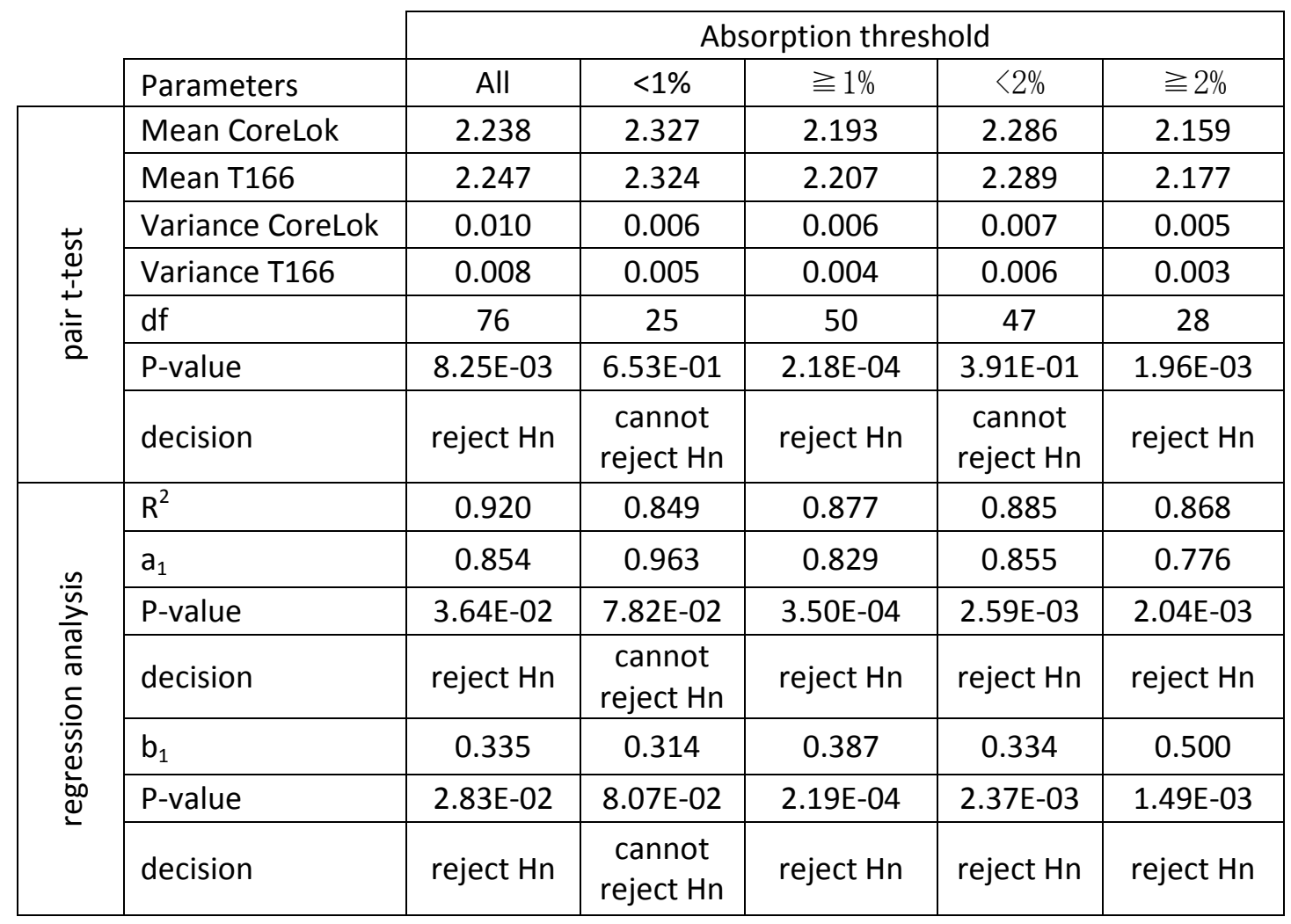

\subsection{Laboratory Permeability Test Results of Field Cores}

One of the primary goals of this research was to evaluate the relationship between laboratory permeability and in-place density. Laboratory permeability tests were performed on 45 field cores from I-79, 24 from I-64, and 8 from Route-19. The air voids content were determined based upon the bulk specific gravity of cores measured by T166 and maximum theoretical specific gravities supplied by the contractors for plant-produced mix.

\subsubsection{Permeability analysis of I-79 Cores}

Figure 41 presents the data for the laboratory permeability and percent air voids for the cores from $\mathrm{I}-79^{8}$. The coefficient of determination, $\mathrm{R}^{2}$, of 0.883 indicates that most of the variation in permeability is attributed the percent air voids. At percent air voids below 6

\footnotetext{
${ }^{8}$ The percent air voids was $17 \%$ for one core. This is sufficiently high to trigger concern that the tests were performed correctly. However, tests by the contractor, and the WVUATL using both the CoreLok and T 166 were all in agreement.
} 
percent, the permeability is very low. The permeability increases at a greater rate with changes in percent air voids from 6 to 8 percent air voids. At percent air voids above 8 percent, small changes in air voids leads to a large increases in permeability.

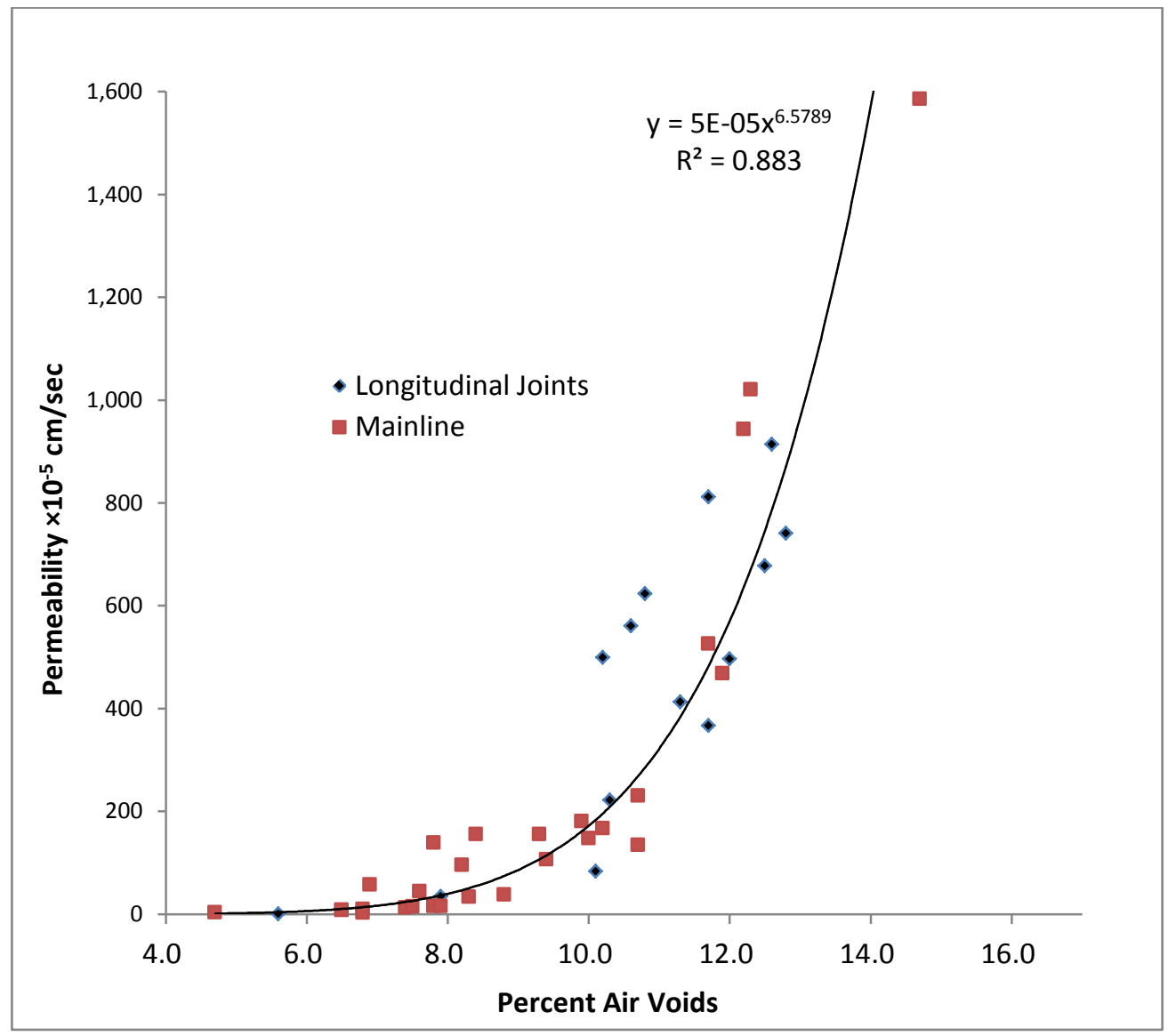

Figure 41 Relationship between permeability and percent air voids I-79 Project

Inspection of Figure 41 demonstrates that in general the percent air voids of the cores are greater than the percent air voids of the mainline cores. The higher air voids is associated with higher permeability which is in turn associated with accelerated pavement deterioration. The commonly accepted criterion for permeability is $100 \times 10^{-5}$ to $125 \times 10^{-5} \mathrm{~cm} / \mathrm{s}$ (see Table 5) which corresponded to approximately 8 percent air voids. 13 out of 15 longitudinal samples and 16 out of 30 mainline samples have the air voids content greater than 8 percent.

\subsubsection{Permeability analysis of I-64 and Route-19 Projects}

Figures 42 and 43 illustrate the permeability-density relationship for the cores collected from I-64 and Route-19, respectively. Two 9.5 mm cores from I-64 project have high percent air voids content and correspondingly high permeability. The power functional form was used for modeling the other comparisons as this is the functional form most 
commonly used in the literature. However, as shown on Figure 42 the exponential functional form does a better job of capturing the rapid increase in permeability with air voids for this data set.

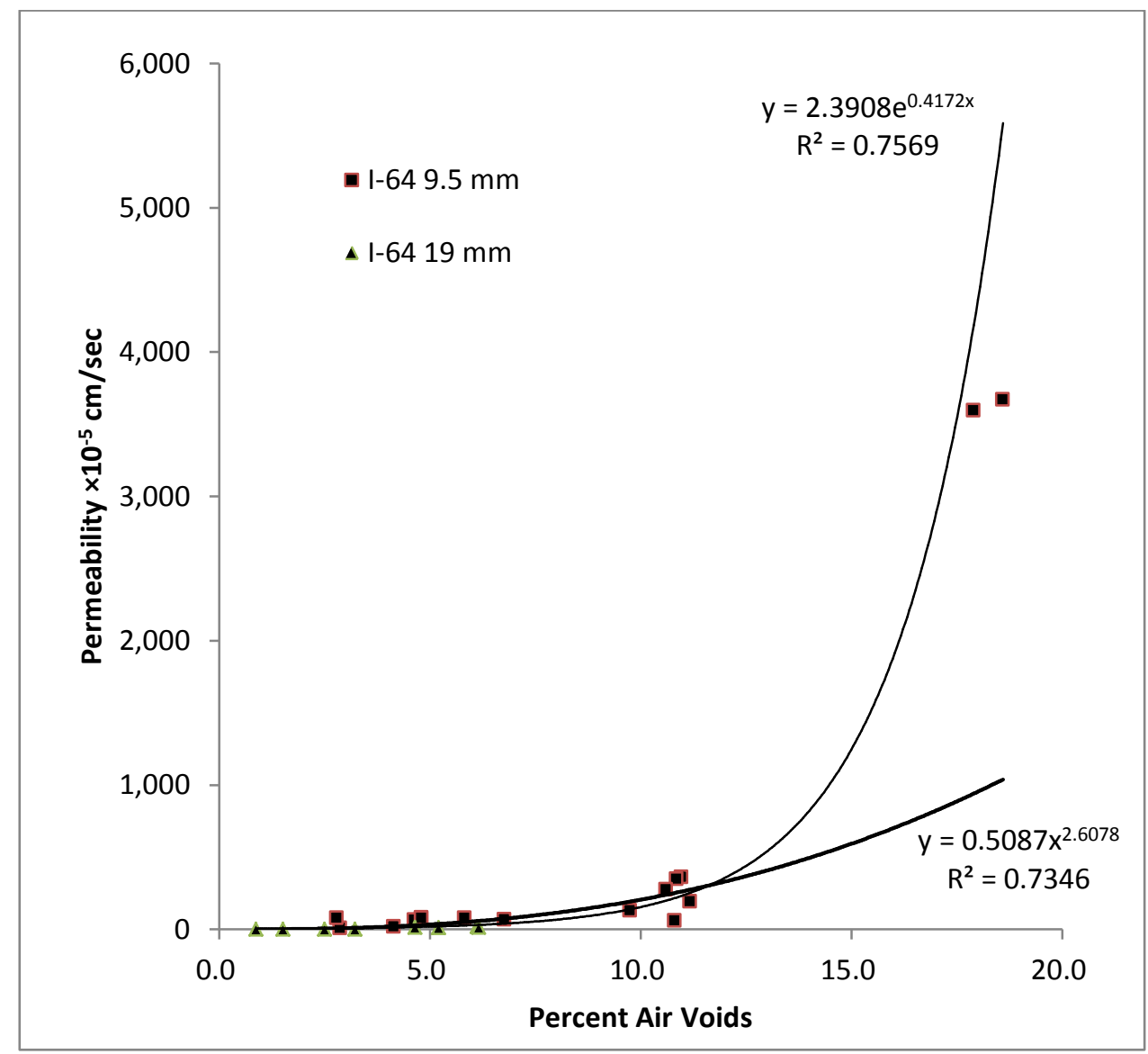

Figure 42 Relationship between permeability and percent air voids I-64 Project

Figure 43 shows the percent air voids versus permeability for the $9.5 \mathrm{~mm}$ mix used on Route 19. For a given level of air voids this mix has a much lower permeability than the other mixes both in this study and in the literature. The reason for this anomaly is unknown.

\subsubsection{Composite Analysis of Samples from All Construction Projects}

Figure 44 presents the permeability - percent air void data for all the projects. As expected the amount of scatter is greater than for the analysis of the individual projects. However, the $\mathrm{R}^{2}$ values for both the power and the exponential functions are reasonable. As was the case for the I-64 analyses, the exponential model appears to capture the extreme permeability values better than the power function. Cooley et al. (57) reported a $R^{2}$ of 0.69 for a power equation fit of field permeability and percent air voids. As shown on Figure 43 the Cooley equation predicts higher permeability than the data from this study. This may be due to the fact that the NCAT Permeameter used by Cooley allows three dimensional flows 


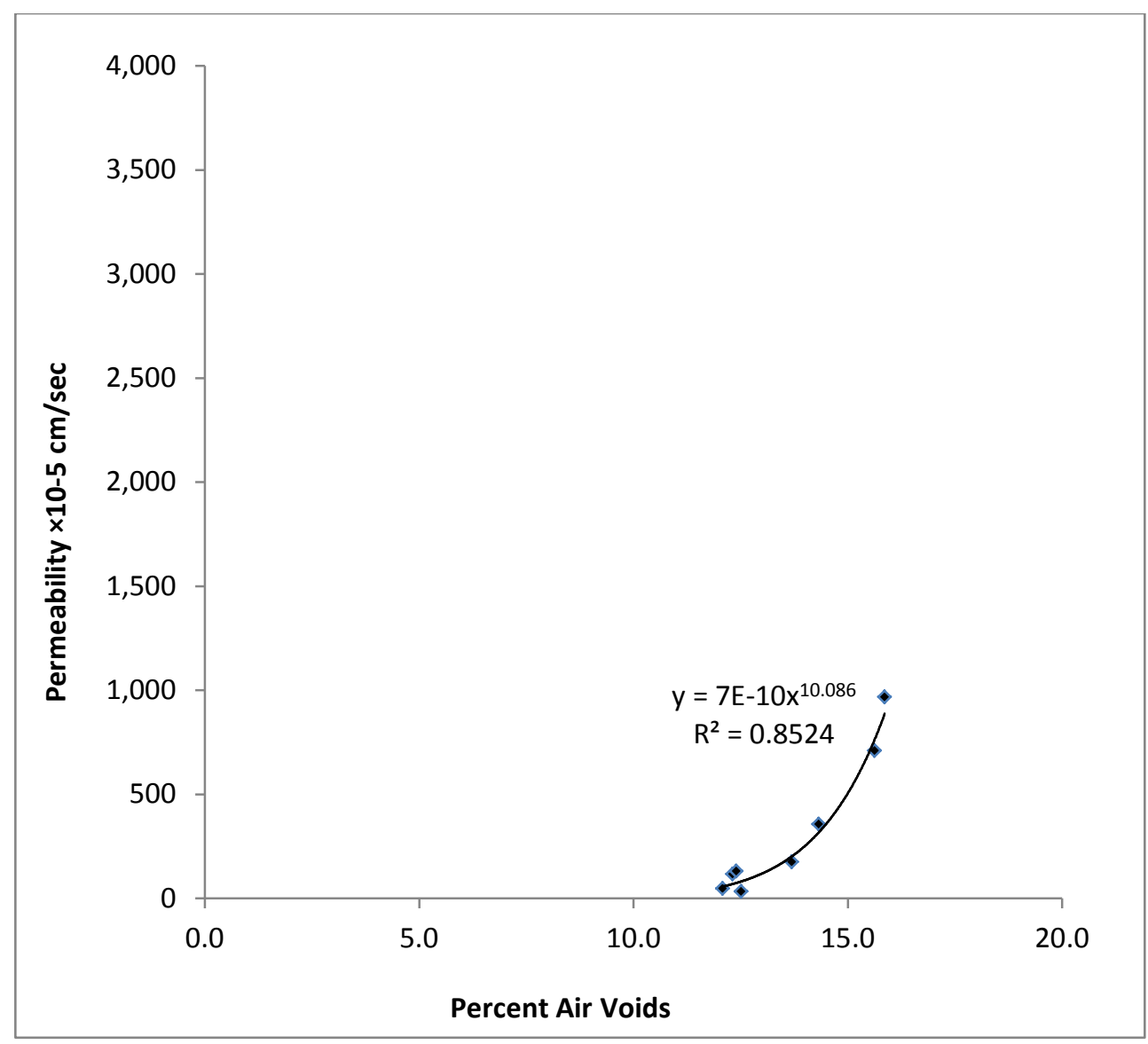

Figure 43 Relationship between permeability and percent air voids $\sim$ Route-19 Project

versus the one dimensional flow of the permeameter used in this study. Hainin et al. (35) tested field cores using the Florida method. Figure 44 shows Hainin's equation falls between the Cooley's and the one developed in this study. The $\mathrm{R}^{2}$ of Hainin's equation was 0.501 .

\subsection{Laboratory Permeability Test Results of Gyratory Compacted Pills}

Table 18 presents the density and permeability results of gyratory compacted pills at the WVUATL. At 4 percent air voids, most of the samples have permeability value of 0 , and for these samples a value of 1.0 was used to permit use of the power model. Figure 45 presents all the data and power models together. In the following sections the data are grouped to allow better understanding of the trends. 


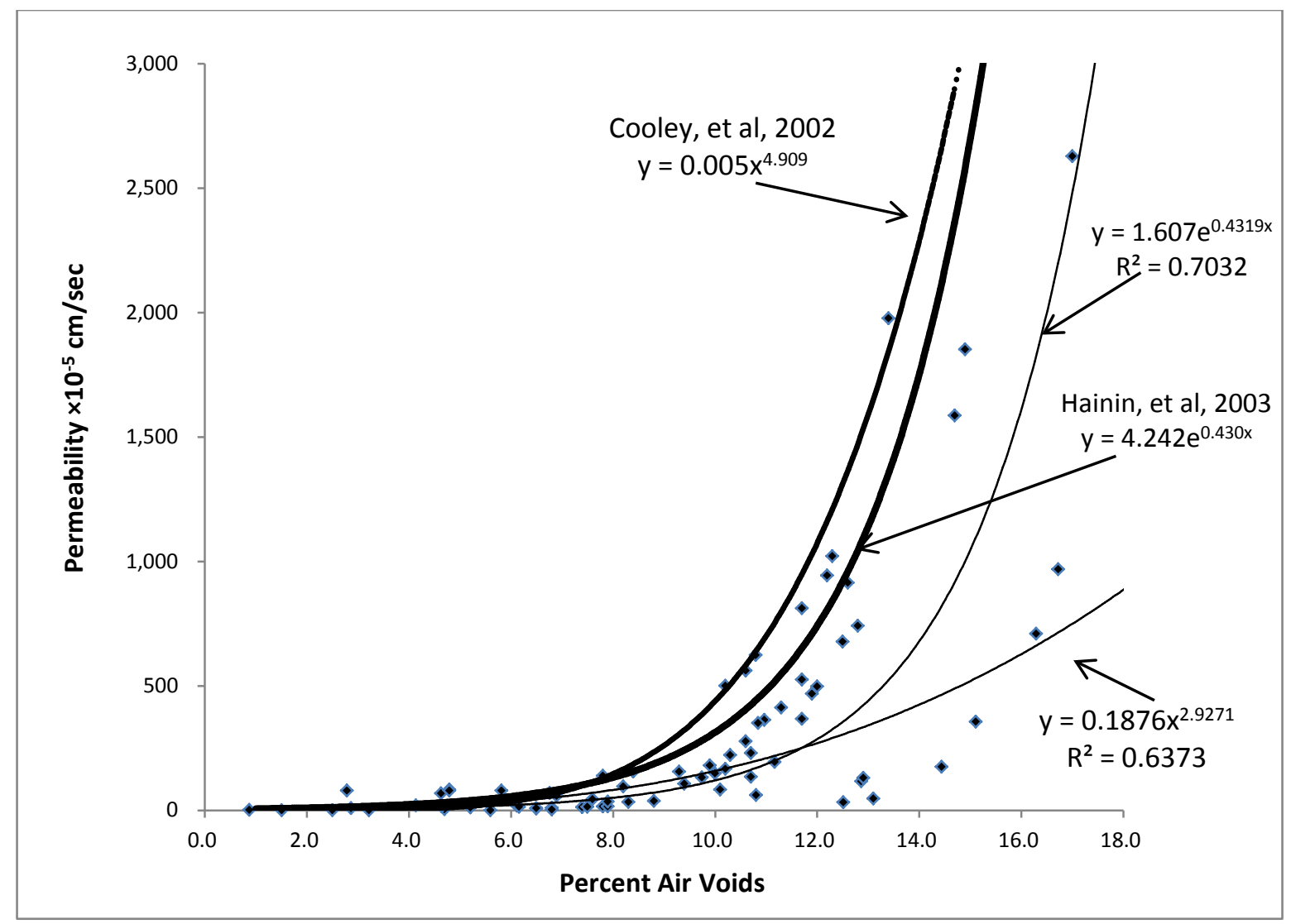

Figure 44 Permeability - Air Voids Data and Models for All Three Projects. 
Table 18 Density and permeability results

\begin{tabular}{|c|c|c|c|c|c|}
\hline \multirow{9}{*}{ 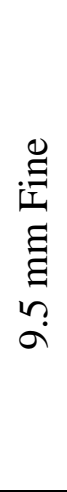 } & Air Voids (\%) & $\begin{array}{l}\text { Permeability } \\
(\mathrm{E}-5 \mathrm{~cm} / \mathrm{s})\end{array}$ & \multirow{9}{*}{ 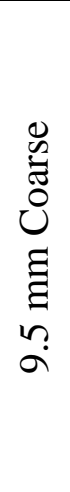 } & Air Voids (\%) & $\begin{array}{l}\text { Permeability } \\
(\mathrm{E}-5 \mathrm{~cm} / \mathrm{s})\end{array}$ \\
\hline & 3.9 & 0 & & 4.1 & 0 \\
\hline & 4.0 & 0 & & 4.1 & 0 \\
\hline & 7.1 & 11.4 & & 6.9 & 2.1 \\
\hline & 7.1 & 19.2 & & 7.3 & 2.3 \\
\hline & 9.0 & 75.2 & & 8.7 & 95.9 \\
\hline & 9.5 & 84.7 & & 8.9 & 92.7 \\
\hline & 10.7 & 112.2 & & 11.2 & 573.9 \\
\hline & 11.7 & 180.9 & & 11.5 & 441.6 \\
\hline \multirow{8}{*}{ 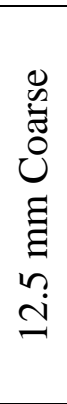 } & 4.1 & 0 & \multirow{8}{*}{ 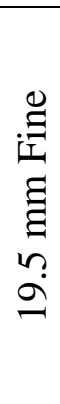 } & 3.8 & 0 \\
\hline & 4.3 & 0 & & 4.3 & 0.1 \\
\hline & 7.2 & 3.4 & & 6.6 & 1.1 \\
\hline & 7.5 & 6.8 & & 7.0 & 5.9 \\
\hline & 8.8 & 109.4 & & 8.5 & 73.3 \\
\hline & 8.9 & 68.2 & & 8.8 & 85.7 \\
\hline & 11.4 & 928.5 & & 10.2 & 676.7 \\
\hline & 11.8 & 686.9 & & 11.9 & 1294.7 \\
\hline \multirow{8}{*}{ 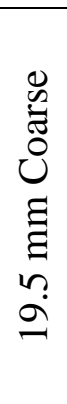 } & 4.2 & 0 & \multirow{8}{*}{$\begin{array}{l}\text { 臭 } \\
\text { 园 } \\
\text { 吕 }\end{array}$} & 3.7 & 0 \\
\hline & 4.5 & 0.2 & & 4.2 & 0 \\
\hline & 6.6 & 68 & & 7.2 & 61 \\
\hline & 7.2 & 50.9 & & 7.4 & 98.5 \\
\hline & 8.6 & 195.1 & & 9.3 & 536.4 \\
\hline & 8.7 & 308.8 & & 9.8 & 187 \\
\hline & 10.0 & 1103.6 & & 10.5 & 1012.7 \\
\hline & 10.2 & 1704.7 & & 11.1 & 1498.5 \\
\hline \multirow{8}{*}{ 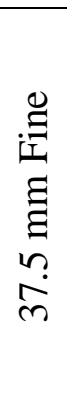 } & 3.6 & 0 & \multirow{8}{*}{ 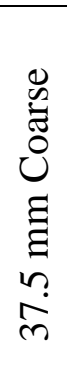 } & 3.2 & 0 \\
\hline & 4.4 & 30.7 & & 4.5 & 0 \\
\hline & 7.0 & 1180.9 & & 7.5 & 934.9 \\
\hline & 7.1 & 1121.9 & & 7.8 & 1036.4 \\
\hline & 8.5 & 1869.8 & & 9.0 & 2493.1 \\
\hline & 8.5 & 1980.7 & & 9.3 & 3451.9 \\
\hline & 9.3 & 2449.3 & & 10.3 & 3134.1 \\
\hline & 10.4 & 2639.7 & & 11.0 & 4351.5 \\
\hline
\end{tabular}




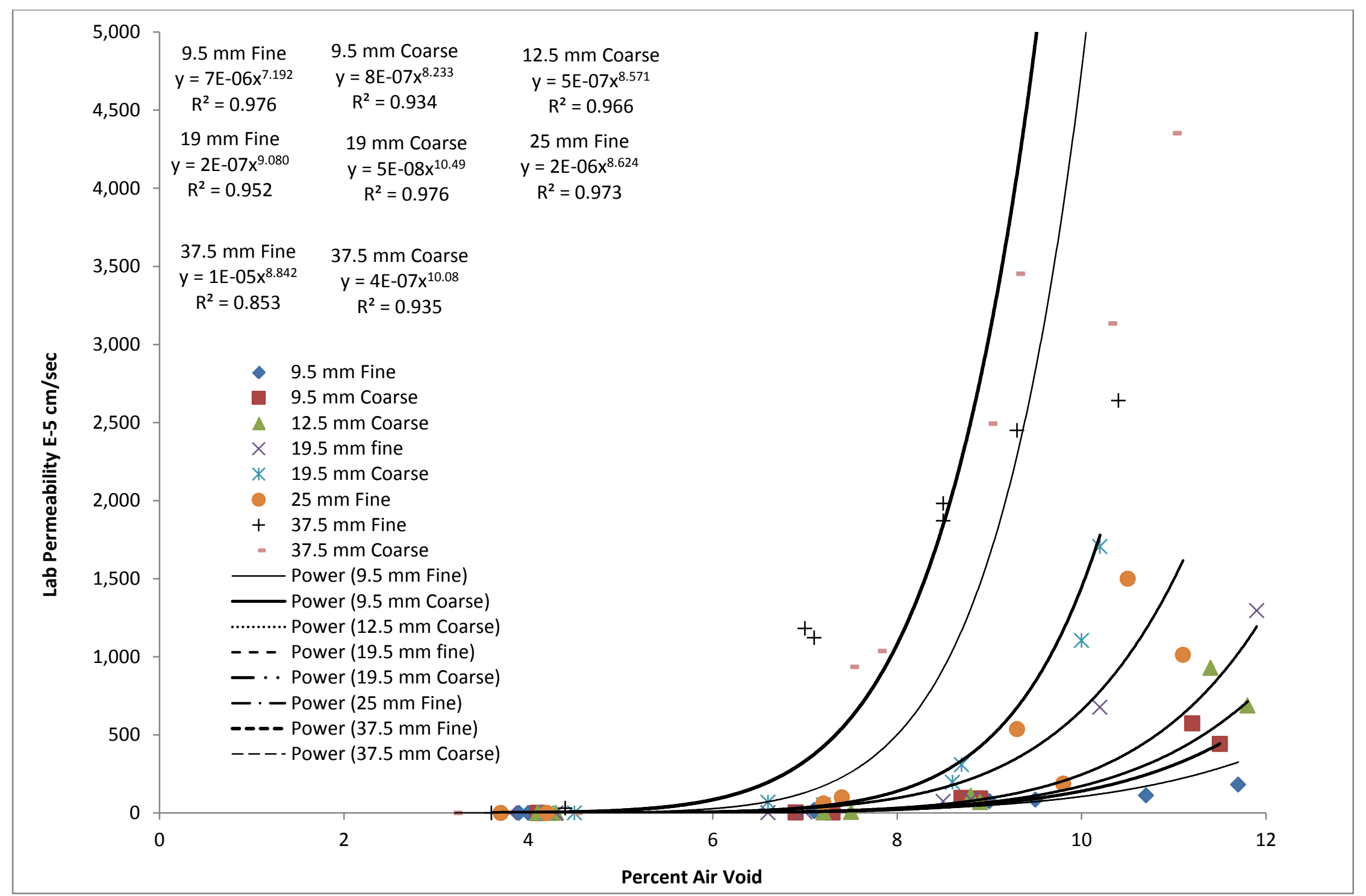

Figure 45 Permeability and percent air voids value ofe HMA mixes 


\subsubsection{Relationship between Permeability and Percent Air Voids}

Figure 46 through 53 present the relationship between in-place air voids content and permeability separately for each mix. The coefficients of determination, $\mathrm{R}^{2}$, of all mixes are excellent with only $37.5 \mathrm{~mm}$ fine mix lower than 90 percent, which means a very strong relationship is established between permeability and air voids content.

The 9.5 mm, 12.5 and 19 mm mixes, Figure 46, 47 and 48, show similar trends:

- at air voids below 6 percent, the samples were impermeable,

- from 6 to 7 percent, the permeability started to increase with the increase of air voids content, and

- at air voids level above 8 percent permeability increases sharply with small increase in in-place air voids content.

Cooley et al. (32) reported similar observations for 9.5 and $12.5 \mathrm{~mm}$ mixes.

Figures 49 and 50 illustrate the relationship between laboratory permeability and inplace air voids for 19 mm NMAS fine and coarse mixes. The permeability is typically low at low air voids content, and it increases with the increase of air voids content. Above 7 percent, a small change in air voids content results in a large increase in permeability.

Figure 51 illustrates the relationship between permeability and in-place air voids for 25 mm NMAS fine mix. In this study, only 25 mm fine-graded mix was prepared, and data in Figure 51 suggests that $25 \mathrm{~mm}$ fine-graded Superpave mix can be excessive permeable above 7 percent in-place air voids. Cooley et al. (32) suggested 4.4 percent in-place air voids should be a threshold for $25 \mathrm{~mm}$ coarse-graded Superpave mixes.

Figures 52 and 53 show the relationship between permeability and in-place air voids for 37.5 mm NMAS fine and coarse mixes. The samples are impermeable with air voids level lower than approximately 4.5 percent. For $37.5 \mathrm{~mm}$ fine-graded and coarse-graded, when the air voids were higher than 5 and 6 percent, the permeability values increased significantly with small changes in in-place air voids content. The maximum permeability value obtained in this study is $4350 \mathrm{~cm} / \mathrm{sec}$ from a $37.5 \mathrm{~mm}$ NMAS coarse-graded sample with 11 percent in-place air voids. 


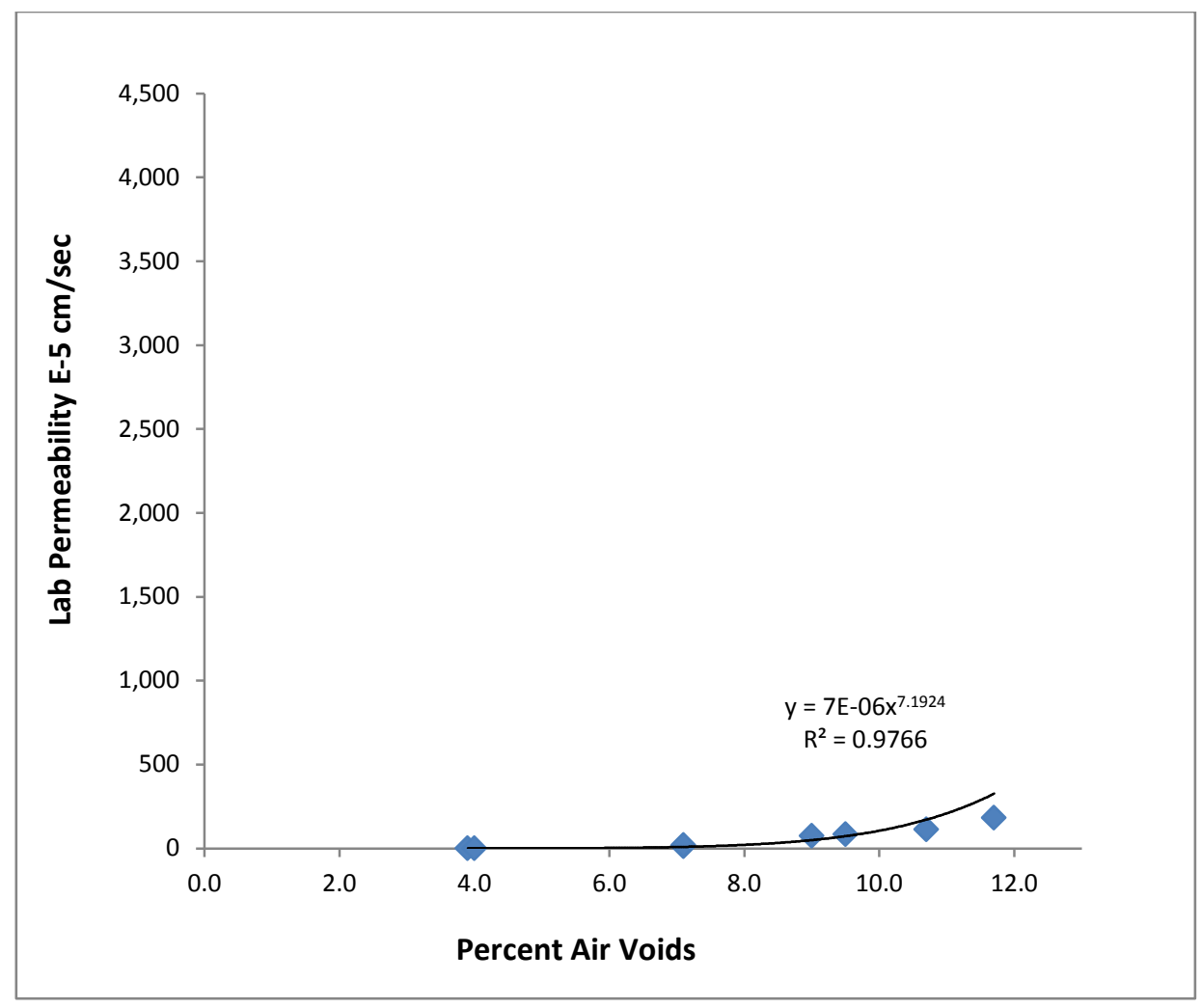

Figure 46 Permeability vs. percent air voids, $9.5 \mathrm{~mm}$ fine mixes

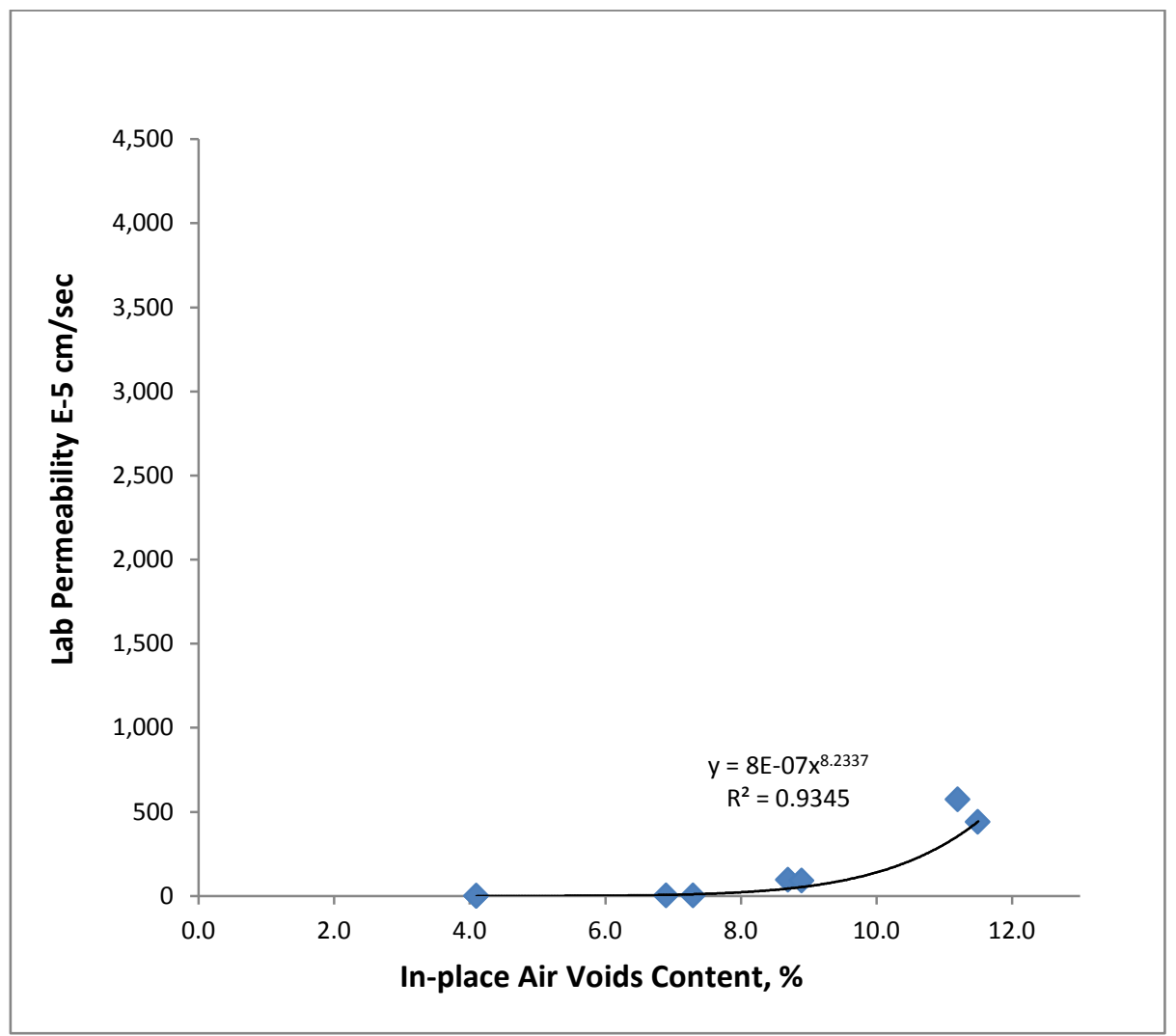

Figure 47 Permeability vs. percent air voids, $9.5 \mathrm{~mm}$ coarse mixes 


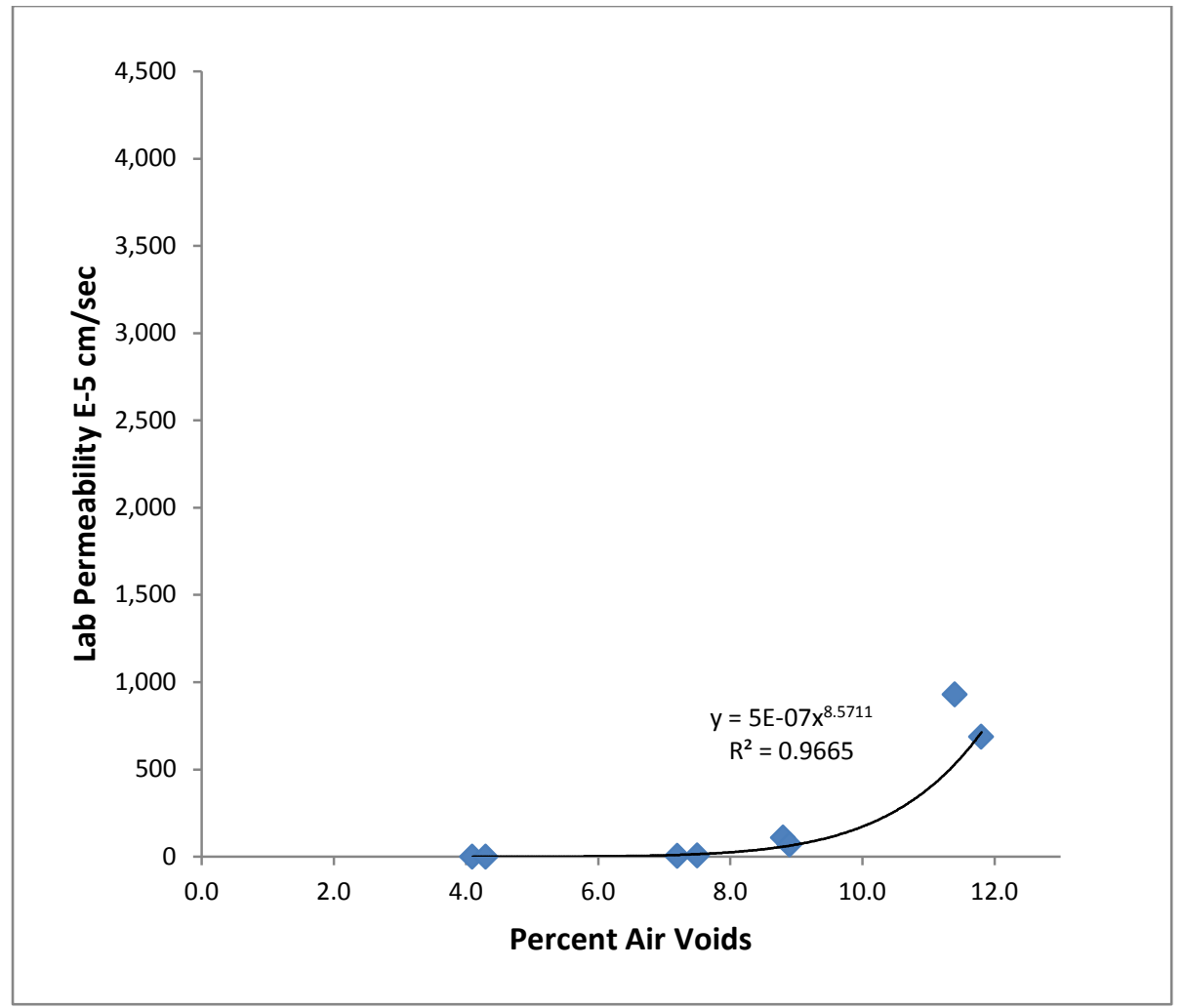

Figure 48 Permeability vs. percent air voids, 12.5 coarse mixes

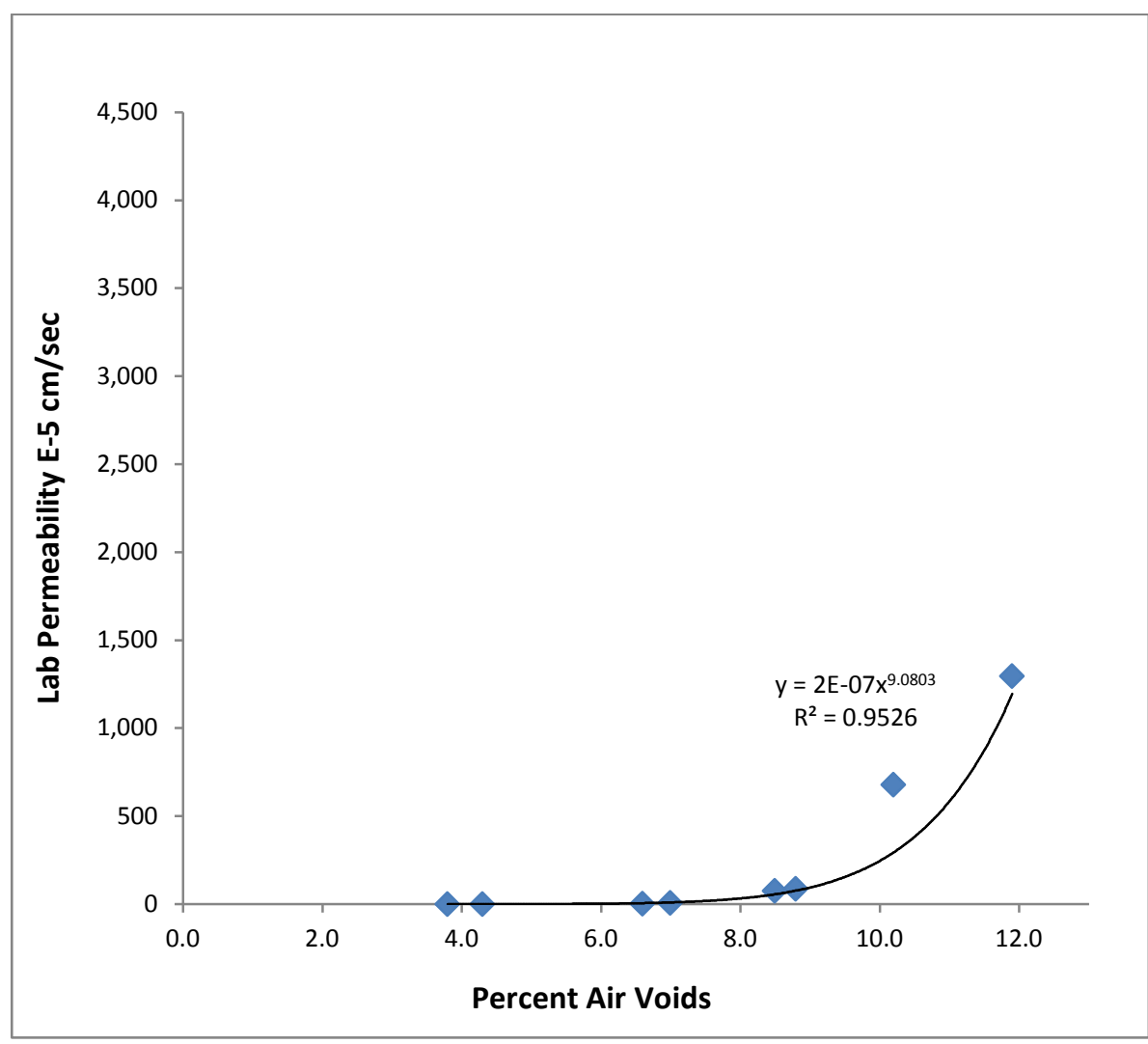

Figure 49 Permeability vs. percent air voids, 19 mm fine mixes 


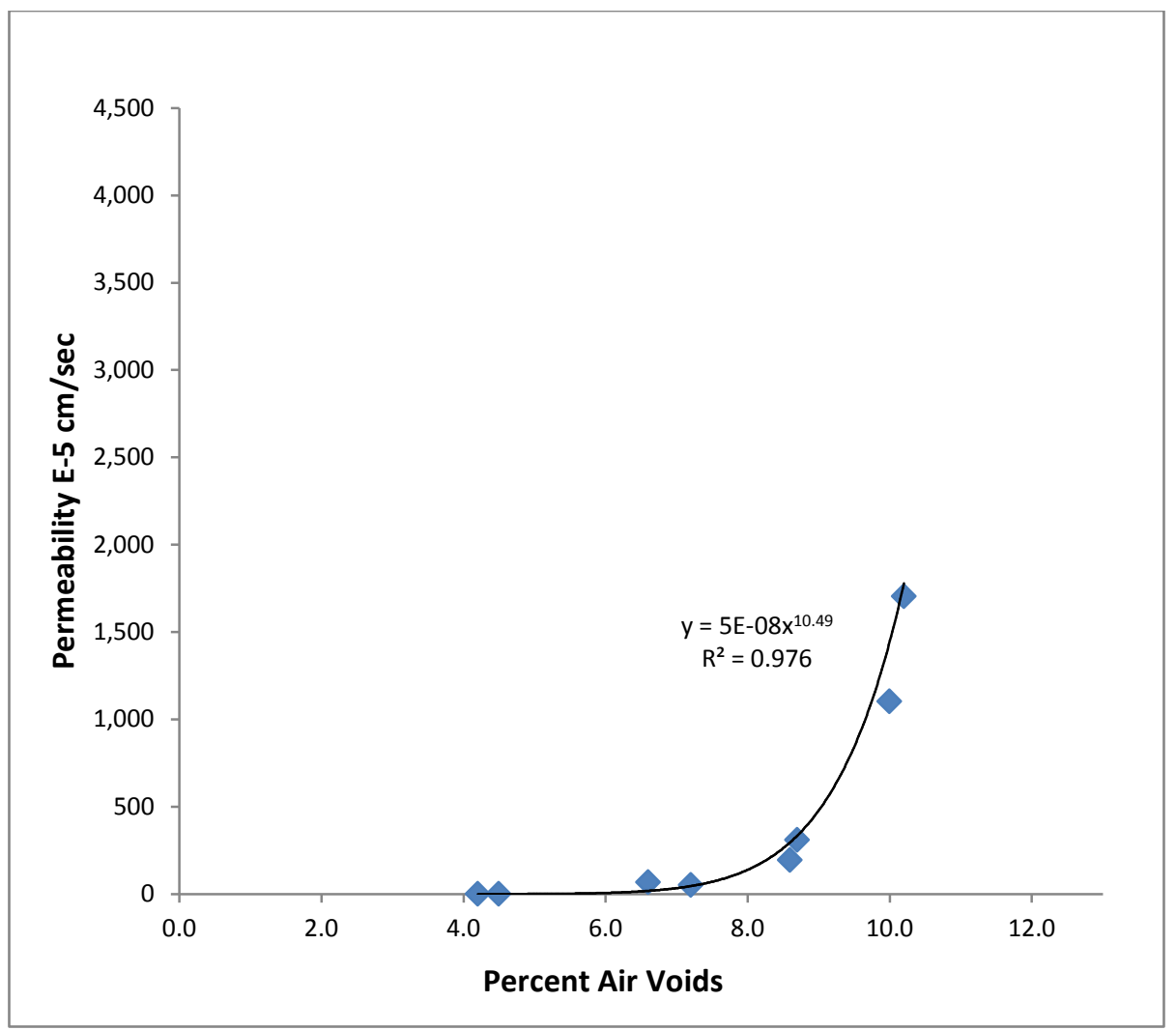

Figure 50 Permeability vs. percent air voids, 19 mm coarse mixes

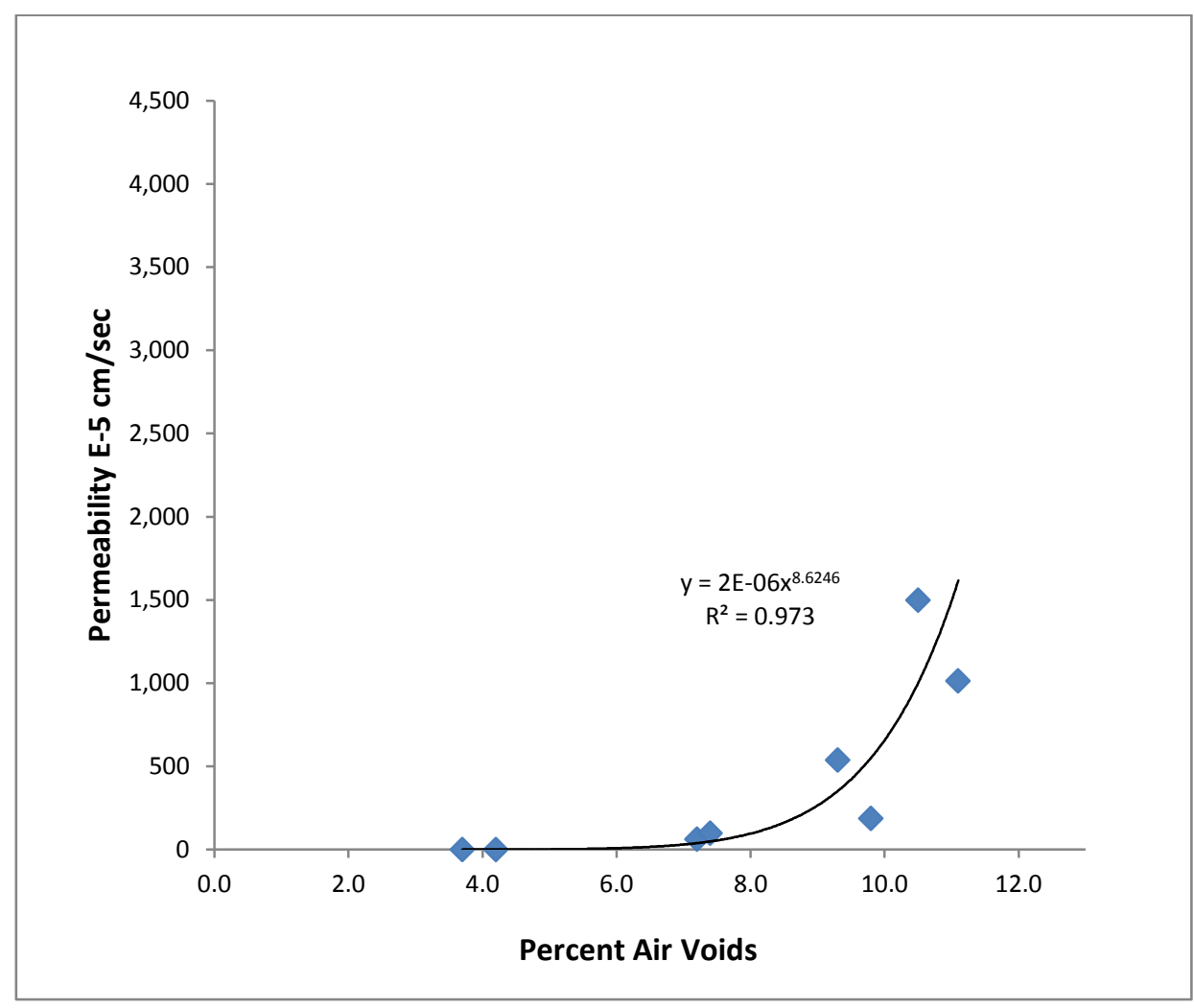

Figure 51 Permeability vs. Percent Air Voids, 25 mm fine mixes 


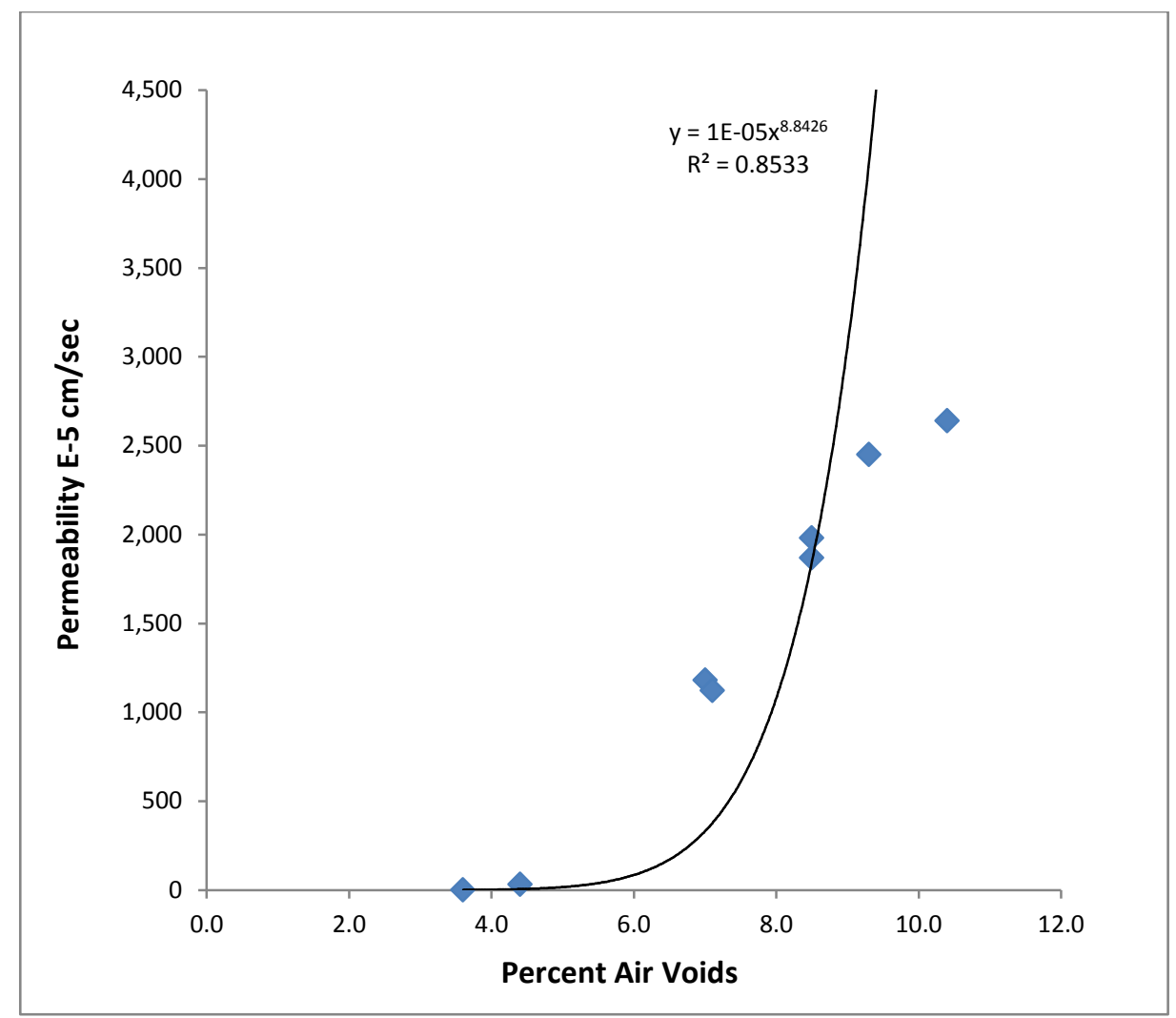

Figure 52 Permeability vs. percent air voids, $37.5 \mathrm{~mm}$ fine mixes

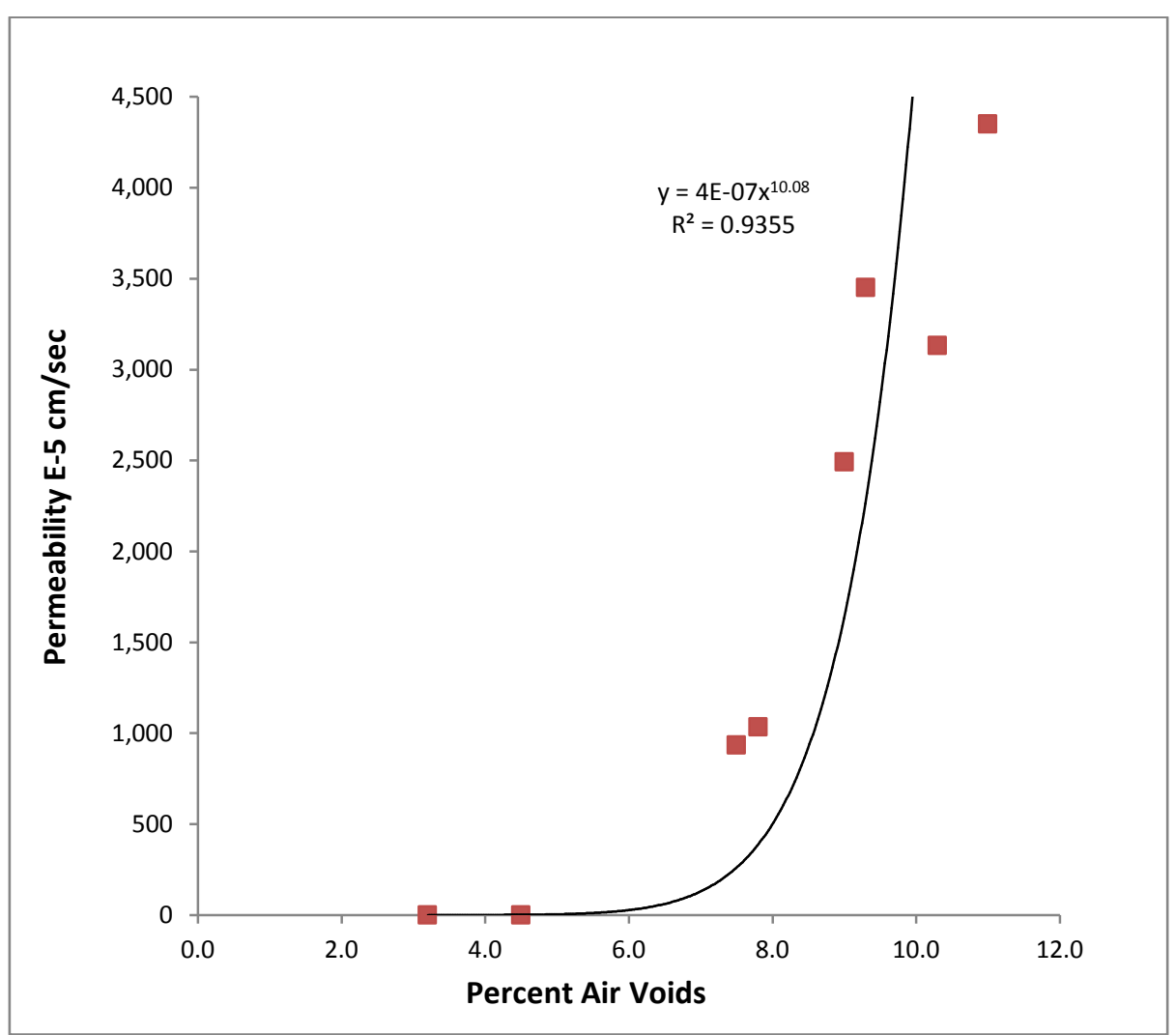

Figure 53 Permeability vs. percent air voids, $37.5 \mathrm{~mm}$ coarse mixes 
Identified in the literature review (55), the upper limit of in-place air voids for constructing an impermeable 9.5 and $12.5 \mathrm{~mm}$ NMAS HMA mixes is approximately 8 percent. Table 19 presents the permeability value of all eight HMA mixes based upon the 8 percent air voids threshold. The $9.5 \mathrm{~mm}$ fine and coarse, $12.5 \mathrm{~mm}$ coarse and $19 \mathrm{~mm}$ fine mixes meet the requirement with permeability value lower than $1 \times 10^{-3} \mathrm{~cm} / \mathrm{sec}$ at eight percent air voids. The $19 \mathrm{~mm}$ coarse, $25 \mathrm{~mm}$ fine, $37.5 \mathrm{~mm}$ fine and coarse mixes have permeability greater than $1 \times 10^{-3} \mathrm{~cm} / \mathrm{sec}$ at 8 percent air voids. Using the 8 percent criteria for these mixes would result in pavement with unacceptable high permeability.

The original upper limit permeability value used by FDOT for quality-control was $1 \times 10^{-3} \mathrm{~cm} / \mathrm{sec}$ and was later increased to $1.25 \times 10^{-3} \mathrm{~cm} / \mathrm{sec}$, cited by Maupin (42). The VDOT requires a permeability value of $1.5 \times 10^{-3} \mathrm{~cm} / \mathrm{sec}$ or less at 7.5 percent air voids as cited Maupin (29). Table 20 presents the air voids value for eight HMA mixes at $1 \times 10^{-3}$ and $1.25 \times 10^{-3} \mathrm{~cm} / \mathrm{sec}$ permeability based on the relationship plotted on Figure 46 through 53.

If $1 \times 10^{-3} \mathrm{~cm} / \mathrm{sec}$ is selected as the permeability threshold, then the $9.5 \mathrm{~mm}$ fine and coarse, $12.5 \mathrm{~mm}$ coarse, and $19 \mathrm{~mm}$ fine HMA mixes would meet the air voids content requirement at eight percent air voids. If $1.25 \times 10^{-3} \mathrm{~cm} / \mathrm{sec}$ is chosen as the criterion, then 37.5 $\mathrm{mm}$ fine and coarse needed to be compacted to initial air voids of approximately 6 to 7 percent.

\subsubsection{Relationship between permeability and Gradation of HMA mixes}

The data plotted in Figure 54 through 56 illustrate how aggregate gradation affects the permeability. Literature review indicates that the permeability of HMA mixtures cannot be controlled by air voids content alone, it also depends on the aggregate gradation. At a similar air voids content, coarse-graded Superpave mixes appear to be more permeable than conventional dense-graded mixes (7).

Figure 54 illustrates the relationship between permeability and in-place air voids for $9.5 \mathrm{~mm}$ fine and coarse mixes. It is observed that the permeability value is similar at low inplace air voids value. At air voids approximately above 8 percent, the permeability of coarse mix started to increase faster than the fine mix with twice higher permeability value at 10 percent air voids level and three times higher than fine mix at 11 percent air voids level. 
Table 19 Permeability value at eight percent air voids

\begin{tabular}{|c|c|c|c|}
\hline NMAS (mm) & Gradation & $\begin{array}{c}\text { Air Voids, } \\
\text { percent }\end{array}$ & $\begin{array}{c}\text { Permeability } \\
(10-5 \mathrm{~cm} / \mathrm{sec})\end{array}$ \\
\hline 9.5 & Fine & 8 & 22 \\
\hline 9.5 & Coarse & 8 & 22 \\
\hline 12.5 & Coarse & 8 & 28 \\
\hline 19 & Fine & 8 & 32 \\
\hline 19 & Coarse & 8 & 149 \\
\hline 25 & Fine & 8 & 123 \\
\hline 37.5 & Fine & 8 & 966 \\
\hline 37.5 & Coarse & 8 & 507 \\
\hline
\end{tabular}

Table 20 Air voids content corresponding to select permeability values

\begin{tabular}{|c|c|c|c|c|c|}
\hline $\begin{array}{l}\text { NMAS } \\
(\mathrm{mm})\end{array}$ & Gradation & $\begin{array}{l}\text { Permeability } \\
(\mathrm{E}-5 \mathrm{~cm} / \mathrm{sec})\end{array}$ & $\begin{array}{l}\text { Air voids, } \\
\text { percent }\end{array}$ & $\begin{array}{l}\text { Permeability } \\
(\mathrm{E}-5 \mathrm{~cm} / \mathrm{sec})\end{array}$ & $\begin{array}{l}\text { Air } \\
\text { voids, } \\
\text { percent }\end{array}$ \\
\hline 9.5 & Fine & 100 & 9.9 & 125 & 10.2 \\
\hline 9.5 & Coarse & 100 & 9.6 & 125 & 9.9 \\
\hline 12.5 & Coarse & 100 & 9.3 & 125 & 9.5 \\
\hline 19 & Fine & 100 & 9.1 & 125 & 9.3 \\
\hline 19 & Coarse & 100 & 7.7 & 125 & 7.9 \\
\hline 25 & Fine & 100 & 7.8 & 125 & 8.0 \\
\hline 37.5 & Fine & 100 & 6.2 & 125 & 6.3 \\
\hline 37.5 & Coarse & 100 & 6.8 & 125 & 7.0 \\
\hline
\end{tabular}




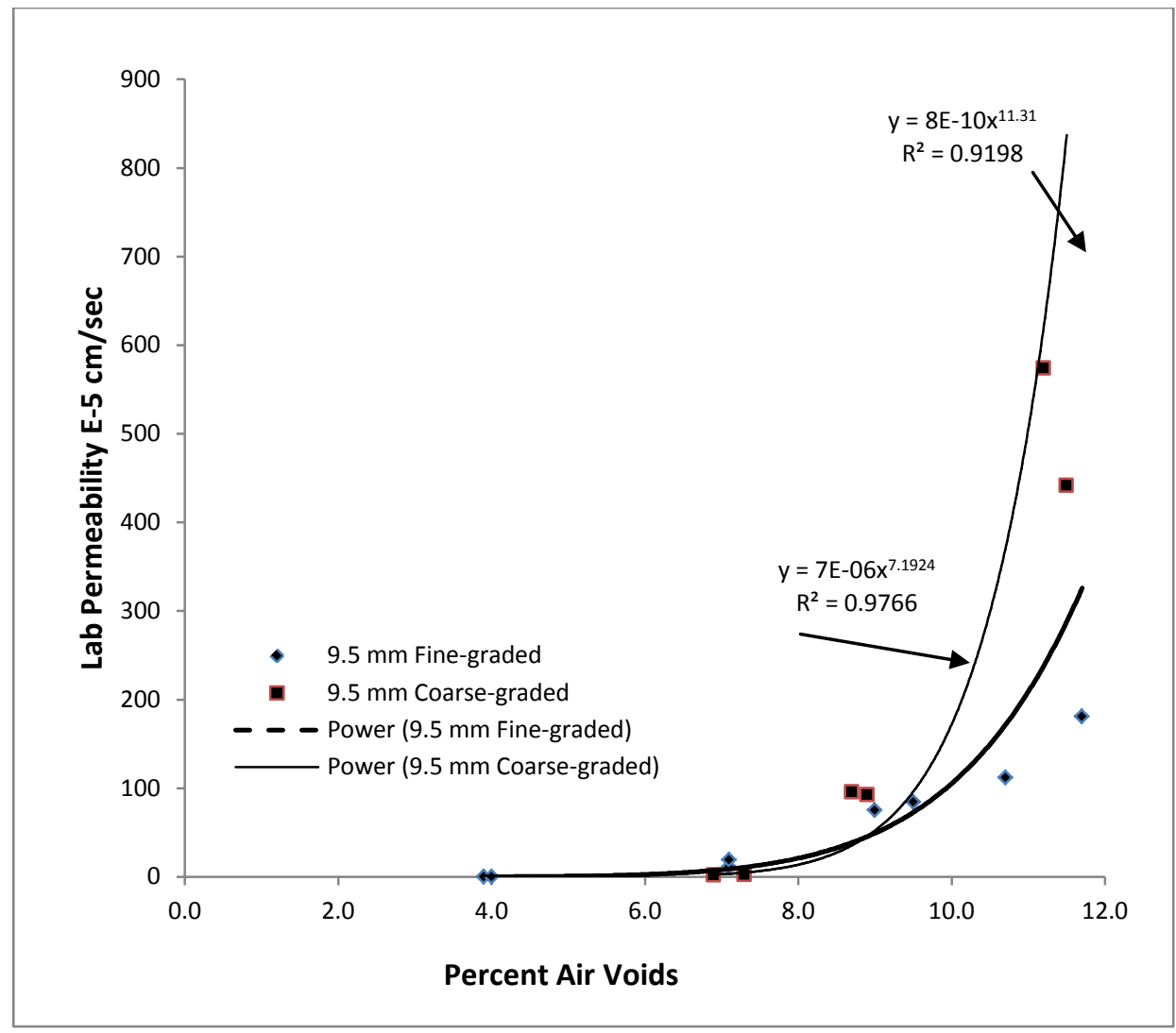

Figure 54 Permeability versus percent air voids, $9.5 \mathrm{~mm}$ fine and coarse mixes

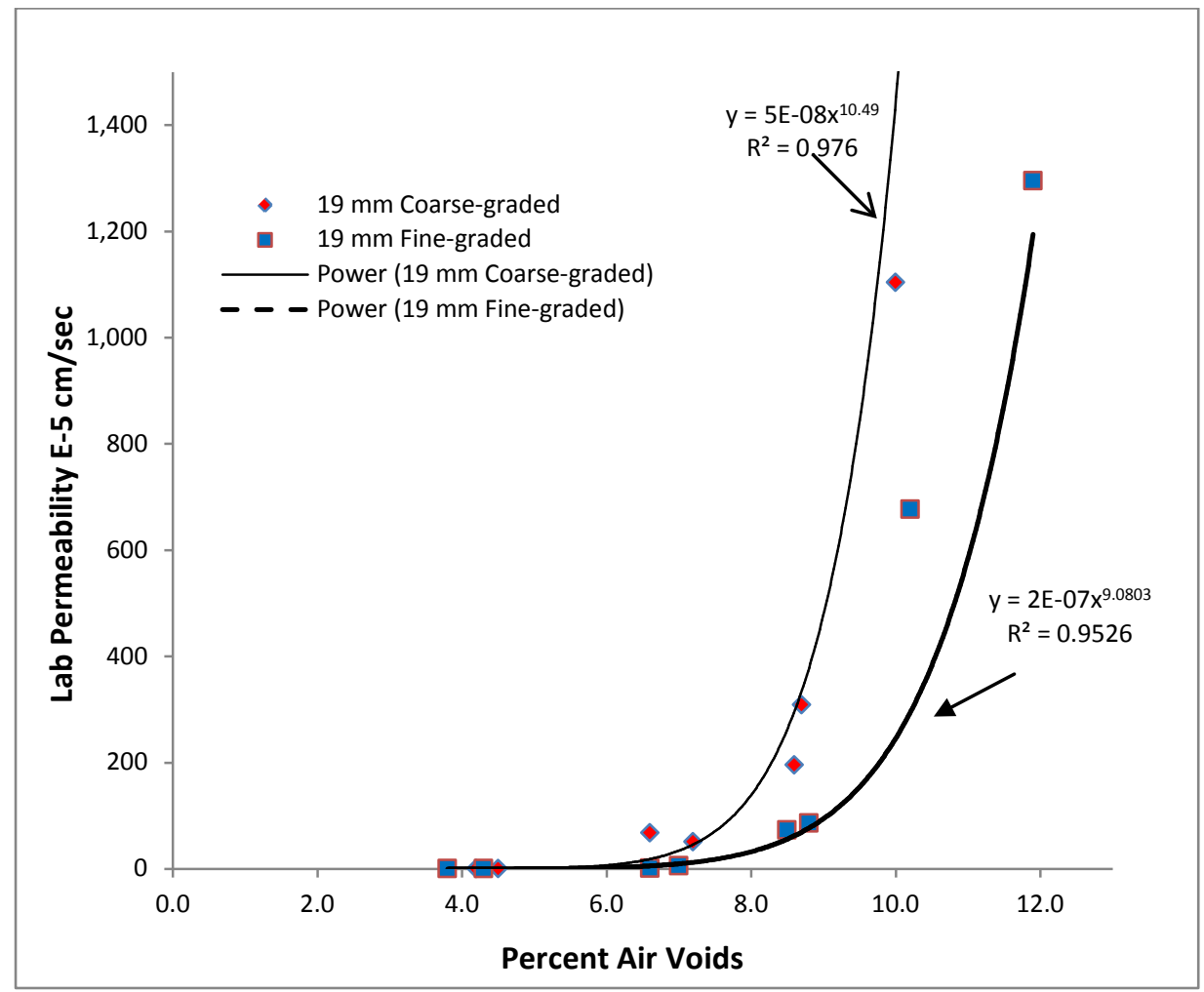

Figure 55 Permeability versus percent air voids, $19 \mathrm{~mm}$ fine and coarse mixes 


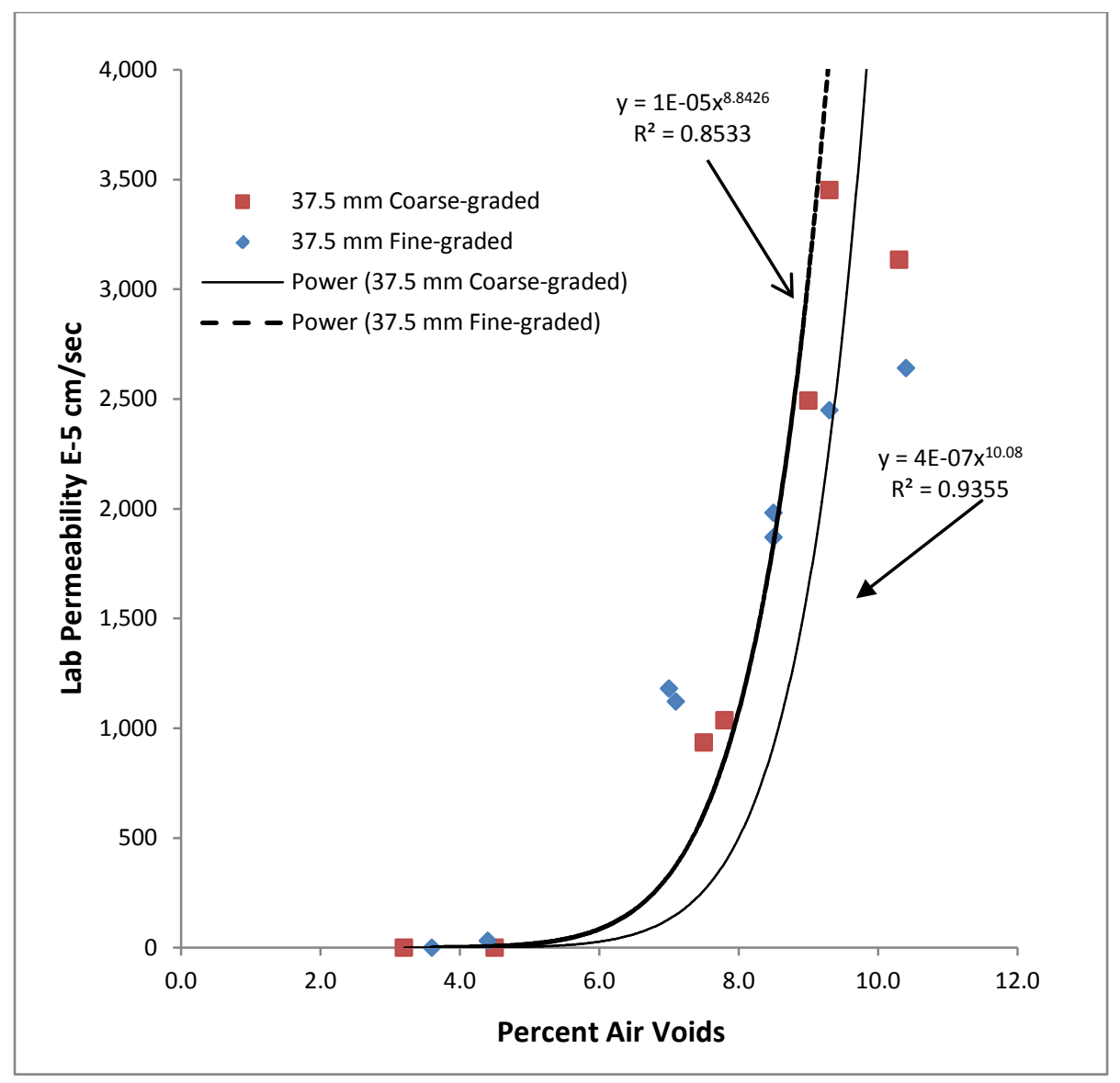

Figure 56 Permeability versus percent air voids, $37.5 \mathrm{~mm}$ fine and coarse mixes

Figure 55 illustrates how aggregate gradation affects the permeability characteristics of 19 mm NMAS HMA mixes. At 4 percent in-place air voids content, both fine and coarsegraded mixes have low permeability values. Above 5.5 percent air voids, the permeability started to increase. The coarse-graded mix became excessive permeable much faster than the fine-graded mix.

Figure 56 illustrates the relationship between permeability and in-place air voids for $37.5 \mathrm{~mm}$ fine-graded and coarse-graded mixes. As the trend lines show, the fine-graded mix reached the permeability threshold earlier than the coarse-graded mix, and this can be caused by the data obtained from samples at approximately 7 percent air voids. Based upon data in Figure 68, the coarse-graded mix has higher permeability than fine-graded mix with in-place air voids above 8 percent. At high air voids level, the difference between $37.5 \mathrm{~mm}$ finegraded and coarse-graded mixes was not as obvious as the ones obtained from $9.5 \mathrm{~mm}$ and 19 mm mixes. 


\subsubsection{Relationship between permeability and NMAS}

Based upon NMAS and aggregate gradation, the eight different HMA mixes were arranged on Figure 57 to show the mix type effect on permeability. In general, at similar air voids larger NMAS results in higher permeability. The $25 \mathrm{~mm}$ fine-graded mix does not follow this observation, and has lower permeability compared to the $19 \mathrm{~mm}$ coarse-graded mix at approximately 11 percent air voids. This deviation from the general trend may be explained by the either data variance or the influence of gradation, coarse versus fine, on the permeability characteristics. By only considering the fine or coarse gradations, the effect of increasing permeability with increasing NMAS is consistent for both gradation types.

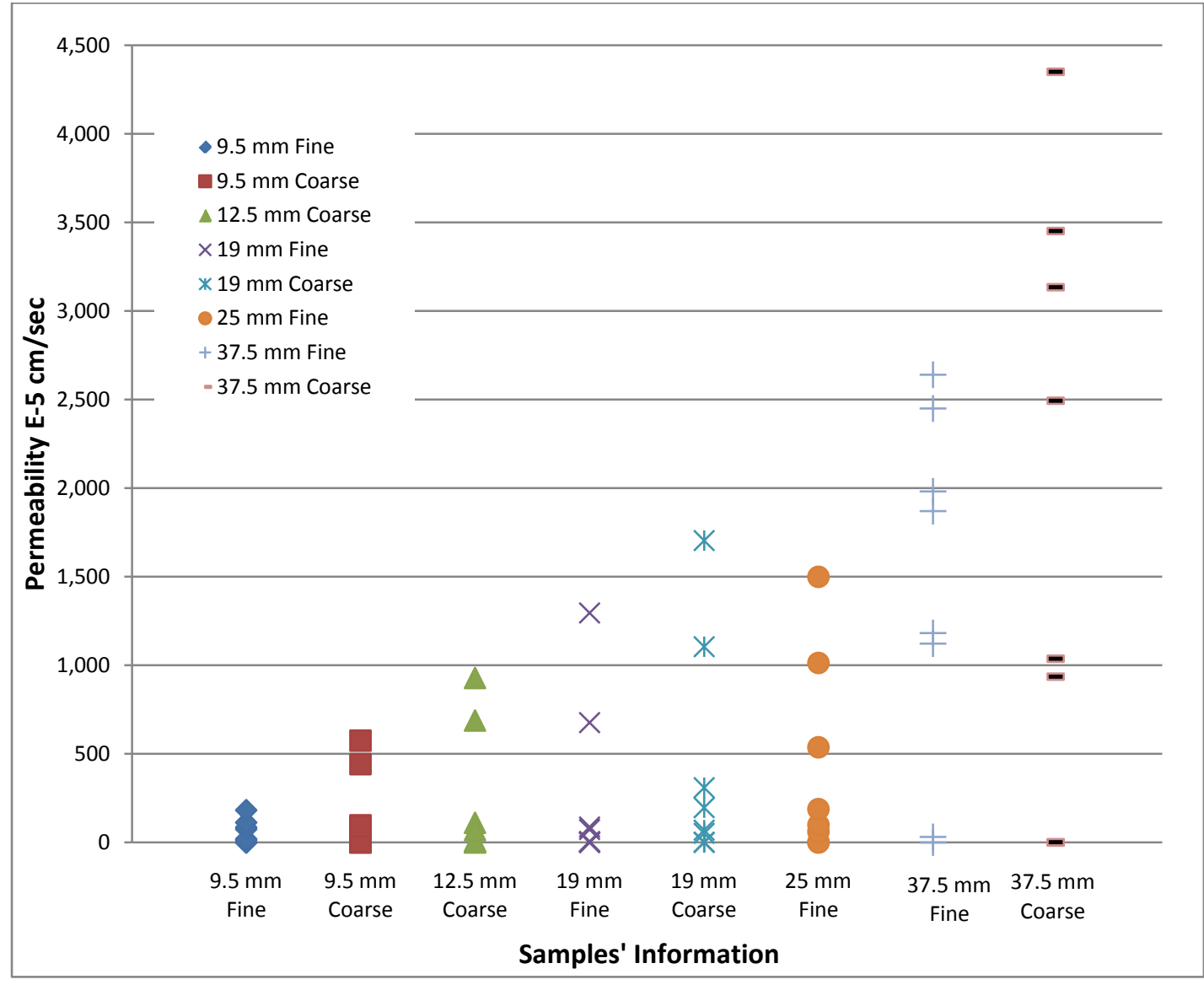

Figure 57 Relationship between NMAS and gradation versus permeability

At 4 percent in-place air voids, all gyratory compacted samples are impermeable except one from $37.5 \mathrm{~mm}$ fine-graded mix with $30.7 \mathrm{~cm} / \mathrm{sec}$. Permeability data collected from samples at 7, 9 and 11 percent air voids levels are presented in Figure 58, 59 and 60, 
respectively. For each mix, two samples were produced for the laboratory permeability tests, and so 16 samples were arranged based on their NMAS and gradation on the x-axis.

At the 7 percent air voids, Figure 58, the permeability values obtained from $9.5 \mathrm{~mm}$, $12.5 \mathrm{~mm}$ fine-graded and coarse-graded, and $19 \mathrm{~mm}$ fine-graded samples are very low. A huge gap of permeability values was observed between $25 \mathrm{~mm}$ fine-grade and $37.5 \mathrm{~mm}$ finegraded mixes.

Figure 59 and 60 illustrates how NMAS affects the permeability of gyratory compacted samples with approximately 9 and 11 percent in-place air voids, respectively. With the increase of the NMAS, the permeability increases. The second $25 \mathrm{~mm}$ fine-graded sample consistently has a lower permeability value at target air voids level when compared with the first $25 \mathrm{~mm}$ fine-graded sample and the $19 \mathrm{~mm}$ coarse-graded samples. At a given air voids level, the $37.5 \mathrm{~mm}$ NMAS mixes have higher permeability than $9.5 \mathrm{~mm}, 12.5 \mathrm{~mm}$, $19 \mathrm{~mm}$ and $25 \mathrm{~mm}$ NMAS mixes.

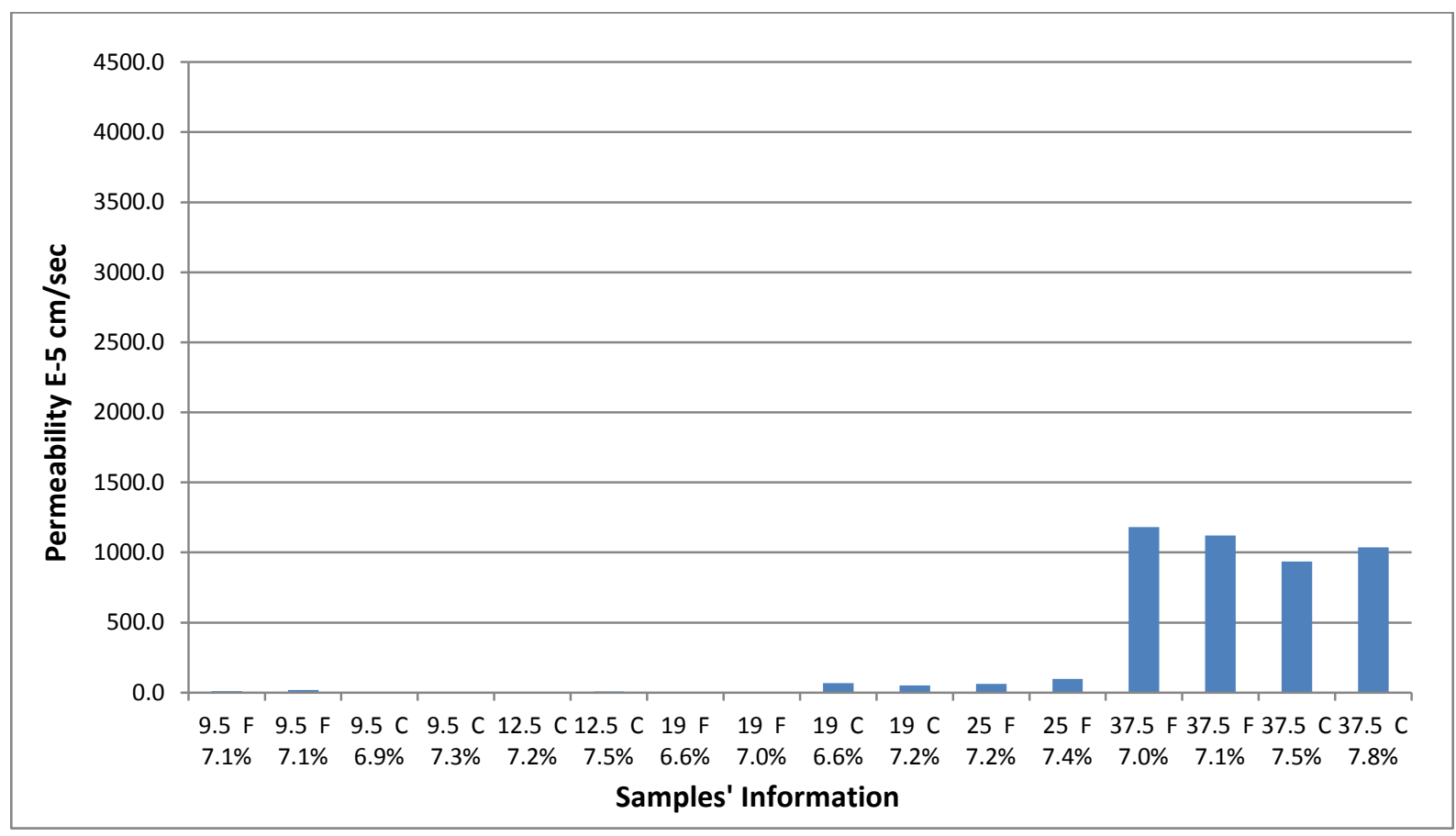

Figure 58 Effect of NMAS on permeability of sample at 7 percent air voids level 


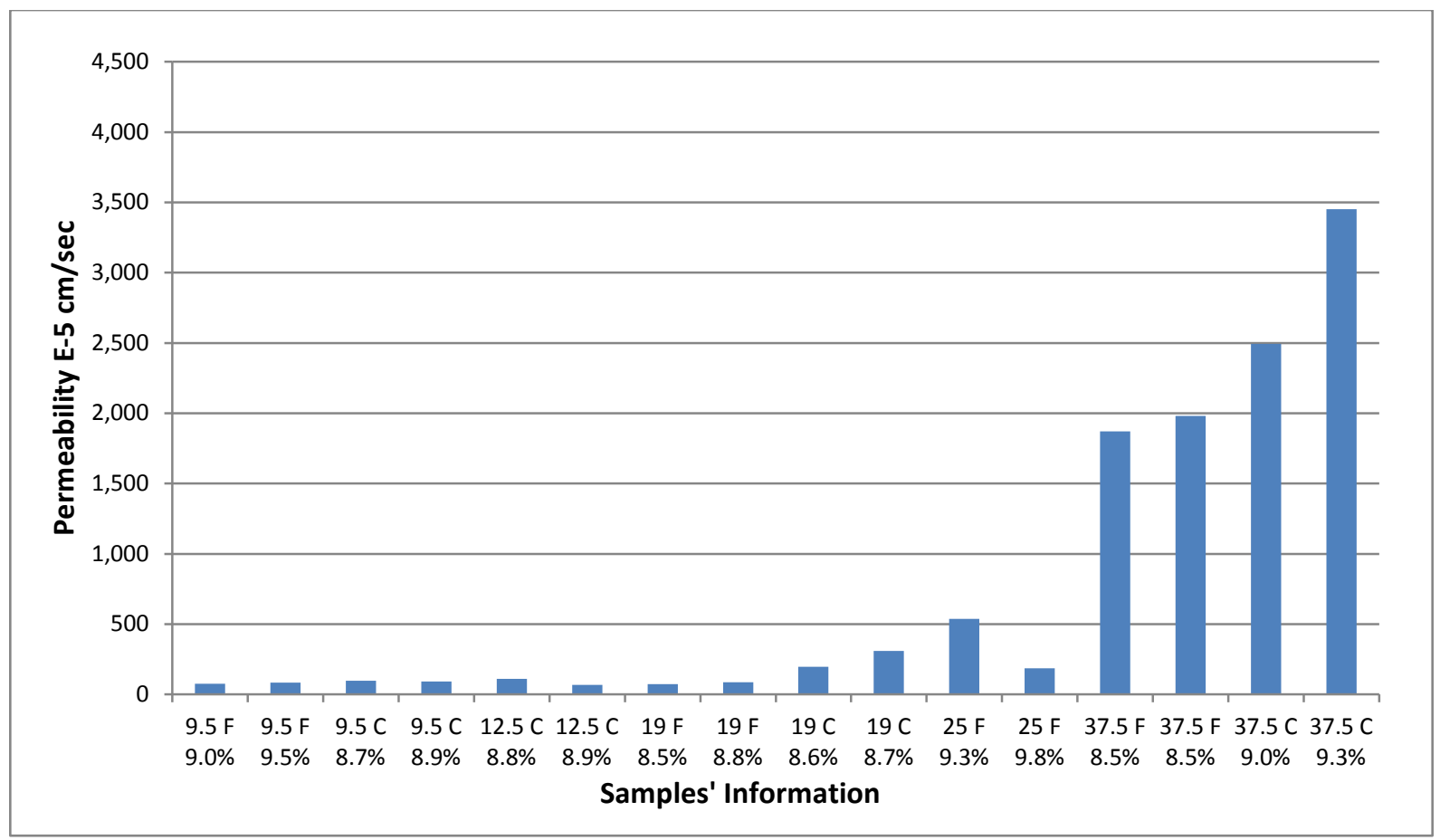

Figure 59 Effect of NMAS on permeability of sample at 9 percent air voids level

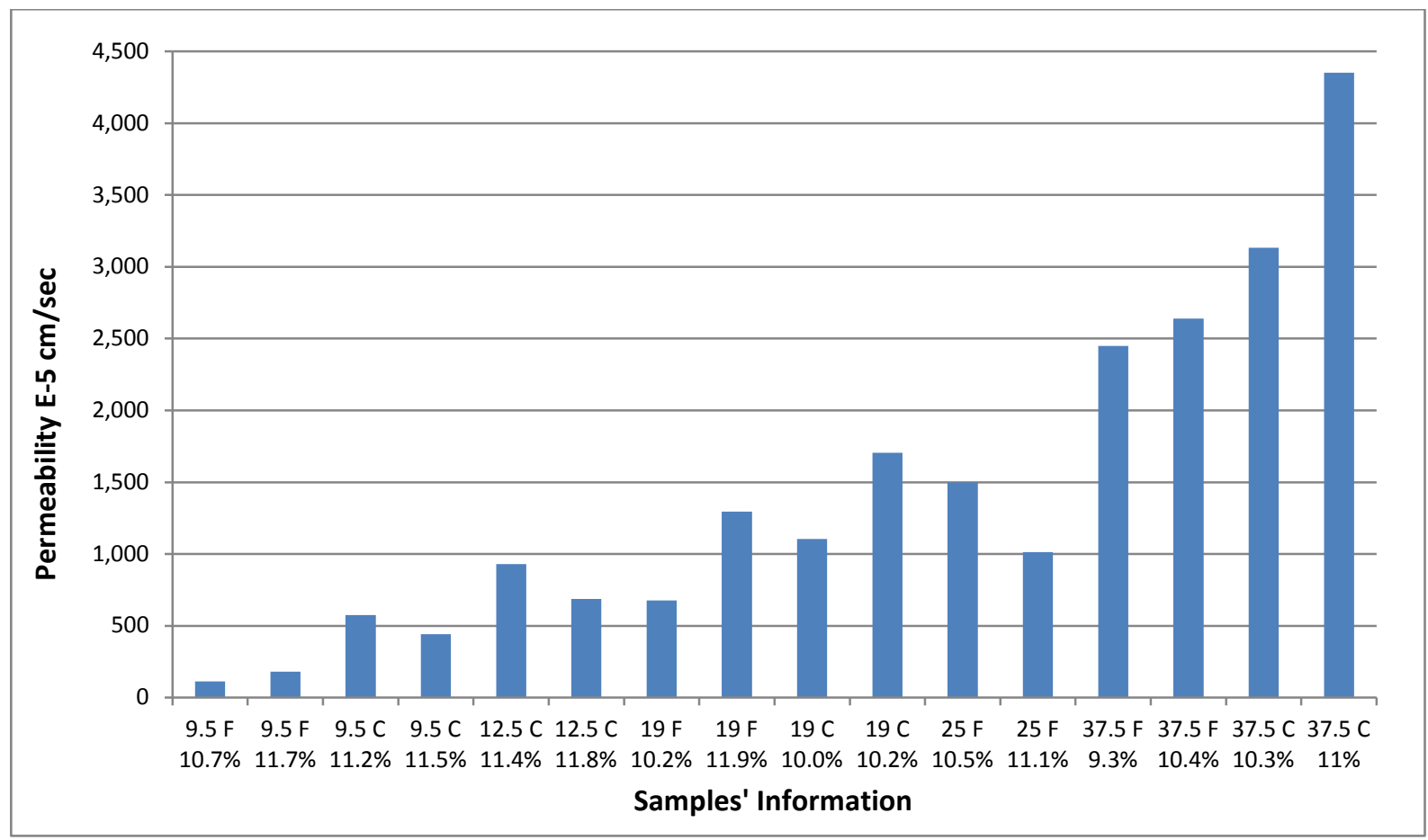

Figure 60 Effect of NMAS on permeability of sample at 11 percent air voids level 


\subsubsection{Composite Analysis of Permeability Results}

The preceding sections demonstrate that percent air voids, NMAS and gradation type all appear to affect permeability, but there was not a statistical analysis. Vivar and Haddock (55) used a composite power and exponential model in the analysis of a similar but more limited data set, the functional form was:

$$
K=V T M^{a} e^{(b N M A S+c G R A D A T I O N+d)}
$$

where:

$$
\begin{aligned}
& \mathrm{K}=\text { permeability }(10-5 \mathrm{~cm} / \mathrm{s}) \\
& \text { NMAS }=\text { Nominal Maximum Aggregate Size }(\mathrm{mm}) ; \\
& \text { VTM }=\text { Voids in the Total Mixture; } \\
& \text { Gradation }= 0 \text { for coarse-graded, } 1 \text { for fine-graded } \\
& \text { and a, b, c, d are regression constant. }
\end{aligned}
$$

Through algebraic manipulation the equation can be transformed to:

$$
\ln (K)=\operatorname{aln}(V T M)+\mathrm{b} N M A S+\mathrm{c} G R A D A T I O N+\mathrm{d}
$$

The transformed equation is then suitable for analysis using the multi-regression function of Excel. The regression output using the Vivar functional model to fit the WVUATL data are given in Table 21.

The adjusted $\mathrm{R}^{2}$ indicates the equation explains most of the variation in the data. This conclusion is supported by the finding of the F test showing the equation has statistical significance at $\alpha=0.05$. The significance of the coefficients is evaluated with the t-test; if the P-value is greater than 0.05 the coefficient is considered to be statistically insignificant. In this case, the c coefficient for GRADATION is statistically insignificant and should not be included in the equation. The regression analysis was repeated without the c term producing the results in Table 22.The adjusted $\mathrm{R}^{2}$ indicates the equation explains most of the variation in the data. The F test demonstrates statistical significance of the equation and the t-test shows both independent variables are significant at $\alpha=0.05$. The P-value of the t-test supports inclusion of the percent air voids and NMAS variables. 
Table 21 Power-exponential model of all laboratory permeability data

\begin{tabular}{lc}
\hline \multicolumn{2}{c}{ Regression Statistics } \\
\hline Multiple R & 0.946 \\
R Square & 0.894 \\
Adjusted R & \\
Square & 0.889 \\
Standard Error & 0.428 \\
Observations & 64 \\
\hline
\end{tabular}

ANOVA

\begin{tabular}{|c|c|c|c|c|c|}
\hline & $d f$ & SS & $M S$ & $F$ & $\begin{array}{c}\text { Significance } \\
F\end{array}$ \\
\hline Regression & 3 & 492.262 & 164.087 & 168.800 & 3.34E-29 \\
\hline Residual & 60 & 58.325 & 0.972 & & \\
\hline \multirow[t]{3}{*}{ Total } & 63 & 550.587 & & & \\
\hline & & Standard & & & \\
\hline & Coefficients & Error & t Stat & P-value & \\
\hline $\mathrm{d}$ & -11.72 & 0.724 & -16.205 & $1.38 \mathrm{E}-23$ & \\
\hline $\mathrm{a}$ & 6.76 & 0.330 & 20.499 & 8.71E-29 & \\
\hline $\mathrm{b}$ & 0.12 & 0.012 & 9.882 & 3.34E-14 & \\
\hline C & -0.17 & 0.249 & -0.665 & 0.508814 & \\
\hline
\end{tabular}

Table 22 Power-exponential model of laboratory permeability data without gradation variable

\begin{tabular}{lc}
\hline \multicolumn{2}{c}{ Regression Statistics } \\
\hline Multiple R & 0.945 \\
R Square & 0.893 \\
Adjusted R & \\
Square & 0.890 \\
Standard Error & 0.426 \\
Observations & 64 \\
\hline
\end{tabular}

ANOVA

\begin{tabular}{lccccc}
\hline & \multicolumn{3}{c}{ Significance } \\
& $d f$ & SS & MS & $F$ & $F$ \\
\hline Regression & 2 & 491.833 & 245.916 & 255.316 & $2.29 \mathrm{E}-30$ \\
Residual & 61 & 58.754 & 0.963 & & \\
Total & 63 & 550.587 & & & \\
\hline \multicolumn{5}{c}{ Standard } \\
\multicolumn{1}{c}{ Coefficients } & Error & t Stat & P-value & \\
\hline a & -11.79 & 0.713 & -16.527 & $3.33 \mathrm{E}-24$ & \\
\multicolumn{1}{c}{$\mathrm{b}$} & 6.77 & 0.328 & 20.608 & $3.58 \mathrm{E}-29$ & \\
\hline
\end{tabular}


The coefficients from the regression analysis were transformed to match the functional form of Equation 4.1. The three models are:

\begin{tabular}{cccc} 
Coefficient & Vivar & $\begin{array}{c}\text { WVUATL Results } \\
\text { with GRADATION }\end{array}$ & $\begin{array}{c}\text { WVUATL Results } \\
\text { without GRADATION }\end{array}$ \\
\hline a & 6.8 & 6.76 & 6.77 \\
$\mathrm{~b}$ & 0.11 & 0.12 & 0.11 \\
$\mathrm{c}$ & -0.89 & -0.17 & NA \\
$\mathrm{d}$ & -10.97 & -11.72 & -11.79
\end{tabular}

The various models are compared in Figure 61 for the $9.5 \mathrm{~mm}$ mix. The $9.5 \mathrm{~mm}$ mix type was selected for this comparison as it is the only mix type with sufficient field data for modeling. The Vivar model with for the fine gradation compares very favorably with the WVUATL model of the laboratory permeability data. With respect to the effect of coarse versus fine gradation, the Vivar model shows a major difference between the coarse and fine mixes. This amount of difference did not exist in the WVUATL data set. The model developed from the WVUATL data for only the $9.5 \mathrm{~mm}$ samples shows a greater effect of gradation type than the general WVUATL model, but this difference is still much less than for the Vivar model.

Finally the model developed for the field cores is included on Figure 60. The trend of field cores having measureable permeability at low air voids and the model of the lab data having a greater slope at high air voids is very similar to Cooley et al.'s (57) conclusion as shown on Figure 22. While the trend found in the WVUATL data and Cooley's results are similar, the magnitude of the permeability in the Cooley study was higher. For example at 10 percent air voids the permeability of the Cooley and WVUATL results are approximately $400 \times 10^{-5}$ and $200 \times 10^{-5} \mathrm{~cm} / \mathrm{sec}$, respectively. The difference in the permeability between the Cooley and the WVUATL results may be explained by the fact that Cooley used $50 \mathrm{~mm}$ samples and the WVUATL samples were $75 \mathrm{~mm}$. Solaimanian (41) found for laboratory compacted pills the permeability is influenced by sample height even though the height of the sample is theoretically accounted for in Equation 2.8. Solaimanian did not present the data to support this observation and did not identify if increasing height increases or decreased permeability. By comparing laboratory permeability of compacted samples with different thickness, Hanin et al. (35) found an increase in thickness of SGC sample will results in a decrease in permeability. 


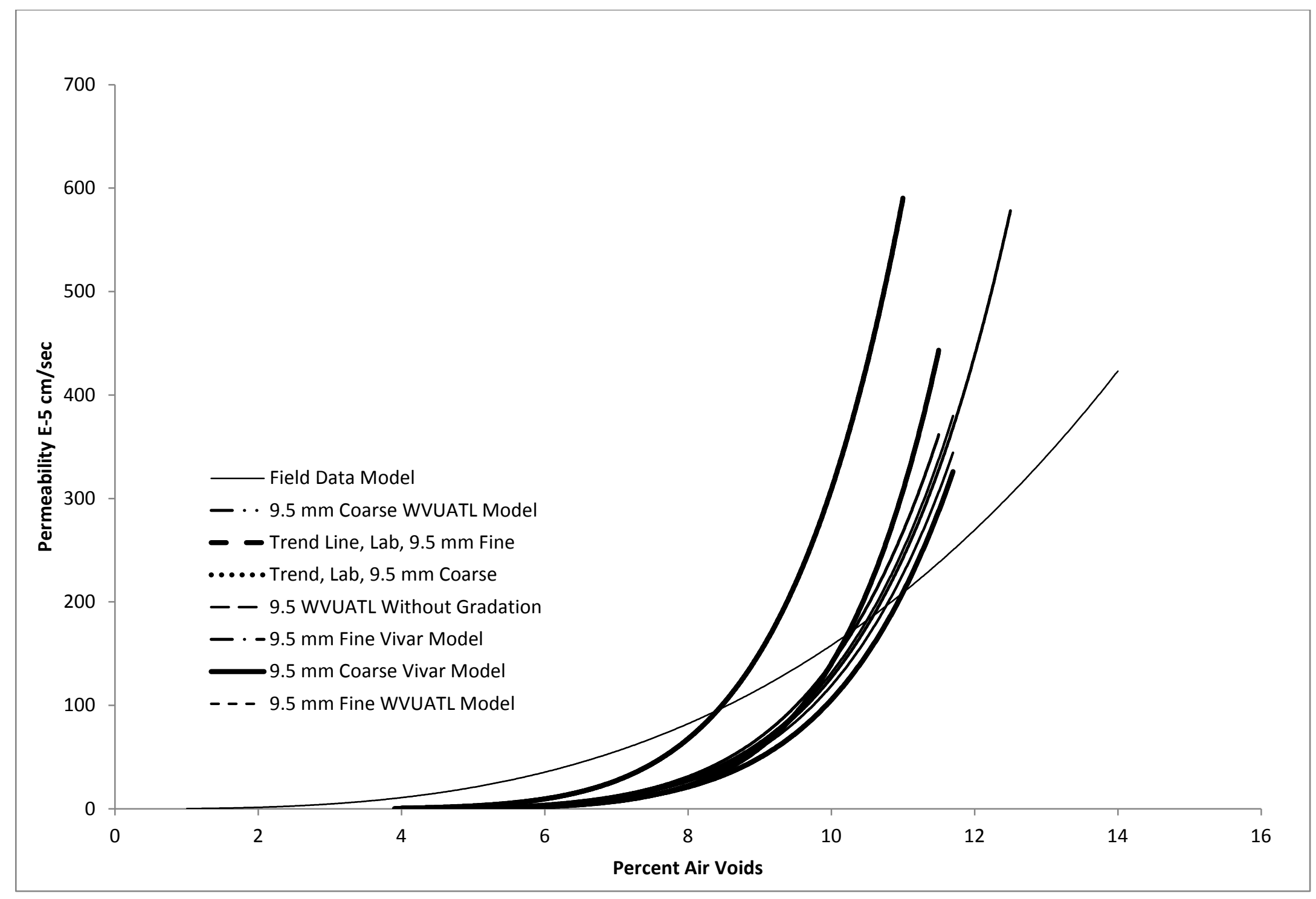

Figure 61 Comparison of permeability models 


\section{Chapter 5 Conclusions and Recommendations}

\subsection{Conclusions}

The work performed in this research can be grouped into four topics:

- Field permeability/ infiltration rates

- Density and bulk specific gravity test methods on field cores

- Permeability of field cores

- Permeability of laboratory pills

\subsubsection{Field permeability/ Infiltration Rates}

The field permeability tests conducted on the 1.5 inch overlay project was not successful, and potential reason can be: 1 . the pavement surface was too hot, 2 . the sealing material was not reliable, and 3. the NCAT Permeameter cannot be applied for measuring the field permeability of overlay projects. At the other three project sites, useful data were collected, but in practice, it is difficult to determine the thickness of the pavement underneath the NCAT Permeameter, so "infiltrate rate", which estimates the flow rate of water penetrate the pavement surface can be a better descriptor than permeability for the measurements made with the NCAT Permeameter. While measurements were collected at Chestnut Ridge, the lack of measurements before the application of the fog seal eliminated the possibility of evaluating the effectiveness of the treatment. On the Mon-Fayette Expressway and Quarry Run Road, the measurements before and after the fog seal indicated a reduction in infiltration rate. However there were too few data points for a meaningful statistical analysis.

\subsubsection{Density and Bulk Specific Gravity Test Methods on Field Cores}

Although no statistically designed experiment was performed, data from an I-79 project were evaluated which produced several interesting observations. The thin-lift gauge had smaller correction factors than the standard nuclear gauges. The correction factors for joint locations were greater than mainline correction factors. Developing correction factors based on the ration of the means may be better than using the difference of means methods. The standard nuclear gauges and thin-lift gauge did have strong correlation to laboratory $\mathrm{G}_{\mathrm{mb}}$ measurements.

Pair $t$ test was conducted to identify if significant difference existed in $G_{m b}$ data collected by the contractor and WVUATL using T 166, and the computed p-value suggested 
that null hypothesis that the two dataset are different, cannot be rejected. The line on equality regression also indicates the results from the two labs are statistically similar.

The WVUATL CoreLok was used to evaluate a set of cores at the contractor's lab. These cores were reevaluated in the WVUATL. The pair t-test of the two sets of results resulted in rejecting the null hypothesis. However, the variance of the test results was so small that even a small difference in mean values would result in rejecting the null hypothesis, indicating that the results of the t-test may not be reliable for this situation. The line on equality regression also indicates the results from the two labs are statistically similar.

$\mathrm{G}_{\mathrm{mb}}$ data from a contractor's CoreLok and the corresponding cores from a project on I-64 were provided to the WVUATL and tested with the CoreLok. Both the t-test and the line of equality regression reject the statistical probability that the data from the two tests are similar. This result is in conflict with the conclusions of Cooley et al. (6).

The comparison between $\mathrm{G}_{\mathrm{mb}}$ data measured by T166 and CoreLok methods indicates that CoreLok is a viable device for determining the $G_{m b}$ and corresponding air voids of field cores. Based upon the data collected, the CoreLok method did in general result in lower $G_{m b}$ values and thus higher air voids content than T166. The statistical analysis rejected the null hypothesis for the entire data set. The current $\mathrm{T} 166$ requires the use of the paraffin, AASHTO T $275^{9}$, method when the water absorption is greater than two percent by volume. The comparison of T 166 to the CoreLok method, AASHTO T 331, rejected the null hypothesis of equal means when the absorption is greater than two percent. The null hypothesis was not rejected when the percent absorption is less than two percent. This analysis supports the current T 166 threshold. There is a proposed change to T166 to change the threshold to one percent, and use $\mathrm{T} 331$, the vacuum sealing method in lieu of $\mathrm{T} 275$. The t-test results indicate this is an acceptable policy as there was a significant difference in the means of the two test methods for absorption greater than one percent, but at absorption values less than one percent the null hypothesis was not rejected. The data collected in this study shown that a threshold of one percent may be a conservative but it is accurate. From a practical point of view, absorption is greater than one percent for many of the pills and cores. Hence the contractors and WVDOH labs will need the vacuum seal equipment for measuring $\mathrm{G}_{\mathrm{mb}}$. If the vacuum seal equipment is available it could, and probably should, be used for all measurements of $G_{m b}$.

\footnotetext{
${ }^{9}$ AASHTO T 275 is a difficult method and is being displaced by the vacuum seal method, AASHTO T 331.
} 


\subsubsection{Permeability of Field Cores}

The laboratory permeability results collected from field cores confirm that a strong relationship exists between permeability and air voids content. At a low air voids content, the permeability is typically low, and when the air voids content above certain point, a small increase in air voids causes the correspondingly permeability value changes greatly. Cores from longitudinal joints have higher in-place air voids than the mainline cores. In this study, most of the cores from the longitudinal joints failed to meet the density requirement and showed excessive permeability characteristics.

In general the permeability of the field cores on this project is consistent with the rule of thumb that permeability becomes an issue when the air voids of the sample are greater than eight percent. The regression model of the field cores permeability indicates that at eight percent air voids the permeability is about $80 \times 10^{-5} \mathrm{~cm} / \mathrm{sec}$ which is less than the recommended criteria of $100 \times 10^{-5} \mathrm{~cm} / \mathrm{sec}$ to $125 \times 10^{-5} \mathrm{~cm} / \mathrm{sec}$.

\subsubsection{Permeability of Laboratory Pills}

The designed experiment to study the effects of mix type, gradation, and percent air voids produced results similar to what is in the literature. As expected air voids has the greatest effect on permeability. The mix type, as defined by the NMAS, was also a significant effect. Contrary to the finding of some researchers gradation, classified as either coarse or fine, was not a significant factor. There was a trend for coarse graded mixes to have higher permeability than fine graded mixes, but the effect was not large enough to be captured in the regression analysis. The laboratory permeability data were modeled using a functional form developed by Vivar (55) and the regression coefficients for percent air voids and NMAS were very similar with the exception of the gradation factor. The degree of agreement between the Vivar model and the model developed from the WVUATL data was unexpected as the inference space of Vivar's model was limited to $9.5 \mathrm{~mm}$ and $19 \mathrm{~mm}$ mixes, so it was an extrapolation to compare Vivar's model to one developed from data for the full range of available Superpave mix types.

The comparison of the permeability of field cores to laboratory pills showed a similar trend to the findings in the literature (57). Field cores have measureable permeability at lower percent air voids than laboratory pills, but following the onset of permeability the slope with respect to percent air voids of the laboratory pills is greater than the field cores. 


\subsection{Recommendations}

Most of the field cores that been sent to the WVUATL were from $9.5 \mathrm{~mm}$ NMAS mixes; only eight cores from 19 mm NMAS were evaluated. The conclusions of this research would be enhanced if field cores for the full range of mix types were evaluated.

Eight different HMA mixes were prepared for the density and laboratory permeability measurements, with $37.5 \mathrm{~mm}$ coarse-graded mix simply prepared for purpose of permeability measurements. To complete the understanding of how air voids content, aggregate gradation and NMAS affect the permeability characteristics of HMA mixes, the $12.5 \mathrm{~mm}$ fine-graded, 25 mm coarse -graded and 37.5 mm coarse-graded HMA mixes should be designed and prepared and tested for permeability.

The effect of gradation on permeability was not significant in this study. This may be the result of the gradations being too similar to find capture this effect. The classification of mix as either a coarse or fine can be a difference of two percent of the material passing the primary control sieve. The need for developing an alternative definition for coarse and fine mixes for classifying the gradation with respect to permeability should be evaluated.

The laboratory permeability collected from the gyratory compacted pills shows that the HMA samples tend to have low permeability value below approximately 6.5 percent air voids content except the $37.5 \mathrm{~mm}$ fine-grade and coarse-graded HMA mixes. The $19 \mathrm{~mm}$ NMAS and 25 mm NMAS HMA mixes seems to have lower permeability than the information stated in literature review. One potential reason can be the thickness of gyratory compacted samples. Presented in the Florida Method of Laboratory Permeability Test, the thickness of the sample should be less than $80 \mathrm{~mm}$ which is the capability of the calibrated cylinder. However, according to Virginia Test Method 120, "Method of Test for Measurement of Permeability of Bituminous Paving Mixtures Using a Flexible Wall Permeameter”, for $9.5 \mathrm{~mm}$ NMAS mixtures, the required height is $38 \pm 2 \mathrm{~mm}$, for $19 \mathrm{~mm}$ NMAS mixtures, the required height is $50 \pm 2 \mathrm{~mm}$. So, samples should be prepared at different thickness for the purpose of determining the permeability threshold of a HMA mixes. 


\section{References}

(1) Williams. R. C., Early Permeability test for Asphalt Mixture, Final Report R107-053., Missouri Department of Transportation, 2009.

(2) Brown, E. R, D. Decker, R. B. Mallick, and J. Bukowski. Superpave Construction Issues and Early Performance Evaluations. Journal of the Association of Asphalt Paving Technologists, Volume 68, Chicago, Illinois, 1999.

(3) Zube, E. Compaction Studies of Asphalt Concrete Pavements as Related to the Water Permeability Test. Bulletin 358. Highway Research Board, National Research Council, Washington, D.C., 1962.

(4) Choubane, B, G.C. Page, and J.A. Musselman. Investigation of Water Permeability of Coarse Graded Superpave Pavements. Journal of the Association of Asphalt Paving Technologists, Volume 67,St. Paul, Minn., 1998.

(5) Cooley, Jr., L.A., and E.R. Brown. Selection and Evaluation of a Field Permeability Device for Asphalt Pavements. Transportation Research Board. No. 1723, Part 2: Asphalt Mixtures 2000, Washington, D.C., 2000.

(6) Cooley, Jr., L.A., Brain D. P., M.R. Hainin., M.S. Buchanan., and J. Harrington., Bulk Specific Gravity Round-Robin Using the CoreLok Vacuum Sealing Device. NCAT Report 02-11, 2002.

(7) Kanitpong, K., C. H. Benson., and H. U. Bahia., Hydraulic Conductivity of Laboratory Compacted Asphalt Mixtures. Transportation Research Record: Journal of the Transportation Research Board, Volume 1767/2001, Page 25-32, Washington, D.C., 2001.

(8) Williams, S. G., Non-nuclear methods for HMA density measurements, MBTC 2075 Final Report, Arkansas, 2008.

(9) Pratico, F. G., et al., Comparing Different of Procedures for the Measurement of the Bulk Specific Gravity for Compacted HMA samples, $4^{\text {th }}$ International Siiv CongressPalermo (Italy), 2007.

(10) Buchanan, M. S., An Evaluation of Selected Methods for Measuring the Bulk Specific Gravity of Compacted Hot Mix Asphalt (HMA) Mixes. Association of Asphalt Paving Technologist, Vol. 69, pp. 608-634, St. Paul, Minn., 2000. 
(11) Bhattacharjee, S., and Mallick, R. B., An Alternative Approach to Determination of Bulk Specific Gravity and Permeability of Hot Mix Asphalt (HMA).International Journal of Pavement Engineering, Volume 3, Page 143-152, Washington DC, 2002.

(12) http://www.instrotek.com/pdfs/CoreLok_Manual.pdf, CoreLok Operator’s Guide, accessed 6/17/2012

(13) Buchanan, M. S. and T. D. White., Hot Mix Asphalt Mix Design Evaluation Using the CoreLok Vacuum-Sealing Device. Journal of Materials in Civil Engineering, ASCE, Vol.17, No. 2, pp. 137-142, 2005

(14) Williams, Brett A., Williams, R. Christopher, and Bausano, Jason P, Criterion Test for Method Selection in Determining the Bulk Specific Gravity of Hot Mix Asphalt, Journal of ASTM International, Volume 4, Issue I, 2007.

(15) Hall, K. D., F. T. Griffith, and S. G. Williams. Examination of Operator Variability for Selected Methods for Measuring Bulk Specific Gravity of Hot Mix Asphalt Concrete. In Transportation Research Record: Journal of the Transportation Research Board, No. 1761, TRB, National Research Council, Washington, D.C., 2001, pp. 81-85.

(16) Padlo, P. T., J. Mahoney, L. Aultman-Hall., and S. Zinke., Correlation of Nuclear Density Readings with Cores Cut from Compacted Roadways, Connecticut Department of Transportation, Report CT-2242-F-05-5, 2005

(17) Pavement Guide Interactive, http://www.pavementinteractive.org/article/nucleardensity-gauge/,2010,accessed 6/17/2012

(18) Malpass, G., and N. P. Khosla., Evaluation of Gamma Ray Technology for the Measurement of Bulk Specific Gravity of Compacted Asphalt Concrete Specimens, Asphalt Paving Technology: Association of Asphalt Paving Technology-Proceedings of the Technical Sessions 2002, page 352-367.

(19) Mitchell, T.M., Density Monitoring on Asphalt pavement. Better Roads, Volume 54, Issue Number 12, Page 22-25, 1984.

(20) Zha, J., Revisions of California Testing Method 11 for Nuclear Gage Calibration. 2000, California Department of Transportation: Sacramento. P. 1-18.

(21) Zha, J., Method of Developing Density and moisture calibration tables for the nuclear gage, California Test 111, 2002. 
(22) Parker, F. and M.S. Hossain., An Analysis of Hot mix Asphalt mat density measurement. Journal of Testing and Evaluation, ASTM, Vol.23, No. 6, pp415-423, 1995.

(23) Smith, B. C.., and B. K. Diefenderfer., Comparison of Nuclear and Nonnuclear Pavement Density Testing Devices. Transportation Research Record: Journal of the Transportation Research Board, No. 2081, page 121-129, 2008.

(24) Williams, S. G., Non-nuclear Methods for HMA Density Measurements, MBTC 2075 Final Report, Arkansas, 2008.

(25) Romero, P. Laboratory Evaluation of the PQI Model 300. Project Report. Multiple State Pooled Fund Study, DTFH61-00-P-00549, 2000.

(26) NCHRP-IDEA, Pavement Quality Indicator, NCHRP Project 32 and 47, Transportation Research Board, Washington, D.C., 1999

(27) Brown, G. O., “Henry Darcy and the making of a law”, Water Resources Research, Vol. 38, No.7, 2002.

(28) Maupin, Jr., G.W., Asphalt Permeability Testing Between Laboratories, Virginia Transportation Research Council, Final Report, VTRC 05-R24, 2005

(29) Maupin, Jr., G.W., Examination of an Implemented Asphalt Permeability Specification, Final Report VTRC 11-R7, 2010. http://www.virginiadot.org/vtrc/main/online_reports/pdf/11-r7.pdf, accessed 6/17/2012

(30) Hudson, S.B. and R.L. Davis. Relationship of Aggregate Voidage to Gradation. Journal of the Association of Asphalt Paving Technologists, Volume 34. Page 574-593, 1965.

(31) Choubane, B., G.C. Page, and J.A. Musselman. Investigation of Water Permeability of Coarse Graded Superpave Pavements. Journal of the Association of Asphalt Paving Technologists, Volume 67. 1998.

(32) Cooley, L.A. Jr., E.R. Brown., and S. Maghsoodloo., Development of Critical Field Permeability and Pavement Density Values for Coarse Graded Superpave Pavements. NCAT Report 01-03, 2001. 
(33) Fwa, T.F., S.A. Tan., and Y.K. Guwe., Laboratory Evaluation of Clogging Potential of Porous Asphalt Mix. Transportation Research Board of the National Academies, Volume 1681/1999, Page 43-49, 2007.

(34) Mallick, R.B., L. Allen Cooley, Jr., M.R. Teto., R.L. Bradbury., and D. Peabody., An Evaluation of Factors Affecting Permeability of Superpave Designed Pavements, NCAT Report 03-02, 2003.

(35) Hainin, M.R., L.A. Cooley, Jr., and B.D. Prowell., An Investigation of Factors Influencing Permeability of Superpave Mixes, International Journal of Pavements, Volume 2, Page 41-52, 2003.

(36) Ford, M.C., and C.E. McWilliams. Asphalt Mix Permeability. University of Arkansas, Fayettville, AR, 1988.

(37) Gogula, A. K., M. Hossain., and S. A. Romanoschi., A Study of Factors Affecting the Permeability of Superpave Mixes in Kansas, Final Report No. K-TRAN: KUS-00-2, KDOT, 2004.

(38) Giompalo, J. A., Permeability of Hot Mix Asphalt Concrete as Affected by Binder Content, Master Dissertation, West Virginia University, 2010.

(39) Brown, E. R., M. R. Hainin., L.A. Cooley, Jr., and G. Hurley., Relationships of HMA In-Place Air Voids, Lift Thickness, and Permeability, NCHRP Report 531, Transportation Research Board of the National Academies, 2004.

(40) Retzer, N., Permeability Research with the Romus Air Permeameter, Report No. CDOT-2008-5, Final Report, Colorado Department of Transportation, 2008.

(41) Solaimanian, M., Correlation of Laboratory-Compacted and Field-Compacted HotMix Asphalt Permeability, Final Report, Project No. 060704, Pennsylvania Department of Transportation, 2010.

(42) Maupin, G.W. Jr., Investigation of Test Methods, Pavement, and Laboratory Design Related to Asphalt Permeability. Final Report, VTRC 00-R24, Virginia Transportation Research Council, 2000.

(43) Florida Method of Test for Measurement of Water Permeability of Compacted Asphalt Paving Mixtures, Designation: FM 5-565, 2000, Revised 2006. 
(44) Cooley, L.A., Jr., "Permeability of Superpave Mixtures: Evaluation of Field Permeameters”, NCAT, Report No. 99-1, National Center for Asphalt Technology, February 1999.

(45) Daniel, J.S., R.B. Mallick., and W.S. Mogawer., Evaluation of a Field Permeameter as a Longitudinal Joint Quality Indicator, NETCR 64, Project No.03-5, New England Transportation Consortium, 2007

(46) Williams, S.G., A. Pervis., L.S. Bhupathiraju., and A, Porter., Methods for Evaluating Longitudinal Joint Quality in Asphalt Pavements, Transportation Research Board: Journal of the Transportation Research Board, No.2098, Transportation Research Board of the National Academies, Page 113-123, Washington, D.C., 2009

(47) Williams, S. G., A Comprehensive Study of Field Permeability Using the Vacuum Permeameter, Project MBTC-2054, 2006

(48) Allen, L. D., D. B. Schultz, Jr. and L. J. Fleckenstein., Development and Proposed Implementation of a Field Permeability Test for Asphalt Concrete, Research Report KTC-01-19/SPR216-00-1F, Kentucky Transportation Center, Lexington, KY, June 2003.

(49) Russell, J., H. U. Bahia., K. Kanitpong., Effect of Pavement Lift Thickness on Superpave Mix Permeability and Density. SPR \# 0092-02-14c, Wisconsin Highway Research Program, Wisconsin DOT, Madison, WI, April, 2005.

(50) Masad, E., B. Birgisson., A. Al-Omari., A. Cooley., Analysis of Permeability and Fluid Flow in Asphalt Mixes, $82^{\text {nd }}$ Annual Transportation Research Board for Presentation and Publication, Washington, D.C., 2002.

(51) Westerman, J.R., AHTD’s Experience with Superpave Pavement Permeability, <http://www.utexas.edu/research/superpave/articles/jrw10a.html>, Arkansas State Highway and Transportation Department, 1998

(52) Haddock, J.E., and M. Prather., Investigation of Permeability on Indiana SR38.Journal of Performance of Constructed Facilities, ASCE, 2008.

(53) Mohammad, L.N., A, Herath., and B. Huang., Evaluation of Permeability of Superpave Asphalt Mixtures, Transportation Research Board: Journal of the Transportation Research Board, Volume 1832/2003, Page 50-58, 2003 
(54) Vardanega, P. J., and T. J. Waters., Analysis of Asphalt Concrete Permeability Data Using Representative Pore Size, Journal of Material in Civil Engineering, ASCE, 2011.

(55) Vivar. E., and J. E. Haddock., Hot-Mix Asphalt Permeability and Porosity, Asphalt Paving Technology: Association of Asphalt Paving Technologists-Proceedings of the Technical Sessions, Volume 76, Page 953-979, 2007.

(56) Cameron, C, 2012, EXCEL 2007: Multiple Regression, Univ. of Calif. Davis,http://cameron.econ.ucdavis.edu/excel/ex61multipleregression.html, accessed 6/13/2012.

(57) Cooley, L.A., Jr., Prowell, B. D., and Brown, E.R., Issues Pertaining to the Permeability Characteristics of Coarse-Graded Superpave Mixes, NCAT Report 02-06, 2002. 


\section{Appendix 1}

\section{Stockpile and Blend Gradations}

Table 239.5 mm NMAS Fine Gradation

\begin{tabular}{|c|c|c|c|c|c|c|c|c|c|c|}
\hline \multirow{4}{*}{ Sieve Size } & \multicolumn{2}{|c|}{ Bin \#1 } & \multicolumn{2}{|c|}{ Bin \#2 } & \multicolumn{2}{|c|}{ Bin \#3 } & \multicolumn{2}{|c|}{ Bin \#4 } & \multirow{4}{*}{$\begin{array}{c}\text { Comb. } \\
\text { Gradation }\end{array}$} & \multirow{4}{*}{$\begin{array}{c}\text { Control } \\
\text { Points }\end{array}$} \\
\hline & \multicolumn{2}{|c|}{ Elkins SKID 8's } & \multicolumn{2}{|c|}{ Elkins 9's } & \multicolumn{2}{|c|}{ Elkins SAND } & \multicolumn{2}{|c|}{ Baghouse Fine } & & \\
\hline & \% Used: & 26 & \% Used: & 15 & \% Used: & 58 & \% Used: & 1 & & \\
\hline & Passing & \% Total & Passing & \% Total & Passing & $\%$ Total & Passing & $\%$ Total & & \\
\hline 2"(50 mm) & 100.00 & 26.00 & 100.00 & 15.00 & 100.00 & 58.00 & 100.00 & 1.00 & 100.00 & \\
\hline 1.5"(37.5 mm) & 100.00 & 26.00 & 100.00 & 15.00 & 100.00 & 58.00 & 100.00 & 1.00 & 100.00 & \\
\hline 1"(25 mm) & 100.00 & 26.00 & 100.00 & 15.00 & 100.00 & 58.00 & 100.00 & 1.00 & 100.00 & \\
\hline 3/4"(19 mm) & 100.00 & 26.00 & 100.00 & 15.00 & 100.00 & 58.00 & 100.00 & 1.00 & 100.00 & \\
\hline 1/2"(12.5 mm) & 100.00 & 26.00 & 100.00 & 15.00 & 100.00 & 58.00 & 100.00 & 1.00 & 100.00 & 100 \\
\hline 3/8" (9.5 mm) & 93.40 & 24.30 & 100.00 & 15.00 & 100.00 & 58.00 & 100.00 & 1.00 & 98.30 & $90-100$ \\
\hline \#4 (4.75 mm) & 7.90 & 2.10 & 76.00 & 11.40 & 99.90 & 57.90 & 100.00 & 1.00 & 72.40 & $90 \max$ \\
\hline \#8 (2.36 mm) & 2.10 & 0.60 & 8.20 & 1.20 & 82.40 & 47.80 & 100.00 & 1.00 & 50.60 & $32-67$ \\
\hline \#16 (1.18 mm) & 1.90 & 0.50 & 3.50 & 0.50 & 51.20 & 29.70 & 100.00 & 1.00 & 31.70 & \\
\hline$\# 30(600 \mu \mathrm{m})$ & 1.80 & 0.50 & 2.90 & 0.40 & 32.00 & 18.60 & 99.90 & 1.00 & 20.50 & \\
\hline$\# 50(300 \mu \mathrm{m})$ & 1.70 & 0.40 & 2.60 & 0.40 & 19.80 & 11.50 & 99.70 & 1.00 & 13.30 & \\
\hline$\# 100(150 \mu \mathrm{m})$ & 1.60 & 0.40 & 2.50 & 0.40 & 12.30 & 7.10 & 95.40 & 1.00 & 8.90 & \\
\hline$\# 200(75 \mu \mathrm{m})$ & 1.40 & 0.40 & 2.20 & 0.30 & 8.00 & 4.60 & 70.10 & 0.70 & 6.00 & $2-10$ \\
\hline
\end{tabular}

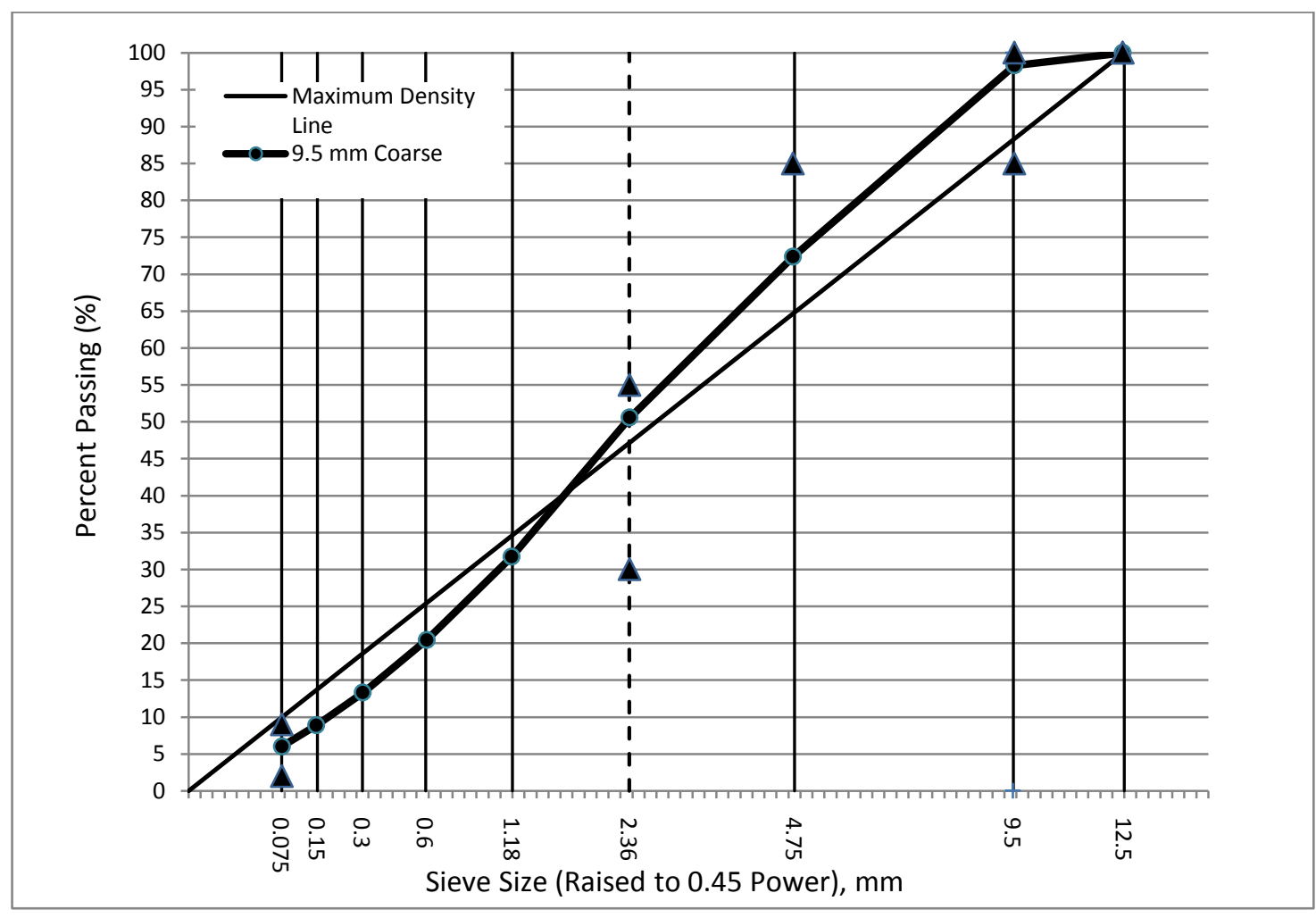

Figure 62 Combined Gradation Charts for NMAS 9.5 mm Fine Superpave Mixes 
Table 249.5 mm NMAS Coarse Gradation

\begin{tabular}{|c|c|c|c|c|c|c|c|c|c|c|}
\hline & \multicolumn{2}{|c|}{ Bin \#1 } & \multicolumn{2}{|c|}{ Bin \#2 } & \multicolumn{2}{|c|}{ Bin \#3 } & \multicolumn{2}{|c|}{ Bin \#4 } & & \multirow{4}{*}{$\begin{array}{l}\text { Control } \\
\text { Points }\end{array}$} \\
\hline & \multicolumn{2}{|c|}{ Elkins SKID 8's } & \multicolumn{2}{|c|}{ Elkins 9's } & \multicolumn{2}{|c|}{ Elkins SAND } & \multicolumn{2}{|c|}{ Baghouse Fine } & \multirow{3}{*}{$\begin{array}{l}\text { Comb. } \\
\text { Gradation }\end{array}$} & \\
\hline & \multicolumn{2}{|l|}{ \% Used: } & \multicolumn{2}{|l|}{ \% Used: } & \multicolumn{2}{|l|}{ \% Used: } & \multicolumn{2}{|l|}{ \% Used: } & & \\
\hline Sieve Size & Passing & $\%$ Total & Passing & $\%$ Total & Passing & $\%$ Total & Passing & $\%$ Total & & \\
\hline 2"(50 mm) & 100.00 & 37.00 & 100.00 & 25.00 & 100.00 & 37.00 & 100.00 & 1.00 & 100.00 & \\
\hline $1.5 "(37.5 \mathrm{~mm})$ & 100.00 & 37.00 & 100.00 & 25.00 & 100.00 & 37.00 & 100.00 & 1.00 & 100.00 & \\
\hline $1 "(25 \mathrm{~mm})$ & 100.00 & 37.00 & 100.00 & 25.00 & 100.00 & 37.00 & 100.00 & 1.00 & 100.00 & \\
\hline 3/4"(19 mm) & 100.00 & 37.00 & 100.00 & 25.00 & 100.00 & 37.00 & 100.00 & 1.00 & 100.00 & \\
\hline 1/2"(12.5 mm) & 100.00 & 37.00 & 100.00 & 25.00 & 100.00 & 37.00 & 100.00 & 1.00 & 100.00 & 100 \\
\hline 3/8" (9.5 mm) & 93.40 & 34.55 & 100.00 & 25.00 & 100.00 & 37.00 & 100.00 & 1.00 & 97.55 & $90-100$ \\
\hline \#4 (4.75 mm) & 7.90 & 2.91 & 76.00 & 19.00 & 99.90 & 36.96 & 100.00 & 1.00 & 59.87 & $90 \max$ \\
\hline \#8 (2.36 mm) & 2.10 & 0.79 & 8.20 & 2.05 & 82.40 & 30.49 & 100.00 & 1.00 & 34.33 & $32-67$ \\
\hline \#16 (1.18 mm) & 1.90 & 0.70 & 3.50 & 0.88 & 51.20 & 18.94 & 100.00 & 1.00 & 21.52 & \\
\hline$\# 30(600 \mu \mathrm{m})$ & 1.80 & 0.67 & 2.90 & 0.73 & 32.00 & 11.84 & 99.90 & 1.00 & 14.23 & \\
\hline$\# 50(300 \mu \mathrm{m})$ & 1.70 & 0.64 & 2.60 & 0.65 & 19.80 & 7.33 & 99.70 & 1.00 & 9.62 & \\
\hline$\# 100(150 \mu \mathrm{m})$ & 1.60 & 0.59 & 2.50 & 0.63 & 12.30 & 4.55 & 95.40 & 0.95 & 6.72 & \\
\hline \#200 (75 $\mu \mathrm{m})$ & 1.40 & 0.52 & 2.20 & 0.56 & 8.00 & 2.96 & 70.10 & 0.70 & 4.74 & $2-10$ \\
\hline
\end{tabular}

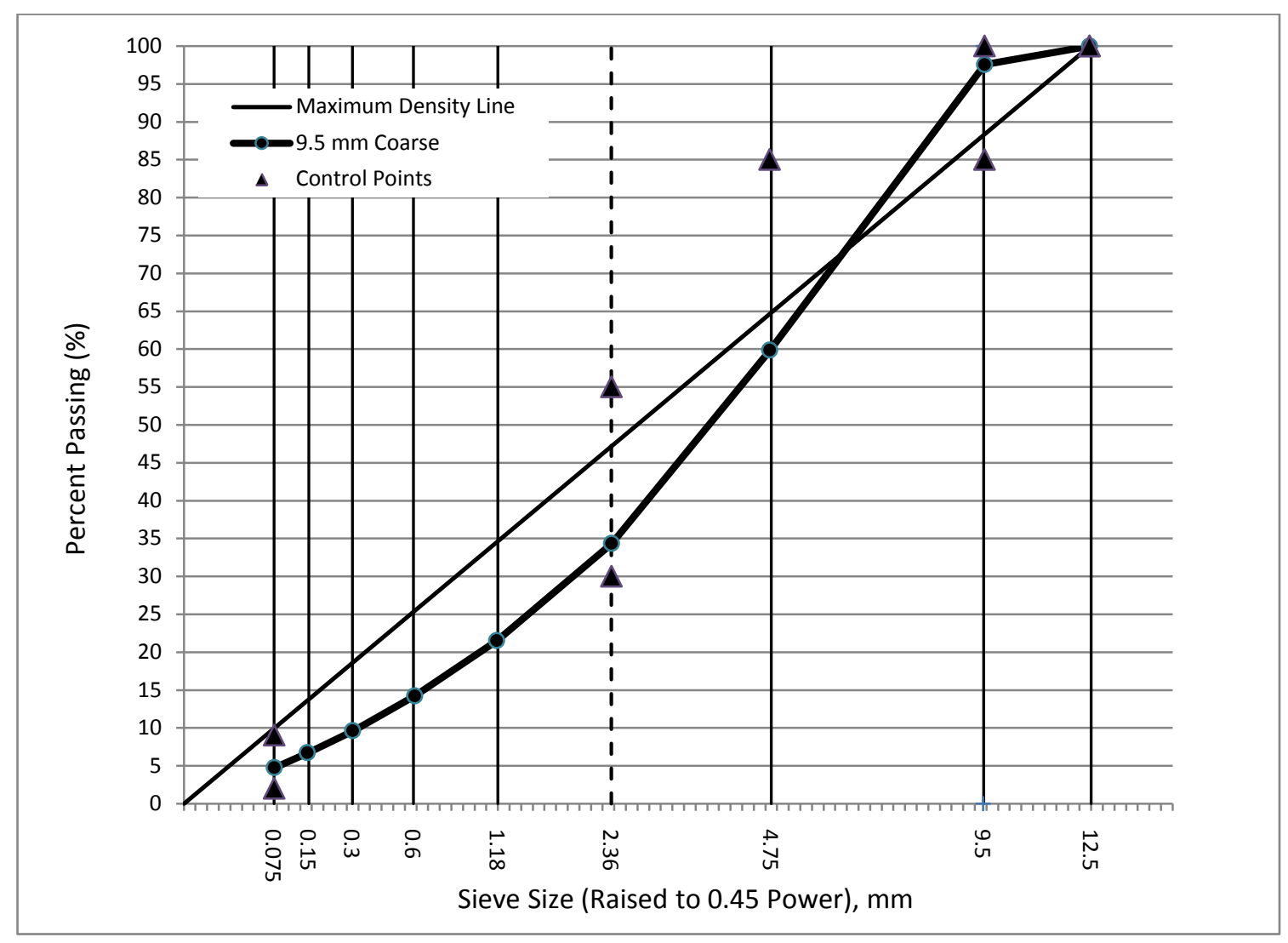

Figure 63 Combined gradation charts for NMAS 9.5 mm coarse Superpave mixes 
Table 2512.5 mm NMAS Coarse Gradation

\begin{tabular}{|c|c|c|c|c|c|c|c|c|c|c|c|c|}
\hline & \multicolumn{2}{|c|}{ Bin \#1 } & \multicolumn{2}{|c|}{ Bin \#2 } & \multicolumn{2}{|c|}{ Bin \#3 } & \multicolumn{2}{|c|}{ Bin \#4 } & \multicolumn{2}{|c|}{ Bin \#5 } & \multirow{4}{*}{$\begin{array}{l}\text { Comb. } \\
\text { Gradation }\end{array}$} & \multirow{4}{*}{$\begin{array}{c}\text { Control } \\
\text { Points }\end{array}$} \\
\hline & \multicolumn{2}{|c|}{ Elkins SKID 78's } & \multicolumn{2}{|c|}{ Elkins Skid 8's } & \multicolumn{2}{|c|}{ Elkins 9's } & \multicolumn{2}{|c|}{ Elkins SAND } & \multicolumn{2}{|c|}{ Baghoues Fine } & & \\
\hline & \% Used: & 15 & \% Used: & 41 & \% Used: & 13 & \% Used: & 30 & \% Used: & 1 & & \\
\hline Sieve Size & Passing & $\%$ Total & Passing & $\%$ Total & Passing & $\%$ Total & Passing & $\%$ Total & Passing & \%Total & & \\
\hline 2"(50 mm) & 100.00 & 15.00 & 100.00 & 41.00 & 100.00 & 13.00 & 100.00 & 30.00 & 100.00 & 1.00 & 100.00 & \\
\hline 1.5"(37.5 mm) & 100.00 & 15.00 & 100.00 & 41.00 & 100.00 & 13.00 & 100.00 & 30.00 & 100.00 & 1.00 & 100.00 & \\
\hline $1 "(25 \mathrm{~mm})$ & 100.00 & 15.00 & 100.00 & 41.00 & 100.00 & 13.00 & 100.00 & 30.00 & 100.00 & 1.00 & 100.00 & \\
\hline 3/4"(19 mm) & 100.00 & 15.00 & 100.00 & 41.00 & 100.00 & 13.00 & 100.00 & 30.00 & 100.00 & 1.00 & 100.00 & 100 \\
\hline 1/2"(12.5 mm) & 87.20 & 13.08 & 100.00 & 41.00 & 100.00 & 13.00 & 100.00 & 30.00 & 100.00 & 1.00 & 98.08 & $90-100$ \\
\hline 3/8" (2.36 mm) & 36.90 & 5.54 & 93.40 & 38.29 & 100.00 & 13.00 & 100.00 & 30.00 & 100.00 & 1.00 & 87.83 & $90 \max$ \\
\hline \#4 (4.75 mm) & 6.10 & 0.92 & 7.90 & 3.24 & 76.00 & 9.88 & 99.90 & 29.97 & 100.00 & 1.00 & 45.00 & \\
\hline \#8 (2.36 mm) & 4.00 & 0.60 & 2.10 & 0.86 & 8.20 & 1.07 & 82.40 & 24.72 & 100.00 & 1.00 & 28.25 & $28-58$ \\
\hline \#16 (1.18 mm) & 3.50 & 0.53 & 1.90 & 0.78 & 3.50 & 0.46 & 51.20 & 15.36 & 100.00 & 1.00 & 18.12 & \\
\hline$\# 30(600 \mu \mathrm{m})$ & 3.40 & 0.51 & 1.80 & 0.74 & 2.90 & 0.38 & 32.00 & 9.60 & 99.90 & 1.00 & 12.22 & \\
\hline \#50 (300 $\mu \mathrm{m})$ & 3.30 & 0.50 & 1.70 & 0.70 & 2.60 & 0.34 & 19.80 & 5.94 & 99.70 & 1.00 & 8.47 & \\
\hline$\# 100(150 \mu \mathrm{m})$ & 2.80 & 0.42 & 1.60 & 0.66 & 2.50 & 0.33 & 12.30 & 3.69 & 95.40 & 0.95 & 6.05 & \\
\hline \#200 (75 $\mu \mathrm{m})$ & 2.60 & 0.39 & 1.40 & 0.57 & 2.20 & 0.29 & 8.00 & 2.40 & 70.10 & 0.70 & 4.35 & $2-10$ \\
\hline
\end{tabular}

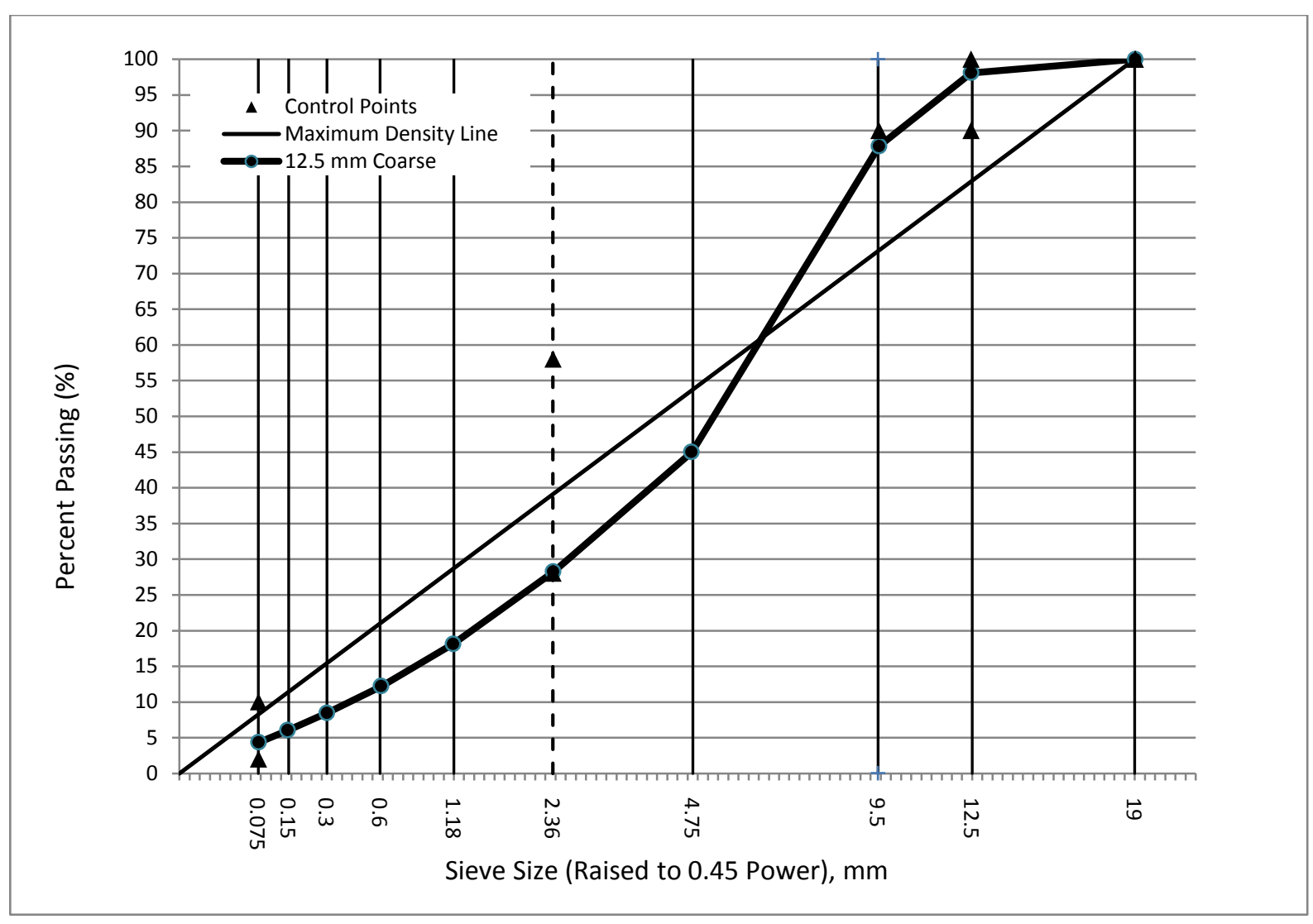

Figure 64 Combined gradation charts for NMAS 12.5 mm coarse Superpave mixes 
Table 2619 mm NMAS Fine Gradation

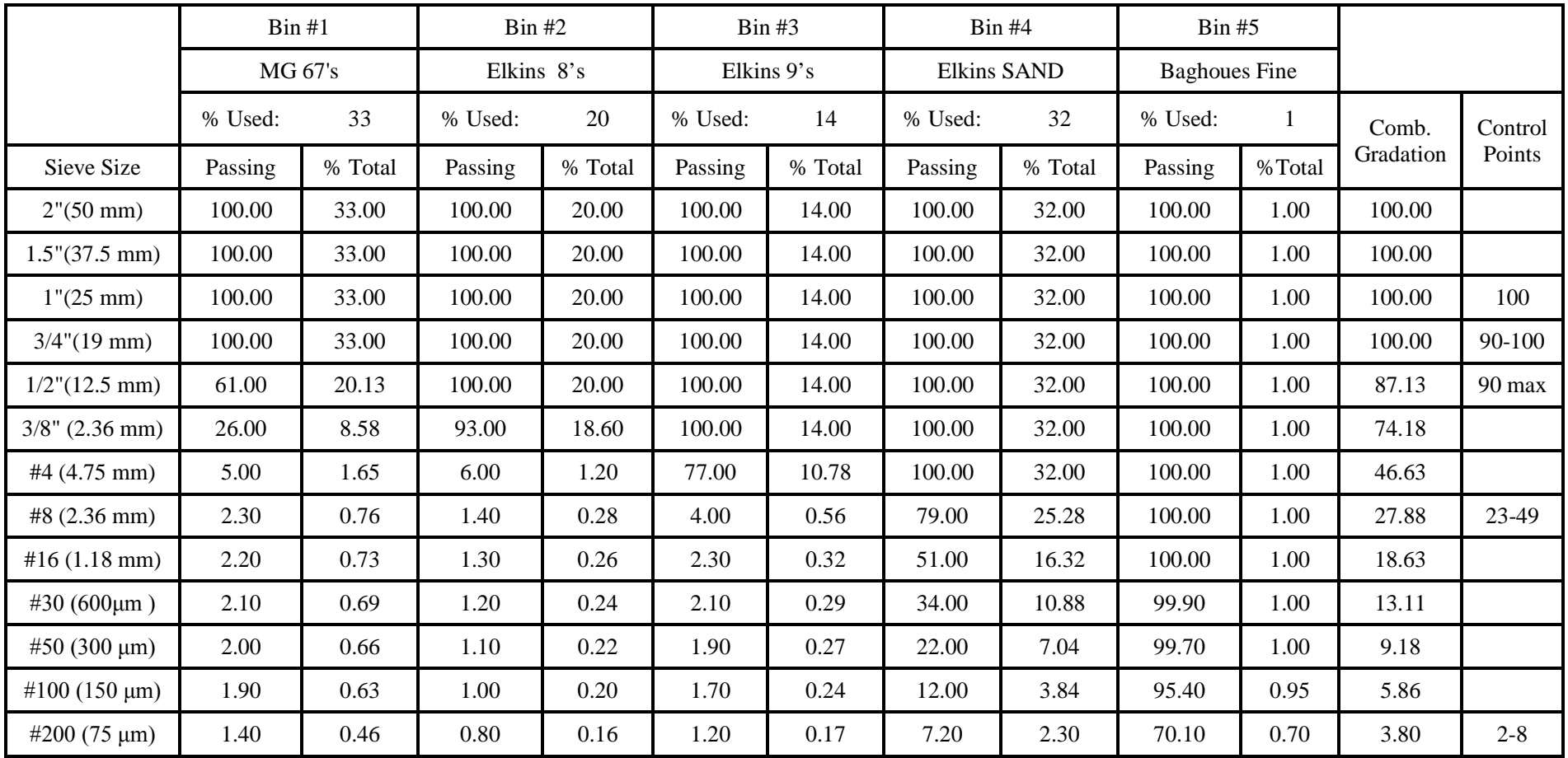

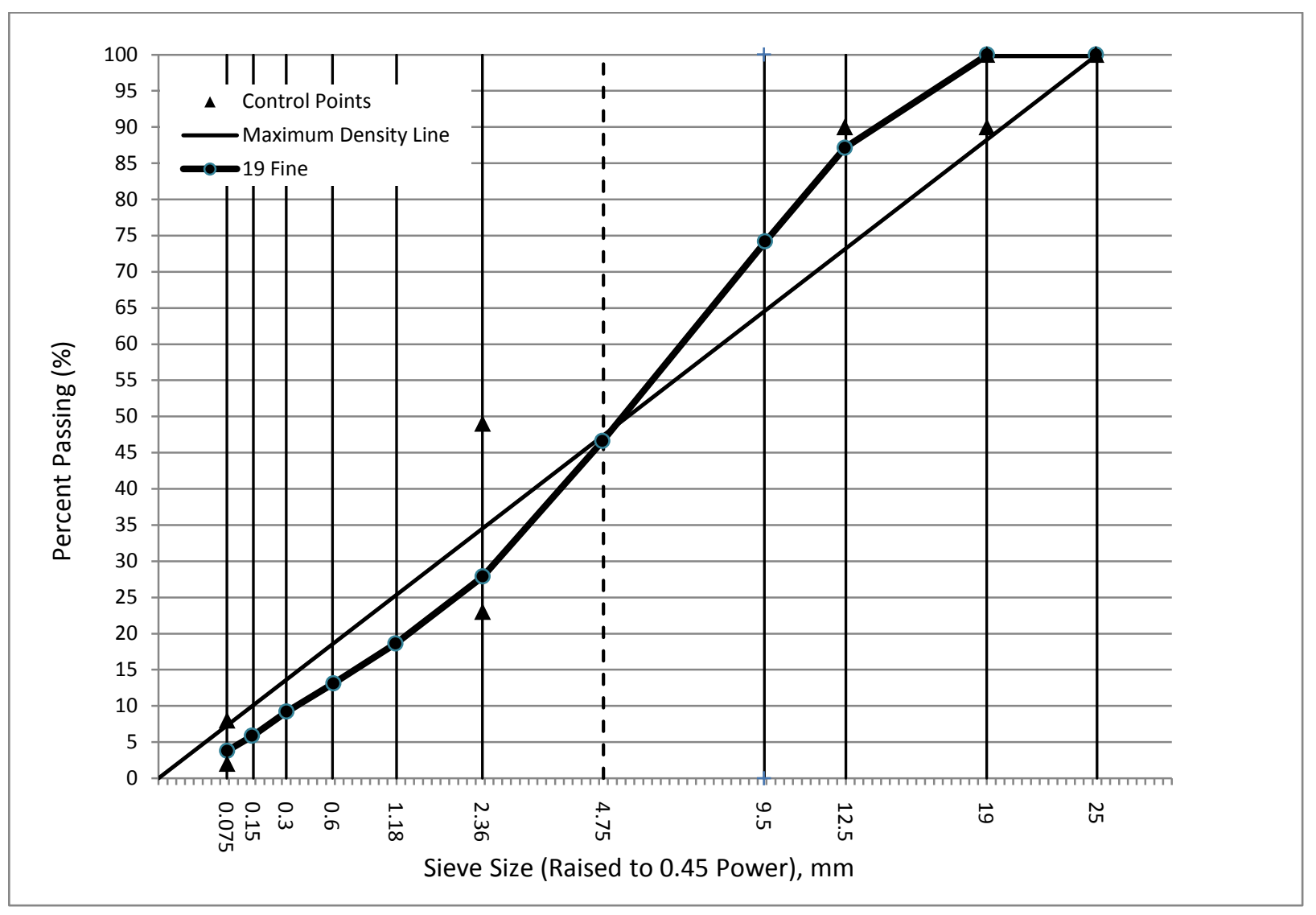

Figure 65 Combined gradation charts for NMAS 19 mm fine Superpave mixes 
Table 2719 mm NMAS Coarse Gradation

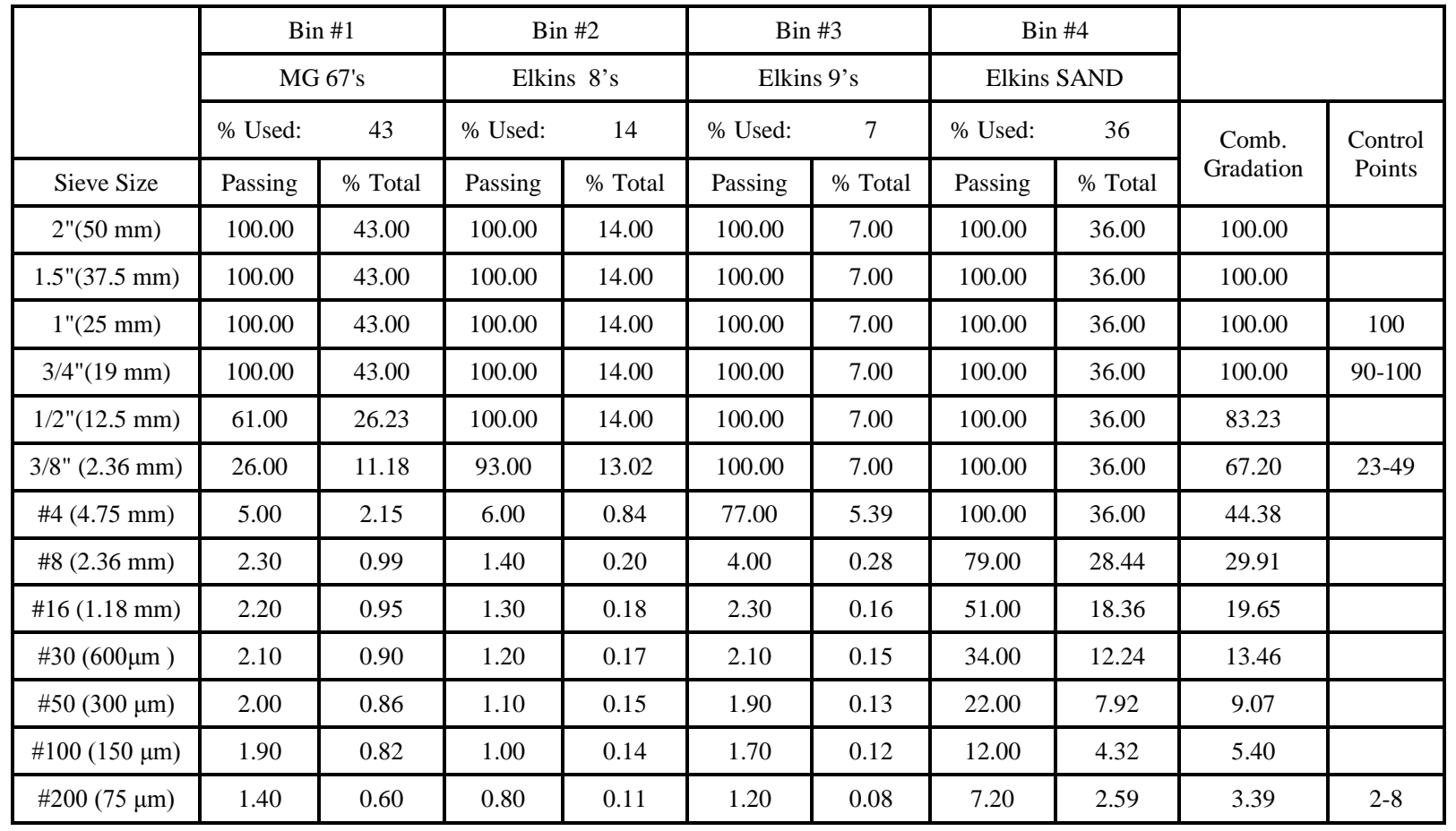

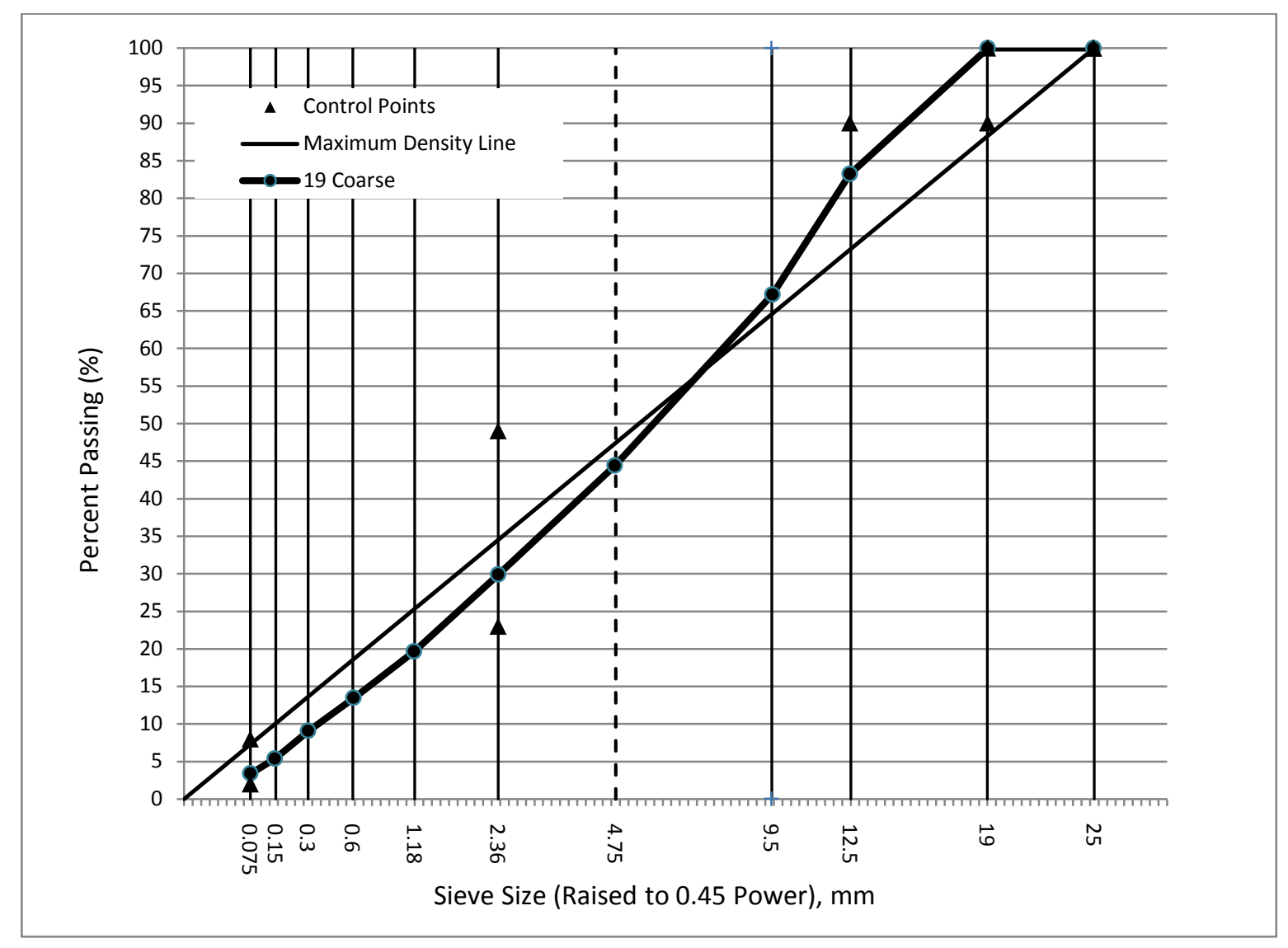

Figure 66 Combined gradation charts for NMAS 19 mm coarse Superpave mixes 
Table 2825 mm NMAS Fine Gradation

\begin{tabular}{|c|c|c|c|c|c|c|c|c|c|c|}
\hline & \multicolumn{2}{|c|}{ Bin \#1 } & \multicolumn{2}{|c|}{ Bin \#2 } & \multicolumn{2}{|c|}{ Bin \#3 } & \multicolumn{2}{|c|}{ Bin \#4 } & \multirow{4}{*}{$\begin{array}{c}\text { Comb. } \\
\text { Gradation }\end{array}$} & \multirow{4}{*}{$\begin{array}{c}\text { Control } \\
\text { Points }\end{array}$} \\
\hline & \multicolumn{2}{|c|}{ Elkins 57's } & \multicolumn{2}{|c|}{ Elkins 8's } & \multicolumn{2}{|c|}{ Elkins 9's } & \multicolumn{2}{|c|}{ MG SAND } & & \\
\hline & \% Used: & & \% Used: & & \% Used: & & \% Used: & 36 & & \\
\hline Sieve Size & Passing & $\%$ Total & Passing & $\%$ Total & Passing & $\%$ Total & Passing & $\%$ Total & & \\
\hline 2"(50 mm) & 100.00 & 43.00 & 100.00 & 14.00 & 100.00 & 7.00 & 100.00 & 36.00 & 100.00 & \\
\hline 1.5"(37.5 mm) & 100.00 & 43.00 & 100.00 & 14.00 & 100.00 & 7.00 & 100.00 & 36.00 & 100.00 & 100 \\
\hline $1 "(25 \mathrm{~mm})$ & 92.00 & 39.56 & 100.00 & 14.00 & 100.00 & 7.00 & 100.00 & 36.00 & 96.56 & $90-100$ \\
\hline 3/4"(19 mm) & 69.00 & 29.67 & 100.00 & 14.00 & 100.00 & 7.00 & 100.00 & 36.00 & 86.67 & $90 \max$ \\
\hline 1/2"(12.5 mm) & 29.00 & 12.47 & 100.00 & 14.00 & 100.00 & 7.00 & 100.00 & 36.00 & 69.47 & \\
\hline 3/8" (9.5mm) & 10.00 & 4.30 & 93.00 & 13.02 & 100.00 & 7.00 & 100.00 & 36.00 & 60.32 & \\
\hline \#4 (4.75 mm) & 1.70 & 0.73 & 6.00 & 0.84 & 77.00 & 5.39 & 100.00 & 36.00 & 42.96 & \\
\hline \#8 (2.36 mm) & 1.60 & 0.69 & 1.40 & 0.20 & 4.00 & 0.28 & 78.00 & 28.08 & 29.24 & $19-45$ \\
\hline \#16 (1.18 mm) & 1.50 & 0.65 & 1.30 & 0.18 & 2.30 & 0.16 & 48.00 & 17.28 & 18.27 & \\
\hline$\# 30(600 \mu \mathrm{m})$ & 1.40 & 0.60 & 1.20 & 0.17 & 2.10 & 0.15 & 28.00 & 10.08 & 11.00 & \\
\hline$\# 50(300 \mu \mathrm{m})$ & 1.30 & 0.56 & 1.10 & 0.15 & 1.90 & 0.13 & 17.00 & 6.12 & 6.97 & \\
\hline$\# 100(150 \mu \mathrm{m})$ & 1.20 & 0.52 & 1.00 & 0.14 & 1.70 & 0.12 & 11.00 & 3.96 & 4.74 & \\
\hline$\# 200(75 \mu \mathrm{m})$ & 1.12 & 0.48 & 0.80 & 0.11 & 1.20 & 0.08 & 8.20 & 2.95 & 3.63 & $2-7$ \\
\hline
\end{tabular}

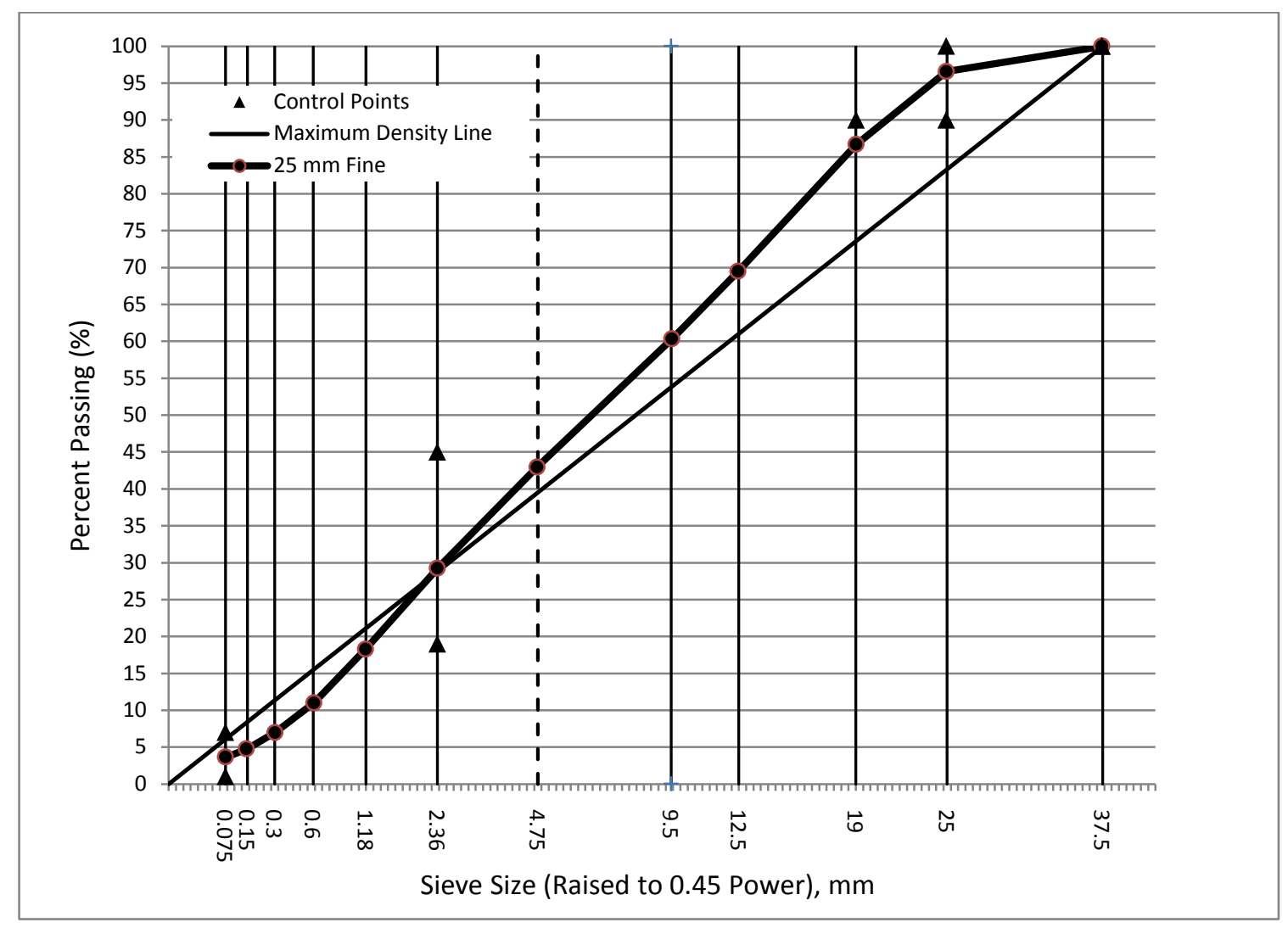

Figure 67 Combined gradation charts for NMAS $25 \mathrm{~mm}$ fine Superpave mixes 
Table 2937.5 mm NMAS Fine Gradation

\begin{tabular}{|c|c|c|c|c|c|c|c|c|c|c|c|c|}
\hline & \multicolumn{2}{|c|}{ Bin \#1 } & \multicolumn{2}{|c|}{ Bin \#2 } & \multicolumn{2}{|c|}{ Bin \#3 } & \multicolumn{2}{|c|}{ Bin \#4 } & \multicolumn{2}{|c|}{ Bin \#5 } & & \\
\hline & \multicolumn{2}{|c|}{ Elkins 4's } & \multicolumn{2}{|c|}{ MG 67's } & \multicolumn{2}{|c|}{ MG 8's } & \multicolumn{2}{|c|}{ Elk SAND } & \multicolumn{2}{|c|}{$\mathrm{BHF}$} & & \\
\hline & \% Used: & 29 & \% Used: & 29 & \% Used: & 20 & \% Used: & 21 & \% Used: & 1 & Comb. & Control \\
\hline Sieve Size & Passing & \% Total & Passing & \% Total & Passing & \% Total & Passing & \% Total & Passing & \%Total & Gradation & Points \\
\hline $2 "(50 \mathrm{~mm})$ & 100.00 & 29.00 & 100.00 & 29.00 & 100.00 & 20.00 & 100.00 & 21.00 & 100.00 & 1.00 & 100.00 & \\
\hline $1.5 "(37.5 \mathrm{~mm})$ & 100.00 & 29.00 & 100.00 & 29.00 & 100.00 & 20.00 & 100.00 & 21.00 & 100.00 & 1.00 & 100.00 & 100 \\
\hline $1 "(25 \mathrm{~mm})$ & 45.70 & 13.25 & 100.00 & 29.00 & 100.00 & 20.00 & 100.00 & 21.00 & 100.00 & 1.00 & 84.25 & $90-100$ \\
\hline 3/4"(19 mm) & 4.40 & 1.28 & 100.00 & 29.00 & 100.00 & 20.00 & 100.00 & 21.00 & 100.00 & 1.00 & 72.28 & $90 \max$ \\
\hline 1/2"(12.5 mm) & 1.30 & 0.38 & 40.80 & 11.83 & 100.00 & 20.00 & 100.00 & 21.00 & 100.00 & 1.00 & 54.21 & \\
\hline 3/8" (9.5 mm) & 1.20 & 0.35 & 9.50 & 2.76 & 97.40 & 19.48 & 100.00 & 21.00 & 100.00 & 1.00 & 44.58 & \\
\hline \#4 (4.75 mm) & 1.10 & 0.32 & 2.00 & 0.58 & 23.70 & 4.74 & 100.00 & 21.00 & 100.00 & 1.00 & 27.64 & \\
\hline \#8 (2.36mm) & 1.08 & 0.31 & 1.60 & 0.46 & 3.30 & 0.66 & 82.40 & 17.30 & 100.00 & 1.00 & 19.74 & $27-39$ \\
\hline$\# 16(1.18 \mathrm{~mm})$ & 1.07 & 0.31 & 1.50 & 0.44 & 2.80 & 0.56 & 51.20 & 10.75 & 100.00 & 1.00 & 13.06 & \\
\hline$\# 30(600 \mu \mathrm{m})$ & 1.06 & 0.31 & 1.40 & 0.41 & 2.40 & 0.48 & 32.00 & 6.72 & 99.90 & 1.00 & 8.91 & \\
\hline$\# 50(300 \mu \mathrm{m})$ & 1.05 & 0.30 & 1.30 & 0.38 & 2.30 & 0.46 & 19.80 & 4.16 & 99.70 & 1.00 & 6.30 & \\
\hline$\# 100(150 \mu \mathrm{m})$ & 1.04 & 0.30 & 1.20 & 0.35 & 1.90 & 0.38 & 12.30 & 2.58 & 95.40 & 0.95 & 4.57 & \\
\hline$\# 200(75 \mu \mathrm{m})$ & 0.84 & 0.24 & 1.03 & 0.30 & 1.83 & 0.37 & 8.00 & 1.68 & 70.10 & 0.70 & 3.29 & $0-6$ \\
\hline
\end{tabular}

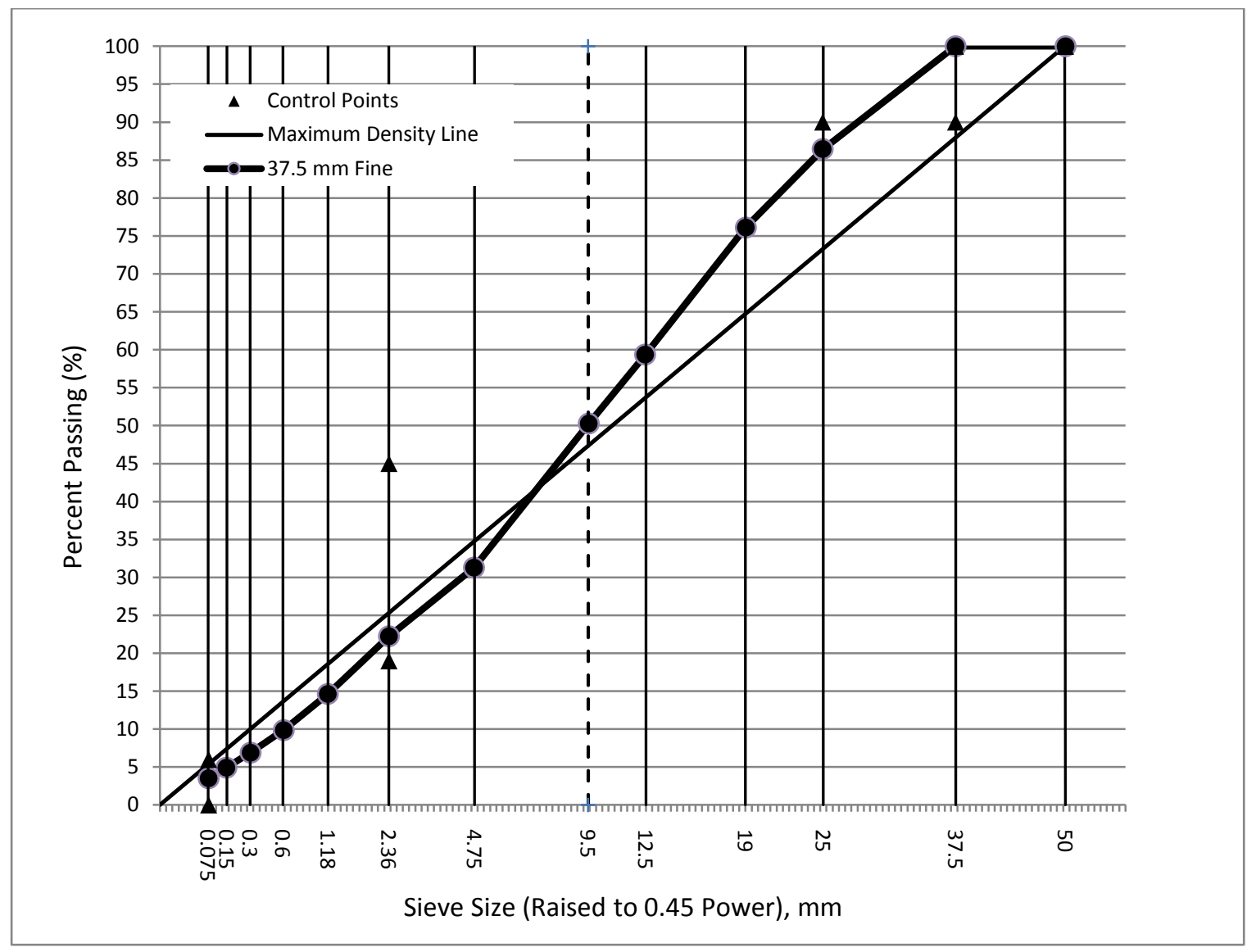

Figure 68 Combined gradation charts for NMAS $37.5 \mathrm{~mm}$ fine Superpave mixes 
Table 3037.5 mm NMAS Coarse Gradation

\begin{tabular}{|c|c|c|c|c|c|c|c|c|c|c|c|c|}
\hline & \multicolumn{2}{|c|}{ Bin \#1 } & \multicolumn{2}{|c|}{ Bin \#2 } & \multicolumn{2}{|c|}{ Bin \#3 } & \multicolumn{2}{|c|}{ Bin \#4 } & \multicolumn{2}{|c|}{ Bin \#5 } & & \\
\hline & \multicolumn{2}{|c|}{ Elkins 4's } & \multicolumn{2}{|c|}{ MG 67’s } & \multicolumn{2}{|c|}{ MG 8’s } & \multicolumn{2}{|c|}{ Elk SAND } & \multicolumn{2}{|c|}{$\mathrm{BHF}$} & & \\
\hline & \% Used: & 25 & \% Used: & 27 & \% Used: & 23 & \% Used: & 24 & \% Used: & 1 & Comb. & Control \\
\hline Sieve Size & Passing & \% Total & Passing & $\%$ Total & Passing & $\%$ Total & Passing & $\%$ Total & Passing & \%Total & Gradation & Points \\
\hline $2 "(50 \mathrm{~mm})$ & 100.00 & 25.00 & 100.00 & 27.00 & 100.00 & 23.00 & 100.00 & 24.00 & 100.00 & 1.00 & 100.00 & \\
\hline 1.5"(37.5 mm) & 100.00 & 25.00 & 100.00 & 27.00 & 100.00 & 23.00 & 100.00 & 24.00 & 100.00 & 1.00 & 100.00 & 100 \\
\hline $1 "(25 \mathrm{~mm})$ & 45.70 & 11.43 & 100.00 & 27.00 & 100.00 & 23.00 & 100.00 & 24.00 & 100.00 & 1.00 & 86.43 & $90-100$ \\
\hline 3/4"(19 mm) & 4.40 & 1.10 & 100.00 & 27.00 & 100.00 & 23.00 & 100.00 & 24.00 & 100.00 & 1.00 & 76.10 & $90 \max$ \\
\hline 1/2"(12.5 mm) & 1.30 & 0.33 & 40.80 & 11.02 & 100.00 & 23.00 & 100.00 & 24.00 & 100.00 & 1.00 & 59.34 & \\
\hline 3/8" (9.5 mm) & 1.20 & 0.30 & 9.50 & 2.57 & 97.40 & 22.40 & 100.00 & 24.00 & 100.00 & 1.00 & 50.27 & \\
\hline \#4 (4.75 mm) & 1.10 & 0.28 & 2.00 & 0.54 & 23.70 & 5.45 & 100.00 & 24.00 & 100.00 & 1.00 & 31.27 & \\
\hline \#8 (2.36 mm) & 1.08 & 0.27 & 1.60 & 0.43 & 3.30 & 0.76 & 82.40 & 19.78 & 100.00 & 1.00 & 22.24 & $15-41$ \\
\hline$\# 16(1.18 \mathrm{~mm})$ & 1.07 & 0.27 & 1.50 & 0.41 & 2.80 & 0.64 & 51.20 & 12.29 & 100.00 & 1.00 & 14.60 & \\
\hline$\# 30(600 \mu \mathrm{m})$ & 1.06 & 0.27 & 1.40 & 0.38 & 2.40 & 0.55 & 32.00 & 7.68 & 99.90 & 1.00 & 9.87 & \\
\hline$\# 50(300 \mu \mathrm{m})$ & 1.05 & 0.26 & 1.30 & 0.35 & 2.30 & 0.53 & 19.80 & 4.75 & 99.70 & 1.00 & 6.89 & \\
\hline$\# 100(150 \mu \mathrm{m})$ & 1.04 & 0.26 & 1.20 & 0.32 & 1.90 & 0.44 & 12.30 & 2.95 & 95.40 & 0.95 & 4.93 & \\
\hline$\# 200(75 \mu \mathrm{m})$ & 0.84 & 0.21 & 1.03 & 0.28 & 1.83 & 0.42 & 8.00 & 1.92 & 70.10 & 0.70 & 3.53 & $0-6$ \\
\hline
\end{tabular}

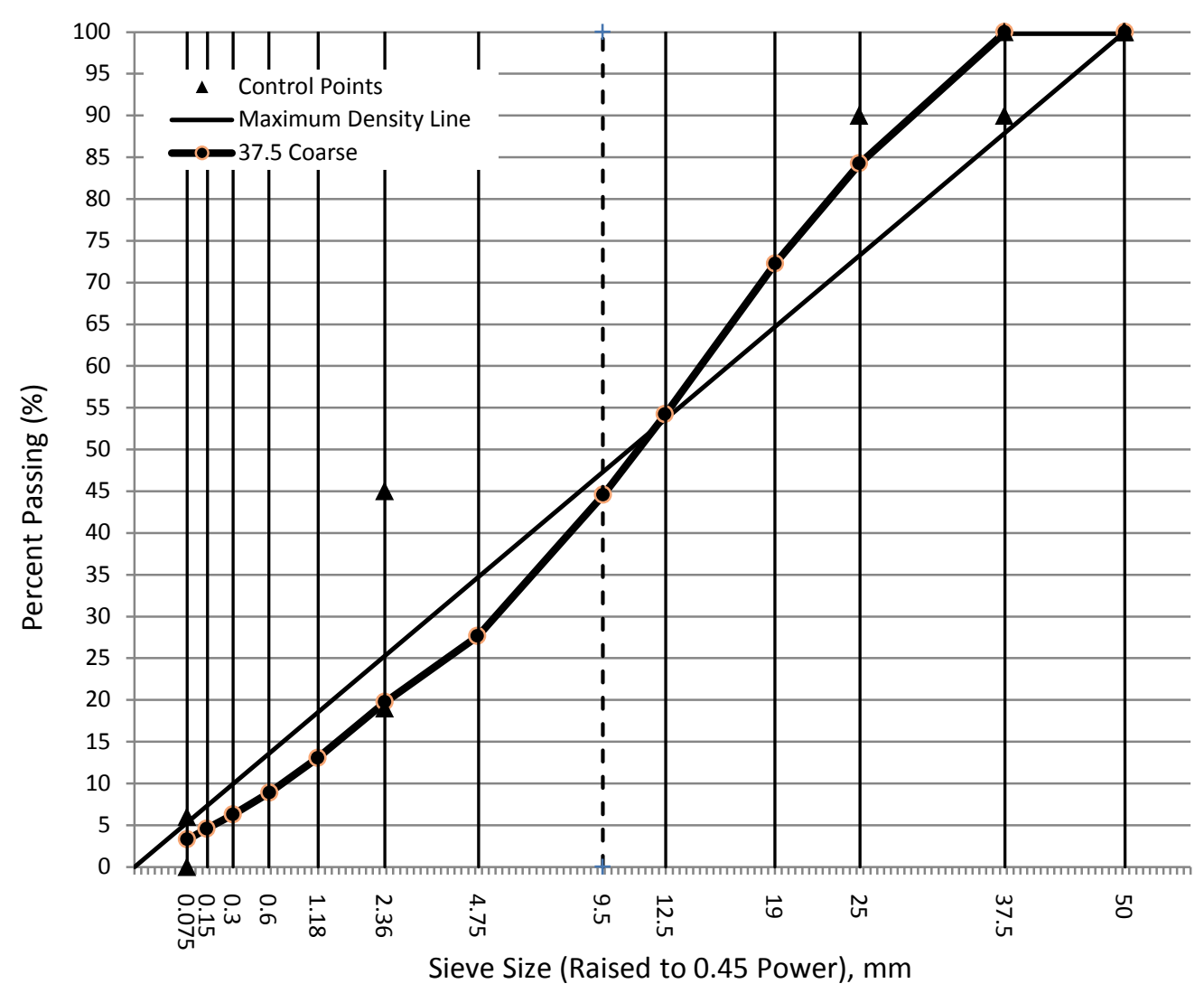

Figure 69 Combined gradation charts for NMAS $37.5 \mathrm{~mm}$ coarse Superpave mixes 


\section{Appendix 2}

Field Density Data and Bulk Specific Gravity of Field Cores

\begin{tabular}{|c|c|c|c|c|c|c|c|}
\hline $\begin{array}{l}\text { WVUATL } \\
\text { Number }\end{array}$ & Project & Project & $\begin{array}{l}\text { Mixes } \\
\text { Type } \\
(\mathrm{mm})\end{array}$ & Lab Number & Location & $\mathrm{M} / \mathrm{J}$ & $\begin{array}{c}\mathrm{G}_{\mathrm{mm}} \\
\text { Contractor }\end{array}$ \\
\hline 1 & IM-0792(142)D/XC2187T & I-79 & 9.5 & JFA-A49-M & 4190+19/9'SBSL & M & 2.461 \\
\hline 2 & IM-0792(142)D/XC2187T & I-79 & 9.5 & DOH-A49-M & 4196+79/7'SBSL & M & 2.461 \\
\hline 3 & IM-0792(142)D/XC2187T & $\mathrm{I}-79$ & 9.5 & JFA-A49-J & 4190+19/4"SBSL & $\mathrm{J}$ & 2.461 \\
\hline 4 & IM-0792(142)D/XC2187T & I-79 & 9.5 & DOH-A49-J & 4196+79/4"SBSL & $\mathrm{J}$ & 2.461 \\
\hline 5 & IM-0792(142)D/XC2187T & I-79 & 9.5 & JFA-A57-M & $4113+01 / 5$ 'SBSL & M & 2.461 \\
\hline 6 & IM-0792(142)D/XC2187T & I-79 & 9.5 & DOH-A57-M & $4116+55 / 2$ 'SBSL & M & 2.461 \\
\hline 7 & IM-0792(142)D/XC2187T & I-79 & 9.5 & JFA-A57-J & 4113+01/4"SBSL & $\mathrm{J}$ & 2.461 \\
\hline 8 & IM-0792(142)D/XC2187T & I-79 & 9.5 & DOH-A57-J & 4116+55/4"SBSL & $\mathrm{J}$ & 2.461 \\
\hline 9 & IM-0792(142)D/XC2187T & I-79 & 9.5 & JFA-A65-M & 4037+50/10'SBSL & M & 2.461 \\
\hline 10 & IM-0792(142)D/XC2187T & I-79 & 9.5 & DOH-A65-M & 4032+87/4'SBSL & M & 2.461 \\
\hline 11 & IM-0792(142)D/XC2187T & I-79 & 9.5 & JFA-A65-J & 4037+50/4"SBSL & $\mathrm{J}$ & 2.461 \\
\hline 12 & IM-0792(142)D/XC2187T & I-79 & 9.5 & DOH-A65-J & 4032+87/4"SBSL & $\mathrm{J}$ & 2.461 \\
\hline 13 & IM-0792(142)D/XC2187T & I-79 & 9.5 & JFA-A71-M & 4035+81/5'NBSL & M & 2.461 \\
\hline 14 & IM-0792(142)D/XC2187T & I-79 & 9.5 & DOH-A71-M & 4033+42/6'NBSL & M & 2.461 \\
\hline 15 & IM-0792(142)D/XC2187T & I-79 & 9.5 & JFA-A71-J & 4035+81/4"NBSL & $\mathrm{J}$ & 2.461 \\
\hline 16 & IM-0792(142)D/XC2187T & I-79 & 9.5 & DOH-A71-J & 4033+42/4"NBSL & $\mathrm{J}$ & 2.461 \\
\hline 17 & IM-0792(142)D/XC2187T & I-79 & 9.5 & $4222+95$ / 3' & $4222+95 / 3^{\prime}$ & M & 2.462 \\
\hline 18 & IM-0792(142)D/XC2187T & I-79 & 9.5 & $4222+36 / 7^{\prime}$ & $4222+36 / 7^{\prime}$ & M & 2.462 \\
\hline 19 & IM-0792(142)D/XC2187T & I-79 & 9.5 & $4222+00 / 4^{\prime}$ & $4222+00 / 4^{\prime}$ & M & 2.462 \\
\hline 20 & IM-0792(142)D/XC2187T & I-79 & 9.5 & $4221+53 / 2^{\prime}$ & $4221+53 / 2^{\prime}$ & M & 2.462 \\
\hline 21 & IM-0792(142)D/XC2187T & I-79 & 9.5 & $4221+17 / 1^{\prime}$ & $4221+17 / 1^{\prime}$ & M & 2.462 \\
\hline 22 & IM-0792(142)D/XC2187T & I-79 & 9.5 & $4220+84 / 6^{\prime}$ & $4220+84 / 6^{\prime}$ & M & 2.462 \\
\hline 23 & IM-0792(142)D/XC2187T & I-79 & 9.5 & $4220+67 / 6^{\prime}$ & $4220+67 / 6^{\prime}$ & M & 2.462 \\
\hline 24 & IM-0792(142)D/XC2187T & $\mathrm{I}-79$ & 9.5 & $4220+33 / 10^{\prime}$ & $4220+33 / 10^{\prime}$ & M & 2.462 \\
\hline 25 & $\mathrm{IM}-0793(210) \mathrm{D} / \mathrm{XC} 2186 \mathrm{~T}$ & I-79 & 9.5 & $-9+51 / 12^{\prime}$ & $(-) 9+51 / 12^{\prime}$ & M & 2.463 \\
\hline 26 & IM-0793(210)D/XC2186T & I-79 & 9.5 & $-9+15 / 11^{\prime}$ & $(-) 9+51 / 11^{\prime}$ & M & 2.463 \\
\hline 27 & $\mathrm{IM}-0793(210) \mathrm{D} / \mathrm{XC} 2186 \mathrm{~T}$ & I-79 & 9.5 & $-8+52 / 6 '$ & $(-) 8+52 / 6^{\prime}$ & M & 2.463 \\
\hline 28 & IM-0793(210)D/XC2186T & I-79 & 9.5 & $-8+23 / 10^{\prime}$ & $(-) 8+23 / 10^{\prime}$ & M & 2.463 \\
\hline 29 & $\mathrm{IM}-0793(210) \mathrm{D} / \mathrm{XC} 2186 \mathrm{~T}$ & I-79 & 9.5 & $-7+76 / 10^{\prime}$ & $(-) 7+76 / 10^{\prime}$ & M & 2.463 \\
\hline 30 & IM-0793(210)D/XC2186T & I-79 & 9.5 & $-7+56 / 6^{\prime}$ & $(-) 7+56 / 6^{\prime}$ & M & 2.463 \\
\hline 31 & IM-0793(210)D/XC2186T & I-79 & 9.5 & $-6+53 / 8$ & $(-) 6+53 / 8$ & M & 2.463 \\
\hline
\end{tabular}




\begin{tabular}{|c|c|c|c|c|c|c|c|}
\hline $\begin{array}{c}\text { WVUATL } \\
\text { Number }\end{array}$ & Project & Project & $\begin{array}{c}\text { Mixes } \\
\text { Type } \\
(\mathrm{mm})\end{array}$ & Lab number & Location & M/L & G $\mathrm{mm}_{\text {Contractor }}$ \\
\hline 32 & IM-0793(210)D/XC2186T & I-79 & 9.5 & A23M-B & $10+00$ NBML/7' & M & 2.456 \\
\hline 33 & IM-0793(210)D/XC2186T & I-79 & 9.5 & A44M-A & $6+00$ NBSL/9' & M & 2.456 \\
\hline 34 & IM-0793(210)D/XC2186T & I-79 & 9.5 & A44M-B & $10+00$ NBSL/4" & M & 2.456 \\
\hline 35 & IM-0793(210)D/XC2186T & I-79 & 9.5 & JFA-A103-M & $161+32$ SBML/4' & M & 2.456 \\
\hline 36 & IM-0793(210)D/XC2186T & I-79 & 9.5 & DOH-A103-M & $165+53$ SBML/4' & M & 2.456 \\
\hline 37 & IM-0793(210)D/XC2186T & I-79 & 9.5 & DOH-A104-M & $178+56$ SBML/3' & M & 2.456 \\
\hline 38 & IM-0793(210)D/XC2186T & I-79 & 9.5 & JFA-A104-M & $171+56$ SBML/6' & M & 2.456 \\
\hline 39 & IM-0793(210)D/XC2186T & I-79 & 9.5 & A23J-B & $10+00$ NBML/4" & J & 2.456 \\
\hline 40 & IM-0793(210)D/XC2186T & I-79 & 9.5 & A23J-A & $6+00$ NBML/4" & J & 2.456 \\
\hline 41 & IM-0793(210)D/XC2186T & I-79 & 9.5 & A44J-A & $6+00$ NBSL/4" & J & 2.456 \\
\hline 42 & IM-0793(210)D/XC2186T & I-79 & 9.5 & A44J-B & $10+00$ NBML/4" & J & 2.456 \\
\hline 43 & IM-0793(210)D/XC2186T & I-79 & 9.5 & DOH-A103-J & $165+53$ SBML/4" & J & 2.456 \\
\hline 44 & IM-0793(210)D/XC2186T & I-79 & 9.5 & DOH-A104-J & $178+56$ SBML/4" & J & 2.456 \\
\hline 45 & IM-0793(210)D/XC2186T & I-79 & 9.5 & JFA-104-J & $171+56$ SBML/4" & J & 2.456 \\
\hline
\end{tabular}




\begin{tabular}{|c|c|c|c|c|c|c|c|}
\hline $\begin{array}{l}\text { WVUATL } \\
\text { Number }\end{array}$ & Project & Project & $\begin{array}{l}\text { Mixes Type } \\
(\mathrm{mm})\end{array}$ & Lab number & Location & $\mathrm{M} / \mathrm{L}$ & $\mathrm{G}_{\mathrm{mm}}$ Contractor \\
\hline 46 & Route-19 & Route-19 & 9.5 & \multirow{32}{*}{$\mathrm{NA}$} & & \multirow{32}{*}{ NA } & 2.541 \\
\hline 47 & Route-19 & Route-19 & 9.5 & & & & 2.541 \\
\hline 48 & Route-19 & Route-19 & 9.5 & & & & 2.541 \\
\hline 49 & Route-19 & Route-19 & 9.5 & & & & 2.541 \\
\hline 50 & Route-19 & Route-19 & 9.5 & & & & 2.541 \\
\hline 51 & Route-19 & Route-19 & 9.5 & & & & 2.541 \\
\hline 52 & Route-19 & Route-19 & 9.5 & & & & 2.541 \\
\hline 53 & Route-19 & Route-19 & 9.5 & & & & 2.541 \\
\hline 54 & I-64 & I-64 & 9.5 & & & & 2.453 \\
\hline 55 & I-64 & I-64 & 9.5 & & & & 2.453 \\
\hline 56 & I-64 & I-64 & 9.5 & & & & 2.453 \\
\hline 57 & I-64 & $\mathrm{I}-64$ & 9.5 & & & & 2.453 \\
\hline 58 & I-64 & I-64 & 9.5 & & & & 2.453 \\
\hline 59 & I-64 & I-64 & 9.5 & & & & 2.453 \\
\hline 60 & I-64 & I-64 & 9.5 & & & & 2.453 \\
\hline 61 & I-64 & I-64 & 9.5 & & & & 2.453 \\
\hline 62 & I-64 & I-64 & 9.5 & & & & 2.441 \\
\hline 63 & I-64 & I-64 & 9.5 & & & & 2.441 \\
\hline 64 & I-64 & I-64 & 9.5 & & & & 2.441 \\
\hline 65 & I-64 & $\mathrm{I}-64$ & 9.5 & & & & 2.441 \\
\hline 66 & I-64 & I-64 & 9.5 & & & & 2.441 \\
\hline 67 & I-64 & I-64 & 9.5 & & & & 2.441 \\
\hline 68 & I-64 & I-64 & 9.5 & & & & 2.441 \\
\hline 69 & I-64 & I-64 & 9.5 & & & & 2.441 \\
\hline 70 & I-64 & I-64 & 19 & & & & 2.517 \\
\hline 71 & I-64 & I-64 & 19 & & & & 2.517 \\
\hline 72 & I-64 & I-64 & 19 & & & & 2.517 \\
\hline 73 & I-64 & I-64 & 19 & & & & 2.517 \\
\hline 74 & I-64 & I-64 & 19 & & & & 2.517 \\
\hline 75 & I-64 & I-64 & 19 & & & & 2.517 \\
\hline 76 & I-64 & I-64 & 19 & & & & 2.517 \\
\hline 77 & I-64 & I-64 & 19 & & & & 2.517 \\
\hline
\end{tabular}




\begin{tabular}{|c|c|c|c|c|c|c|c|}
\hline $\begin{array}{l}\text { WVUATL } \\
\text { Number }\end{array}$ & $\begin{array}{c}\mathrm{G}_{\mathrm{mb}} \\
\text { (Contractor } \\
\text { CoreLok) }\end{array}$ & $\begin{array}{c}\mathrm{G}_{\mathrm{mb}}(\text { WVUATL } \\
\text { CoreLok Performed } \\
\text { at Contractor Lab) }\end{array}$ & $\begin{array}{c}\mathrm{G}_{\mathrm{mb}} \\
\text { (WVUATL } \\
\text { CoreLok) }\end{array}$ & $\begin{array}{c}\mathrm{G}_{\mathrm{mb}} \\
\text { (Contractor } \\
\mathrm{T} 166)\end{array}$ & $\begin{array}{c}\mathrm{G}_{\mathrm{mb}} \\
(\mathrm{WVDOH} \\
\mathrm{T} 166)\end{array}$ & $\begin{array}{c}\mathrm{G}_{\mathrm{mb}} \\
\text { (WVUATL } \\
\text { T166) }\end{array}$ & $\begin{array}{c}\text { Water } \\
\text { Absorption }\end{array}$ \\
\hline 1 & \multirow{31}{*}{ NA } & \multirow{31}{*}{ NA } & 2.218 & 2.241 & & 2.236 & 1.4 \\
\hline 2 & & & 2.302 & & 2.320 & 2.311 & 0.4 \\
\hline 3 & & & 2.210 & 2.218 & & 2.230 & 1.5 \\
\hline 4 & & & 2.184 & & 2.206 & 2.197 & 3.0 \\
\hline 5 & & & 2.280 & 2.292 & & 2.290 & 0.4 \\
\hline 6 & & & 2.269 & & 2.288 & 2.282 & 0.7 \\
\hline 7 & & & 2.207 & 2.218 & & 2.220 & 1.3 \\
\hline 8 & & & 2.165 & & 2.198 & 2.188 & 3.4 \\
\hline 9 & & & 2.173 & 2.201 & & 2.200 & 2.4 \\
\hline 10 & & & 2.345 & & 2.353 & 2.353 & 0.4 \\
\hline 11 & & & 2.174 & 2.209 & & 2.209 & 2.3 \\
\hline 12 & & & 2.152 & & 2.187 & 2.181 & 3.5 \\
\hline 13 & & & 2.302 & 2.318 & & 2.313 & 0.4 \\
\hline 14 & & & 2.293 & & 2.311 & 2.307 & 0.7 \\
\hline 15 & & & 2.146 & 2.163 & & 2.159 & 3.3 \\
\hline 16 & & & 2.213 & & 2.230 & 2.233 & 2.0 \\
\hline 17 & & & 2.277 & 2.302 & & 2.286 & 0.6 \\
\hline 18 & & & 2.234 & 2.258 & & 2.240 & 1.0 \\
\hline 19 & & & 2.271 & 2.298 & & 2.280 & 0.7 \\
\hline 20 & & & 2.199 & 2.232 & & 2.221 & 1.1 \\
\hline 21 & & & 2.159 & 2.194 & & 2.162 & 1.7 \\
\hline 22 & & & 2.210 & 2.228 & & 2.218 & 1.1 \\
\hline 23 & & & 2.258 & 2.272 & & 2.264 & 0.7 \\
\hline 24 & & & 2.267 & 2.280 & & 2.281 & 0.7 \\
\hline 25 & & & 2.163 & 2.176 & & 2.164 & 3.4 \\
\hline 26 & & & 2.170 & 2.176 & & 2.173 & 3.1 \\
\hline 27 & & & 2.216 & 2.223 & & 2.217 & 2.4 \\
\hline 28 & & & 2.044 & 2.050 & & 2.048 & 7.9 \\
\hline 29 & & & 2.102 & 2.107 & & 2.109 & 3.6 \\
\hline 30 & & & 2.199 & 2.201 & & 2.204 & 1.8 \\
\hline 31 & & & 2.255 & 2.214 & & 2.257 & 2.8 \\
\hline
\end{tabular}




\begin{tabular}{|c|c|c|c|c|c|c|c|}
\hline $\begin{array}{l}\text { WVUATL } \\
\text { Number }\end{array}$ & $\begin{array}{c}\mathrm{G}_{\mathrm{mb}} \\
\text { (Contractor } \\
\text { CoreLok) }\end{array}$ & $\begin{array}{l}\mathrm{G}_{\mathrm{mb}}(\text { WVUATL } \\
\text { CoreLok Performed } \\
\text { at Contractor Lab) }\end{array}$ & $\begin{array}{c}\mathrm{G}_{\mathrm{mb}} \\
\text { (WVUATL } \\
\text { CoreLok) }\end{array}$ & $\begin{array}{c}\mathrm{G}_{\mathrm{mb}} \\
\text { (Contractor } \\
\mathrm{T} 166)\end{array}$ & $\begin{array}{c}\mathrm{G}_{\mathrm{mb}} \\
\text { (WVDOH } \\
\text { T166) }\end{array}$ & $\begin{array}{c}\mathrm{G}_{\mathrm{mb}} \\
\text { (WVUATL } \\
\text { T166) }\end{array}$ & $\begin{array}{c}\text { Water } \\
\text { Absorption }\end{array}$ \\
\hline 1 & \multirow{31}{*}{ NA } & \multirow{31}{*}{ NA } & 2.218 & 2.241 & & 2.236 & 1.4 \\
\hline 2 & & & 2.302 & & 2.320 & 2.311 & 0.4 \\
\hline 3 & & & 2.210 & 2.218 & & 2.230 & 1.5 \\
\hline 4 & & & 2.184 & & 2.206 & 2.197 & 3.0 \\
\hline 5 & & & 2.280 & 2.292 & & 2.290 & 0.4 \\
\hline 6 & & & 2.269 & & 2.288 & 2.282 & 0.7 \\
\hline 7 & & & 2.207 & 2.218 & & 2.220 & 1.3 \\
\hline 8 & & & 2.165 & & 2.198 & 2.188 & 3.4 \\
\hline 9 & & & 2.173 & 2.201 & & 2.200 & 2.4 \\
\hline 10 & & & 2.345 & & 2.353 & 2.353 & 0.4 \\
\hline 11 & & & 2.174 & 2.209 & & 2.209 & 2.3 \\
\hline 12 & & & 2.152 & & 2.187 & 2.181 & 3.5 \\
\hline 13 & & & 2.302 & 2.318 & & 2.313 & 0.4 \\
\hline 14 & & & 2.293 & & 2.311 & 2.307 & 0.7 \\
\hline 15 & & & 2.146 & 2.163 & & 2.159 & 3.3 \\
\hline 16 & & & 2.213 & & 2.230 & 2.233 & 2.0 \\
\hline 17 & & & 2.277 & 2.302 & & 2.286 & 0.6 \\
\hline 18 & & & 2.234 & 2.258 & & 2.240 & 1.0 \\
\hline 19 & & & 2.271 & 2.298 & & 2.280 & 0.7 \\
\hline 20 & & & 2.199 & 2.232 & & 2.221 & 1.1 \\
\hline 21 & & & 2.159 & 2.194 & & 2.162 & 1.7 \\
\hline 22 & & & 2.210 & 2.228 & & 2.218 & 1.1 \\
\hline 23 & & & 2.258 & 2.272 & & 2.264 & 0.7 \\
\hline 24 & & & 2.267 & 2.280 & & 2.281 & 0.7 \\
\hline 25 & & & 2.163 & 2.176 & & 2.164 & 3.4 \\
\hline 26 & & & 2.170 & 2.176 & & 2.173 & 3.1 \\
\hline 27 & & & 2.216 & 2.223 & & 2.217 & 2.4 \\
\hline 28 & & & 2.044 & 2.050 & & 2.048 & 7.9 \\
\hline 29 & & & 2.102 & 2.107 & & 2.109 & 3.6 \\
\hline 30 & & & 2.199 & 2.201 & & 2.204 & 1.8 \\
\hline 31 & & & 2.255 & 2.214 & & 2.257 & 2.8 \\
\hline
\end{tabular}




\begin{tabular}{|c|c|c|c|c|c|c|c|}
\hline $\begin{array}{l}\text { WVUATL } \\
\text { Number }\end{array}$ & $\begin{array}{c}\mathrm{G}_{\mathrm{mb}} \\
\text { (Contractor } \\
\text { CoreLok) }\end{array}$ & $\begin{array}{l}\mathrm{G}_{\mathrm{mb}} \text { (WVUATL } \\
\text { CoreLok Performed } \\
\text { at Contractor Lab) }\end{array}$ & $\begin{array}{c}\mathrm{G}_{\mathrm{mb}} \\
\text { (WVUATL } \\
\text { CoreLok) }\end{array}$ & $\begin{array}{c}\mathrm{G}_{\mathrm{mb}} \\
\text { (Contractor } \\
\text { T166) }\end{array}$ & $\begin{array}{c}\mathrm{G}_{\mathrm{mb}}(\mathrm{DOH} \\
\mathrm{T} 166)\end{array}$ & $\begin{array}{c}\mathrm{G}_{\mathrm{mb}} \\
\text { (WVUATL } \\
\text { T166) }\end{array}$ & $\begin{array}{c}\text { Water } \\
\text { Absorption }\end{array}$ \\
\hline 32 & \multirow{14}{*}{ NA } & 2.263 & 2.255 & 2.214 & & 2.257 & 1.3 \\
\hline 33 & & 2.285 & 2.287 & 2.286 & & 2.277 & 0.8 \\
\hline 34 & & 2.275 & 2.269 & 2.277 & & 2.270 & 0.5 \\
\hline 35 & & 2.296 & 2.290 & 2.295 & & 2.310 & 4.8 \\
\hline 36 & & 2.238 & 2.226 & & 2.245 & 2.241 & 1.2 \\
\hline 37 & & 2.246 & 2.239 & & 2.252 & 2.273 & 1.0 \\
\hline 38 & & 2.136 & 2.128 & 2.139 & & 2.144 & 6.5 \\
\hline 39 & & 2.157 & 2.150 & 2.267 & & 2.237 & 5.4 \\
\hline 40 & & 2.177 & 2.169 & 2.180 & & 2.181 & 4.4 \\
\hline 41 & & 2.204 & 2.191 & 2.212 & & 2.199 & 1.3 \\
\hline 42 & & 2.327 & 2.318 & 2.329 & & 2.330 & 0.3 \\
\hline 43 & & 2.267 & 2.262 & & 2.275 & 2.272 & 0.9 \\
\hline 44 & & 2.195 & 2.196 & & 2.199 & 2.206 & 2.5 \\
\hline 45 & & 2.097 & 2.089 & 2.110 & & 2.123 & 7.5 \\
\hline
\end{tabular}




\begin{tabular}{|c|c|c|c|c|c|c|c|}
\hline $\begin{array}{l}\text { WVUATL } \\
\text { Number }\end{array}$ & $\begin{array}{c}\mathrm{G}_{\mathrm{mb}} \\
\text { (Contractor } \\
\text { CoreLok) }\end{array}$ & $\begin{array}{c}\mathrm{G}_{\mathrm{mb}}(\text { WVUATL } \\
\text { CoreLok Performed } \\
\text { at Contractor Lab) }\end{array}$ & $\begin{array}{c}\mathrm{G}_{\mathrm{mb}} \\
\text { (WVUATL } \\
\text { CoreLok) }\end{array}$ & $\begin{array}{c}\mathrm{G}_{\mathrm{mb}} \\
\text { (Contractor } \\
\mathrm{T} 166)\end{array}$ & $\begin{array}{c}\mathrm{G}_{\mathrm{mb}}(\mathrm{DOH} \\
\mathrm{T} 166)\end{array}$ & $\begin{array}{c}\mathrm{G}_{\mathrm{mb}} \\
\text { (WVUATL } \\
\text { T166) }\end{array}$ & $\begin{array}{c}\text { Water } \\
\text { Absorption }\end{array}$ \\
\hline 46 & \multirow{8}{*}{ NA } & \multirow{32}{*}{ NA } & 2.157 & NA & & 2.177 & 3.0 \\
\hline 47 & & & 2.223 & 2.232 & & 2.223 & 0.8 \\
\hline 48 & & & 2.214 & 2.232 & & 2.228 & 1.0 \\
\hline 49 & & & 2.213 & 2.224 & & 2.226 & 0.7 \\
\hline 50 & & & 2.127 & 2.156 & & 2.144 & 2.6 \\
\hline 51 & & & 2.174 & 2.189 & & 2.193 & 2.5 \\
\hline 52 & & & 2.116 & 2.152 & & 2.138 & 4.4 \\
\hline 53 & & & 2.208 & 2.234 & & 2.234 & 1.5 \\
\hline 54 & 2.213 & & 2.214 & NA & & 2.250 & 1.6 \\
\hline 55 & 2.204 & & 2.188 & NA & & 2.220 & 1.7 \\
\hline 56 & 2.182 & & 2.179 & NA & & 2.200 & 2.2 \\
\hline 57 & 2.190 & & 2.184 & NA & & 2.215 & 2.6 \\
\hline 58 & 2.001 & & 1.997 & NA & & 2.064 & 6.7 \\
\hline 59 & 2.020 & & 2.014 & NA & & 2.057 & 8.0 \\
\hline 60 & 2.200 & & 2.187 & NA & & 2.198 & 1.3 \\
\hline 61 & 2.195 & & 2.193 & NA & & 2.224 & 2.5 \\
\hline 62 & 2.304 & & 2.371 & NA & & 2.378 & 0.4 \\
\hline 63 & 2.276 & & 2.373 & NA & & 2.294 & 0.7 \\
\hline 64 & 2.260 & & 2.324 & NA & & 2.287 & 1.1 \\
\hline 65 & 2.318 & & 2.299 & NA & & 2.240 & 2.2 \\
\hline 66 & 2.280 & & 2.340 & NA & & 2.267 & 1.4 \\
\hline 67 & 2.294 & & 2.328 & NA & & 2.332 & 0.5 \\
\hline 68 & 2.268 & & 2.324 & NA & & 2.349 & 1.0 \\
\hline 69 & 2.234 & & 2.276 & NA & & 2.299 & 1.9 \\
\hline 70 & 2.435 & & 2.454 & NA & & 2.457 & 0.1 \\
\hline 71 & 2.434 & & 2.436 & NA & & 2.457 & 0.2 \\
\hline 72 & 2.363 & & 2.363 & NA & & 2.376 & 0.5 \\
\hline 73 & 2.421 & & 2.479 & NA & & 2.449 & 0.2 \\
\hline 74 & 2.390 & & 2.400 & NA & & 2.392 & 0.4 \\
\hline 75 & 2.340 & & 2.386 & NA & & 2.411 & 1.4 \\
\hline 76 & 2.411 & & 2.362 & NA & & 2.396 & 0.9 \\
\hline 77 & 2.332 & & 2.495 & NA & & 2.432 & 0.3 \\
\hline
\end{tabular}




\begin{tabular}{|c|c|c|c|c|c|c|c|}
\hline $\begin{array}{l}\text { WVUATL } \\
\text { Number }\end{array}$ & $\begin{array}{c}\text { VTM } \\
\text { (Contractor } \\
\text { CoreLok) }\end{array}$ & $\begin{array}{c}\text { VTM } \\
\text { (WVU CoreLok } \\
\text { Performed at } \\
\text { Contractor Lab) }\end{array}$ & $\begin{array}{c}\text { VTM } \\
\text { (WVU } \\
\text { CoreLok) }\end{array}$ & $\begin{array}{c}\text { VTM } \\
\text { (Contractor } \\
\text { T166) }\end{array}$ & $\begin{array}{c}\text { VTM } \\
\text { (Contractor } \\
\text { T166) }\end{array}$ & $\begin{array}{l}\text { VTM (WVU } \\
\text { T166) }\end{array}$ & $\begin{array}{c}\text { Permeability } 10 \\
5 \mathrm{~cm} / \mathrm{sec}\end{array}$ \\
\hline 1 & \multirow{31}{*}{ NA } & \multirow{31}{*}{ NA } & 9.9 & 8.9 & & 9.1 & 181 \\
\hline 2 & & & 6.5 & & 5.7 & 6.1 & 8 \\
\hline 3 & & & 10.2 & 9.9 & & 9.4 & 500 \\
\hline 4 & & & 11.3 & & 10.4 & 10.7 & 413 \\
\hline 5 & & & 7.4 & 6.9 & & 6.9 & 13 \\
\hline 6 & & & 7.8 & & 7.0 & 7.3 & 139 \\
\hline 7 & & & 10.3 & 9.9 & & 9.8 & 222 \\
\hline 8 & & & 12.0 & & 10.7 & 11.1 & 497 \\
\hline 9 & & & 11.7 & 10.6 & & 10.6 & 526 \\
\hline 10 & & & 4.7 & & 4.4 & 4.4 & 4 \\
\hline 11 & & & 11.7 & 10.2 & & 10.2 & 367 \\
\hline 12 & & & 12.6 & & 11.1 & 11.4 & 914 \\
\hline 13 & & & 6.5 & 5.8 & & 6.0 & 9 \\
\hline 14 & & & 6.8 & & 6.1 & 6.3 & 10 \\
\hline 15 & & & 12.8 & 12.1 & & 12.3 & 741 \\
\hline 16 & & & 10.1 & & 9.4 & 9.3 & 84 \\
\hline 17 & & & 7.5 & 6.5 & & 7.1 & 15 \\
\hline 18 & & & 9.3 & 8.3 & & 9.0 & 156 \\
\hline 19 & & & 7.8 & 6.7 & & 7.4 & 16 \\
\hline 20 & & & 10.7 & 9.3 & & 9.8 & 231 \\
\hline 21 & & & 12.3 & 10.9 & & 12.2 & 1021 \\
\hline 22 & & & 10.2 & 9.5 & & 9.9 & 167 \\
\hline 23 & & & 8.3 & 7.7 & & 8.0 & 34 \\
\hline 24 & & & 7.9 & 7.4 & & 7.4 & 16 \\
\hline 25 & & & 12.2 & 11.7 & & 12.1 & 944 \\
\hline 26 & & & 11.9 & 11.7 & & 11.8 & 469 \\
\hline 27 & & & 10.0 & 9.7 & & 10.0 & 148 \\
\hline 28 & & & 17.0 & 16.8 & & 16.8 & 2628 \\
\hline 29 & & & 14.7 & 14.5 & & 14.4 & 1586 \\
\hline 30 & & & 10.7 & 10.6 & & 10.5 & 135 \\
\hline 31 & & & 8.4 & 10.1 & & 10.7 & 156 \\
\hline
\end{tabular}




\begin{tabular}{|c|c|c|c|c|c|c|c|}
\hline $\begin{array}{l}\text { WVUATL } \\
\text { Number }\end{array}$ & $\begin{array}{c}\text { VTM } \\
\text { (Contractor } \\
\text { CoreLok) }\end{array}$ & $\begin{array}{c}\text { VTM (WVU } \\
\text { CoreLok } \\
\text { Performed at } \\
\text { Contractor Lab) }\end{array}$ & $\begin{array}{l}\text { VTM (WVU } \\
\text { CoreLok) }\end{array}$ & $\begin{array}{c}\text { VTM } \\
\text { (Contractor } \\
\text { AASHTO T166) }\end{array}$ & $\begin{array}{c}\text { VTM } \\
\text { (Contractor } \\
\text { AASHTO T166) }\end{array}$ & $\begin{array}{c}\text { VTM (WVU } \\
\text { AASHTO T166) }\end{array}$ & $\begin{array}{l}\text { Permeability } \\
10^{-5} \mathrm{~cm} / \mathrm{sec}\end{array}$ \\
\hline 32 & \multirow{14}{*}{ NA } & 7.9 & 8.2 & 9.9 & & 8.1 & 96 \\
\hline 33 & & 7.0 & 6.9 & 6.9 & & 7.3 & 58 \\
\hline 34 & & 7.4 & 7.6 & 7.3 & & 7.6 & 45 \\
\hline 35 & & 6.5 & 6.8 & 6.6 & & 5.9 & 3 \\
\hline 36 & & 8.9 & 9.4 & & 8.6 & 8.8 & 107 \\
\hline 37 & & 8.6 & 8.8 & & 8.3 & 7.5 & 38 \\
\hline 38 & & 13.0 & 13.4 & 12.9 & & 12.7 & 1976 \\
\hline 39 & & 12.2 & 12.5 & 7.7 & & 8.9 & 678 \\
\hline 40 & & 11.4 & 11.7 & 11.2 & & 11.2 & 812 \\
\hline 41 & & 10.3 & 10.8 & 9.9 & & 10.5 & 624 \\
\hline 42 & & 5.3 & 5.6 & 5.2 & & 9.2 & 1 \\
\hline 43 & & 7.7 & 7.9 & & 7.4 & 7.5 & 35 \\
\hline 44 & & 10.6 & 10.6 & & 10.5 & 10.2 & 561 \\
\hline 45 & & 14.6 & 14.9 & 14.1 & & 13.6 & 1852 \\
\hline
\end{tabular}




\begin{tabular}{|c|c|c|c|c|c|c|c|}
\hline $\begin{array}{l}\text { WVUATL } \\
\text { Number }\end{array}$ & $\begin{array}{l}\text { VTM } \\
\text { (Contractor } \\
\text { CoreLok) }\end{array}$ & $\begin{array}{c}\text { VTM (WVU } \\
\text { CoreLok } \\
\text { Performed at } \\
\text { Contractor Lab) }\end{array}$ & $\begin{array}{l}\text { VTM (WVU } \\
\text { CoreLok) }\end{array}$ & $\begin{array}{c}\text { VTM } \\
\text { (Contractor } \\
\text { AASHTO T166) }\end{array}$ & $\begin{array}{c}\text { VTM } \\
\text { (Contractor } \\
\text { AASHTO T166) }\end{array}$ & $\begin{array}{c}\text { VTM (WVU } \\
\text { AASHTO T166) }\end{array}$ & $\begin{array}{c}\text { Permeability } \\
10^{-5} \mathrm{~cm} / \mathrm{sec}\end{array}$ \\
\hline 46 & \multirow{8}{*}{ NA } & \multirow{32}{*}{ NA } & 15.1 & NA & & 14.3 & 357 \\
\hline 47 & & & 12.5 & 12.2 & & 12.5 & 33 \\
\hline 48 & & & 12.9 & 12.2 & & 12.3 & 117 \\
\hline 49 & & & 12.9 & 12.5 & & 12.4 & 131 \\
\hline 50 & & & 16.3 & 15.2 & & 15.6 & 709 \\
\hline 51 & & & 14.4 & 13.9 & & 13.7 & 175 \\
\hline 52 & & & 16.7 & 15.3 & & 15.9 & 968 \\
\hline 53 & & & 13.1 & 12.1 & & 12.1 & 48 \\
\hline 54 & 9.784 & & 9.7 & NA & & 8.3 & 132 \\
\hline 55 & 10.151 & & 10.8 & NA & & 9.5 & 62 \\
\hline 56 & 11.048 & & 11.2 & NA & & 10.3 & 194 \\
\hline 57 & 10.722 & & 11.0 & NA & & 9.7 & 364 \\
\hline 58 & 18.426 & & 18.6 & NA & & 15.9 & 3673 \\
\hline 59 & 17.652 & & 17.9 & NA & & 16.1 & 3596 \\
\hline 60 & 10.314 & & 10.8 & NA & & 10.4 & 351 \\
\hline 61 & 10.518 & & 10.6 & NA & & 9.3 & 277 \\
\hline 62 & 5.612 & & 2.9 & NA & & 2.6 & 9 \\
\hline 63 & 6.760 & & 2.8 & NA & & 6.0 & 79 \\
\hline 64 & 7.415 & & 4.8 & NA & & 6.3 & 83 \\
\hline 65 & 5.039 & & 5.8 & NA & & 8.2 & 79 \\
\hline 66 & 6.596 & & 4.1 & NA & & 7.1 & 20 \\
\hline 67 & 6.022 & & 4.6 & NA & & 4.5 & 68 \\
\hline 68 & 7.087 & & 4.8 & NA & & 3.8 & 79 \\
\hline 69 & 8.480 & & 6.8 & NA & & 5.8 & 70 \\
\hline 70 & 3.258 & & 2.5 & NA & & 2.4 & 1 \\
\hline 71 & 3.298 & & 3.2 & NA & & 2.4 & 1 \\
\hline 72 & 6.118 & & 6.1 & NA & & 5.6 & 19 \\
\hline 73 & 3.814 & & 1.5 & NA & & 2.7 & 1 \\
\hline 74 & 5.046 & & 4.6 & NA & & 5.0 & 16 \\
\hline 75 & 7.032 & & 5.2 & NA & & 4.2 & 12 \\
\hline 76 & 4.211 & & 6.2 & NA & & 4.8 & 14 \\
\hline 77 & 7.350 & & 0.9 & NA & & 3.4 & 2 \\
\hline
\end{tabular}




\begin{tabular}{|c|c|c|c|c|c|c|c|c|}
\hline $\begin{array}{l}\text { WVUATL } \\
\text { Number }\end{array}$ & $\begin{array}{l}\text { Contractor } \\
\text { NG } 35998\end{array}$ & $\begin{array}{c}\text { Contractor NG } \\
25500\end{array}$ & $\begin{array}{c}\text { DOH NG } \\
29368\end{array}$ & $\begin{array}{c}\text { DOH NG } \\
29353\end{array}$ & $\begin{array}{c}\text { DOH NG } \\
30771\end{array}$ & $\begin{array}{l}\text { DOH NG } \\
28066\end{array}$ & $\begin{array}{c}\text { DOH } \\
\text { THIN } \\
\text { LIFT } \\
\text { Offset }\end{array}$ & $\begin{array}{c}\text { DOH } \\
\text { THIN } \\
\text { LIFT } \\
\text { Centered }\end{array}$ \\
\hline 1 & 2349 & 2309 & 2321 & \multirow{24}{*}{ NA } & \multirow{24}{*}{ NA } & \multirow{16}{*}{ NA } & 2264 & 2263 \\
\hline 2 & 2374 & 2308 & 2388 & & & & 2324 & 2329 \\
\hline 3 & 2326 & 2258 & 2322 & & & & 2196 & 2214 \\
\hline 4 & 2237 & 2206 & 2306 & & & & 2194 & 2172 \\
\hline 5 & 2384 & 2324 & 2369 & & & & 2289 & 2287 \\
\hline 6 & 2390 & 2300 & 2386 & & & & 2290 & 2284 \\
\hline 7 & 2306 & 2233 & 2307 & & & & 2191 & 2192 \\
\hline 8 & 2212 & 2185 & 2194 & & & & 2158 & 2141 \\
\hline 9 & 2332 & 2275 & 2329 & & & & 2241 & 2232 \\
\hline 10 & 2355 & 2388 & 2428 & & & & 2361 & 2361 \\
\hline 11 & 2301 & 2253 & 2317 & & & & 2191 & 2178 \\
\hline 12 & 2260 & 2269 & 2305 & & & & 2172 & 2152 \\
\hline 13 & 2390 & 2348 & 2404 & & & & 2300 & 2315 \\
\hline 14 & 2373 & 2317 & 2410 & & & & 2257 & 2270 \\
\hline 15 & 2229 & 2222 & 2260 & & & & 2145 & 2148 \\
\hline 16 & 2283 & 2228 & 2319 & & & & 2213 & 2216 \\
\hline 17 & 2380 & 2334 & 2366 & & & 2378 & \multirow{8}{*}{ NA } & \multirow{8}{*}{ NA } \\
\hline 18 & 2332 & 2287 & 2330 & & & 2347 & & \\
\hline 19 & 2378 & 2324 & 2371 & & & 2373 & & \\
\hline 20 & 2276 & 2246 & 2291 & & & 2289 & & \\
\hline 21 & 2229 & 2188 & 2232 & & & 2247 & & \\
\hline 22 & 2308 & 2284 & 2310 & & & 2334 & & \\
\hline 23 & 2347 & 2299 & 2336 & & & 2339 & & \\
\hline 24 & 2349 & 2314 & 2334 & & & 2364 & & \\
\hline 25 & 2270 & 2235 & \multirow{7}{*}{ NA } & 2301 & 2309 & \multirow{7}{*}{ NA } & 2204 & \multirow{7}{*}{ NA } \\
\hline 26 & 2254 & 2208 & & 2290 & 2298 & & 2194 & \\
\hline 27 & 2330 & 2262 & & 2362 & 2367 & & 2262 & \\
\hline 28 & 2152 & 2170 & & 2168 & 2191 & & 2064 & \\
\hline 29 & 2215 & 2192 & & 2204 & 2239 & & 2130 & \\
\hline 30 & 2282 & 2260 & & 2295 & 2318 & & 2218 & \\
\hline 31 & 2281 & 2270 & & 2308 & 2326 & & 2245 & \\
\hline
\end{tabular}




\begin{tabular}{|c|c|c|c|c|c|c|c|c|}
\hline $\begin{array}{l}\text { WVUATL } \\
\text { Number }\end{array}$ & $\begin{array}{l}\text { Contractor } \\
\text { NG } 35998\end{array}$ & $\begin{array}{c}\text { Contractor NG } \\
25500\end{array}$ & $\begin{array}{c}\text { DOH NG } \\
29368\end{array}$ & $\begin{array}{c}\text { DOH NG } \\
29353\end{array}$ & $\begin{array}{c}\text { DOH NG } \\
30771\end{array}$ & $\begin{array}{c}\text { DOH NG } \\
28066\end{array}$ & $\begin{array}{c}\text { DOH } \\
\text { THIN } \\
\text { LIFT } \\
\text { Offset }\end{array}$ & $\begin{array}{c}\text { DOH } \\
\text { THIN } \\
\text { LIFT } \\
\text { Centered }\end{array}$ \\
\hline 32 & 2275 & 2257 & \multirow{14}{*}{ NA } & \multirow{14}{*}{ NA } & 2267 & \multirow{14}{*}{ NA } & \multirow{14}{*}{ NA } & \multirow{14}{*}{ NA } \\
\hline 33 & 2248 & 2254 & & & 2270 & & & \\
\hline 34 & 2248 & 2282 & & & 2266 & & & \\
\hline 35 & 2290 & 2306 & & & 2287 & & & \\
\hline 36 & 2263 & 2235 & & & 2269 & & & \\
\hline 37 & 2234 & 2259 & & & 2239 & & & \\
\hline 38 & 2180 & 2157 & & & 2162 & & & \\
\hline 39 & 2106 & 2123 & & & 2152 & & & \\
\hline 40 & 2188 & 2179 & & & 2164 & & & \\
\hline 41 & 2231 & 2181 & & & 2176 & & & \\
\hline 42 & 2305 & 2309 & & & 2249 & & & \\
\hline 43 & 2252 & 2266 & & & 2228 & & & \\
\hline 44 & 2181 & 2215 & & & 2180 & & & \\
\hline 45 & 2071 & 2093 & & & 2103 & & & \\
\hline
\end{tabular}




\section{Appendix 3}

\section{Statistical Analysis Data}

1. WVUATL CoreLok Conducted at WVUATL vs. at the Contractor Lab

t-Test: Paired Two Sample for Means

\begin{tabular}{lcc}
\hline & Variable 1 & Variable 2 \\
\hline Mean & 2.219 & 2.226 \\
Variance & 0.005 & 0.004 \\
Observations & 14 & 14 \\
Pearson Correlation & 0.998 & \\
Hypothesized Mean Difference & 0 & \\
df & 13 & \\
t Stat & -6.122 & \\
$\mathrm{P}(\mathrm{T}<=\mathrm{t})$ one-tail & $1.82 \mathrm{E}-05$ & \\
$\mathrm{t}$ Critical one-tail & 1.770 & \\
$\mathrm{P}(\mathrm{T}<=\mathrm{t})$ two-tail & $3.64 \mathrm{E}-05$ \\
$\mathrm{t}$ Critical two-tail & 2.160 \\
\hline Decision & reject Hn \\
\hline
\end{tabular}

\begin{tabular}{ll}
\multicolumn{2}{l}{ SUMMARY OUTPUT } \\
\hline Regression Statistics \\
\hline Multiple R & 0.998 \\
R Square & 0.996 \\
Adjusted R Square & 0.996 \\
Standard Error & 0.004 \\
Observations & 14 \\
\hline
\end{tabular}

\begin{tabular}{|c|c|c|c|c|}
\hline \multicolumn{5}{|l|}{ ANOVA } \\
\hline & $\mathrm{df}$ & SS & MS & $\mathrm{F}$ \\
\hline Regression & 1 & 5.77E-02 & 5.77E-02 & $3.33 \mathrm{E}+03$ \\
\hline Residual & 12 & $2.08 \mathrm{E}-04$ & $1.73 \mathrm{E}-05$ & \\
\hline \multirow[t]{2}{*}{ Total } & 13 & 5.79E-02 & & \\
\hline & Coefficients & Standard Error & t Stat & P-value \\
\hline Intercept & 0.036801 & 0.037949 & $9.70 \mathrm{E}-01$ & 3.51E-01 \\
\hline X Variable 1 & 0.986443 & 0.017093 & $5.77 \mathrm{E}+01$ & $4.84 \mathrm{E}-16$ \\
\hline tails & 2 & & Decision & \\
\hline $\mathrm{t}$ for $\mathrm{Hn}=1$ & -0.793 & & Intercept & cannot reject Hn \\
\hline $\mathrm{p}$-value for $\mathrm{Hn}=1$ & 0.443 & & Slope & cannot reject Hn \\
\hline
\end{tabular}




\section{WVUATL CoreLok vs. Contractor CoreLok}

t-Test: Paired Two Sample for Means

\begin{tabular}{lcc} 
t-Test: Paired Two Sample for Means & & \\
\hline & Variable 1 & Variable 2 \\
\hline Mean & 2.299 & 2.274 \\
Variance & 0.017 & 0.013 \\
Observations & 24 & 24 \\
Pearson Correlation & 0.940 & \\
Hypothesized Mean Difference & 0 & \\
df & 23 & \\
t Stat & 2.674 & \\
P(T<=t) one-tail & 0.007 & \\
t Critical one-tail & 1.714 & \\
P(T<=t) two-tail & $2.34 \mathrm{E}-02$ & \\
t Critical two-tail & 2.067 & \\
\hline Decision & reject Hn & \\
\hline
\end{tabular}

SUMMARY OUTPUT

\begin{tabular}{|c|c|c|c|c|c|}
\hline Multiple R & 0.940 & & & & \\
\hline Adjusted R Square & 0.878 & & & & \\
\hline Standard Error & 0.034 & & & & \\
\hline \multicolumn{6}{|l|}{ ANOVA } \\
\hline & $\mathrm{df}$ & SS & MS & $\mathrm{F}$ & Significance F \\
\hline Regression & 1 & $2.66 \mathrm{E}-01$ & $2.66 \mathrm{E}-01$ & $1.66 \mathrm{E}+02$ & $9.82 \mathrm{E}-12$ \\
\hline Intercept & 0.394428 & $1.46 \mathrm{E}-01$ & $2.70 \mathrm{E}+00$ & $1.30 \mathrm{E}-02$ & \\
\hline X Variable 1 & 0.817509 & 6.34E-02 & $1.29 \mathrm{E}+01$ & $9.82 \mathrm{E}-12$ & \\
\hline tails & 2 & & Decision & & \\
\hline $\mathrm{t}$ for $\mathrm{Hn}=1$ & -2.879 & & Intercept & reject $\mathrm{Hn}$ & \\
\hline $\mathrm{p}$-value for $\mathrm{Hn}=1$ & 0.009 & & Slope & reject $\mathrm{Hn}$ & \\
\hline
\end{tabular}


3. CoreLok vs. T166 Data Divided Based on Water Absorption

3.1 All Sample Included

\begin{tabular}{lcc} 
& & \\
\hline $\mathrm{t}-$ Test: Paired Two Sample for Means & Variable 1 & Variable 2 \\
\hline Mean & 2.238 & 2.247 \\
Variance & 0.010 & 0.008 \\
Observations & 77 & 77 \\
Pearson Correlation & 0.959 & \\
Hypothesized Mean Difference & 0 & \\
df & 76 & \\
t Stat & -2.713 & \\
P(T<=t) one-tail & 0.004 & \\
t Critical one-tail & 1.665 & \\
P(T<=t) two-tail & $8.24 \mathrm{E}-03$ & \\
$\mathrm{t}$ Critical two-tail & 1.992 & \\
\hline Decision & Reject Hn & \\
\hline
\end{tabular}

\begin{tabular}{|c|c|c|c|c|c|}
\hline \multicolumn{6}{|c|}{ SUMMARY OUTPUT } \\
\hline \multicolumn{2}{|l|}{ Regression Statistics } & & & & \\
\hline Multiple R & 0.959 & & & & \\
\hline R Square & 0.921 & & & & \\
\hline Adjusted R Square & 0.920 & & & & \\
\hline Standard Error & 0.028 & & & & \\
\hline Observations & 77 & & & & \\
\hline \multicolumn{6}{|l|}{ ANOVA } \\
\hline & $\mathrm{df}$ & SS & MS & $\mathrm{F}$ & Significance F \\
\hline Regression & 1 & $6.74 \mathrm{E}-01$ & 6.74E-01 & $8.69 \mathrm{E}+02$ & 5.32117E-43 \\
\hline Residual & 75 & 5.81E-02 & 7.75E-04 & & \\
\hline \multirow[t]{2}{*}{ Total } & 76 & 7.32E-01 & & & \\
\hline & Coefficients & Standard Error & $t$ Stat & $P$-value & \\
\hline Intercept & -0.18384 & 0.082194 & $-2.24 \mathrm{E}+00$ & 2.83E-02 & \\
\hline $\mathrm{X}$ Variable 1 & 1.077906 & 0.036556 & $2.95 \mathrm{E}+01$ & $5.32 \mathrm{E}-43$ & \\
\hline tails & 2 & & Decision & & \\
\hline $\mathrm{t}$ for $\mathrm{Hn}=1$ & 2.131 & & Intercept & reject Hn & \\
\hline $\mathrm{p}$-value for $\mathrm{Hn}=1$ & 0.036 & & Slope & reject $\mathrm{Hn}$ & \\
\hline
\end{tabular}


3.2 Water Absorption <1\%

t-Test: Paired Two Sample for Means

\begin{tabular}{lcc}
\hline & Variable1 & Variable 2 \\
\hline Mean & 2.327 & 2.324 \\
Variance & 0.006 & 0.005 \\
Observations & 26 & 26 \\
Pearson Correlation & 0.922 & \\
Hypothesized Mean Difference & 0 & \\
df & 25 & \\
t Stat & 0.455 & \\
$\mathrm{P}(\mathrm{T}<=\mathrm{t})$ one-tail & 0.326 & \\
$\mathrm{t}$ Critical one-tail & 1.708 & \\
$\mathrm{P}(\mathrm{T}<=\mathrm{t})$ two-tail & $6.53 \mathrm{E}-01$ & \\
$\mathrm{t}$ Critical two-tail & 2.060 & \\
\hline Decision & cannot eject Hn \\
\hline
\end{tabular}

\section{SUMMARY OUTPUT}

\begin{tabular}{|c|c|c|c|c|c|}
\hline \multicolumn{2}{|l|}{ Regression Statistics } & & & & \\
\hline Multiple R & 0.922 & & & & \\
\hline R Square & 0.850 & & & & \\
\hline Adjusted R Square & 0.843 & & & & \\
\hline Standard Error & 0.028 & & & & \\
\hline Observations & 26 & & & & \\
\hline \multicolumn{6}{|l|}{ ANOVA } \\
\hline & $\mathrm{df}$ & SS & MS & $\mathrm{F}$ & Significance F \\
\hline Regression & 1 & 1.09E-01 & $1.09 \mathrm{E}-01$ & $1.36 \mathrm{E}+02$ & 2.30722E-11 \\
\hline Residual & 24 & 1.93E-02 & 8.06E-04 & & \\
\hline \multirow[t]{2}{*}{ Total } & 25 & 1.29E-01 & & & \\
\hline & Coefficients & Standard Error & t Stat & $P$-value & \\
\hline Intercept & 0.314691352 & 1.73E-01 & $1.82 \mathrm{E}+00$ & 8.07E-02 & \\
\hline $\mathrm{X}$ Variable 1 & 0.863613482 & 7.41E-02 & $1.16 \mathrm{E}+01$ & 2.31E-11 & \\
\hline tails & 2 & & Decision & & \\
\hline $\mathrm{t}$ for $\mathrm{Hn}=1$ & -1.840 & & Intercept & cannot reject Hn & \\
\hline $\mathrm{p}$-value for $\mathrm{Hn}=1$ & 0.078 & & Slope & cannot reject Hn & \\
\hline
\end{tabular}


3.3 Water Absorption $\geq 1 \%$

t-Test: Paired Two Sample for Means

\begin{tabular}{lcc}
\hline & Variable 1 & Variable 2 \\
\hline Mean & 2.193 & 2.207 \\
Variance & 0.006 & 0.004 \\
Observations & 51 & 51 \\
Pearson Correlation & 0.937 & \\
Hypothesized Mean Difference & 0 & \\
$\mathrm{df}$ & 50 & \\
$\mathrm{t}$ Stat & -3.987 & \\
$\mathrm{P}(\mathrm{T}<=\mathrm{t})$ one-tail & 0.000 & \\
$\mathrm{t}$ Critical one-tail & 1.676 & \\
$\mathrm{P}(\mathrm{T}<=\mathrm{t})$ two-tail & $2.18 \mathrm{E}-04$ & \\
$\mathrm{t}$ Critical two-tail & 2.009 & \\
\hline Decision & reject Hn \\
\hline
\end{tabular}

\section{SUMMARY OUTPUT}

\begin{tabular}{|c|c|c|c|c|c|}
\hline \multicolumn{2}{|l|}{ Regression Statistics } & & & & \\
\hline Multiple R & 0.937 & & & & \\
\hline R Square & 0.878 & & & & \\
\hline Adjusted R Square & 0.875 & & & & \\
\hline Standard Error & 0.023 & & & & \\
\hline Observations & 51 & & & & \\
\hline \multicolumn{6}{|l|}{ ANOVA } \\
\hline & df & SS & MS & $\mathrm{F}$ & Significance F \\
\hline Regression & 1 & $1.90 \mathrm{E}-01$ & $1.90 \mathrm{E}-01$ & $3.52 \mathrm{E}+02$ & $5.30201 \mathrm{E}-24$ \\
\hline Residual & 49 & 2.65E-02 & $5.40 \mathrm{E}-04$ & & \\
\hline \multirow[t]{2}{*}{ Total } & 50 & 2.16E-01 & & & \\
\hline & Coefficients & Standard Error & $t$ Stat & P-value & \\
\hline Intercept & 0.387598819 & $9.71 \mathrm{E}-02$ & $3.99 \mathrm{E}+00$ & 2.19E-04 & \\
\hline $\mathrm{X}$ Variable 1 & 0.829911025 & 4.43E-02 & $1.88 \mathrm{E}+01$ & 5.30E-24 & \\
\hline tails & 2 & & Decision & & \\
\hline $\mathrm{t}$ for $\mathrm{Hn}=1$ & -3.843 & & Intercept & reject Hn & \\
\hline $\mathrm{p}$-value for $\mathrm{Hn}=1$ & 0.000 & & Slope & reject $\mathrm{Hn}$ & \\
\hline
\end{tabular}


3.4 Water Absorption <2\%

t-Test: Paired Two Sample for Means

\begin{tabular}{lcc}
\hline & Variable 1 & Variable 2 \\
\hline Mean & 2.286 & 2.289 \\
Variance & 0.007 & 0.006 \\
Observations & 48 & 48 \\
Pearson Correlation & 0.941 & \\
Hypothesized Mean Difference & 0 & \\
$\mathrm{df}$ & 47 & \\
$\mathrm{t}$ Stat & -0.866 \\
$\mathrm{P}(\mathrm{T}<=\mathrm{t})$ one-tail & 0.195 & \\
$\mathrm{t}$ Critical one-tail & 1.678 \\
$\mathrm{P}(\mathrm{T}<=\mathrm{t})$ two-tail & $3.91 \mathrm{E}-01$ \\
$\mathrm{t}$ Critical two-tail & 2.012 \\
\hline Decision & \multicolumn{2}{c}{ cannot reject Hn } \\
\hline
\end{tabular}

\section{SUMMARY OUTPUT}

\begin{tabular}{|c|c|c|c|c|c|}
\hline \multicolumn{2}{|l|}{ Regression Statistics } & & & & \\
\hline Multiple R & 0.941 & & & & \\
\hline R Square & 0.885 & & & & \\
\hline Adjusted R Square & 0.882 & & & & \\
\hline Standard Error & 0.025 & & & & \\
\hline Observations & 48 & & & & \\
\hline \multicolumn{6}{|l|}{ ANOVA } \\
\hline & $\mathrm{df}$ & SS & MS & $\mathrm{F}$ & Significance F \\
\hline Regression & 1 & $2.30 \mathrm{E}-01$ & $2.30 \mathrm{E}-01$ & $3.54 \mathrm{E}+02$ & $3.11608 \mathrm{E}-23$ \\
\hline Residual & 46 & $2.98 \mathrm{E}-02$ & $6.49 \mathrm{E}-04$ & & \\
\hline \multirow[t]{2}{*}{ Total } & 47 & 2.59E-01 & & & \\
\hline & Coefficients & Standard Error & t Stat & $P$-value & \\
\hline Intercept & 0.334489671 & $1.04 \mathrm{E}-01$ & $3.22 \mathrm{E}+00$ & 2.37E-03 & \\
\hline $\mathrm{X}$ Variable 1 & 0.855170647 & 4.55E-02 & $1.88 \mathrm{E}+01$ & $3.12 \mathrm{E}-23$ & \\
\hline tails & 2 & & Decision & & \\
\hline $\mathrm{t}$ for $\mathrm{Hn}=1$ & -3.186 & & Intercept & reject Hn & \\
\hline $\mathrm{p}$-value for $\mathrm{Hn}=1$ & 0.003 & & Slope & reject $\mathrm{Hn}$ & \\
\hline
\end{tabular}




\subsection{Water Absorption $\geq 2 \%$.}

t-Test: Paired Two Sample for Means

\begin{tabular}{lcc}
\hline & Variable 1 & Variable 2 \\
\hline Mean & 2.159 & 2.177 \\
Variance & 0.005 & 0.003 \\
Observations & 29 & 29 \\
Pearson Correlation & 0.916 & \\
Hypothesized Mean Difference & 0 & \\
df & 28 & \\
t Stat & -3.416 \\
$\mathrm{P}(\mathrm{T}<=\mathrm{t})$ one-tail & 0.001 & \\
$\mathrm{t}$ Critical one-tail & 1.701 & \\
$\mathrm{P}(\mathrm{T}<=\mathrm{t})$ two-tail & $1.96 \mathrm{E}-03$ \\
$\mathrm{t}$ Critical two-tail & 2.048 \\
\hline Decision & \multicolumn{2}{c}{ reject Hn } \\
\hline
\end{tabular}

SUMMARY OUTPUT

\begin{tabular}{|c|c|c|c|c|c|}
\hline \multicolumn{2}{|l|}{ Regression Statistics } & & & & \\
\hline Multiple R & 0.916 & & & & \\
\hline R Square & 0.838 & & & & \\
\hline Adjusted R Square & 0.832 & & & & \\
\hline Standard Error & 0.024 & & & & \\
\hline Observations & 29 & & & & \\
\hline \multicolumn{6}{|l|}{ ANOVA } \\
\hline & $\mathrm{df}$ & SS & MS & $\mathrm{F}$ & Significance F \\
\hline Regression & 1 & 7.83E-02 & 7.83E-02 & $1.40 \mathrm{E}+02$ & 3.40095E-12 \\
\hline Residual & 27 & $1.51 \mathrm{E}-02$ & $5.59 \mathrm{E}-04$ & & \\
\hline \multirow[t]{2}{*}{ Total } & 28 & $9.34 \mathrm{E}-02$ & & & \\
\hline & Coefficients & Standard Error & $t$ Stat & $P$-value & \\
\hline Intercept & 0.500947652 & $1.42 \mathrm{E}-01$ & $3.54 \mathrm{E}+00$ & 1.49E-03 & \\
\hline $\mathrm{X}$ Variable 1 & 0.776162476 & $6.56 \mathrm{E}-02$ & $1.18 \mathrm{E}+01$ & $3.40 \mathrm{E}-12$ & \\
\hline tails & 2 & & Decision & & \\
\hline $\mathrm{t}$ for $\mathrm{Hn}=1$ & -3.413 & & Intercept & reject $\mathrm{Hn}$ & \\
\hline $\mathrm{p}$-value for $\mathrm{Hn}=1$ & 0.002 & & Slope & reject Hn & \\
\hline
\end{tabular}

